\title{
THE ANAESTHESIA MACHINE: QUESTIONING A DESIGN EVOLUTION
}

\author{
by \\ Bernard Guy \\ A thesis submitted to the Victoria \\ University of Wellington in fulfillment \\ of the requirements for the degree of
}

\section{Master of Design}

Victoria University of Wellington 
THE ANAESTHESIA MACHINE:

QUESTIONING A DESIGN

EVOLUTION

by Bernard Guy 


\title{
THE ANAESTHESIA MACHINE: \\ QUESTIONING A DESIGN \\ EVOLUTION
}

\begin{abstract}
An underlying fear for many in using new digital systems is not the 'digital' but the struggle to trust and see reality; this may represent the loss of an art or aesthetic judgement, over an empirical measurement ${ }^{1}$
\end{abstract}

Why do we have what we have - and what could we have?

Since the acceptance of the "Boyle's" configuration as a design standard, the evolution of anaesthesia equipment has predominantly remained tethered to this design icon. ${ }^{2}$ Increasingly governed by historical habits and industrial ideologies, significant gains in technology have denied anaesthetists ergonomic advantage, due in part, to a design stagnation of physical composition.

In doing so, it has become a legend of origin and a convention of machine use, a situation that is traced back to the evolution of rag and bottle, portable inhaler, and the asymmetric layout of anaesthetic apparatus.

One of the key difficulties or questions for design is how to implement new technologies to retain and strengthen the established product-person trust. ${ }^{3}$ The past reveals two methods; first the traditional addition of technology to historical brands and established formats; and second, the innovative embodiment of task and technology in a search for better systems. ${ }^{4}$

1. B Guy, "The anaesthesia machine: questioning a design evolution" (Thesis., Victoria University of Wellington, 2010), vii

2. K Bryn Thomas, The development of anaesthetic apparatus ( London UK: Blackwell Scientific Publications, 1975), viii

3. M B. Weinger, "Anesthesia equipment and human error," Journal Clinical Monitoring and Computing 15 (Jul 1999): 319-323.

4. O M. Watt, “The evolution of the Boyle apparatus, 1917-67," Anaesthesia 23 (1968): 103-118. ; G Boquet. J A. Bushman. H T. Davenport, "The anaesthesia machine: a study of function and design," British Journal of Anaesthesia 52 (1980): 61-67. ; Jeffrey B. Cooper. Ronald S. Newbower. Jeffrey W. Moore. Edwin D. Trautman, “A new anesthesia delivery system,” Anesthesiology Vol 49 No 5 (1978): 310-318. 
Within the evolution of the anaesthesia machine, design methodologies have colluded to satisfy safety, ignoring a profession's habits, resulting in a complex lamination of engineering (technology), interaction (ergonomics) and aesthetics (path dependence and manufactured style). The application of new digital technology demands a physical design response that can satisfy clinician needs, patient safety and the commercial goals of industry in balancing technology and safety to clinical outputs and user satisfaction. ${ }^{5}$

The study presents an informative and investigative methodology to construct a proactive design base, cumulating in active involvement, an informed critical analysis and a prospective methodological vision. The concluding experiment focuses on information and ideals from anaesthetists, to firstly test the established composition; secondly to inform us of how anaesthetists envisage their equipment; and thirdly, how simulation and industrial design may partner in unlocking the transfer of creative knowledge. In applying this partnership as a strategic design confidant, a new understanding of design process and concomitant design within an elite profession is established.

Altogether this thesis seeks to explore the anaesthesia machine, to investigate the past, create closer relationships with anaesthetists and act together prospectively towards questioning the established. It may be 'it is not a solution we are looking for but the right way (or process) to ask the questions' to manifest a new answer. 


\section{ACKNOWLEDGEMENTS}

I would like to thank the following in assisting and supporting this work.

Dr Brian Robinson. Dr Paul Dalley. Dr Sandy Garden. The National Patient Simulation Centre. Anaesthetists from Capital \& Coast District Health Board. The staff and support of Capital \& Coast District Health Board. The J. Campbell Barrett Wellington Anaesthesia Trust. The Geoffrey Kaye Museum of Anaesthetic History, Melbourne, Australia. The Foundation for Research Science and Technology. The staff of Victoria University of Wellington. Johann Norjte. John Muir. My family and friends. 


\section{CONTENTS}

ABSTRACT $\quad$ V

ACKNOWLEDGEMENTS

LIST OF FIGURES I XI

INTRODUCTION 3

1 Background to study 3

1.1 The research problem 6

$\begin{array}{lll}1.2 & \text { The status of healthcare and design } & 10\end{array}$

RESEARCH METHODOLOGIES 19

2 Reasoning behind the question 19

2.1 Framing the research approach 23

2.2 Method of approach 29

2.3 Design methods as; results, relationships, and simulation 32

\section{PART ONE - LOOKING BACK}

EXAMINING THE PAST

3 Examining the past 41

3.1 The age of enlightenment, reason and modernism 43

3.2 Life, death, and the elite 45

3.3 The activity of design and medicine 53

ANAESTHESIA MACHINE GENEALOGY 63

$4 \quad$ Hand held to hand operated, early innovations. 65

4.1 The left handed origin, normal use or one mans legacy 73

$\begin{array}{lll}4.2 & \text { Implications for acceptance } & 78\end{array}$

$\begin{array}{lll}\text { 4.3 Digital and physical, a new composition } & 80\end{array}$

$\begin{array}{lll}4.4 & \text { Chapter conclusions } & 84\end{array}$ 


\section{PART TWO - PROSPECTIVE INITIATIVE}

DEVELOPING THE METHODOLOGY

$5 \quad$ Current context and the assembly of knowledge 93

5.1 Physiology and pharmacology in anaesthesia 94

5.2 Simulation: the venue of vision 98

$\begin{array}{lll}5.3 & \text { Ethics and the gatekeepers } & 102\end{array}$

$\begin{array}{lll}5.4 & \text { Defining usability } & 107\end{array}$

$\begin{array}{lll}5.5 & \text { Discussing knowledge assimilation } & 111\end{array}$

FIELDWORK: OBSERVATION AND EXPERIMENT 117

6 Fieldwork, observation and experiment 118

$\begin{array}{lll}\text { 6.1 Clinical observation } & 118\end{array}$

$\begin{array}{lll}6.2 & \text { Experiment } & 126\end{array}$

6.3 Results and analysis 129

$\begin{array}{lll}6.4 & \text { Key findings } & 141\end{array}$

DISCUSSION AND CONCLUSIONS 147

$\begin{array}{lll}7 & \text { Discussion } & 147\end{array}$

$\begin{array}{lll}7.1 & \text { Disproving the hypothesis } & 148\end{array}$

7.2 Form follows habit and habit follows form 153

7.3 The safe precedent, or form as a safe precedent 154

$\begin{array}{lll}\text { 7.4 Pushing the evolution } & 156\end{array}$

$\begin{array}{lll}7.5 & \text { Conclusions } & 158\end{array}$

APPENDICES 1

8.1 Appendix $1 \quad 1$

8.2 Appendix 2 8

8.3 Appendix 3

BIBLIOGRAPHY 15

$\begin{array}{ll}\text { GLOSSARY } & 23\end{array}$ 


\section{LIST OF FIGURES}

1.0 Crawford W Long. Source: Thomas E Keys. The history of Surgical anesthesia. New York, Schuman's 1945. Fig 8.

1.1 Skinner's chloroform mask 1862. Source: G Kaye Museum Melbourne 6

1.2 Datex Ohmeda Aestiva flowmeters. Source: Author

1.3 Datex Ohmeda Aestiva. Source: http://www.gehealthcare.com/ euen/anesthesia/products/aestiva-5-family/index.html

2.0 Typical distractions away from the patient. Source: Albert B. Drui. Robert J. Behm. Wayne E. Martin, "Predesign investigation of the anesthesia operational environment," Anesthesia and Analgesia Vol. 52 No. 4 (1973): 584-591.

2.1 Innovation diagram from author's initial proposal. Source: B Guy 200618

2.2 The Boston Anesthesia System. Source: Jeffrey B. Cooper, Ronald S. Newbower, Jeffrey W. Moore, Edwin D. Trautman, A New Anesthesia Delivery System Anesthesiology Vol 49, No 5, Nov 1978 pp310-318

2.3 A study of function and design. Source: G Boquet.J A. Bushman. H T. Davenport, "The anaesthesia machine: a study of function and design," British Journal of Anaesthesia 52 (1980): 61-67.

2.4 Developing the Gyrus Diego. Source: Amy Schwartz, "Collaborative design: turning surgeons into design partners" (Paper presented at the AAMI Human factors, ergonomics, and patient safety for medical devices meeting, Washington, DC. June 28-30, 2005).

3.0 Intern training, 1940. Source: Alfred Eisenstaedt/Time \& Life Pictures/Getty Images (72399511)2009. http://www. gettyimages.com/detail/72399511?esource=life CGetty Images,Inc. 39 
3.1 Amputation. Source: Feldtbuch der wundartzney, Hans von Gersdorff 1517; http://clendening.kumc.edu/dc/rm/16_33p.jpg

3.2 Simpson's method of administering chloroform. Source: K Bryn Thomas, The development of anaesthetic apparatus (London UK: Blackwell Scientific Publications, 1975), 249 Fig 7.1

3.3 Dental surgery 1900. Source: Geoffrey Kaye Museum of Anaesthetic history, Melbourne, Australia.

3.4 Distribution of global mortality. Source: WHO Global burden of disease project 2002, version 1. http:/ /www.automotive-online. com/articles/2008/05/top-10-fatal-road-crash-risk-f.html Accessed 5-10-2009

3.5 D E Jacksons 1918 machine. Source: D E. Jackson, Anesthesia equipment from 1914 to 1954 and experiments leading to its development. Nov 1955, fig 5, pp 962 Vol 16 Anesthesiology, 953-969.

3.6 Dreyfuss drawings. Source: Henry Dreyfuss Associates, The measure of man, (New York: Whitney library of design, 1959).

3.7 ASA Closed claims study. Source: A R Aitkenhead, Injuries associated with anaesthesia. A global perspective. BJA 952005 95-109. (From pp 100), From K L. Posner Anesthesia Patient Safety Foundation Newsletter 2001.

4.0 Open drop method of anaesthesia. Source: Geoffrey Kaye Museum of Anaesthetic history, Melbourne, Australia.

4.1 The developing convention of use. Source: B Guy 2009

4.2 Boyle machine 1930 with right exit and flowmeters. Source: O M. Watt, The evolution of the Boyle apparatus, 1917-67. Anaesthesia Vol 23 No 1 1968, 106. 
4.3 Clover inhaler 1877. Source: K Bryn Thomas, The development of anaesthetic apparatus ( London UK: Blackwell Scientific Publications, 1975), 17. fig 1.12.

4.4 Wilson-Smith Ether inhaler 1899. Source: K Bryn Thomas, The development of anaesthetic apparatus (London UK: Blackwell Scientific Publications, 1975), 22. fig 1.18 (CKC 13).

4.5 Joseph Thomas Clover administering chloroform anaesthesia with Cattlin bag and face piece. Source: K Bryn Thomas, The development of anaesthetic apparatus (London UK: Blackwell Scientific Publications, 1975), 15, fig 1.10

4.6 Gwathmey 1914. Source: K Bryn Thomas, The development of anaesthetic apparatus (London UK: Blackwell Scientific Publications, 1975),141 fig 3.38 (from Gwathmey, J T. Anesthesia, New York: Appleton), 174.

4.7 Marshall apparatus 1917. Source: K Bryn Thomas, The development of anaesthetic apparatus (London UK: Blackwell Scientific Publications, 1975), 145 fig 3.42 (from Marshall G. 1920 Two types of portable gas-oxygen apparatus. Proc. Roy. Soc. Med. 13, Pt 1 (Anaesth Sect), 18.

4.8 Boyle apparatus 1919. Source: K Bryn Thomas, The development of anaesthetic apparatus (London UK: Blackwell Scientific Publications, 1975), 148. fig 3.46 (from the Lancet 1919, i,),226.

4.9 Connell machine 1937. Source: K Bryn Thomas, The development of anaesthetic apparatus ( London UK: Blackwell Scientific Publications, 1975),168. fig 3.71 (CKC 71)

4.10 Manufacturing styles, MIE Comprex. Source: Geoffrey Kaye Museum of Anaesthetic history, Melbourne, Australia.

4.11 BOC Boyle machine 1965. Source: D J. Wilkinson, "Henry Edmund Gaskin Boyle 1875-1941," in The History of Anesthesia: Fifth International Congress ed. Jose C. Diz. 
Avelino Franco. Douglas R. Bacon. (Amsterdam: Elsevier Science, 2002), 613-617.

4.12 Boyles Model G. Source: Geoffrey Kaye Museum of Anaesthetic history, Melbourne, Australia.; Datex Ohmeda Astevia. Source:http://www.gehealthcare.com/euen/anesthesia/ products/aestiva-5-family/index.html;

4.13 Dräger apparatus 1910 and 1902. Source: DrägerMedical, The History of Anaesthesia at Dräger, Drägerwerk AG. Vol 1. (1996):14,18.

4.14 ICI film still. Source: Margaret Thomson, director, "the technique of Anaesthesia Series No 2. Open drop ether," ICI productions, Produced by Realist Film Unit, 1944.

4.15 Gillies Mark III machine 1951. Source: A G McKenzie, Anaesthesia 200863 771-777 (fig 7 p 774) (BOC pamphlet 1951)

4.16 Left and right versions of the Aestiva. Source: Author 2008

4.17 Boston Anesthesia System. Source: ASA Newsletter September 2006 Volume 70 No 9. World's first computer-controlled anesthesia machine donated to WLM.http://www.asahq.org/ Newsletters/2006/09-06/kitz09_06.html

4.19 Dräger Physioflex. Source: http://www.anesth.hama-med.ac.jp/ Anedepartment/museum-masuiki.asp). (accessed 2/12/2008)

4.20 Dräger Zeus. Source: Left magazine CARE Drager article in UK (22-2-2007). Right Dräger http:/ /www.dräger.com (1-7-2009)

4.21 GE Aysis. Source: GE http://www.gehealthcare.com/usen/ anesthesia/products/anesth_aisyscarestation.html (accessed $22 / 2 / 2007)$ 
5.2 Edgar Pask. Source: Maltby J Roger. Notable names in Anaesthesia. (London, Royal Society of Medicine Press Ltd. 2002) 161. From the Nuffield Department of Anaesthetics

5.3 The waiting hand. Source: Amy Schwartz, "Collaborative design: turning surgeons into design partners" (Paper presented at the AAMI Human factors, ergonomics, and patient safety for medical devices meeting, Washington, DC. June 28-30, 2005).

5.4 Examples of a misinterpreting oven controls and the results. Source: Author 2009

6.0 Anaesthetists passing on knowledge through design experiments Source: Author 2009

6.1 Housekeeping observation Source: Author 2009

6.2 Operating theatre dynamics observation Source: Author 2009

6.3 Machine customisation observation. Source: http://www. anesth.hama-med.ac.jp/Anedepartment/museum-masuiki.asp) accessed 1/10/2007

6.4 Posture and fatigue observation Source: Author 2009

6.5 Communication observation Source: Author 2009

6.6 Particapant drawing Source: Author 2009

6.7 Participant communicating Source: Author 2009 
6.8 Participant making Source: Author 2009

6.9 Participant playing out Source: Author 2009

6.10 Simulation validation Source: Author 2009

6.11 Component mapping Source: Author 2009

6.12 Component spheres Source: Author 2009

6.13 Screen positions Source: Author 2009

6.14 General layout Source: Author 2009

6.15 Covered wagon and the rear of a machine Source: Author 2009 


\section{INTRODUCTION}

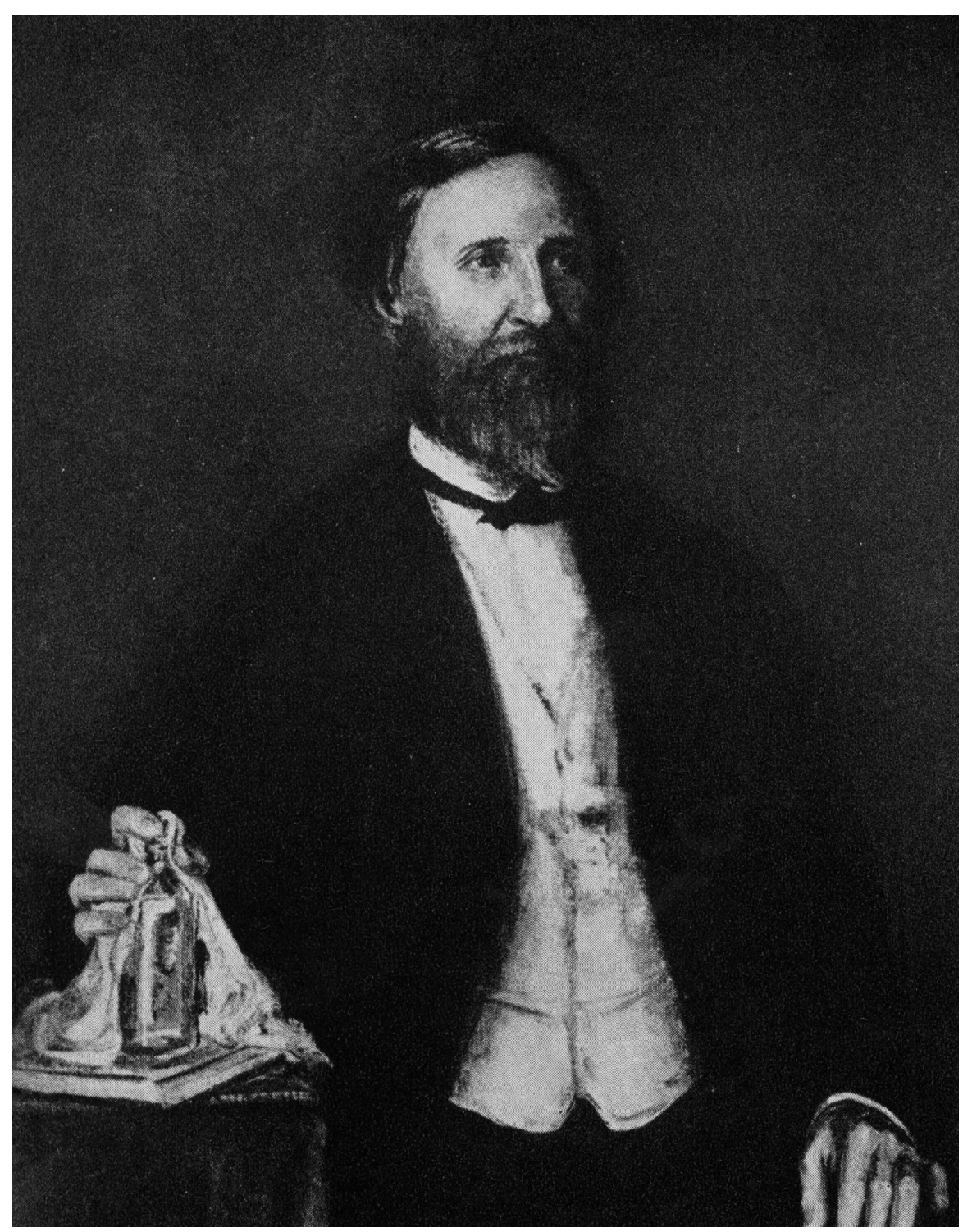

Fig 1.0 Crawford W. Long. First to use ether for the purpose of producing surgical anaesthesia for other than dental operations. This portrait portrays the early anaesthetists on the frontier of pain and suffering, armed only with rag, bottle and good judgment.

Source: Portrait by Richard Lahey. Thomas E Keys 1945 



\section{INTRODUCTION}

To err is human; to forgive divine ${ }^{6}$

\section{Background to study}

The rise of technology has become so interwoven into society that it may now emerge as surrogate humanity; a relationship where society at most levels is ignorant of technology's complexities yet retains faith in use. This movement challenges the traditional methods of creativity and innovation with the task of applying the sensitivity of humanity to technology.

This is one view - that often we do not fully understand the technologies we use or how the result of our actions occurred. This task-artefact relationship has developed in the progressive movement of socio-tool to socio-technical, ${ }^{7}$ carrying an explicit residue of old relationships and new latent complexity in every technological step forward. The forum of healthcare patient safety is continually bombarded with criticism lending itself to incubating a patchwork of new, technology derived, phenological solutions. ${ }^{8}$ In effect many of these solutions break new ground and prove indispensable, whilst others release a potential for mishap upon an already burdened workforce. ${ }^{9}$

Today's digital crossroad of technology presentation and the physicality of products deny users an enlightened interaction - each is restrained by technical and physical qualities, held apart by their genetic origins. The future and the past,

6. Alexander Pope, An Essay on Criticism (1711)

7. David Woods and Sidney Dekker, "Anticipating the effects of technological change: a new era of dynamics for human factors," Theoretical issues in ergonomics science Vol 1, No 3, (2000): 272-282.

8. National Patient Safety Foundation at the AMA. "Public opinion of patient safety issues research findings," (Louis Harris \& Associates. September 1997): http:/ /www.npsf.org/pdf/ r/1997survey.pdf (accessed 1/8/2008). ; Phenology, the study of recurring phenomena. Collins English dictionary.

9. Weinger, "Anesthesia equipment and human error," 319-323. 
information and artefact, these properties should partner in innovation rather than literally support each other. Problems are no longer restricted or reside with an individual but are autonomously transforming complete systems. How new insight may be conceived to aid innovation is at the heart of this work. Thus I ask the question; why do we have what we have and what could we have?

\section{The clinical focus}

The study will focus on the physical 'composition' or designed 'form' of the anaesthetic machine and its interactions with anaesthetists. The field of anaesthesia predominantly exists as a service to surgery - to balance human interest, pain and life, with the optimisation of physiological and anatomical conditions. Effectively providing the best state of; muscular, tissue, vascular, respiratory, and neurological conditions for surgical intervention.

Technology's advancement through digitisation necessitates the translation of information and actions as an understandable and trustworthy link to the user. A script of numbers may be the values of an action, or an electronic decision resulting in a patient's physiological change, but as an interface it lacks recognition of the balancing act undertaken in human cognition. ${ }^{10}$

This advancement, ${ }^{11}$ implementation and presentation of technology upon equipment inflicts changes in use. Direct or indirect physical interactions confluence with the functionally intentioned aesthetic form, becoming the ergonomic environment. These changes alter human behaviour and response through lost affinities and confusion; hindering the solving of many critical yet controlled occurrences, creating black holes of confusion. ${ }^{12}$ Cognitive overload is present in the mental translation of information to knowledge, and hence actions. Within a high risk environment, complex culture and physical tasks

10. M B. Weinger, Foreword A Clinician's perspective on designing better medical devices; in Designing usability into medical products, by Michael E. Wiklund and Stephen B. Wilcox, (Boca Raton : CRC Press 2005) ix. ; Frank A. Drews and Dwayne R. Westenskow, "The right picture is worth a thousand numbers: data displays in anesthesia," Human Factors Vol 48 No 1 (2006): 59-71. ; Weinger, "Anesthesia equipment and human error," 319-323.

11. Moores law.

12. P Dalley. B Robinson. J Weller. C Caldwell, "The use of high fidelity human patient simulation and the introduction of new anaesthesia delivery systems," Anesthesia and Analgesia 58 (2004): $1737-1741$ 
deems technology as no quick fix panacea. ${ }^{13}$ In the hope of alleviating concerns and refreshing the bond of trust between user and equipment, demonstration of new capabilities arrives in the form of a bigger manual and additional training.

\section{Thesis audience}

Although the work of a thesis is essentially academic, I consider this work is about the learning relationship of creative and clinical professions embarking on concomitant research. In considering the target audience for this thesis, principally this work is for and about designers and anaesthetists. In summary, the subject matter may be rendered accordingly. First it may be read by all interested in design and the design process. Second, it may be read by those in the healthcare and critical industries who are interested in equipment design and user interaction. Third it may be of interest to those seeking future design initiatives and who are occupied in areas where the clinical or professional group under study is complex in its activities, difficult to access, address or generalise about.

This study is about overcoming assumptions, and presents a note of caution in applying design intuition to gain deep knowledge of interactions, environments and equipment - questions that may be asked of a designer or the related design profession. Targeting new angles to view or understand humanity and technology in complex environments, the study seeks to demonstrate the reward and ramification of investigating the elite professions.

Presented as a broad informative and investigative methodology, the research constructs a proactive design base, cumulating in active involvement, an informed critical analysis and methodological vision.

The research does not seek to mirror complex Human Factors engineering studies, nor warrant a dismissal of established research methods. The study intends to present a unique research trajectory directed at a similar target.

\section{Thesis layout}

Chapters One and Two present the project, introducing the subject matter, context

13. Steve Lohr, "Doctors journal says computing is no panacea," New York Times, March 3, 2005, http//www.nytimes.com/2005/03/09/technology/09compute.html (accessed January 18, 2008). 
and research approach. Part One provides a historical account of the advent of anaesthesia and equipment design, while investigating ergonomic origins and the paradox of design and activity. Part Two formulates a methodology to move forward and apply early findings to design experiments; detailing the immersion into a clinical context and the process of designing with anaesthetists, concluding in a discussion of the project and future initiatives.

\subsection{The research problem}

The development of anaesthesia equipment over the last 160 years began with hand-made and often home-made personal items. Many of these early items display immense sophistication in the working of rudimentary materials whilst instigating new design criteria for a new profession - In one example, made to a size appropriate to fit under a top hat (Figure 1.1).

With the advent of the modern hospital, ${ }^{14}$ various rudimentary components came together, first as apparatus, then as furniture dressed with a chemistry set. In moving from scientific apparatus to industrial machine, much of the

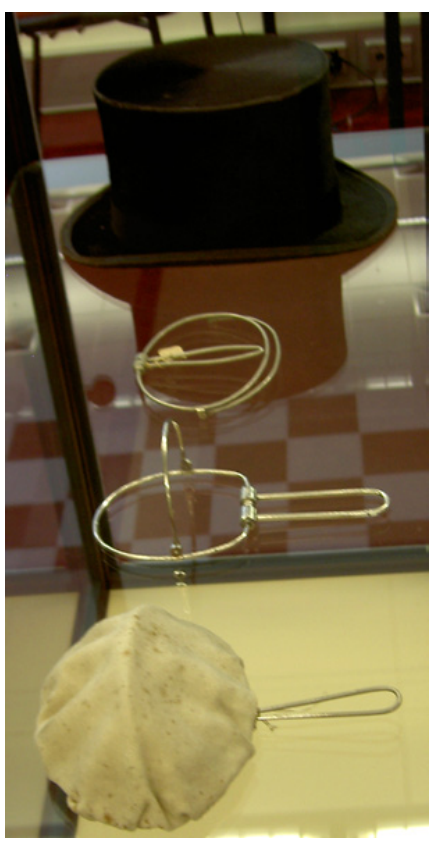

Fig 1.1 Skinner's chloroform mask 1862

Source: Author (Geoffrey Kaye Museum)

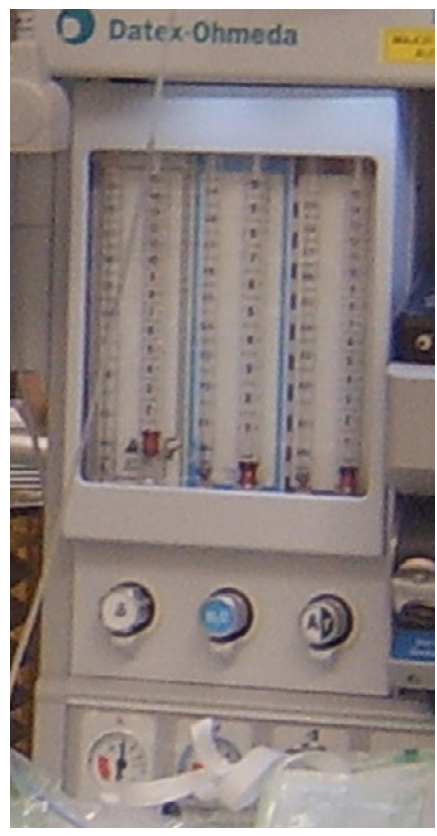

Fig 1.2 Flowmeters or Rotameters

Source: Author

14. Roy Porter, Blood and guts, a short history of medicine (London: Penguin Books, 2002), 135. ; Prior to the 1800s hospitals were institutions of care, compassion and convalescence. 
chemistry was buried within, controlled and relayed to the patient through jewel like flowmeters (Figure 1.2).

For most manufacturers, the current the anaesthetic machine, renamed the workstation, still retains its early structural form, (a chassis carrying components, table and draws). In doing so, it has become an ergonomic dilemma of electronic wizardry and symbolic form. ${ }^{15}$ Although now cleansed to a showroom statuary medical aesthetic, in reality it is overweight and bedraggled with auxiliary equipment, consumables, cables, sounds and screens (Figure 1.3). This suggests that this situation is a design problem between artefact, context and technology encompassing use, safety, environment and user. ${ }^{16}$ Few studies exist
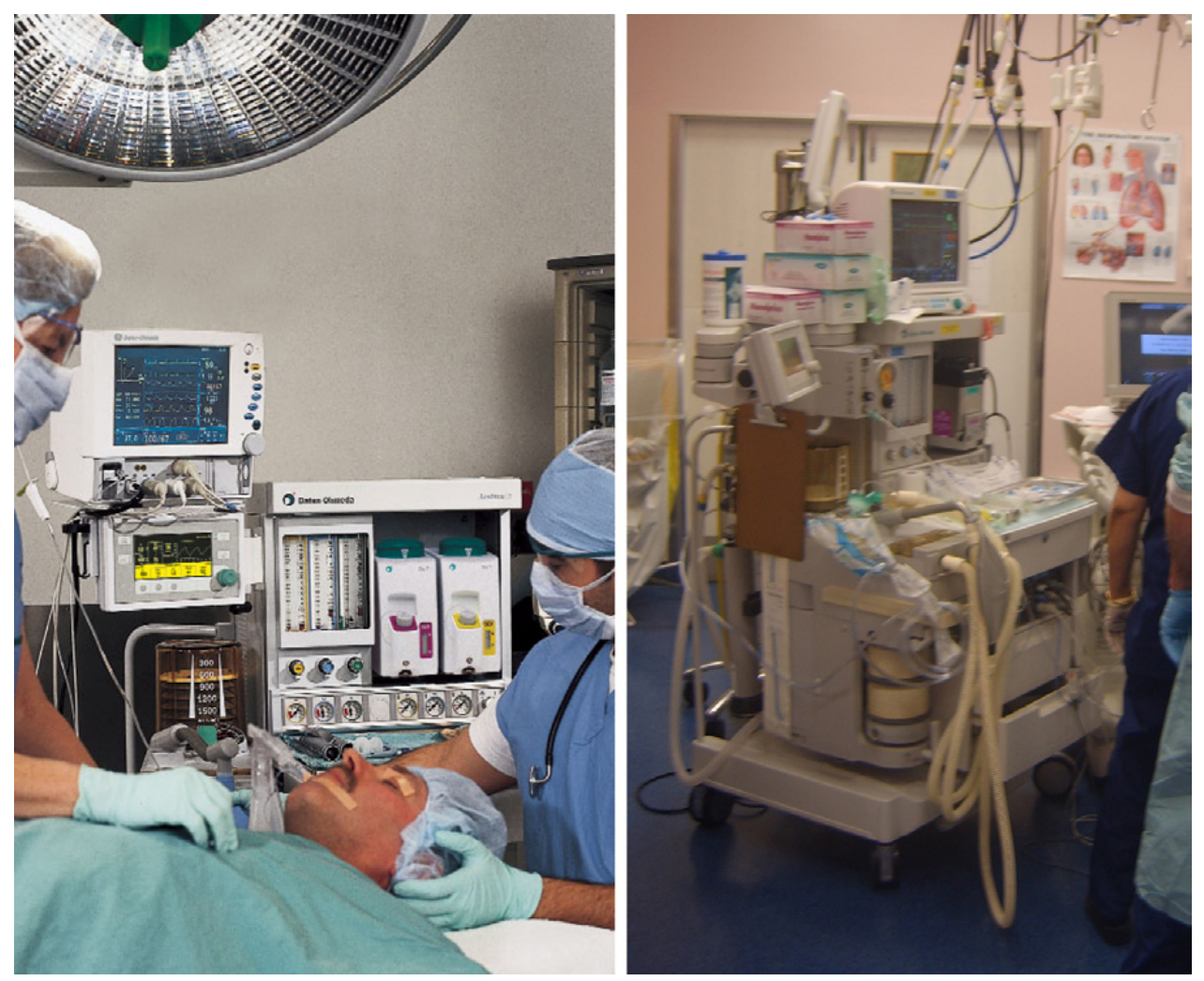

Fig 1.3 As advertised and as used Datex Ohmeda Aestiva Source: Image left GE Healthcare. Image right Author

15. Dräger AG continues an independence in design that differs in both aesthetics and technology approach. ; J.W.R. McIntyre, "Man-machine interface: The position of the anaesthetic machine in the operating room," Can. Anaesth. Soc. J Vol. 29, No. 1 (1982): 74-78. ; Jacob F, Seagull. Russ Ward. Julie Mills. Christopher Goodrich. Yan Xiao, "Measuring awkwardness of workplace layout: dispersion of attentional and psychomotor resources within the anesthesia workspace," Proceedings of the buman factors and ergonomics society 48th annual meeting (2004): 1755-1758.

16. K. Decker and M. Bauer, "Ergonomics in the operating room-from the anesthesiologist's point of view," Minimally Invasive Therapy \& Allied Technolologies Vol.12, No. 6 (2003): 268-277. 
to demonstrate or promote alternative design discussion.

\section{In quest of the problem}

What design process can be developed, tested, and applied to examine, question, and influence the future design evolution of the anaesthesia machine?

- First, the understanding of what an elite profession is - in this case what anaesthetists are and do - is fundamental to this study.

- Second, design acting as confidant may allow anaesthetists to express their ideas and become designers.

- Third, challenging anaesthetists to present their knowledge and desires as prototypes.

Evidence from these will provide a first-hand insight into activities, affinities and aspirations. The resulting findings are posed as directions and not directives in the demonstration of users capability in the advancement and use of technology in healthcare. These propositions underpin the growing complexity and desires of healthcare in the future, including the needs of those that choose an elite profession within a hidden environment of high risk and continued public desire.

\section{Evolution as a hypothesis?}

What constitutes an evolution in medical equipment when design is both implicated and responsible for delivering technology while balancing safety? This question frames the work in developing critical thought on a design evolution, in the light of a pervasive dominance in engineering design, standards, regulations and the practices of humans. To gauge the capability for design methods to adapt to technology, ${ }^{17}$ and the plethora of medical change, we must understand the evolutionary passage within the context of elite professions where human life is at stake.

To answer 'why do we have what we have - and what could we have?' The study aims to present an historical overview of anaesthesiology, to explore the relationship between designer and user, and suggest through prototype

17. Ken Friedman and G K. VanPatter, "New Design Research: Leading or Following?," NextD Journal ReReThinking Design. Issue 1 Conversation 1.2 (2003): 8. 
experiments, new prospective design concepts derived by anaesthetists. Responding to the defining question of this study contributes an understanding of motivating influences in the development of medical equipment and the implementation of technologies. This study illustrates an in-depth roadmap, tethering these influences to the design capability of collaborative experiments and new design initiatives.

\section{Defining the questions}

- What connections do the origins and development of anaesthesia have with current design and equipment use?

- What constrains the fostering of new ideas?

- What relationships and constructive methods can designers make with elite professions/anaesthetists?

- Can a specialist group provide evaluative new visions and knowledge?

The research question's aim is to understand a profession from within its context; to understand the changes that technology and legislation are bringing; and how these changes may be explored to elicit insight and communicate future possibilities. This positions the research within a historical and contemporary field and endeavours to balance the considerations of science with those of society.

Accumulating knowledge for design in the field of elite professions means developing new methods that identify areas that are important. ${ }^{18}$ These can be defined as:

- The rapid rise of technology and the shift from analogous mechanical systems to digital 'thinking' systems.

- The physical presence of equipment and design as evidence based directives rooted in the task.

- An awareness of anaesthetists' manipulation of their habitat and equipment to control their tasks.

18. Sidney W. Dekker, "The re-invention of human error," (Technical report, Lund School of Aviation, Ljungbyhed Sweden, 2002-01), 1-15. 
Brought together, is design accounting for the task of patient management, or an anaesthetist's management of operative care?

One of the key difficulties or questions for healthcare design is how to complement tradition with new technologies while retaining the product/ person trust (often presented as a visual interface). If designers choose not to utilise physical features to retain this, the design must be delivered in such a way that knowledge can be transparently applied and understood. An example is the difference between training to operate equipment and training to facilitate surgery. New technology is often dispensed to healthcare as a screen based presentation defaulting to a black box administration of information and interactions. The problem of reduced situational awareness due to a troubled hierarchy between screen, form and environment are realised as a work-around. ${ }^{19}$ These avoidance conflicts in design are well recognised by users yet subjective, due to the diversity of anthropometric values and constant variations in procedures, techniques, nuances and habits. ${ }^{20}$

This research aims to investigate design issues not from within technology as an engineering perspective, but as design originating from the user, embracing humanity, physiology, satisfaction, task, and environment. In questioning an evolution, an overarching implication is the method of bringing designers into the realm of elite professions to develop:

- Trust in this relationship.

- Truth in the passage of information, ideals, and insight.

- Support and methods to enable participants to freely communicate ideas.

- A design based evidential dialogue suitable for the clinical and design professions.

19. Drews, "The right picture is worth a thousand numbers: data displays in anesthesia," 59-71.

20. Richard I. Cook. David D. Woods. Charlotte Miller. "A Tale of Two Stories: Contrasting Views of Patient Safety," (Report from a workshop on assembling the scientific basis for progress on patient safety, National Health Care Safety Council of the National Patient Safety Foundation at the AMA, 1998), 40. 


\subsection{The status of healthcare and design}

To Err is Human, ${ }^{21}$ a document released in 2000, drew worldwide attention to the status of the healthcare industry; the prevalence of error resulting in significant mortality and morbidity, and the impact technology is having on clinical equipment. The staggering statistics of 44,000 to 98,000 preventable deaths annually due to medical error within the United States is relative to a 747 crashing every working day. This has not been the first 'wake up call' to the medical profession and it will not be the last. The difference in this document is the substantial proof in the complexities of operating equipment at the sharp end - the connection between clinician and patient and the influential effects of the managerial and institutional blunt end. To err may be human but to forgive may no longer be acceptable.

Considering the cultural aspect in the concrete realisation of products is a goal of industrial design; to see as a whole, to empower function with technology, and humanity with understanding and emotion. The culture of healthcare is steeped in specialisation, hierarchies, personalities and environments; adjacent yet far removed from everyday trivialities - an occupation submerged in reward and risk.

\section{Safety and technology}

There is increasing awareness of the interactions between the health environment, biomedical devices, health professionals and patients. This generally comes under the heading patient safety, and may be described in design terms as ergonomics, human factors, and usability engineering. Biomedical equipment exists to engage and facilitate operative intervention, pain management and physiological stability. Each of these must be tailored to the unique physiology of the patient via human interaction. There is now recognition of the importance of medical device and equipment design in healthcare. Device design, and the interaction with users can result in unintended use or non-deliberate misuse of equipment. The result ranges from minor damage of equipment through to significant harm to patients or health professionals. This is becoming recognised as an area of importance in the application of research and development in equipment design, 
increasingly evident in the progression from operating theatre and hospital care to home based care. ${ }^{22}$

The June 2005 meeting "Human Factors, Ergonomics, and Patient Safety for Medical Devices" in Washington DC, (organised by the Association for the Advancement of Medical Instrumentation AAMI), highlighted the benefits of including industrial designers in the development of biomedical devices. This was demonstrated in a broad range of devices from hand held tools for nasal surgery through to the digital interface of computer assisted surgery for knee joint replacement. However, it was also commented that many other devices, such as intravenous infusion pumps and patient controlled analgesia syringe drives, ${ }^{23}$ remain the 'whipping boys' of biomedical device usability. These devices are a significant cause of patient morbidity and mortality, and despite the biomedical engineering being significantly advanced there are still significant gaps in the interface between users and the digital control technologies within them.

These complexities come at a time of society's avid interest, expectations and criticism of healthcare. This is reflected in an increased workload applying new procedures, drugs and technology ensuring extended human life - and for some, a more beautiful life. The influence of computers has revolutionised this industry and parallels technology used in everyday life. As in everyday life, technology aligns to the needs of our immediate culture, and in doing so, influences the culture of our greater society.

New design methods are required to understand the unique viewpoint, tasks and non linear interactions between clinicians and their equipment. Clinicians may be defined as those whose tasks directly affect the patient in operative procedures i.e. surgeons, anaesthetists, perfusionists and nurses.

\section{Human-tech ${ }^{24}$ connections}

Complex research methodologies in technology and humanity are well established

22. R K. Webb. W J. Russell. I Klepper. W B. Runciman, "Equipment failure: an analysis of 2000 incident reports," Anaesthesia and Intensive Care 21 (1993): 673-677. ; Weinger "Anesthesia equipment and human error," 319-323.

23. Kim Vicente, The buman factor: revolutionizing the way people live with technology (Toronto, Canada: Alfred A. Knopf, 2003), 42. ; Kohn, To err is human: building a safer health system, 24. Vicente, The buman factor: revolutionizing the way people live with technology, 50 
but the broader understanding of how these meet and work together as one, is in its infancy. ${ }^{25} \mathrm{Kim}$ Vicente examples the work of scientist and academic C P Snow's 1950s lecture 'the two cultures' to address the chasm between the two. ${ }^{26}$ A chasm Charles Dickens made famous in his pivotal commentaries on society and the evolving ramifications of industrialised change.

Catastrophic incidents or accidents blamed on human technology interactions have opened the floodgates to incident and accident analysis. Defining the causes not only satisfies issues of liability that may weigh heavily on companies and the environment, but also reverberates into society impacting on our trust in technology. Aviation has paved the way in human error studies and the application of technology to fly by wire systems, simulation, cockpit recordings and incident reporting. With these innovations, aviation has created openness in incident reporting and protection from litigation. This field has rapidly become a research ally and methodology resource to healthcare. The link between aviation and healthcare has become a sharing pool, a precedent for healthcare products, user training, and error investigation. ${ }^{27}$ This link is fragile outside of engineering in its comparison of; an aircraft to a human, an aircraft to an anaesthesia machine or cockpit, or flight deck management to operating theatre activities. All leave out an important additional value, the patient. ${ }^{28}$ The team work, decision making and tasks are different, the legalities and consequences of failure differ, and finally the route flown is never the same.

\section{Design visions for an elite profession.}

The airline industry is queuing up to buy the latest technology. The Airbus 380 and the Boeing 787represent design communication, technology presented and valued through new visions of safety, efficiency and progress. What has restricted new visions in anaesthesia? Is it due to context and time; a habit based resilience authored by risk in the operative procedure and underwritten by the hidden nature of the operating theatre; or a social role of care rather than intervention, responsible as much for pain as suffering.

25. Ibid., 29

26. C P. Snow, The two cultures and the scientific revolution, Rede lecture (Cambridge, England: Cambridge University Press,1959).

27. Eduardo Salas. David Baker. Heidi King. James Battles, "Opportunities and challenges for human factors and ergonomics in enhancing patient safety" Human Factors Vol 48 No 1 (2006): 1-4.

28. Drews, "The right picture is worth a thousand numbers: data displays in anesthesia," 59-71. 
Or is it more pragmatic, that technology is the interface conduit - and design, the despondent child? There are already working examples of virtual healthcare and robotic operations, these all return to humanity's view of the surgeon as centre and solving all. Is the answer buried in acknowledging that anaesthetists' tools are so much more complex, yet as personal in use as a surgeon's scalpel, coinciding with a misunderstood reluctance to change?

In the first 100 years of anaesthesia, anaesthetists passed on a rich tradition of interdisciplinary innovation, borrowing and technology adaptation to a multitude of engineers. Anaesthetists are now rarely provided with conceptual ideas, future visions, or prototypes. ${ }^{29}$ Surgeons have a long tradition of innovation in equipment; the tasks are tactile, dexterous and applied directly, indicating a future path towards robotics. Anaesthetists' innovations are typically parts of a greater system i.e. pulse oximetry, capnography and BIS monitoring, applied both directly and indirectly (physiological and pharmacological). ${ }^{30}$ Software and interface may represent the anaesthetic tool of the future.

\section{Chapter conclusions}

The profession of anaesthesia has become a leader in applying human factors research techniques and systems approach to safety in healthcare. Much of this progress can be attributed to academic anaesthetists adopting forward thinking techniques as an 'inside out approach' in which the practitioners are also the researchers. ${ }^{31}$ Suggesting capability may also lie in relationships with industrial designers.

The hypothesis is that the iterative design evolution of the anaesthesia machine's physical design composition is known; therefore it is safe, usable, and acceptable. The investigative issue underlying this is 'why do we have what we have and what could we have'? The hypothesis will be tested through the four defining questions on page 9. These can be summarised as: can we trace the design evolution and

29. M B. Weinger, "Vision of the future of perioperative information management," Anesthesia Patient Safety Foundation Newsletter 15 No 4 ( 2000):

30. 'We are presently operating on patients with instruments.... as crude as agricultural machinery compared with the technology of advanced avionics.' Quoted in J E A. Wickham, "Future developments," British Medical Journal Vol 308 No 6922 (1994): 193-196.

31. David M. Gaba, "Anaesthesiology as a model for patient safety in health care," British Medical Journal 320 (2000): 785-788. 
identify constraints upon new ideas, and can we instigate a contextual inquiry, an experiment to test whether anaesthetists can provide new design knowledge?

How this is studied from a design viewpoint in respect to the hidden nature, prospective methodological approach, and accessibility issues is defined in the next chapter. 


\section{RESEARCH METHODOLOGIES}

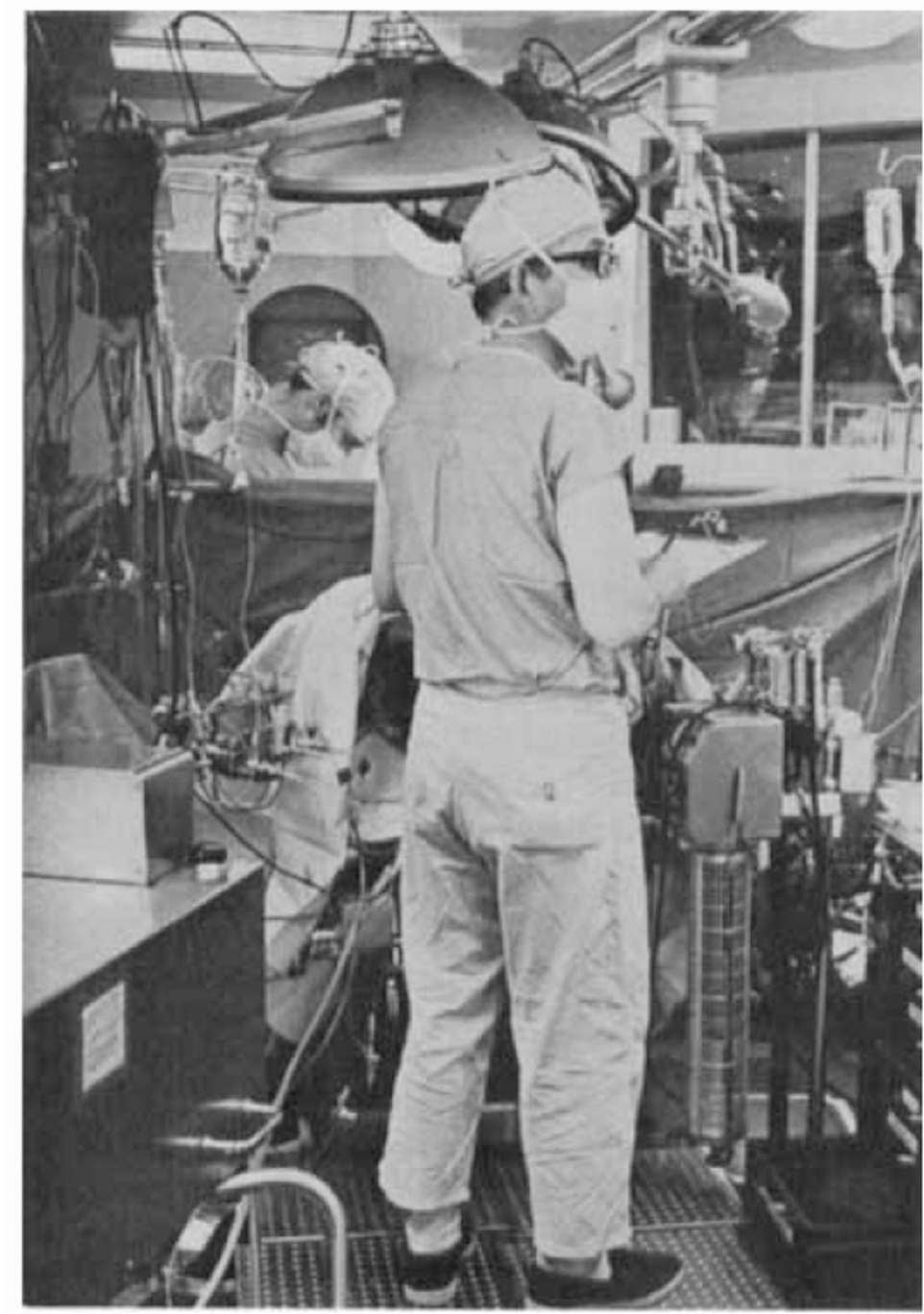

Fig. 1. Typical distractions away from the patient.

Fig 2.0 Albert Drui's 1973 study of the anaesthetists environment, connecting analysis to redesign, anaesthetists to engineers, and the design of a complete system rather than individual components.

Source: Drui et al,1973. 


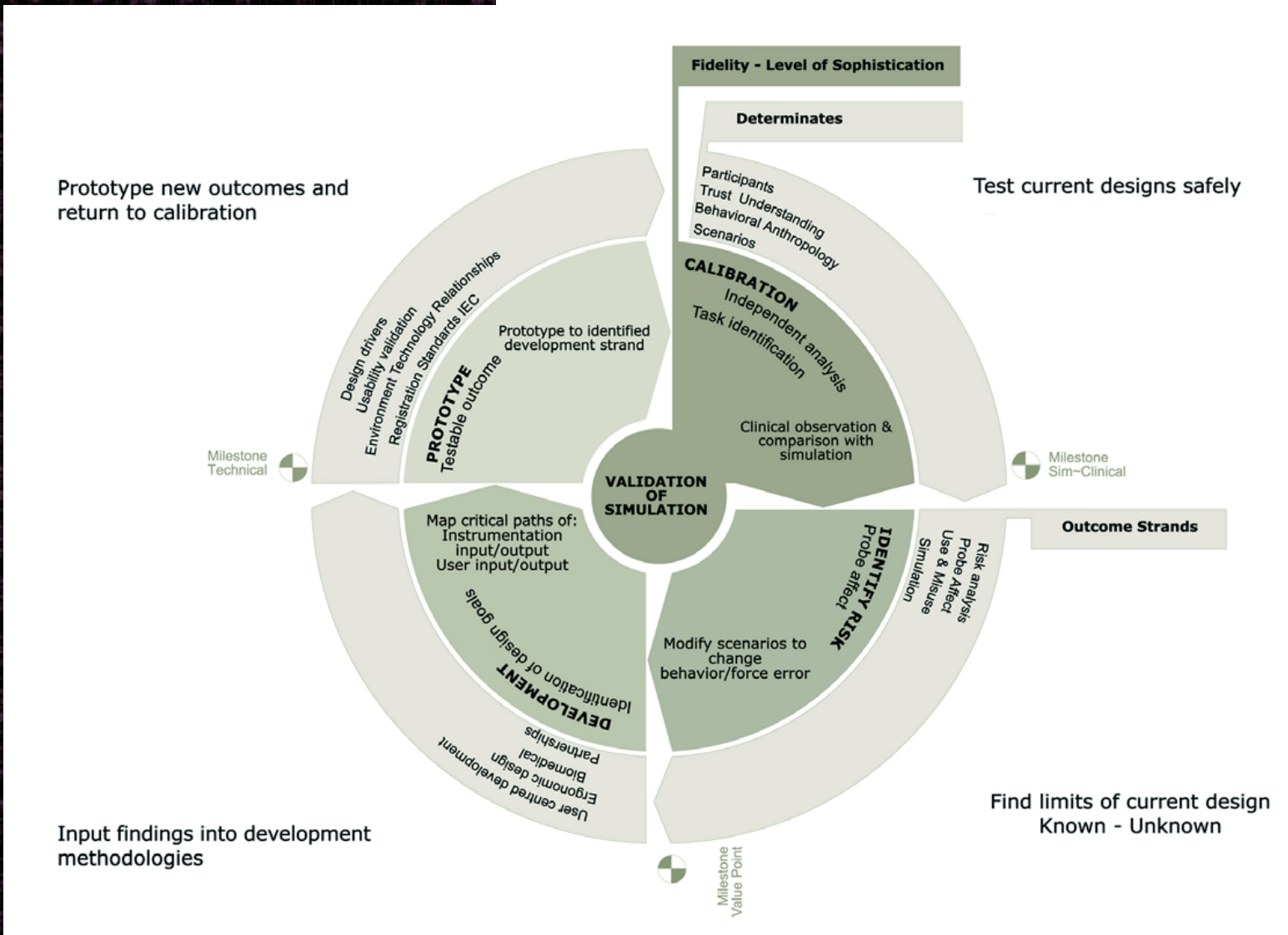

Fig 2.1 Early ideas for the project looked to identify risk through a methodology of probe affect. This required the need to validate simulation, a task later understood as suitable for simulation experts not industrial design.

Source: Author 2009 


\section{RESEARCH METHODOLOGIES}

What we have now is what we are used to rather than the ideal ${ }^{32}$

Chapter one introduced the collective aims of the study with relevance to understanding anaesthesia, equipment, and the operating theatre in the constant uncouple-able relationship of humanity to technology. Less widely discussed than conventional science's confirmation of a hypothesis through controlled experiment, ${ }^{33}$ is the discovery phase of hypothesis generation, integral to this investigation.

\section{Reasoning behind the question}

Outlining 'research methodologies', establishes both a foundation for the question, and the method of inquiry. How literature and subject will be tethered to context, profession and artefact as a prospective methodology for discovery. Revealed here as a linear progression, the process of information gathering and hypothesis generation is entwined and reflective. This epistemological mix will assist in extracting a new and relevant, yet attainable design investigation.

To achieve this, precedent studies pertinent to industrial design, clinical equipment and the anaesthesia machine are discussed. These are balanced against investigative and contextual constraints, concluding with a research approach.

Three studies are identified that contribute synergies to this work, being exponents of innovation and participative design methods within a clinical context. Their methods are interpreted here as philosophies of design.

32. Boquet, "The anaesthesia machine: a study of function and design," 61-67.

33. E M. Roth. C K. Christian. M Gustafson. T B. Seridan. K Dwyer. T K. Gandhi. M J. Zinner. M M. Dierks, "Using field observations as a tool for discovery: analyzing cognitive and collaborative demands in the operating room," Cogn Tech Work 6 (2004): 148-157. 


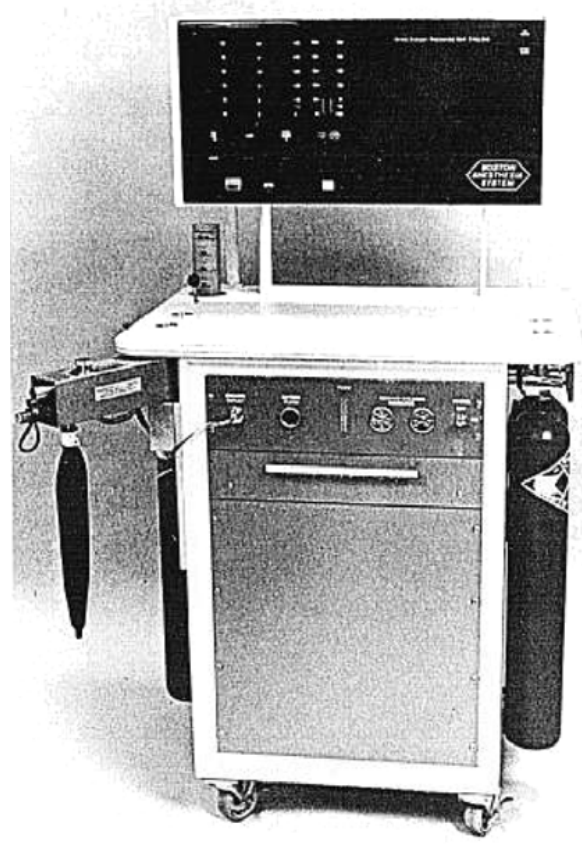

Fig 2.2 The Boston Anesthesia System developed in 1976.

Source: Cooper et al, 1978.

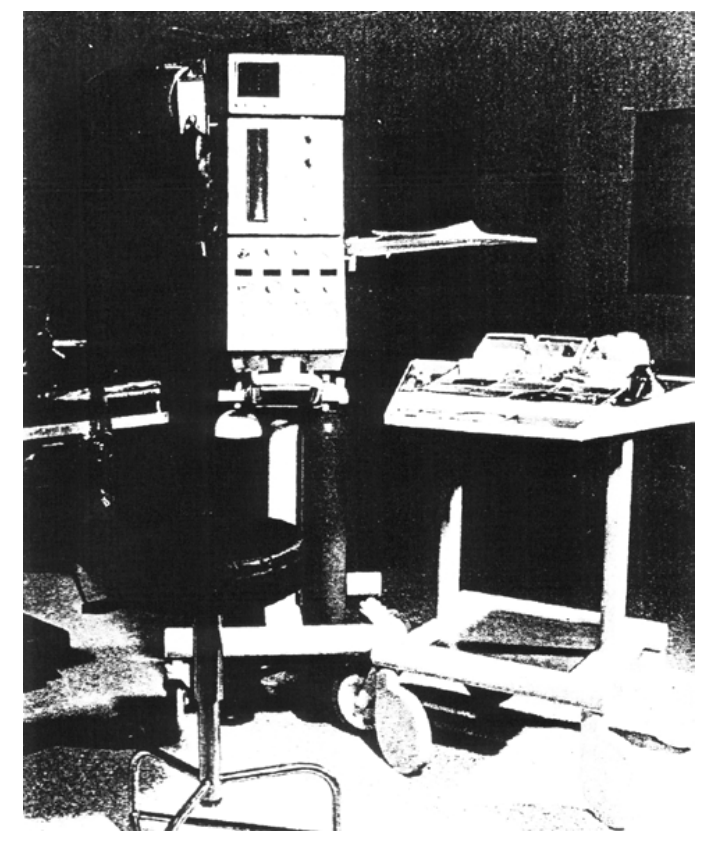

Fig 2.3 A study of function and design, Boquets 1980 form study.

Source: Boquet et al, 1980.

First, passion and naivety: Jeffery Cooper and a research team developed an electronic anaesthesia machine in $1978^{34}$ (Figure 2.2). While this project demonstrated a novel prospective approach generating discussion, it was built on a belief that conceptual ideas, once made can be delivered to a market and desired by industry. ${ }^{35}$ This study is a unique approach in anaesthesia design in applying technology to the role of anaesthesia administration - not as independent features or components but a complete reinvention. Many features from this prototype are now relevant to the acceptance of technology by both users and manufacturers.

Second, industrial designer Gavin Boquet and interdisciplinary collaboration: In 1980, a study was published that has become a key reference in research pertaining to anaesthetic machine design or analysis of anaesthetists tasks ${ }^{36}$ (Figure 2.3). The relevance of this work is the collaboration of industrial design and clinicians within the context of the operating theatre.

34. Cooper, "A New Anesthesia Delivery System," 310-318.

35. Jeffrey B. Cooper, "An accidental life: patient safety and biomedical engineering," in This is no humbug!, Reminisences of the department of anesthesia at the Massachusetts general hospital, ed. Richard J. Kitz (Ohio: Atlas books, 2003), 377-419.

36. Boquet, "The anaesthesia machine - a study of function and design," 61-67. 


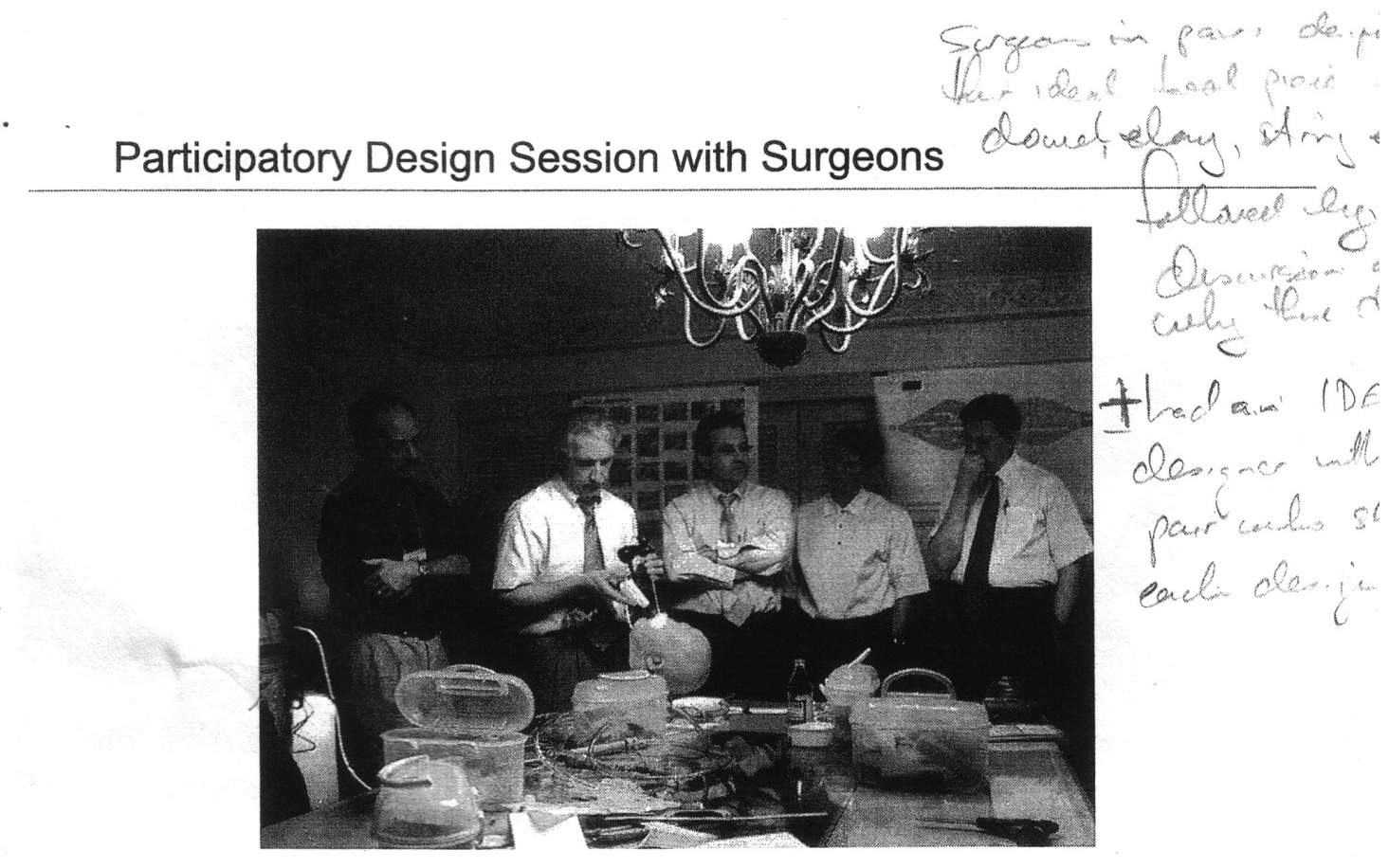

IDDEO

Fig 2.4 Developing the Gyrus Diego by turning Surgeons into design partners, Amy Schwartz and IDEO 2005.

Source: Schwartz, IDEO. 2005.

Third, collaborative design for commercial goals: In 2005 a participatory study was presented by Amy Schwartz that proved the benefit of a qualitative design approach in product development reversing the design instigator from engineering to user creativity and occupational desires ${ }^{37}$ (Figure 2.4).

These three studies underpin the aims of this research. All are collaborative and use clinicians, each partner and centre on the user. Each has narrative with industry during the research process. Finally, each seeks to present findings to the target user group via established professional resources i.e. journal publication. These precedents provide objective starting points by way of comparison in methods, methodologies, ethics, collaboration and outcome.

The precedents are scientific based experiments utilising quantitative and qualitative methodologies, and share a commonality in the targeted professions. The precedent studies span 30 years, differ in global location and

37. Amy Schwartz, "Collaborative design: turning surgeons into design partners" (Paper presented at the AAMI Human factors, ergonomics, and patient safety for medical devices meeting, Washington, DC. June 28-30, 2005). ; Amy Schwartz, http://www.ideo.com/thinking/voice/amyschwartz. 
are ethnographically similar yet differ in design culture. Cited by anaesthesia researchers, all reflect on the end user and activity as a source of design inspiration and information.

The reasoning behind the research question, why and how a prospective method is to be developed and applied, lies in research curiosity and is determined by the established body of knowledge. Essentially, the limitations of critical healthcare industries to produce evaluative, user inspired design hypotheses. To effectively communicate, value, and understand the user, thereby accelerating this understanding in line with technology, translates to safety in the long term. ${ }^{38}$

Gavin Boquet's concluding statement "what we have now is what we are used to rather than the ideal" relays clear findings. Anaesthetists had become used to, or had adapted to technology, and that the configuration of technology could be improved. Boquet's study is the only published research by an industrial designer pertaining to the anaesthesia machine's physical form, and includes one of the most comprehensive task analysis undertaken. ${ }^{39}$ Limitations of Boquet's study lie in his words, "If the prototypes of new concepts could be studied in this way." Boquet founded his design concept by recording interactions with an established format, a reactive design method. Therefore, any design conclusions are based purely on the individual tasks, sequence and frequency constrained by the established machine format, becoming a derivative design composition. Boquet's concept remained untested in any way other than opinion. ${ }^{40}$

The technology designs of Jeffery Cooper differ from Boquet's industrial design bias, and the notion of understanding compositional interaction through task analysis. Cooper and his team proceeded to apply research 'by design', starting with an indictment of the mechanical as an unsafe prescription, and electronics as a new and better method. ${ }^{41}$ In all, taking a deep knowledge of physiology and engineering (design intuition) and 'building' a machine. Thus, applying wisdom

38. Dekker. "The re-invention of human error," 1-15.

39. R Loeb. M B. Weinger. C E. Englund, "Ergonomics of the anesthesia workspace," in Anesthesia equipment:principles and applications, edited by J Ehrenwerth. J B. Eisenkraft, P A. Malvern (Mosby Year Book, 1993), 385-404.

40. Ideas from the Boquet concept were implemented in the Engstrom 2000 machine, from conversations with historians 2008 .

41. Allen K. Ream, "New directions: The anesthesia machine and the practice of anesthesia," Anesthesiology Vol 49, No 5. (1978): 307-308. 
to human factors, technology to the problem, and evaluative testing to the outcome.

The most recent study, although outside of anaesthesia, replaces this designer wisdom with the user as "thought leaders". Amy Schwartz instigates a searching contextual methodology with neither quantified analysis of the tasks or the established design. Schwartz postulates to the users (ENT surgeons) that their ideals, revealed in design assisted prototyping, can be accomplished by engineering through a technological build.

These three precedents exhibit a design led approach; each applies their own professional intuition and response to a problem, each searches through creativity to apply innovation. All lead to discussion, acknowledgment and thus some change. In fact, they have all done their job. Yet due to a variety of reasons (method of publication and limited evaluation), they have failed as a whole to significantly influence the methodologies used by industry (healthcare, manufacture and safety) in searching and communicating alternative design response.

\subsection{Framing the research approach}

This thesis explores the topic of the anaesthesia machine within the paradigm of industrial design, a paradigm originally grounded in form based aesthetics and the pragmatics of manufacture and consumerism, ${ }^{42}$ thereby bridging science, art and humanities. Industrial design as a craft, draws from other disciplines, aligns to the specifics of the given project be it technological, material, social, commercial or ergonomic - ardent in the resulting physical outcome, application and postulation of social good. Industrial design is changing rapidly, adapting to a world that, depending on your status, culture or location, may be in control or spiralling out of - as the implications of a developing society materialise. ${ }^{43}$ This adapting, or adaptation, requires more than ever, an emphasis on past knowledge, new relationships, and a collective understanding of traditions. This allows innovative visions to be forecast to a world that is self governed, aware, and in some way, in control.

42. http://www.idsa.org/absolutenm/templates/?a=89\&z=23. ; http://www.icsid.org/. ; http://www.cca.edu/library/sinel.html

43. Ronald Wright, A short bistory of progress (Toronto: Anasi press, 2004), 130. 
The advent and use of simulation to educate, train, and test procedures may also allow a comprehensive body of knowledge in medical simulation to be applied as a design method. ${ }^{44}$ Primarily this knowledge is held in the capability and limitations of equivalence, scenario scripting, and the recording and analysis of data. In adopting this expertise, simulation may be applied as a record keeper, contextual assurance, and design generator providing an innovation cornerstone.

The methods of simulation, when applied within an interdisciplinary relationship, may become a searching methodology for enticement and extraction. Supplying new visions to an arena dominated by industry and regulatory empirical technical prowess. ${ }^{45}$ This does not apply to all manufactures but defines the backbone of many as a technological governor. ${ }^{46}$ Polarising the application of design to usability, cognitive mapping and human factors engineering - emerges with etiquette steeped in forgotten history and a questioning client base. This statement does not endeavour to discredit the often brilliant work of those in engineering and human factors but draws attention to what we have not yet seen. ${ }^{47}$

The methods for empathetic understanding of desire, satisfaction, capability and culture are well advanced in the consumer product industry through enlisting the public in the research gathering design process. Healthcare is institutional, making accessibility and desire for change complex in comparison.

\section{Studying a profession}

Focusing design research from within a profession is not new and was initially applied to industry to maximise productivity by Fredrick Taylor and Francis Galton. ${ }^{48}$ The institutionalisation of hidden professions has placed limitations on the ease with which these occupations may be studied. Human factors

44. David M. Gaba, Steven K. Howard, Kevin J. Fish, Brian E. Smith, Yasser A. Sowb, "Simulation-based training in anesthesia crisis resource management (ACRM): A decade of experience," Simulation and gaming Vol 32, No 2, (2001): 175-193.

45. Thomas Sutton, "Innovation and control," (2008): http://www.frogdesign.com/designmind/articles/febuary-2008/innovation-and-control.html

46. A device that controls or regulates the speed of machinery. Collins Dictionary.

47. Woods, "Anticipating the effects of technological change: a new era of dynamics for human factors," 272-282.

48. Frederick Winslow Taylor, The principles of scientific management (Harper \& Bros. New York. 1911).; Bulmer, Michael. Francis Galton: Pioneer of Heredity and Biometry (Johns Hopkins University Press. 2003) 
engineering has broached these limitations in allied partnership with cognitive ergonomics and psychology in the need to understand human/technology performance. Early examples are the analysis by Fitts and Jones in 1947, and the critical incident technique described by Flanagan in 1954. ${ }^{49}$ More commonly techniques are applied to ascertain and unravel the origins of disasters. ${ }^{50}$ Within healthcare, much of the research is produced by the medical professions themselves. Due to limited interdisciplinary collaboration and the intensity of professional development, topics remain clinically evidential.

The target of establishing and building relationships as a foundation for user based experiments, necessitates a firsthand understanding of anaesthesia by standing alongside the practitioner. The conduit to entry is a complex negotiation at many levels, with the few guidelines failing to define the multitude of seemingly interested gatekeepers. Gaining an awareness of the complexities abounding within the operating theatre can only be comprehended from within. Studying a profession in this way, although time consuming, requires tenacity to establish trust and a reciprocal interest.

\section{Studying through time}

To focus the study in its early phases necessitates unravelling the development of anaesthesia equipment, design drivers and innovators. Much has been researched of scientific advances in human physiology, chemistry and pharmacology. This has dignified the personalities known for their advancement in equipment, procedures, and patient safety. Yet little evidence exists concerning the design of equipment outside of these technical achievements. The design genealogy of equipment has suffered a similar condition, and although connections are established, the design impact of these has gone unrecognised. The intention here is to understand the situational generators of equipment, how these have lead to a narrow conclusive design policy - and therefore a lack of future indicators.

49. P M. Fitts. R E. Jones, "Analysis of factors contributing to 460 'pilot error' experiences in operating aircraft controls," in Memorandum Report TSEAA-694-12, Aero Medical Laboratory, Air Material Command, Wright-Patterson Air Force Base, (Dayton, Ohio, July 1, 1947). ; John C. Flanagan, “The critical incident technique," Psychological Bulletin Vol 51, No 4. (1954): 327-358.

50. C Perrow, Normal accidents: Living with high risk technologies (NJ: Princeton University Press, 1999). 
While communication with historians provided significant clinically based information, a comprehensive time based search is required to link design advancements to change factors, soliciting evidence against the anecdotal tales that abound.

\section{Studying in context}

The operative team works behind closed doors. Within this vault, the qualities of anaesthesia and its aim of deep sleep, deem, that as a patient, you may never be aware of the activities in the operating theatre. True to its name the operating theatre is a bare room themed with items and equipment. The team and roles are organised under a system evolved through time and practice. The patient is the subject, and thus all within the theatre alter their scripts accordingly to attain the best possible outcome. This context is paramount to any design suggestions, observing the role of teamwork relative to patient safety and procedure, in the application and use of equipment.

\section{Studying through experiments}

A defining covenant is to get anaesthetists to participate in a simulation based design experiment, turning anaesthetists into designers and gathering new visions, whilst gaining a measurable understanding on how they see their tools within an environment.

Action research is inquiry that is done by or with insiders to an organisation or community, but never to or on them ${ }^{51}$

Gathering knowledge through the design process may be termed as 'research through design' or similarly, 'action research', a cyclical approach of action and reflection. ${ }^{52}$ Early ideas of questionnaires and focus groups for data collection were dismissed during the relationship building period when the risks and liabilities of the anaesthetic profession became understood. A limiting factor in applying these traditional methods is the professional bond and rank of

51. K Herr. G L. Anderson, The action research dissertation: a guide for students and faculty (California USA: Sage publications, 2005), 3.

52. Joep Frens, Designing for rich interaction: Integrating form, interaction, and function (Eindhoven: J.F. Schouten School for User-system Interaction Research, 2006), 28. ; B Archer, "The nature of research," Co-Design Journal 2 (1995): 6-13. ; J Whitehead. J McNiff, Action research living theory (London: Sage Publications, 2006), 66. 
clinicians, a group who are fiercely critical of their performance, and dread error and misjudgement. These are deep seated feelings that needed to be overcome and freedom of expression to work within the criteria of prospective design required alternative methods.

The concept of a three dimensional questionnaire where participants would construct and test their own concepts allows for user demonstration. This results in a formative analysis and summative understanding of how a profession sees their tasks, environment, interactions and team relationships.

\section{Organisational approaches to medical equipment design}

Several leading organisations underpin the design of medical devices, overseen by regulatory bodies as follows: ${ }^{53}$

- In the United States the Food and Drug Administration FDA, International Electrotechnical Commission IEC, and the National Patient Safety Foundation NPSF

- In the United Kingdom the National Patient Safety Agency NPSA

- In Australasia the Therapeutic Goods Administration TGA, Australian Patient Safety Foundation APSF (the APSF is not a regulatory body), and Standards (Australia and New Zealand)

This is the top tier, and layers of organisation flow down to the healthcare body or hospital. In the first instance, all seek to protect society by making devices safe, efficient and effective. Second they seek to disseminate research, and thirdly aim to protect their member status. ${ }^{54}$ Underlying this is society's response via laws, ethics and morality, to the consequences of technology, design and the

53. U.S. Food and Drug Administration. http://www.fda.gov/CDRH/ ; International Electrotechnical Commission. http://www.iec.ch/ ; National Patient Safety Foundation. http:// www.npsf.org/ ; National Patient Safety Agency. http://www.npsa.nhs.uk/ ; Australian Patient Safety Foundation. http://www.apsf.net.au/ ; Therapeutic Goods Administration, http://www.tga.gov.au/ ; Standards Australia, http://www.standards.com.au ; Standards New Zealand, http://www.standards. co.nz.

54. AAMI is the primary source of information on medical instrumentation and technology. http://www.aami.org/ ; Note: Societies exist in many countries examples are. American Society of Anesthesiologists. http://www.asahq.org/ Australian Society of Anaesthetists. http://www.asa.org.au/ Default.aspx 
elite. This encapsulates both the higher and lower ground in the advancement of humanity - and the reduction of morbidity and mortality.

\section{Industrial design in healthcare}

Industrial design does not have a governmental organisation devoted to healthcare; instead it works as a contributor. It is only recently that healthcare organisations have recognised the capability of industrial design as more than branding and styling. ${ }^{55}$ In reality, the world of medical design is steeped in instrumentation, engineering and high level human factors. Engineering now plays the role of design visionary, a high figure, gaining elevation through its conversance with accelerating technology. Whilst the culture of engineering is very different from the culture of the user, potential exists for engineering egocentrism. ${ }^{56}$

Publications abound in biomedical device engineering, control equipment, and user cognition of empirical values. Human factor's new catchphrase, 'usability' is now a standard for assessment of device design, ${ }^{57}$ a design enabler and taxonomy of values. When drafted in 2006 the ideals for this standard were more aligned to the embodiment of design in the complete development process, yet in legality and consent they may become a checklist. ${ }^{58}$ This is not to say that industrial design has been ignored by the manufacturing and healthcare community - but it has lacked the confidence to disseminate its position in a dialogue suitable to healthcare users. This can be seen in the minimal publications and the lack of recognition as a significant research player. The critique of much of this work comes from the design community, seen in the many awards for healthcare products in prestigious design publications. Examples of awards for anaesthesia machines are the Siemens Kion winning a design award and failing in clinical acceptance, the Physio BV Physioflex, and the Ulco Signet anaesthesia

55. AAMI Human factors, ergonomics, and patient safety for medical devices meeting, Washington, DC. June 28-30, 2005.

56. Stephen B. Wilcox, "User-centered medical product development and the problem of egocentrism," in Designing usability into medical products by Michael E. Wiklund. Stephen B. Wilcox, (Boca Raton: CRC Press, 2005), 55.

57. IEC 62366, Ed.1: Medical devices - Application of usability engineering to medical Devices (IEC, 2007).

58. Interview: Dr Brian Robinson, Director, National Patient Simulation Training Centre. (C\&C DHB. New Zealand, 2007) ; Sutton, "Innovation and control," 
workstation. ${ }^{59}$ Positive critiques do arrive from the medical community, but in anaesthesia the number is minimal and anecdotal. This may reflect the complexity of anaesthesia equipment. The tight rein on decision making, functionality and engineering places industrial design's status as contributor or a tooth on the wheels of technology, not a wheel (or the oil) in itself. Medical equipment is rarely presented by the design community or manufacturer in context; two rooms would seem to be present, the design studio and the operating theatre. In contrast, consumer industries reveal through advertisement, an often embellished context of the product, applying emotion, risk and embodiment of the user.

Healthcare and consumer products are two very different domains for industrial designers to apply their traditional skills of visual form, brand development and product packaging. With the technical complexities of contemporary anaesthesia equipment rapidly evolving, conventional design approaches may only add embellishment to the established, in avoidance of the nature of the environment. In this work the relationship between design and the anaesthetist is foremost to position industrial design as the inquiry tool and partner in realising design ideas.

\subsection{Method of approach}

It is expected that issues of time and culture are relevant to this research, in understanding the operating theatre, anaesthesia, and equipment. The symbiosis of four factors: profession, time, context, and experiment are utilised to seek answers to the questions posed:

- Profession and origins will be researched through literature and interviews to answer how this profession came about.

- Historical literature, an archival search will be made to extrapolate relevant design junctions capable of formulating an ergonomic 'design genealogy' of anaesthesia equipment, as little exists.

- Context covers all four of the tiers and involves real time observation and conversation within the operating theatre, including studies of 
error and usability from literature.

- Experiment is the pinnacle of the study, where a refined methodology developed from the distillation of the three initial tiers is implemented applying simulation to the design equation.

Applying these factors as tools in interpretation, accreditation and trust towards exposing user derived prototypical visions (design physiology) is termed in this study as prospective design, and circumscribed by relationship centred research. Within this work the historical and contemporary perspectives of anaesthesia are positioned as guides for methodology refinement, clinical interactions, experiments and discussion. These are undertaken as: contextual observation, relationship building and design composition.

\section{Taxonomies for an experiment}

These factors (profession, history, context and experiment) are conspired and applied as an investigative confidant. Anaesthetists are encouraged to critically search and present findings that may indicate a rich seam. The analysis of the findings comes from designers, through communication with prospectors (anaesthetists), and simulation experts (assurance). Establishing a picture of the possibilities (indication of richness) is realised in the prototypes. The term and application of prototype requires some form of definition. For this study, prototype has no connotation of finality, or even a projected product. It is employed as an indicator of process and design cognition, having an analytical outcome in representation, thoughts and knowledge; and a local outcome to the maker in physicality, feeling and engagement. ${ }^{60}$

The following taxonomies present a design philosophy and study approach.

\section{Prospective}

Prospective relates to the search for wealth by informed people that understand the environment and have a keen sense of material source, not the capability to produce or manifest the findings. The explorative approach refers to the innovative embodiment of task and technology in a search for better systems. ${ }^{61}$

60. B Moggridge, Designing interactions (Cambridge, Mass: MIT Press, 2007), 685.

61. Boquet "The anaesthesia machine - a study of function and design," 61-67.; Cooper, "A new anesthesia delivery system," 310-318. 
Whilst those that are iterative apply new ideas and technology to historically established and proven formats. ${ }^{62}$

The study proposes to pursue a prospective approach rather than an iterative or incremental design methodology. Prospective draws similarity to conceptual design but in this case the designer users the subjects as prospectors. Allied to this methodology may be participation design, ethnographic research, user centred design, or as Don Norman has recently deemed it, activity centred design. ${ }^{63}$ In this study, the prospective design approach will sit within the overarching theme of relationship centred research. Both of these terms are the author's and will be tested in this study.

Prospective design sets out to provide a vision:

- Search

- Indicate possibility

- Start with an unknown entity or design

- Utilise design as an interpreter of activities early in the development process.

- Provide a user created commentary for technology application

- Engage and measure user/operator behaviour/capability/acceptance

- Elicit desires and satisfaction

- Apply design (relationship) and application (task) as a confidant.

Prospective $=$ new, informed but not established. High risk/high gain a new map or schema.

\section{Iterative}

In polarity to prospective design is iterative design. Critical equipment differs from consumer goods in following an iterative or retrospective design pathway. ${ }^{64}$ This is a hallmark of engineering, human factors and the usability process. The

62. Watt, "The evolution of the Boyle apparatus, 1917-67," 103-118.

63. D. Norman, "Human centered design considered harmful," Interactions 12;4 July August (2005): 14-19.

64. Sutton, Innovation and control. 
capability of new or different critical equipment concepts to perform instantly without error would be paved with use instability and litigation. Consumer goods take risks that often beta users will live with while bugs are removed. Typically first generation products will later fall in price and increase in reliability as second and third generation derivatives are released and used to measure acceptance. Early adopters show the extremes of a product's potential by pushing the technology far beyond the inventors imagination. ${ }^{65}$ In healthcare, this would be termed intentional misuse and be liable. Iterative goes hand in hand with healthcare, and in this context becomes an innovation oxymoron. Iterative has safety on its side, yet design intention is proven capable of becoming technology bewilderment. ${ }^{66}$

Iterative design sets out to produce a product by the following process:

- Improve design through small incremental changes and tests made to an established and proven design

- Make change to a known entity or design

- Implement new technology into an established doctrine

- Act on epidemiological research, usability testing or reported incident, (can happen as a result of an incident where a prior unknown has become known through normal or abnormal use).

- Logical development, allows us to plan and understand.

- Consensus, a derivative of multidisciplinary development.

Iterative $=$ established, known, mitigate risk, but consisting of many layers, carrying low risk and incremental gain. Iterative changes provide opportunities for complex unknown errors to reside within laminations of innovation.

Iterative design should not be dismissed, and is a proven method. The debate here is; should it be used to search, or research concepts of the future as a transferable method applied to users.

65. David Liddle, in "Designing interactions," by Bill Moggridge (Cambridge, Massachusetts: MIT press, 2007), xii and 239.

66. Vicente, The human factor: revolutionizing the way people live with technology, 43-44. ; R I. Cook. David Woods, "Operating at the Sharp end: the complexity of human error," in Human Error in Medicine, edited M S. Bogner (Hove UK: Lawrence Erlbaum Associates, 1994). 302. 


\subsection{Design methods as: Results, relationships and simulation}

The aims of a research based inquiry differ in how ideas are directly pursed, the question to be answered, the capability of the method to reveal, and the body of knowledge assembled to attain the task. Prototype, experiment and concept are all expected to have outcomes that lead to a result. The definition and clarity of this result is determined by the philosophy and structure of the inquiry.

The following taxonomies of methods are related as objective and outcome. Each method is dependant on its methodology and may have a very different outcome or implied outcome, this makes us aware when designing with others, of a misunderstood context.

\section{Results of the design method}

The common result of a prototype is a test, and is typically three dimensional, whereas an experiment has a hypotheses and clearly defined method based on past conclusions. When we come to a concept, the pragmatism is stretched further to encompass two, three, and four dimensional outcomes supported by emotive sprit and personal design philosophy.

We:

- Read a book $=$ Gain knowledge

- Make a prototype $=$ Realise the concept

- $\quad$ Do an experiment $=$ Process information

- Present a concept $=$ Communicate ideas

- Reflect on personal knowledge = Interpret

\section{Relationships with the design method}

The relationships aligned to each method of inquiry are determined by the context. Does the prototype require any relationship or is it a direct realisation of a predefined outcome? An experiment requires methodologies that may be re-enacted. Concepts due to their ill-defined outcomes allow commentary and emotions. Reading a book however may be data collection existing as a subjective 
relationship between author and reader.

Examples of method/process:

- $\quad$ Reading $=$ Personal $/$ relationship

- Prototype $=$ Association

- Experiment $=$ Correlation

- Concept $=$ Behaviour

- $\quad$ Intuitive $=$ Collected knowledge

\section{Simulation of the design method}

Simulation of an inquiry allows for testing, analysis and hypothesis generation. In prototyping essential activity features are reproduced as equivalent. As an experiment it may be the re-enactment. As a concept it may be regarded as an impression.

Enquiry through:

- Reading $=$ study resemblance/examination or test

- Prototype $=$ Imitation $/$ activity cognisance

- $\quad$ Experiment $=$ re-enacting

- $\quad$ Concept $=$ impression

- Critique our knowledge $=$ judgement

Simulation $=$ equivalence and contextual assurance. Simulation applies a function test (the ability to successfully accomplish the required tasks) versus a preference test (asking if subjects like a specific feature).

\section{Chapter conclusion}

This chapter has set out to review and align three studies, not for their success or failure in generating new products, but their design strategies in generating discussion and interdisciplinary awareness. The very limited amount of published design research within anaesthesia promotes the idea that the continued proliferation of devices assembled as equipment; cake iced with design - is 
acceptable, contrary to the rise in technological capability, accreditation, and safety issues.

Extrapolated from this pre-investigation, a range of methods and hypothetical terminology (relationship centred and prospective research) is described. Each of these methods requires partnership, peer leadership and collaboration warranting outcomes capable of attaining the study's aim. This methodology is posed as both a hypothesis generator and an evaluative tool that may be refined and applied with industry partnership in a future study.

Boquet built four concepts. For designers, much of this new knowledge was unpublished as these concepts are neither pictured nor described (the study focused on replicable scientific task analysis). Nor is the response from anaesthetists or industry, and their method of evaluation mentioned in Boquet's paper. These commentaries are invaluable to the design community, and although publication in medical journals targets the profession, these very journal publication methods supposititiously disenfranchise design. Boquet's knowledge is now lost. Cooper's is revealed through a book chapter in 'This is no humbug! ${ }^{167}$ Schwartz's commentary was revealed in person at the AAMI conference rather than publication.

The precedents demonstrate how few concepts have been published, addressing not devices, controls or displays but overall machine form and composition. Boquet's concluding revelation of wishing to confirm his hypothesis through evaluating Cooper's prototype was never realised. This is where simulation could have been applied, a method that Boquet may have not had available due to its infancy in medicine at the time.

These 'staccato' investigations covering 30 years have allowed the ideas of future concepts for discussion to falter, under the guise that current equipment, from an industry interpretation of a user's perspective, is right. Therefore the connectivity and ideological momentum of searching through design ideation becomes tenuous, unsupported and lost. This suggests a need to investigate how healthcare research and publication is acknowledged by the forum of design,

67. Cooper, "An accidental life: patient safety and biomedical engineering," 377-419. 
and safety - irrespective of their often disparate research methods.

These precedents and the nature of the topic are bound and unbound by accessibility to the elite profession in question, and the collective ethical protection of political and professionally aligned gatekeepers that work to advance and retard issues of design. 
PART ONE - LOOKING BACK 


\section{EXAMINING THE PAST}

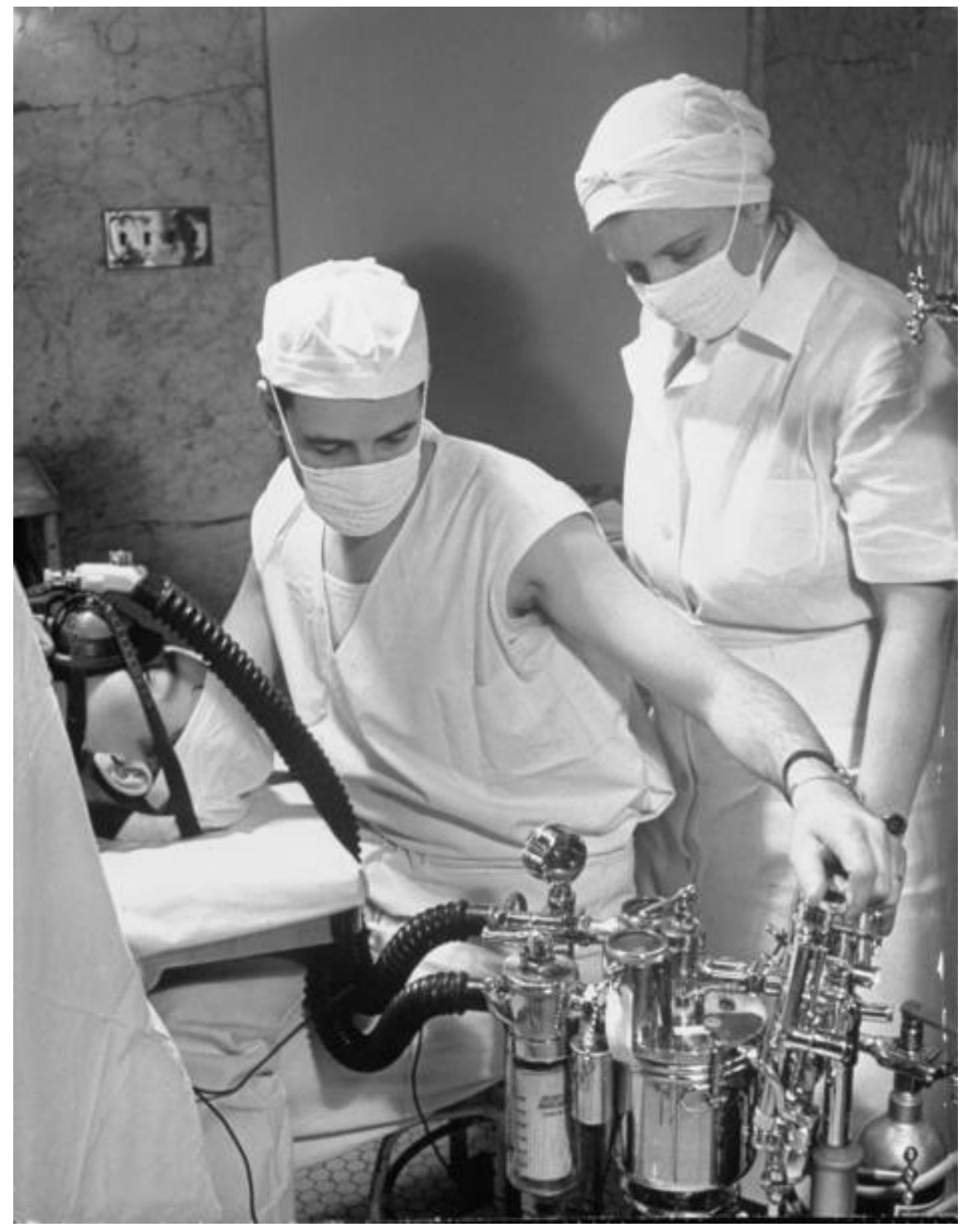

Fig 3.0 Intern training. Habits passed on as knowledge, learning still involves the process of 'see one do one'.

Source: Alfred Eisenstaedt/Time \& Life Pictures/Getty Images (72399511)2009. 



\title{
EXAMINING THE PAST
}

\author{
It is not the pride of knowledge but the bumility of wisdom, it is not the science of \\ technology, but the art of healing that makes a good doctor 68
}

Whilst Boquet and his colleagues arrived at the statement "what we have now is what we are used to rather than the ideal" they did not clarify or show how 'we are used to'. Part one explores both society and technology to uncover this pathway to adoption and adaptation.

Integral to understanding a design evolution, the very landscape in which anaesthesia has evolved is examined in this chapter. Doing so exposes a broader narrative to suggestions of 'why' and 'how'. Many of these suggestive clues lie on the periphery of disciplines and provide reasoning for anaesthesia's quiet leadership in crisis management and patient safety.

Three core analyses are described: Firstly, how the arrival of science has influenced human values, society's needs, and the acceptance of anaesthesia as a faith in science. Secondly, how this faith in science has become a faith in technology and in combination with institutionalism has created elite professions. And thirdly, how design in anaesthesia is guided by medical methodologies and the criticism of outcomes.

When the aim is to look forward, taking a step back is a luxury, yet evidence from the past is paramount to first answering the research question, and later in developing the investigative relationships and experiment.

68. C H. Low, "The Challenges in Surgery-Past, Present and Future, and in Search of the 4Cs," 10th Chapter of Surgeons' Lecture: Ann Acad Med Singapore Vol. 29 No. 1 (January 2000), 140-145. 


\section{Examining the past}

Faith, science or art? Anaesthesia may be all of these; although defined and measured by science, its roots of acceptance lie in faith, and in application may come close to an art. Many great endeavours have brought new wealth and knowledge. Anaesthesia differs in delivering through its innovations, a beneficial compassion to society. Few direct humanitarian interventions exist on this par with the exception of pharmacological advancements and asepsis.

Humankind has undoubtedly struggled with pain and suffering throughout its evolution. In the domain of surgical intervention, anaesthesia is relatively recent, spanning the past 160 years. With the advent of modern (general) anaesthesia, a sanctuary from pain has been offered to both the patient and the surgeon. This sanctuary has become the catalyst for complex surgical endeavours, allowing great benefits for human kind.

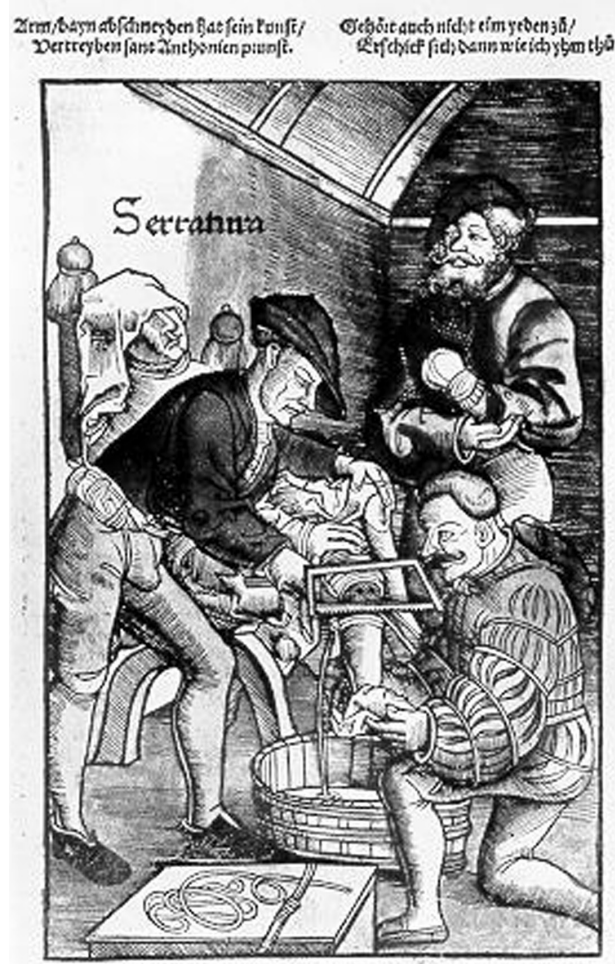

Fig 3.1 Amputation

Source: Feldtbuch der wundartzney, Hans von Gersdorff 1517

\section{Modernism of society, not design.}

Pain is derived from the Latin word poena, meaning punishment, a symbol of fatalistic vulnerability. ${ }^{69}$ This sentence of sufferance on mankind was once a given. In the Middle Ages with a life expectancy of 35 years, life may have seemed like purgatory, and that death would somehow relieve or resolve this punishment. Historically society has for the greater part dealt with injury or malady not as an accident, but as a test, for the outcome was probably great discomfort or death. The act of death, especially in battle, was once seen as superior to the vulnerability of irreparable injury and foreboding simple surgery (Figure 3.1).

In 1591 Eufane MacAyane had just given birth to twins, during her difficult labour she

69. E M. Papper, Romance, poetry, and surgical sleep (London: Greenwood Press, 1995), 32. 
had cried out for pain relief. The response to her pleas was to be thrown in a pit and buried alive. ${ }^{70}$ Just punishment, for going against God's visitation of pain in childbirth.

Just how recently social conditions have lifted this sentence can be explained in the notion of a 'childhood'. Prior to the $19^{\text {th }}$ century children were cared for by faith and valued in earning capability. ${ }^{71}$ Today this situation has been reversed with children cared for by science and valued in youthful reverence.

From the enlightenment period came forth the goal for a better world. An intellectual world dedicated to science, reason and philosophy, removed from authoritarian church and religion. This period seems distant in relation to modern medicine, but when keyed to other significant sociological shifts it defines an era; an age of examination and criticism. These shifts of advancement in society, science and technology demonstrate the power of societal change in the acceptance and development of medical science and pain management. The almost evangelical relief of pain in the 1800s has relegated faith to the scientifically explicable, ${ }^{72}$ although still playing an important part in bioethical decisions of today.

\subsection{The age of enlightenment, reason and modernism}

As a deliverer of ideas and wealth from new sciences, the industrial revolution may be seen as the physical manifestation of the enlightenment, ${ }^{73}$ the engineroom of British commerce. While the enlightenment changed social awareness in an acceptance of applied science, medical science and medical care. The scientific revolution was to herald the very technological basis of our existence, in chemical, atomic and electronic discovery. ${ }^{74}$

The origins of anaesthesia lie much further back in time in crude pain relief, consisting of the brutal application of physical force and potions. Force as

70. T E. Keys, The history of surgical anesthesia (New York: Schumans, 1945), 75.

71. Pike E. Royston, Human documents of the industrial revolution in Britain (UK: Routledge 2006),

\footnotetext{
Inc1999), 216.

73. W D. Hussey, British history 1815-1939 (Cambridge: Cambridge university press, 1971), 105.

74. http://www.bbc.co.uk/radio4/history/inourtime/inourtime_20070329.shtml (accessed $3 / 2 / 2009)$.
}

72. Joel James. Shuman, The Body of Compassion: Ethics, Medicine, and the Church (Westview Press 
in pressure application to nerves and arteries or blows to encourage loss of consciousness, potions as alcohol, opiates, and plant extracts. Increasingly the knowledge of these sedations resided with physicians, a profession held in higher regard than the barber-surgeons of the $16^{\text {th }}$ century.

Surgery has climbed the professional ladder from labourer to tradesman through necessity and skill rather than intellectual prowess. Descriptions of surgery before the days of anaesthesia and asepsis gives relevance and prestige to a surgeon's speed in execution of the task, whilst quietly ignoring the mortality rate. ${ }^{75}$ Surgery had to be 'Quick, Short, but not always Sweet'. Robert Liston was credited as the fastest amputation surgeon in history, performing an amputation in just over 30 seconds. $^{76}$

Surgery before the discovery of anaesthesia was an experience feared in its acknowledgement of pain. 'Cold steel' carries the same emotion today that it did when it was derived, a fear of mortality. This fear was also shared by the surgeon in the act of operations. Cutting into a person who may be stupored by alcohol, but reacting by writhing and screaming, made the act of surgery a difficult task. Surgeons often felt the pain in their inability to precisely operate on a moving object and in the knowledge that death will likely claim the patient. Surgeons suffered similar fates, although drawn out as psychological illness. ${ }^{77}$

Surgery was and still is to an extent, about the apparent, the visible and known: the very mechanics of the body. Anaesthesia was challenged with the non apparent, the effect of chemicals and the pathology of the body. Although the effects of anaesthesia could be diagnosed from simple physiology, early anaesthesia faced criticism in its modernistic approach. ${ }^{78}$

Scientific experimentation with pharmacology and physiology are at the core of modern day anaesthesia. The initiatives that saw the ingredients of anaesthesia develop, reflect the creative aspirations of prominent thinkers. This was not a singular activity but an outcome from a social blend of poets (Samuel Tayor

75. R Hollingham, Blood and guts: a bistory of surgery (UK: BBC books, 2008), 38.

76. Ibid., 38.

77. Papper, Romance, poetry, and surgical sleep, 12-13. 2002), 203.

78. J Rodger Maltby, Notable names in anaesthesia (London: Royal Society of Medicine press, 
Coleridge), artists (Josiah Wedgewood), philosophers (Joseph Priestley), engineers (James Watt), scientists (Joseph Banks, Michael Faraday \& Charles Darwin) and physicians (Thomas Beddoes \& Humphry Davy) that came together to promote not only industry and the arts, but therapeutic benefits. ${ }^{79}$

The discovery of physiological effect and diminished 'feeling' through inducement of chemicals happened like many great discoveries in an indirect path. Nitrous oxide and ether gained notoriety at fashionable laughing gas parties and ether frolics. With the addition of chloroform these agents were to become the mainstays of dental anaesthesia and early anaesthesia. It was not until control of these substances was achieved, that anaesthesia as a profession existed.

In connecting the eras of romanticism, scientific enlightenment and industrialisation, controlled chemically induced pain relief was akin to a replacement for God, a saviour, a direct verification of scientific power. This acceptance of anaesthesia was greatly assisted by James Simpson's quantified argument to religious opposition, ${ }^{80}$ and a distinguished obstetric case. John Snow, Britain's first physician-anaesthetist, administered chloroform during delivery to Queen Victoria via her handkerchief. These efforts helped to popularise anaesthesia in childbirth releasing women from unfounded fears of foetal damage and the mythology of strengthened bonds between mother and child due to pain. ${ }^{81}$ Supporting these role models for new science was the Victorian society's distrust of intellectual philosophy and a growing admiration of practical utility. ${ }^{82}$

To safely administer these new chemical agents necessitated more than a handkerchief (Figure 3.2). Unlike surgeons and their relationship with metallurgy and hand tools, this was a new relationship between apparatus makers, dentists and surgical-physicians ${ }^{83}$ (Figure 3.3). Like a gold rush, a proliferation of simple utensils and instructions were applied unregulated to two very different tasks

79. Papper, Romance, poetry, and surgical sleep, 29-33. ; Meyer Friedman. Gerald W. Friedman, Medicine's 10 greatest discoveries (New Haven: Yale university press,1998), 97. ; A D. Morrison-Low, Making scientific instruments in the industrial revolution (England: Ashgate publishing, 2007), 15.

80. Maltby, Notable names in anaesthesia, 203.

81. Friedman, Medicine's 10 greatest discoveries, 109.

82. Hussey, British history 1815-1939, 119.

83. John Kirkup, The evolution of surgical instruments (Novato, California: Historyofscience, 2006) 


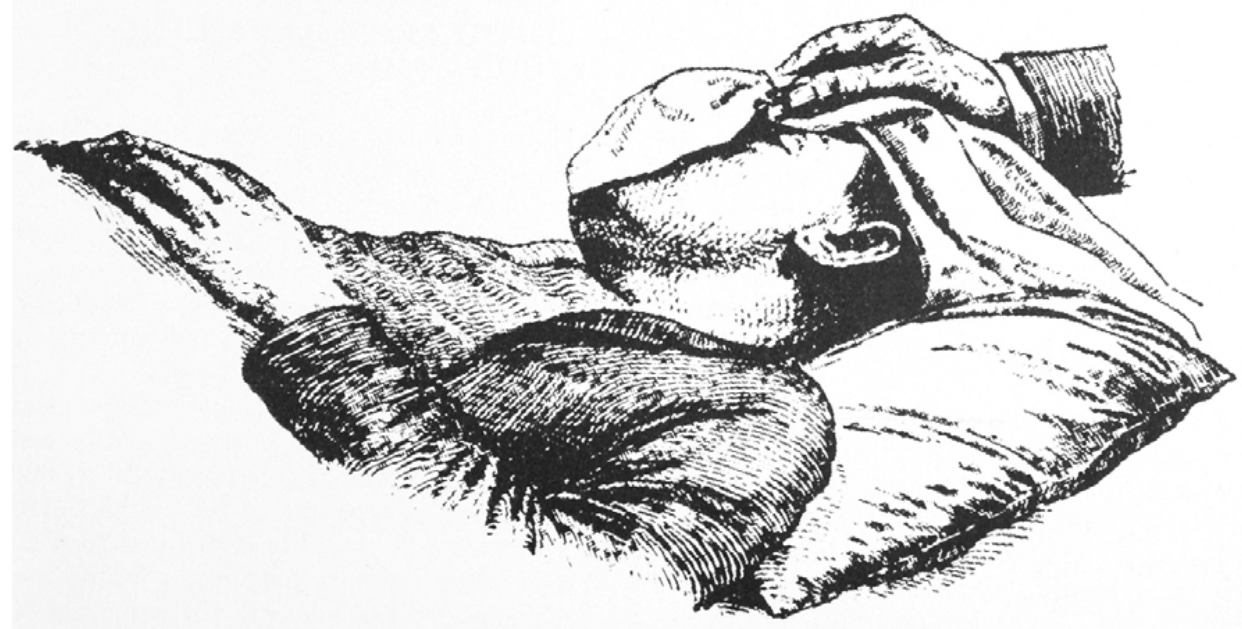

Fig 3.2 Simpson's method of administering chloroform Source: K Bryn Thomas 1975.

requiring very different levels of anaesthesia. Early anaesthesia was ready to integrate medicine and society through a new type of theology; technology. Suggesting the changing attitudes of society to pain and suffering did not lead to the development of anaesthesia but to the acceptance of anaesthesia.

What happens to the human body on the introduction of chemical agents? 150 years ago the clinical signs were apparent; the patient's pupil could be read while a hand upon the pulse provided tactile computation of the heart's performance. Today much has changed, and the patient during surgery is barely visible. With the future of surgical procedures in the hands of anaesthesia, the complex manipulation of human physiology may continue to challenge society's moral views if human nature continues to reduce its physical activities. This lost expenditure is seen as an increase in sedentary ways, as we become more digital, may be controlled and tuned radically through the advancing knowledge of physiology and pharmacology.

\subsection{Life, death, and the elite}

Each of us is solitary: each of us dies alone: that's a fate against which we can't struggle - but there is plenty in our condition which is not fate, and against which we are less than buman unless we do struggle ${ }^{84}$

The value of life changes throughout our lives, when we are small we are unaware of it and adapt to life threatening incidents with an instinctive innate behaviour.

84. Snow, The two cultures and the scientific revolution, 6 . 


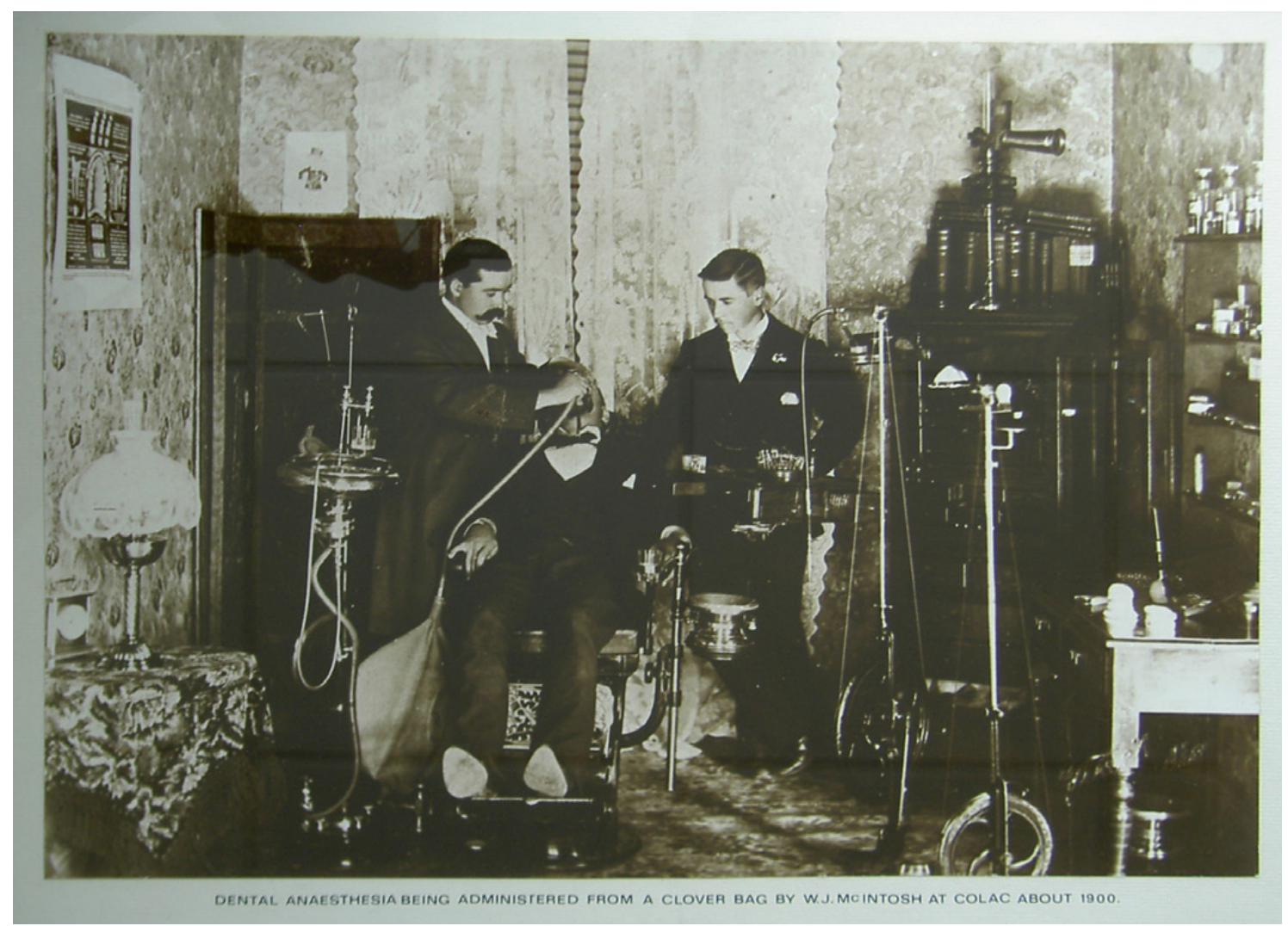

Fig 3.3 Dental anaesthesia in the front room surgery

Source: Geoffrey Kaye Museum

This is carried on into adolescence when risk is increased as self actualisation becomes prevalent. Middle age carries new responsibilities and an awareness of our own vulnerability. In old age, time is short and our life is often reflected in healthy minds but weary bodies. In the last 100 years our lives have been changed at an exponential rate by society, science, and technology. The value and length of life has increased by curtailing insidious disease, extending our capability to survive accidents, ailment, infection and decay.

Science has brought many influential changes; drugs are foremost, and seen as life savers. Derived from the $19^{\text {th }}$ century's crude but exquisitely bottled and labelled compounded substances, later synthesised into chemicals capable of radically altering actions within our bodies. Surgical intervention contradicts the technological rise of drugs in their physical focus and ancient inception. It defines the borders of early science as that which is visible and apparent. As a relative of mechanics it can therefore be understood. Drugs and pharmacology are more recent investigations, micro, hidden and relating to chemistry, these two eras have come together in anaesthesiology. 


\section{Elite intervention}

Some professions rise to the top and are generally (by society) ${ }^{85}$ seen as those with gifted attributes and knowledge capable of becoming catalysts with technology and risk, therefore the elite. In looking at suffering rather than pain, Cassell connects the developing importance of the individual physician to the methodologies of science and technology ${ }^{86}$

Although the anaesthetist may have the most complete understanding of the operative procedure, conversations with clinicians implied that little is known by society about the anaesthetic profession or the anaesthesia process. Anaesthesia does not wear the historical badge of blood, of skill vs patient survival, instead it is an ally to the patient, concerned with engaging knowledge to patient rather than engaging knowledge to disease or ailment. ${ }^{87}$

Surgery has a long history of intervention and elitism, the ultimate act to ward off death or disability, often resulting in death not from surgery itself but also disease aligned to shock, open wounds and inadequate hygiene. The greatest change has been in the expansion of surgery and post operative care through aseptic methods and drugs (antibiotics), ${ }^{88}$ allowing surgeons to practice their trade with a respectable chance of recovery. As if in a play, surgery is the last act, the most dangerous and expensive but often the crescendo.

\section{Institutionalism}

The institutionalism of healthcare is rooted in the philosophy of specific location for specific task. The relevance for this seems apparent with awareness of disease and the need for hygiene. Confusing and contradictory, the New York Times estimates 103,000 people per year dying in the US each year from infections picked up in the hospital. ${ }^{89}$ Institutional environments have evolved from cave or dwelling to battlefield and lodgings to hospital and operating theatre. Physical

85. Ninety-five percent of adults believe that their personal doctor, and $92 \%$ of adults believe that they, themselves, have a positive effect on patient safety. National Patient Safety Foundation at the AMA. Public Opinion of Patient Safety Issues. Louis Harris \& Associates. September 1997. http://www. npsf.org/pdf/r/1997survey.pdf) (accessed 12/1/2008). 1991), viii -28 .

86. Eric J. Cassell, The nature of suffering and the goals of medicine (Oxford: Oxford University Press,

87. Ibid., xi.

88. Kikup, The evolution of surgical instruments, xi.

89. http://travel.booklocker.com/2005/08/28/how-safe-is-travelor-being-home/ 
institutionalism was conceived before anaesthesia, by situating the operating theatre on the top floor of the hospital under a large sky light and at a distance so the patient's screams could not be heard..$^{90}$ Professional institutionalism exists as a slow progression of specialised knowledge and etiquette from master to prodigy.

Governed by a specific purpose and relationship to the community, healthcare suffers from institutionalism. Although narrowness is required to orchestrate efficiently the pain and suffering of society, it does not absolve the need to embrace learning from other quarters. An inclusive partner of institutionalism is specialisation, a two edged innovation sword. Benefits in new tools are balanced against the considerable cost in the required contextual experience to gain and maintain skills.

\section{Societies viewpoint.}

Surgeons now gain the utmost respect, elevated from a trade associated with pain and death, to be named in society and in the tools of their trade. A profession that is appealing to humanity's sense of sole achievement, and in this, becoming the elite. Aligned to surgeons are nurses and anaesthetists, nurses have gained a historical respect similar to that given to teachers and fire-fighters as passionate protectors. Anaesthetists are the mystics, they put you to sleep and awaken you on the passing of pain. Again anaesthetists hold you in sole charge and lie within the elite spectrum, known but unknown.

What constitutes an elite profession is specialisation, remoteness and social conscience. Specialisation embodies the length of time, ability, and dedication required to competently attain high level goals in high risk environments. Remoteness implies that the environments where these tasks are achieved are often exclusive and difficult if not impossible to penetrate with any real understanding of the intricacies of the task. Finally, a social scruple, conscience, eliminates the race car driver and sports people, reflecting the spiritual level of society's hold on the fundamentals of life. Typically these professions have their own compliance, standards, and methods of accreditation and measurement, often including protective and historical aspects that build the elite presence,

90. Friedman, Medicine's 10 greatest discoveries, 96. 
some moving to the point of sainthood others to that of a primadonna. Most of these professions contain a life and death decision making attribute and a highly refined physical element to the task. Pilots, surgeons and anaesthetists make up some of these.

\section{Consultant's viewpoint}

You members of the medical profession, gentlemen, are in a favoured position - the world acclaims your successes and flowers cover your failures ${ }^{91}$

This quote, made in 1974 declared death from anaesthesia as a major public health problem. It represented a paradigm shift in thinking, a profession's self criticism substantiated by research, and revealed through public and political pressure. 34 years later this cynically favoured position may not hold true with litigation and blame now residing as a headstone.

Anaesthesia equates to the singular persona, often in complex circumstances and in a technologically hostile environment unknown to most. Ethical considerations limit real life images or viewing, although television has brought the operating theatre into the public domain as reality entertainment. News of an airliner crash brings home to us, our own vulnerability. Most of us have flown and have come to relax with this technology, yet when incidents occur in this domain, the resulting fatality of multiple lives leaves us momentarily uneasy. An automotive accident impacts on the families of those involved, again the technology is known and we typically lay blame at the fallibility of our own or others capability, and term it an accident.

The act of driving can be related to the quote by Sir William Osler in commenting on the activity of anaesthesia "errors in judgement must occur in the practice of an art which consists largely in balancing probabilities". ${ }^{92}$ The automobile has become an embryonic protective environment open to narcissistic abuse; 'drive how you want for you have air-bags and numerous other safety features to protect you'. The balancing of probability has been partially solved with

91. Ellison C. Pierce, "40 years behind the mask: Safety revisited," Anesthesiology, Vol. 84 No. 4 Special article: The 34th Rovenstine Lecture, (1996): 965-975.

92. A.Jr. Goldstein. AS. Keats, "The risk of anesthesia: wherein lies the cause?," Anesthesiology 50: (1979): 387-392. 
technology and the unintended but implicated concept - that risk can safely be extended.

In the last 100 years automotive accidents have replaced and become the new Tuberculosis that once affected so many. ${ }^{93}$ Technology has its own problems; for each step up there is a step sideways into the unknown. The rapid implementation of technology into medical equipment has had similar outcomes; mortality from syringe pumps, not through deliberate malevolence, but where the interfaces have confused operators in the presentation of data. ${ }^{94}$

What is the significance of this when death is not uncommon on our roads, in our workplace and in the self inflicted (Figure 3.4)? Can society not cope with the margin of error and lapses in judgement, or have they come to expect too much from the health systems of today? ${ }^{95}$ Science is seen as infallible and critical mistakes are to be laid at the feet of the relevant human. Any professional misjudgement causing mortality or morbidity is difficult but not insurmountable to recover from. Misjudgement may be hidden personally, collectively, or through ignorance, completely unrealised. The underreporting of incidents resulting in permanent injury or death is primarily driven by a fear of litigation. ${ }^{96}$ Once exposed, the full extent of liability may be unleashed in litigation, suspicion and blame, resulting in professional and personal dislocation. Blame is a convenient method of resolution

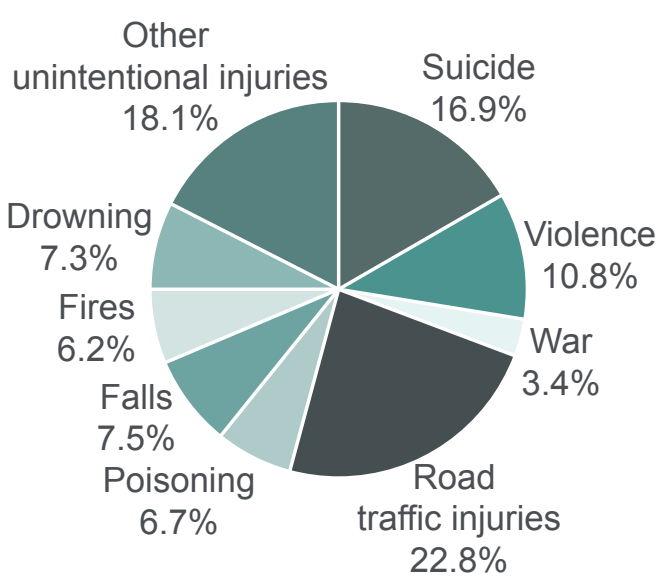

Fig 3.4 Distribution of global mortality Source: Redrawn from WHO 2002 that satisfies the public and political 1999), 30.

93. James Le Fanu, The rise and fall of modern medicine (London: Little, Brown and Company,

94. Cook, "A Tale of Two Stories: Contrasting Views of Patient Safety," 27.; Vicente, The buman factor, 142.

95. National Patient Safety Foundation at the AMA. Public Opinion of Patient Safety Issues, 5. ; Sidney W A Dekker, "Doctors are more dangerous than gun owners," Human factors Vol49. No 2. (2007): 177-184.

96. Joshua A. Perper, "Life-threatening and fatal therapeutic misadventures," in Human Error in Medicine, edited M S. Bogner (Hove UK: Lawrence Erlbaum Associates, 1994), 28. 
requirement for remedies, by focusing on the fallible individuals at the sharp end. ${ }^{97}$

\section{The sharp end}

In 1990 Jim Reason described the sharp end of human tasks in industry aligning those practitioners who work at the hazardous junction between life and death, as those who receive the burden labelled 'human error' ${ }^{98}$ Human error is classified as behavioural, contextual, and conceptual, and defined in terms of error of action, error of cognition and error of omission. This is further classified as mistakes, lapses, and slips tied to the cognitive stages of planning, storage, and execution. ${ }^{99}$ Mistakes are intentional, a mismatch between the intention and the intended consequence i.e. where the wrong switch is used, and lapses and slips unintentional, a mismatch between the intended action and those executed, i.e. turning on the wrong switch in a row of switches. Cook and Woods added to Reason's analogy by defining the blunt end of this system, ${ }^{100}$ as those that can influence, manipulate, or misunderstand the sharp end. Anaesthetists reside at the sharp end along with their colleagues, surgeons. Designers, managers, administrators, and insurers reside within the blunt end. Each influences the other, working together for a common goal. The common goal varies from one viewpoint to another. To satisfactorily reach one, many other goals must be either met, differed, managed, or compromised.

While the sharp end is identified as the connective zone between patient and clinician, ${ }^{101}$ the impact and shape of the sharp end is influenced by the blunt end, with the intention of implicating both in medical error occurrences. This may be seen by some clinicians as an unstable approach to the eradication of scapegoating when phrased as "in the end safety is a dynamic quality created by people at the sharp end". ${ }^{102}$

97. Cook, Operating at the Sharp end: the complexity of human error, in Human Error in Medicine, 292.

98. J Reason, Human Error (England: Cambridge University Press, 1990), 173.

99. Reason, Human Error, 8.

100. Cook, Operating at the Sharp end: the complexity of human error, in Human Error in Medicine, 255

101. Reason, Human Error, 173.

102. Joseph Ibrahim. Jenny Majoor. Bebe Loff, "Combating medical errors," Correspondence The Lancet 356 (2000): 166. 
Instances commonly occur where the only action is to blame and discipline those in direct contact with vulnerable parts of a system, often aided by the weight of uninformed opinions brought about by support of the public and humanity's need to see justice done. The complexities of systems are now at a point where to identify the causal nature of an incident requires expensive multidisciplinary expertise. Again the battle is played out between the public thirst for accountability, professional bodies, and inextricably the nature of the incident. Some incidents reflect their value in the number of deaths, others in the status of the deceased, and largely for the developed technology rich world how. Indirectly these incidents filter down to influence the design process.

The irony that exists between lifestyle, longevity and health on one hand - and obesity, wealth and desires on the other, may challenge society's relationship with elite professions. Will the elite of the future be technology, as figure-head intervention is reduced, or will elite be more about insured protection rather than a philanthropic profession?

\subsection{The activity of design and medicine}

The design process is constrained in some way by science, technology, society, humanity and ethics ${ }^{103}$. Depending on the motivation for innovation, be it wealth, dissatisfaction or philanthropic desire and imagination, the constraints are manipulated. Consider the struggling reconciliation in aircraft seating design to accommodate the world's anthropometric variety, ensuring everyone's comfort and the capability to take off, whilst also making a profit. In the 1980s, the Sony Walkman demonstrated the design application of miniaturised technology in allowing music to become a portable companion.

These two examples signal that not all constraints have tangible equality; that goodness, beauty or elegance in design may be derived from any one or a mix. The aircraft seat is inviting and should support the body over long periods without discomfort; illustrating that great emphasis be placed in understanding human physiology, cultural anthropometrics and ergonomics. The walkman has on the other hand paved the way for the MP3, celebrating new technology as a physiological and psychological appendage, effectively moving design emphasis

103. Don Norman, The design of future things (New York: Basic books, 2007), 173. 
to satisfaction, memories and personal choice.

Upon manufacture, the design activity resides within a product as a physical specification, expected by the user to deliver the perceived objectives. Iterative design provides for safe, incremental change and carefully balances constraints to achieve its goals. Iterative design is cyclical; thereby innovation is tethered to the product's life existence. Whilst this allows safe reassurance that the lamination of old and new ideas with technology will be sympathetic to the user, it does not account for this time lapse between. One way of overcoming this is to retain a visual connection, new technology - old box.

\section{Design art and engineering}

Design sits between the disciplines of art and engineering. Aesthetics are balanced with function, emotion, human behaviour and cognition, resulting over time, in the artefact of personal production. This is then balanced against the artefact

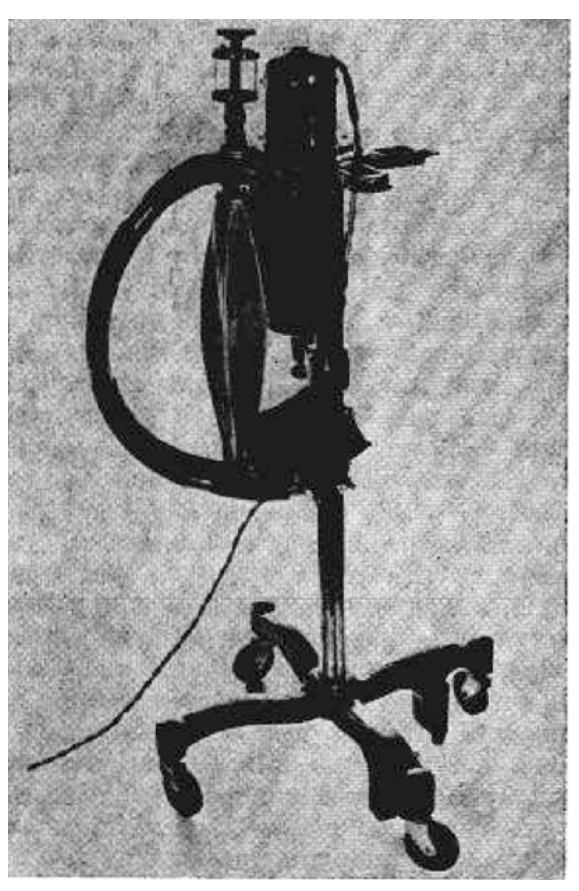

Fig 3.5 D E Jacksons 1918 machine utilised football bladders for rebreathing bag and face mask, ether was admitted by industrial oil cup Source: D E. Jackson 1918 of mass production. Another way to look at this could be 'the design approach' - a methodology to solve a problem. Or 'the approach to design' - a philosophical need. This contradictory position of design in the functional and critical anaesthetic machine has ensured that minimal design resides in the form as structure and composition. The form and brand is applied as a singular objective, non-inclusive of technology and humanity. History provides for a rich background of inclusive application of design, receding in the advent of high technology, lost as to its purpose in the 'seen as safe' quantified dominance of engineering.

\section{Methodology of advancement}

Investigating the rise of science and society has revealed diagnosis as a key scientific element replacing therapeutic ritual. ${ }^{104}$ Medicine has 104. Le Fanu, The rise and fall of modern medicine, 3. 
achieved its advancements from the 1830s in applying meticulous objectivity in observation and experimentation. Terming this a medical methodology, the development of anaesthesia equipment has applied the same methods. This has been achieved by painstaking measurement and observation of physiological reactions, yet pragmatically designed and made by clinicians. This cliniciandesigner as experimenter follows a design route parallel to medicine but borrowing materials and components from any available source (Figure 3.5).

The colliding visions of new knowledge and science, with theology and religion, delivered the artistic values of personal 'making' to mass production. Victorian society accepted anaesthesia as a representation of technology, a way of doing and making things. ${ }^{105}$ Mass production and standardisation has been criticised with an increasingly louder voice for its lack of bond between industrial products and humans. ${ }^{106}$ Although mass production has brought affordable goods and a freedom from menial tasks, it has also brought standardised products, providing little capability of either bridging cultural gaps, or in its simplest ideals, coping with the world's diversity of anthropometric values. Mankind outside of the $50^{\text {th }}$ percentile has been forced to adopt the output of mass production (we may change the colour but not the form or physical dimensions, a direct incurrence of production technologies that may change with new digital manufacture). Challenges now lie within the realm of ecological sustainability, and although this may not drive the medical equipment industry, direct impact from new manufacture and design technologies will reflect upon it.

\section{Revealing the past in the future}

Returning to the challenge of design and engineering; the many physical interactions of a worker and their equipment are defined as human factors, and has since the 1950s, been provided for with specific design data (Figure 3.6). Alvin R Tilley co-developed design definitions for control buttons, knobs and levers determining size, colour, rotation and layout in relation to anthropometrics and safe use. ${ }^{107}$ These interactions, later theoretically termed affordances by J J

105. Morrison-Low, Making scientific instruments in the industrial revolution, 16. Press, 2005)

106. Peter Paul Verbeek, What things do (USA: University park, Pennsylvania State University 1959)

107. Henry Dreyfuss Associates, The measure of man (New York: Whitney Library of Design, 


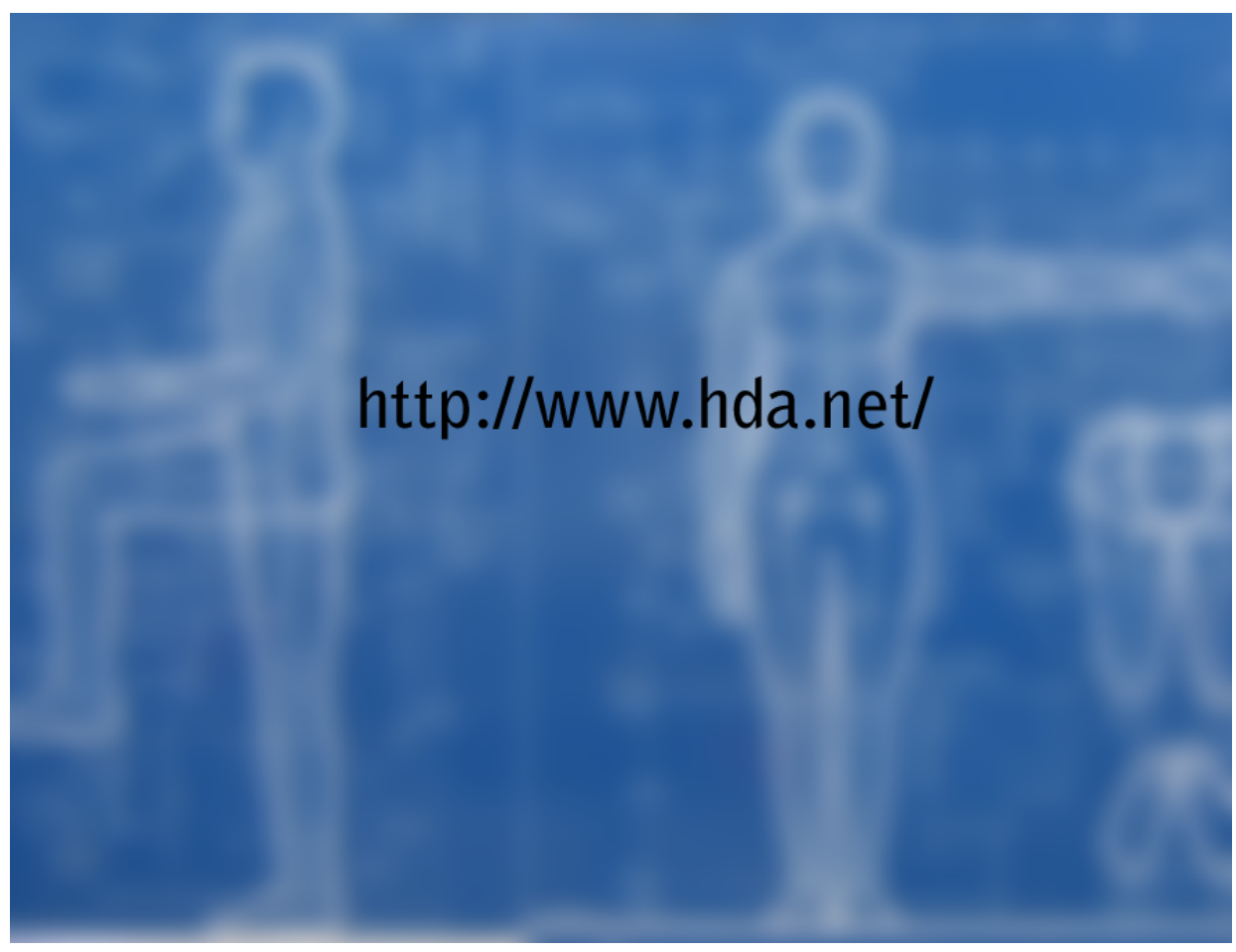

Fig 3.6 Physiology as data

Source: Henry Dreyfuss Associates, The measure of man 1959.

Gibson in 1984, are now interpreted as emotion filled experiences, an ecological relationship of aesthetic interactions between human and environment. ${ }^{108}$ Recent theories in this area may be reflective, having only arrived since the advent of digital technologies, touch screens, and defined measurement rather than guided indications. Digital interfaces have proved slow and feelingless to users with limited tactile feedback. Pure functionality in design is different from functionality in operation, as a benchmark against which to measure mechanics.

Phenology, a term applied to the study of nature's seasons and climate creep is synonymous with technology functionality, and describes in tandem with the iterative process, the continual push-pull cyclical nature of design. The conception, trial, acceptance and change leading to a repetition are design seasons. As with nature, these can be recorded and provide predictive information to aide acceptance, possible error and classic themes. Technology phenology is responsible for design stagnation of the physical form, being predictive and safe, but inconsistent with technology creep, giving way to style and fashion. Just as today, the upsetting factors of climate change and sustainability were talked about but not acted on. This awakening awaits the anaesthesia machine.

108. Frens, Designing for rich interaction: Integrating form, interaction, and function, 57. 
Medical device design is now termed a multidisciplinary activity; a complex process to innovate, apply, test, regulate and sell equipment. We may infer that design has moved forward in complexity but backwards in social knowledge. Priestley and Beddows worked at the scientific, social and political levels within a movement towards scientific advancement, innovation and philosophical thinking. Science is surrounded by humanity, resulting in prospective leaps both for industry and the health of people, although at a time of unknown epidemiological statistics.

Peer to peer interaction may be a better way of describing the developmental or post discovery phase where devices for the delivery of agents were problematic, not the agents themselves. Extreme ingenuity is encountered, as is open communication, presentation, and criticism by most, experimentation curtailed to a great extent by society, and by a profession's reaction to safety.

\section{An awakening to human error}

In the 1950s, two controversial publications pertaining to deaths associated with anaesthesia revealed to the public the dangers associated with anaesthesia, but implicated drugs as responsible. ${ }^{109}$ Following these studies Jeffery Cooper published 'preventable anaesthesia mishaps: a study of human factors' in the journal anaesthesiology. ${ }^{110}$ Cooper adopted Flanagans 'critical incident technique' with an outcome that awoke the anaesthesia profession to human error and equipment interaction. ${ }^{111}$

The work of Cooper changed the liability from anaesthetic agents to the anaesthetists, recording the frequency of human error vs equipment failure.

109. H K. Beecher. D P. Todd, "A study of deaths associated with anesthesia and surgery," Annals of Surgery 140 (1954): 2-24. ; Jr Abajian. J G. Arrowood. R H. Barrett. C S. Dwyer. U H. Eversole. J H. Fine. L V. Hand. W C Jr. Howrie. P S. Marcus. S J. Martin. M J. Nicholson. E Saklad. M Saklad. P Sellman. M. Smith. P D. Woodbridge, "Critique of - A study of deaths associated with anesthesia and surgery," Annals of Surgery 142 (1955): 138-141.

110. J. B. Cooper. R. S. Newbower. C. D. Long. B McPeek, "Preventable anesthesia mishaps: a study of human factors," Anesthesiology Vol 9. No 6. (1978): 399-406.

111. Flanagan, "The critical incident technique," ; J B. Cooper, "Toward prevention of anesthetic mishaps" in Analysis of Anesthetic Mishaps, edited by E C Pierce Jr. J B. Cooper (Boston: Little Brown, 1984): 167-183. ; Note: Cooper, instead of using traditional methods that investigated operative procedures, the patient's disease, age, physical status, or other factors that implicated toxicity and anaesthesia agents, borrowed from aviation the 'critical incident technique' a technique consisting of interviews to recall circumstances surrounding serious events, identifying poor equipment design and work systems. 


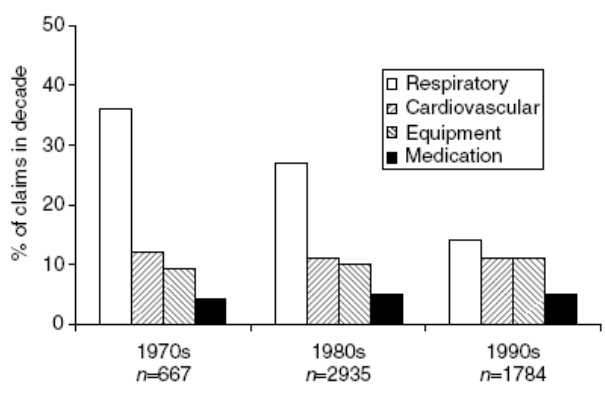

Fig 1 Most common 'damaging events' in the ASA Closed Claims Study, the 'damaging event' is the mechanism which allegedly caused the injury. Data from the ASA Closed Claims Study. ${ }^{79}$ (Figure reproduced with the permission of the Anesthesia Patient Safety Foundation.)

Fig 3.7 ASA closed claims study Anesthesia patient safety foundation 2001

Source: A R. Aitkenhead 2005.
Human error was implicated in $82 \%$ of critical incidents and $14 \%$ involved equipment. Cooper was quick to note the role that equipment plays in human error. This study may have been the incentive for Cooper to act on his research in later developing the BAS prototype, a concept that acknowledged both statistical evidence and qualitative knowledge from relationships with clinicians. More recently the ASA closed claims study

illustrates little decline in equipment related events ${ }^{112}$ (Figure 3.7).

Prior to Cooper's lifting the lid on accidents in technological interactions, usability may have been voiced as common sense, or for those that erred, ineptitude or mistake, remembering that this was a time of mechanist equipment. ${ }^{113}$ Increasingly anaesthesia has come under the spotlight partially due to its own willingness to investigate, find cause and endeavour to remedy; the media have been quick to capitalise. In 1982, the ABC television program 20/20 delivered a revealing account of anaesthesia accidents in 'The Deep Sleep', 6000 Americans die or suffer brain damage related to mishaps. ${ }^{114}$

In 'Designing Usability into Medical Products' Wiklund addresses good design as "designing for the needs of users" stressing that to accomplish this task means "exhaustively investigating the product's functional requirements and the users' needs and preferences". ${ }^{115}$ Although this is a constraint, it is a positive guiding principal, stipulating real risk in off the cuff creativity.

Usability is now integral to medical devices through IEC and FDA legislation.

112. A R. Aitkenhead, "Injuries associated with anaesthesia. A global perspective," British Journal of Anaesthesia May 20, (2005): 6.

113. Vicente, The human factor, 43.

114. Janice Tomlin (producer), "The Deep Sleep: 6,000 will die or suffer brain damage," WLSTV Chicago, 20/20, April 22, 1982.

115. Wiklund, Designing usability into medical products, 3. 
Human error is presented as the key driver for new standards, ${ }^{116}$ being associated with 2 out of 3 accidents which occur with medical devices. In doing so, the IEC have applied a rigorous design constraint in usability engineering. Defining usability as 'characteristic of the USER INTERFACE that establishes EFFECTIVENESS, EFFICIENCY, ease of USER learning and USER satisfaction'. ${ }^{117}$ A tall order for step by step iterative testing that does not account for properties that influence human performance surfacing under conditions of use, often recorded as operator error after the fact, and later still discovered as problems in device features. ${ }^{118}$

Although FDA cannot require manufacturers to implement IEC 62366, Carstensen fully expects the agency to strongly endorse the standard's usability guidelines. "I think a lot of companies are not really sure how to go about doing this stuff," he says, noting that the new standard provides a comprehensive explanation of human factors. "[There are] a lot of informative annexes. I think that will be a big help to them." 119

Cross discipline research and borrowed methodologies have led to the application of ethnographic and anthropological methodologies to medical equipment design. ${ }^{120}$ This is a reflection on the inadequacy of the traditional design toolkit to deal with complex new technologies, pointing to the need for closer relationship between designer and user to overcome natural egocentrism by encouraging a view from the practitioners' perspective. ${ }^{121}$

\section{Chapter conclusions.}

The 1700s showed close alliances between design and society, with society as the client. The 1800s brought user design and the mechanical in close proximity to the patient, and the 1900s manufacturing iterations focused on the operating theatre environment. Now the focus is on the complexity of design requirements

116. Carl Wallroth, Peter Carstensen, Dave Osborn, Gerald Panitz, Charles Sidebottom, Matthew B Weinger, Michael Wiklund, Dwayne Westenskow, "Development of a Standard for Reducing Use Errors with Medical Devices," Society for Technology in Anesthesia January 16-19 (2008) S-24.

117. IEC 62366, Medical devices, $3.17 *$ usability

118. Cook, "A Tale of Two Stories," 31. $3 / 5 / 2008)$

119. http://www.medicaldevicestoday.com/2007/04/new_usability_s.html (accessed

120. Wilcox, "User-centered medical product development and the problem of egocentrism," 55-59.

121. Ibid., 
between technology, task and safety, somewhat overburdened by the wants and expectations of society.

300 years spans the acceptance of pain through birthright, to a premise of good health through technology. In this time frame, speculation and trial and error have produced a rich foundation of physiological knowledge. Design methods wrought from testing ideas upon oneself and others, are no longer ethically acceptable. The results are now manifested and delivered by many clinicians to ever more patients, whilst blame and its partner, legal dogma, prise at any crevice of clinician ineptitude - and in doing so, erase much of the meritorious past of anaesthesia.

From examining the influences on and of anaesthesia, significant design constraints are identified. Primarily, this is a perpetual social expectation, overriding design legislation. Having emerged from epidemiology and clinical complexity, through public criticism and professional research, expectations continue to rise. The ensuing complex legislative standards are now addressing a reducing number of players in the anaesthesia industry, whilst these in turn service an increasing population of anaesthetists. Reactions to airline disasters have demanded new techniques to increase safety. These large scale incidents have driven innovation in safety, passing down through simulation and development of crisis management algorithms now reaching healthcare and anaesthesia. Yet the relationship between one death and 300 speculate that systems in healthcare struggle to control a balance of care, compliance, and blame. On a macro level the profession of anaesthesia is constrained by specialisation and institutionalism that limit new synergies for exploration. Closer up, tradition, user age span, and elite status makes acceptance of change difficult to ascertain.

Although anaesthesia has brought great achievements, new rules coagulate around the safe process of advancement. With increasing public awareness from its openness in research, and the watchful press, the elite come into criticism regarding its capability to provide safe destiny, being judged more now as a commodity. The next chapter continues this examination looking at the personalities, design, and ergonomics of equipment in the context of time and a developing profession. 


\section{ANAESTHESIA MACHINE GENEALOGY}

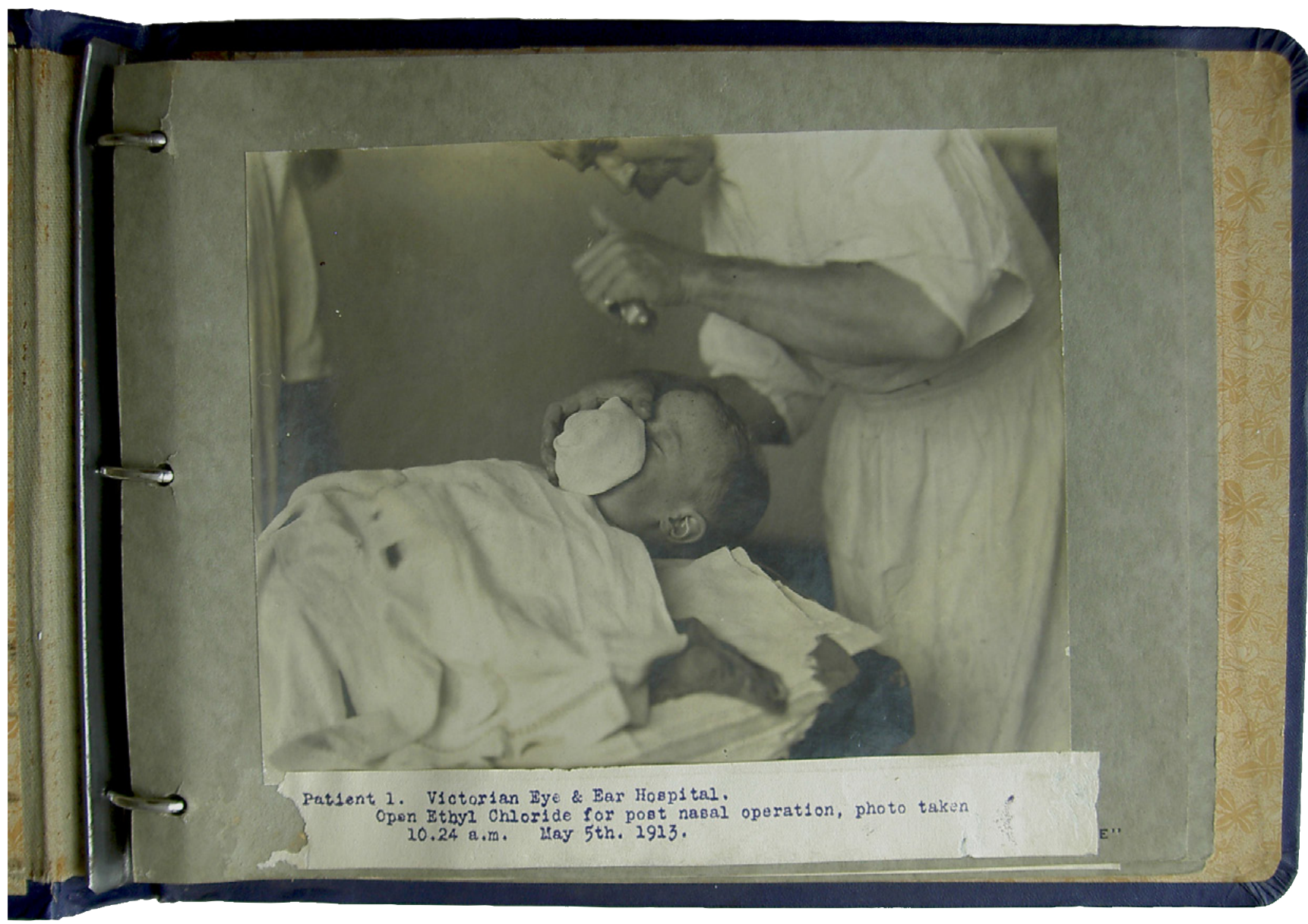

Fig 4.0 Open drop method of anaesthesia administration

Source: Geoffrey Kaye Museum 


\section{Restricted method of use}

\section{Unrestricted method of use}

\section{Unrestricted method of use}

\section{Unrestricted method of use}

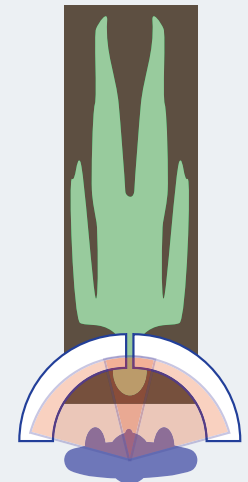

Rag and bottle

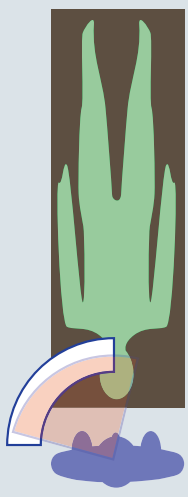

Mask and bottle

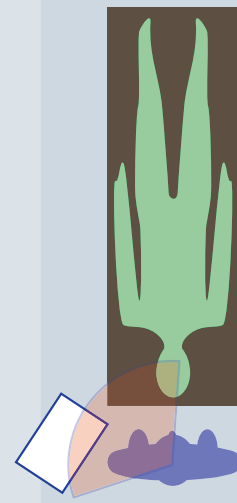

Apparatus

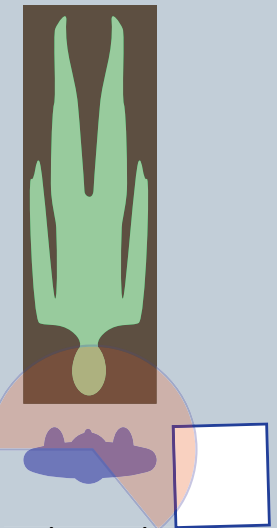

Early machine

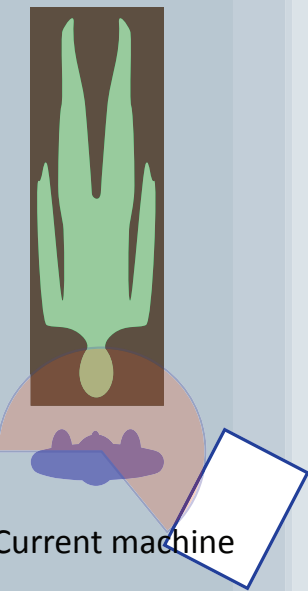

Symmetrical, can be used either left or right

Symmetrical, can be used either left or right, typically right hand holds mask

Early Asymmetery, components reading from left to right to patient

Asymmetrical, flow from gas supply through anaesthesia agent to mask, reads from left to right to left to patient

The developing convention of use
Asymmetrical with table, flow from gas supply through anaesthesia agent to mask, reads from right to left to patient

Fig 4.1 A convention of machine use stems from a design evolution: first the symmetrical and ergonomically unrestricted application of mask and bottle directly translated to apparatus. Second the apparatus component interface translated to furniture and a new position relevant not to task but tools, forcing users to adopt rather than adapt 


$$
\text { Chapter } 4
$$

\section{ANAESTHESIA MACHINE GENEALOGY}

\section{I devised the machine known as 'Boyle's Nitrous oxide Oxygen Ether Outfit' 122}

The previous chapter examined a profession through the context of society, science, and design. This chapter looks at the physical context of equipment to trace an evolution of the 'designed form' (Figure 4.1). How the use of equipment and the growth of scientific anaesthesia has influenced the design outcome, thus impacting on the anaesthetist's environment and activity.

This Chapter examines in detail the origins and use of hand held equipment, the arrival of apparatus, and the implementation of the anaesthesia machine. In this case, the development of the influential Boyle machine and its contribution to contemporary anaesthesia is described. This is investigated through viewing design as a representational outcome of use methods, encompassing a developing profession, early innovators and industry collaboration. It also questions the resulting implications for clinicians and designers from the acceptance and methods of change. The aim is to ascertain the allegiance to a design consensus rather than relying on Boquet's conclusion that the anaesthesia machine has just evolved historically.

It is difficult to examine the entirety of anaesthesia equipment from every country, ${ }^{123}$ the dominant designs looked at are pertinent to New Zealand, Australia, the United Kingdom, Commonwealth, and the United States of America. To achieve this, literature, interview and archives are researched for connections to ascertain a design genealogy spanning the last 150 years of anaesthesia innovation. These are critiqued in the light of a profession's evolutionary influence on design.

122. H E G Boyle, "The use of nitrous oxide and oxygen with rebreathing in military surgery," Lancet 2 (1917): 667-669.

123. Museum of anaesthesia equipment, http://www.anesth.hama-med.ac.jp/Anedepartment/ museum-masuiki.asp). 


\section{Anaesthesia machine genealogy}

L Rendell Baker, writes in the foreword to K Bryn Thomas's book "that after 50 years of development from 1912, the Boyles machine was adopted from a design stand point by US manufacturers. This layout with the flowmeters on the left, and the outlet on the right, was designed by Boyle for convenient use of the machine on his left hand side, as he was left handed"124 (Figure 4.2). Edmund Boyle's left-handedness is often quoted anecdotally as the reason why most anaesthetic machines have conformed to an asymmetrical structure.

Observing activities in the current operating theatre environment, it would seem that the anaesthetist is encumbered with an historical yet worthy artefact. Suggesting a cumulative affect of physical form, location, technology, operation duration and task interactions are a 'design intention' to facilitate safe operative management. This suggestion will be tested in Chapter Six.

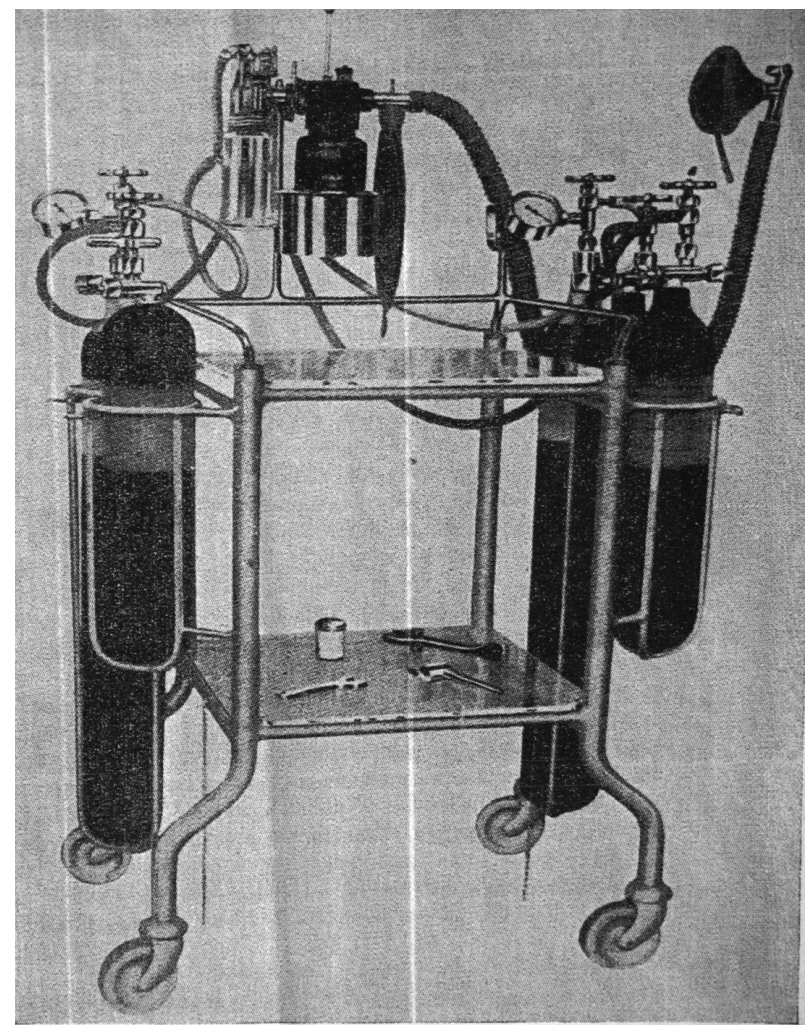

Fig 4.2 The Boyle machine 1930.

Source: O M. Watt, 1968.

124. Thomas, The development of anaesthetic apparatus, viii 


\section{Hand held to hand operated, early innovations.}

Early medical practitioners endeavoured to provide the best physiological conditions for surgery by overcoming limitations imposed by the equipment and drugs of the day. Equally motivated in this period were manufacturing companies that could capitalise on this newly expanding profession. This was a profession whose early anaesthesia methods consisted of the "rag" and bottle (Figure 1.0), and later, the open drop 'mask and bottle', where the "rag" or cloth was applied to a wire frame for the application to the patient's face. These were simple physician owned apparatus that was often hand crafted from scratch or adapted from available resources. The progression from simple items to apparatus required a mechanistic technology transfer through the forming of new interdisciplinary relationships, facilitating the adoption of industrial processes, and skills in materials and technologies.

Between 1870 and 1930 anaesthetic equipment underwent a multitude of innovative developments. Anaesthesia gained credibility as a medical profession and debated patient safety, clinical efficiency, and the merits of a variety of anaesthetic agents including, but not limited to, chloroform, ether, and nitrous oxide. While there were many deaths in this period associated with innovative equipment, ${ }^{125}$ the open drop 'mask and bottle' method of anaesthesia administration survived with remarkably few casualties in light of its crude contrivance. Demonstrating that patient safety was achieved through a practitioner's skill in administration and shrewd judgement, ${ }^{126}$ the Clover inhaler was, in the hands of skilled anaesthetists the

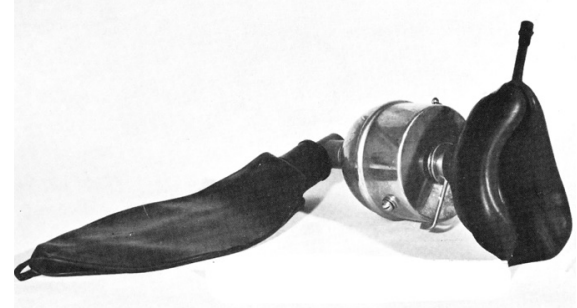

Fig 4.4 Clover inhaler 1877 Source: K Bryn Thomas, 1975.

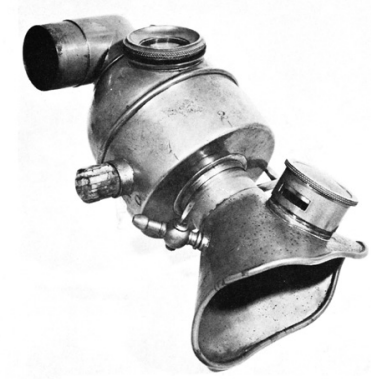

Fig 4.3 Wilson-Smith Ether inhaler 1899

Source: K Bryn Thomas, 1975. technical plateau, of this era (Figure 4.5).

125. Stanley W. Sykes, Essays on the first bundred years of anaesthesia (Edinburgh: E\&S Livingstone Ltd, 1961): Vol II, Chart I, 32-33.

126. Charles F. Hadfield, "Eminent Anaesthetists H. Edmund G. Boyle," British Journal of Anaesthesia 22 (1950): 107-117. 


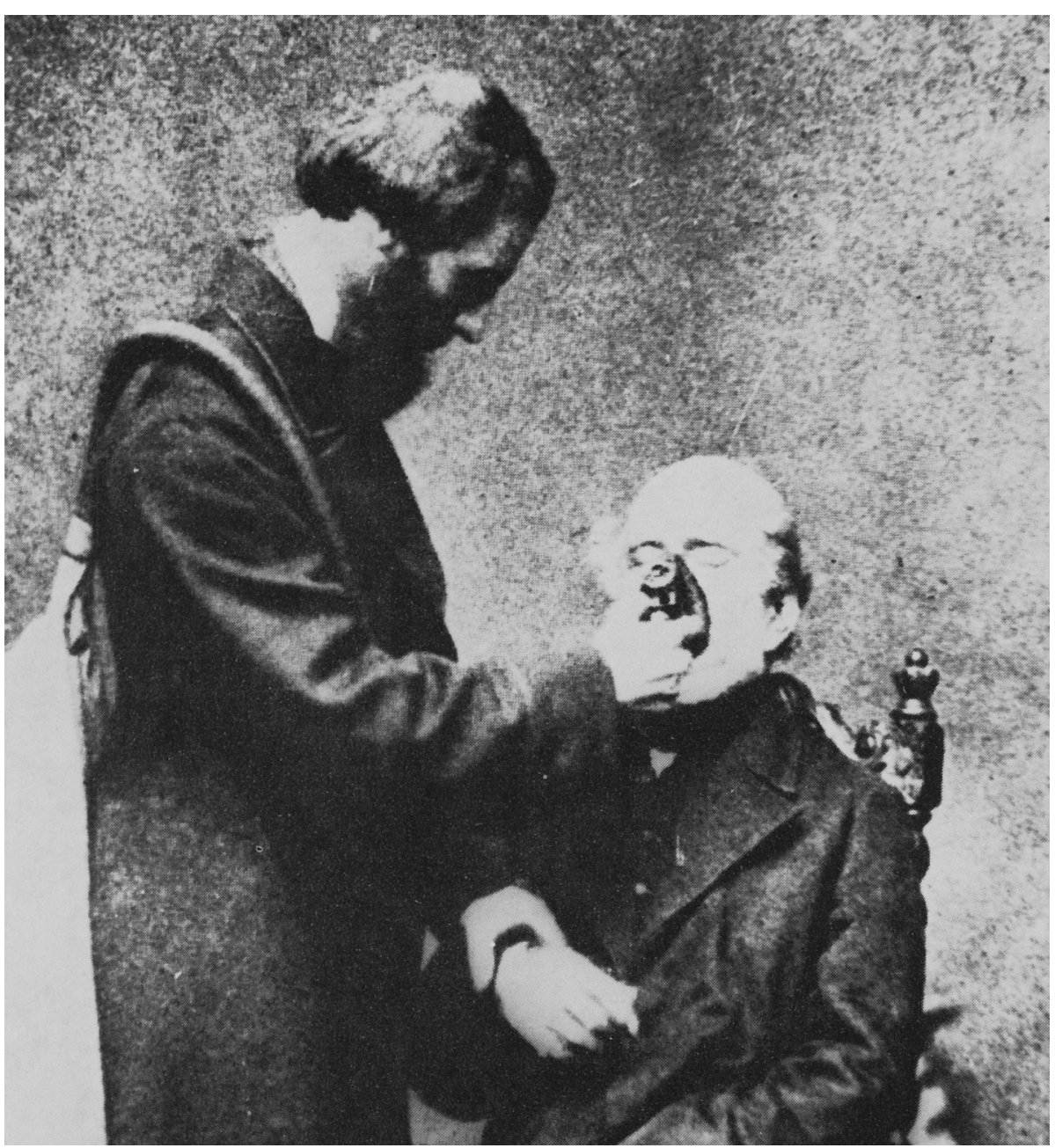

Fig 4.5 Joseph Thomas Clover administering chloroform anaesthesia with bag and face piece

Source: K Bryn Thomas 1975.

Many anaesthetists with the support of manufacturers or able technical assistance endeavoured to refine and quantify the technology of agent administration. Joseph Clover provided early discernible controls by indexing the flow tube position in his inhaler of 1877 , visibly reflecting the extent to which air passes over ether and hence giving some idea of concentration (Figure 4.3). In 1899 Dr Wilson Smith adapted Clovers apparatus by applying watch glasses to view the quantity of ether ${ }^{127}$ (Figure 4.4). These are early examples of innovative anaesthetists designing products with functional control features to predictably assist the safe delivery of anaesthesia by other anaesthetists.

New equipment, drugs and clinical techniques brought forth an innovation pendulum, swinging between depth, duration and complexity of surgery and 127. Thomas, The development of anaesthetic apparatus, 20-23. 
patient physiological stability. By 1917 innovation swung not on a physician's ability to measure a dose of ether in the comfort of the front room dental surgery, but in the anaesthetist's operation of stand-alone equipment specific to the then developing organised hospital. The physical form of the hand-held apparatus was transformed in the early 1900s to free-standing apparatus, and by the 1930 s to the self contained anaesthesia machine. In the last example, the structural chassis and aesthetic were predominantly left to manufacturers, evident in the multitude of formats produced, based on the dominant Boyle arrangement.

\section{Borrowed innovations}

The promotion of gas-oxygen-ether anaesthesia in the early 1900s required oxygen and nitrous oxide gases to be reduced in pressure and administered alongside ether. Design was constrained by the chemical and physical properties of these agents and the manufacturing techniques and materials available. For the innovative anaesthetist, equipment 'design' was a technical arrangement, novel iterations of borrowed technology and components combined to provide safe and controllable administration of a variety of anaesthetic agents.

A design legacy resides in the physical presentation layout and output control of anaesthetic agents. A critical innovation to manage these agents was not in providing an indicative index as Clover had, but a real-time visible reference of gas flow. The technology for this has been attributed to Boothby and Cotton (1910) and the Nitrous Oxide-Oxygen-Ether sight feed bubble bottle. ${ }^{128}$ Boothby's interest in oxygen led to the development of a high altitude oxygen inhalation device utilised by pilots in WWII. ${ }^{129}$ James Tayloe Gwathmey, a New York based practicing anaesthetist, adapted Boothby and Cotton's bottle as a water sight feed bottle, demonstrating his apparatus at the $17^{\text {th }}$ International Medical Congress in London, in August 1913, at which Boyle was present. The Gwathmey machine was refined and produced in 1914 by New York manufacturer and long-time friend and associate Richard von Foregger ${ }^{130}$ (Figure 4.6).

128. Watt, The Evolution of the Boyle apparatus, 103-118.

129. N. Webel. B. Harrison. P. Southorn. "Anaesthesia origins of the intensive care physician," in The History of Anesthesia: Fifth International Congress edited. Jose C. Diz. Avelino Franco. Douglas R. Bacon. (Amsterdam: Elsevier Science, 2002), 613-617.

130. Richard Foregger, "Richard von Foregger, PhD 1872-1960: Manufacturer of Anesthesia Equipment," Anesthesiology Vol 84 No 1. (1996): 190-200. 


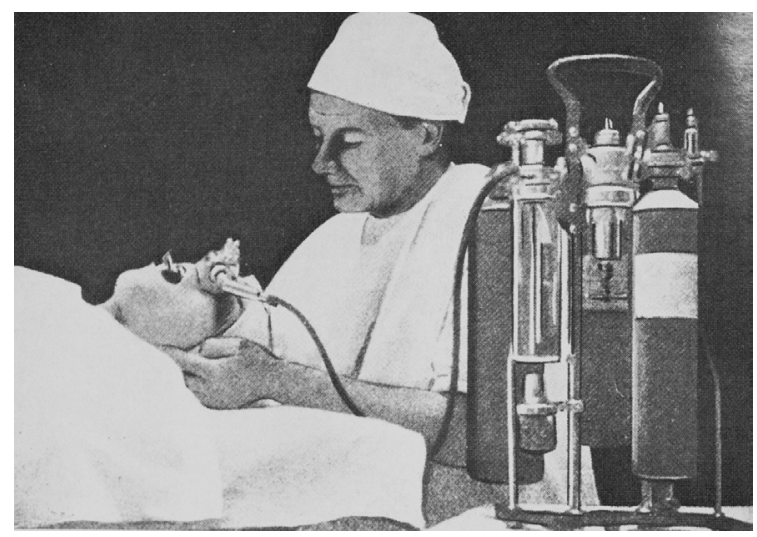

Fig 4.6 Gwathmey administering nitrous oxide/oxygen from his own apparatus 1914

Source: K Bryn Thomas 1975.

During WWI, the Gwathmey machine was utilised by British anaesthetists.

Captain Geoffrey Marshall brought the technology of water sight feed to an

English manufacturer having a machine built by Mess Coxeter and Sons (Figure 4.7).

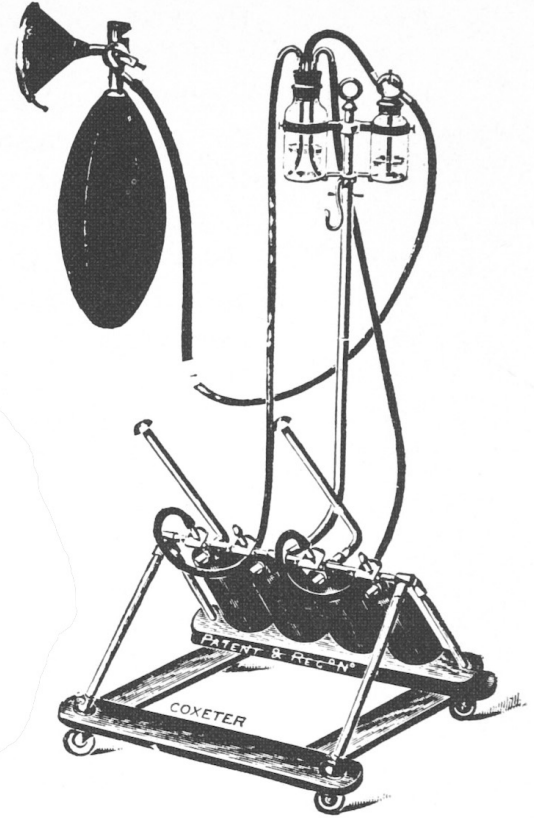

Fig 4.7 Marshall apparatus 1917

Source: K Bryn Thomas 1975.
Boyle met and worked with Gwathmey as both served in the First World War, Gwathmey at the American Red Cross Hospital in France and Boyle at the $1^{\text {st }}$ London General Hospital. A shared common interest is reflected in Gwathmey persuading Boyle to get a machine and try it. ${ }^{131}$ In 1916 Boyle arranged to have two Foregger-Gwathmey machines imported from New York, one portable and one hospital model. ${ }^{132}$ Boyle took over the consultant relationship from Marshall with Coxeters ${ }^{133}$ adapting the Foregger-Gwathmey machine to fit English cylinders thus reducing leaks. Much speculation is evident in the transactions of ideas during this period but it is certain that both Boyle and Lord George Wellesley of Coxeters played ardent leading roles in

131. Thomas, The development of anaesthetic apparatus, 140.

132. Foregger, "Richard von Foregger, PhD 1872-1960: Manufacturer of Anesthesia Equipment," 190-200.

133. Barbara Evans, "A doctor in the great war-an interview with Sir Geoffrey Marshall," British medical journal Vol 285 18-25 (1982): 1780-1783 
design, prototyping and production. ${ }^{134}$ Five years of borrowed, shared and collaborative innovation, originating in the bubble bottle led to the Boyle machine of 1917 (Figure 4.8).

The outcome of these five years was an interface which reads from left to right. First there are water bubble tubes that enabled visual regulation of flow, positioned alongside vaporisers with plungers to increase the concentration of vapour, all supported at a height relevant to visual

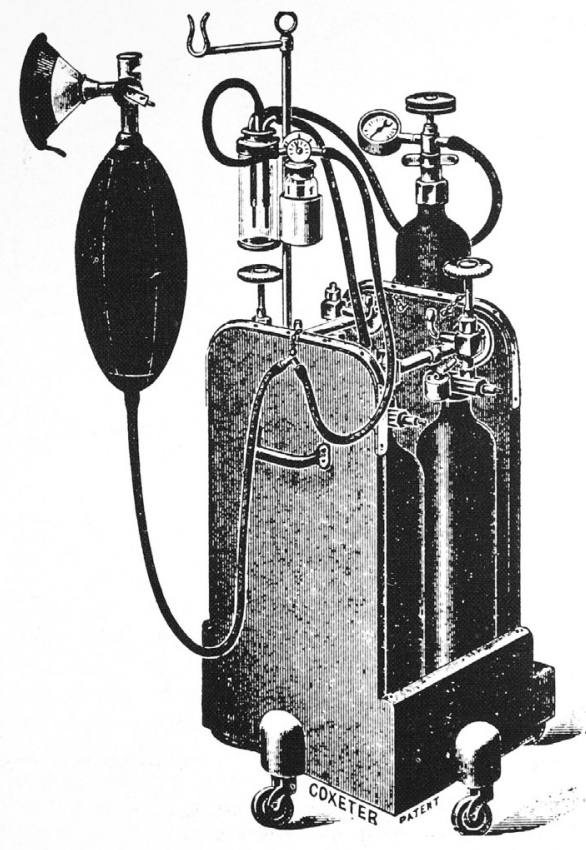
and tactile requirements. Together they resulted in an exposed and comprehendible, Fig 4.8 Boyle apparatus 1919 functional linear interface. Coxeter and Source: K Bryn Thomas 1975. Sons, later assimilated into BOC, continued development to be trademarked and known thereafter as the Boyles machine. ${ }^{135}$ The Boyle interface then developed as the technology of gas flow measurement was refined. The bubble bottle was superseded by the Coxeter dry bobbin meter, leading to rotameters as we know them, being installed in 1937. 136 Mention should also be made of the 1902 innovation by Dräger AG and Otto Roth in developing a suction driven indexed drip feed to visibly measure and ascertain chloroform concentration. ${ }^{137}$

The capability of invention to bring change relies on technology reaching an accessible point, a point where it may be acknowledged, applied, adapted and refined to the parameters of the task. New methods for accessing gas flows with bubble bottles, drip feeds, bobbins, and rotameters stemmed from the industrial requirements for calibration and measurement of gas and liquids. ${ }^{138}$ How

134. Ibid., ; Watt, “The Evolution of the Boyle apparatus, 1917-67,"103-118.

135. C Ball. R Westhorpe, "The Coxeter Bolye gas anaesthesia apparatus," Anaesthesia and intensive care, 27,2. (1999)

136. Maltby, Notable names in Anaesthesia, 25-27.

137. Josef Haupt, The History of Anaesthesia at Dräger (Drägerwerk AG. Vol 1. 1996):13.

138. D E. Jackson, "Anesthesia equipment from 1914 to 1954 and experiments leading to its development," Anesthesiology Vol 16 (1955): 953-969. 
technology is applied, presented and enforced through products, often means that early promising concepts are neglected. The rotameter, invented by Karl Kueppers, had been used as early as 1910 in anaesthesia by Maximilliam Neu. ${ }^{139}$ Later Dr I W Magill sought credit in maintaining to have had rotameters made in 1928 for his own use. Richard Salt's suggestion that rotameters be adapted for anaesthetic use in 1937demonstrates that designs are sometimes thrust upon users and accepted when presented as a credible, capable, or only option. ${ }^{140}$ This time as part of the Boyle machine. ${ }^{141}$

\section{A new workstation, the machine as furniture.}

The addition of the table to the collection of bottles, tubes, vaporisers and flowmeters signifies the shift between collective apparatus and workstation machine. In the early 1930s Dr Nissen Deacon, ${ }^{142}$ the medical superintendent of the Edgware Hospital produced a structure that integrated the required inhalers, masks, and agents with the apparatus by which to administer anaesthetic ${ }^{143}$ (Figure 4.2). This seemingly obvious modification has graduated to every manufacturer since. The ramifications of this now global design change implemented in 1931 is that it brings together controls; both visual and functional, with a furniture like structure as an everlasting precedent for design.

Karl Connell, Instructor in Surgery, Columbia University illustrates that the innovative spirit with similarity in design was widespread. The Connell machine adhered to the new Boyle table top configuration, including a closed circuit system complete with non-return inspiratory and expiry valves visible under glass domes, a measured spirometer, and $\mathrm{CO}_{2}$ absorber (Figure 4.9).

While the Boyle machine of 1931 utilised a tube frame giving clear visibility to all components, Connell demonstrates the use of more sophisticated

139. M Goerig. C Nemes. H Peterman, "Paul Zweifel-his importance in German obstetric anaesthesia," in The History of Anesthesia: Fifth International Congress edited Jose C. Diz. Avelino Franco. Douglas R. Bacon. (Amsterdam: Elsevier Science, 2002).

140. Technician at Nuffield Department of Anaesthetics University of Oxford.

141. Watt, "The Evolution of the Boyle apparatus," 103-118.

142. E-mails to Dr Deacons Son referring to his active involvement in equipment design and standards, also the significant archive held by his Son. 9/11/2007.

143. D J. Wilkinson, "Henry Edmund Gaskin Boyle 1875-1941," in The History of Anesthesia: Fifth International Congress ed. Jose C. Diz. Avelino Franco. Douglas R. Bacon. (Amsterdam: Elsevier Science, 2002). ; Product brochure Section B, A. Charles King Ltd (Undated): 10. 
technology in manufacture employing folded Stainless Steel sheet, thus hiding many of the workings. Although distanced by the Atlantic Ocean, both Boyle and Connell chose or had chosen for them, methods indigenous to their country's manufacturing technologies, resulting in a common form yet two very different aesthetics.

This application of a work-surface table changed the relationship between user and patient. By providing a surface for new drugs and accessories as a response to necessity, the machine was placed in a new position, on the right of the patient, carrying with it the traditional layout of the left-handed

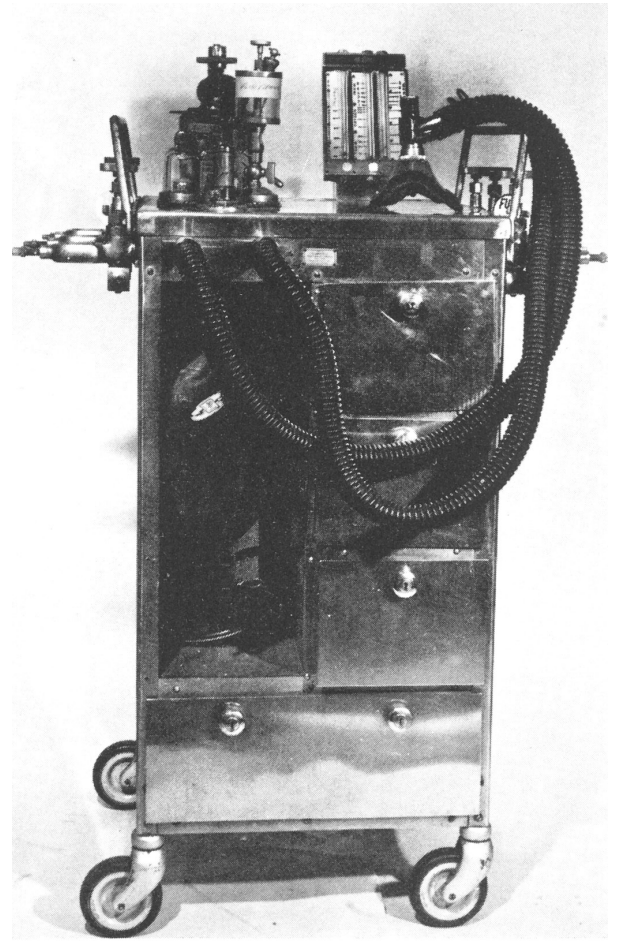

Fig 4.9 Connell machine 1937 apparatus. Consequentially, a new ergonomic apposition was imposed for the anaesthetist in relationship to the patient, field of vision, physical reach, and environment. By 1940, the close proximity to patient and the tactile nature of the mask and bottle had been reduced to the aesthetic of an appliance, yet the component layout retained design residues from anaesthetist's evolving use habits.

This appliance aesthetic was evident in many other products of the 1940s and 1950s. These evolving design styles are a direct result of industry driven design. Desires to utilise new materials and techniques in manufacture were not function driven, instead they took leads from the automotive and domestic manufacturers' mass production for mass consumption methodology. In the example of the MIE Comprex, pressed duralumin, marketed as "unobtrusive modern design"144 (Figure 4.10).

Residues of component placement, influential technological changes and usability issues have slowly manipulated the anaesthesia machine. The right hand Australia. 


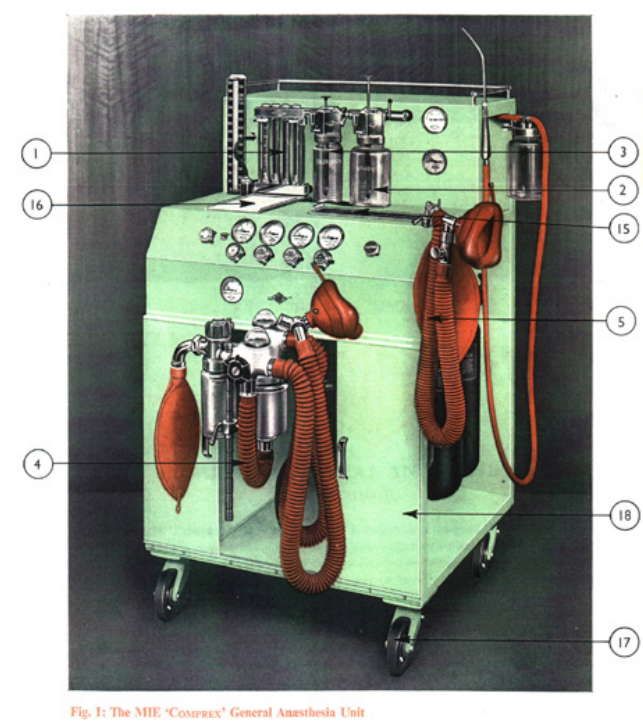

Fig 4.10 Manufacturing styles. MIE Comprex

Source: Geoffrey Kaye Museum

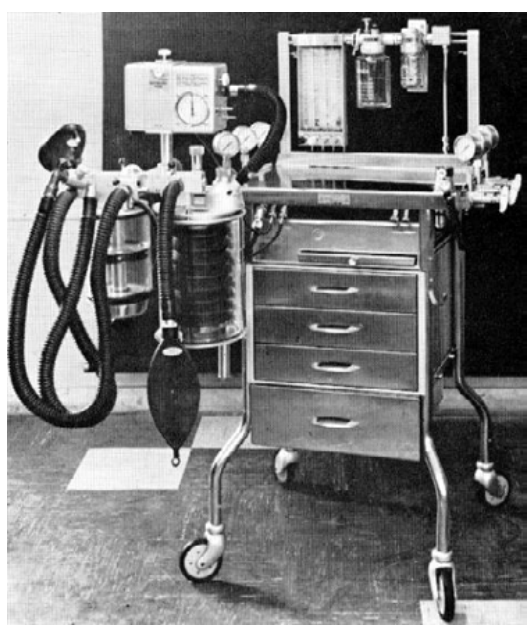

Fig 4.11 Final iterations to the output circle. BOC Boyle machine1965

Source: Wilkinson 2002

outlet moved to the centre in 1941, when fitted with the Coxeter-Mushin circle absorber, and later to the front as an integral part of the machine. This design change is attributable to suggestions by Mushin and Ezard in 1950. Not only was the take off mount moved to the front alleviating the trailing of a corrugated rubber tube across the table, but it also brought with it an emergency push button oxygen bypass. ${ }^{145}$ The progressive movement of $\mathrm{CO}_{2}$ absorbers and ventilation bellows to the left marked a conclusion to output position (Figure 4.11). Thirty years had passed in moving this component from left to right handed operation, yet the layout and reading of rotameter and anaesthesia agent remained in the left to right apparatus position till the 1990s.

From the 1950s onwards, the layout and composition represented as table, storage and controls has remained constant. Yet how anaesthetists see these machines has changed. The early machines of Boyle's era were comparatively simple in following on from the apparatus, revealing workings in a visual schematic of systematic plumbing, connections and anaesthesia agents. The more recent addition of electronics has partnered with a gathering of components within a plastic shell, now hiding most of the connections within an organic weave of technicality, only becoming sensible at the exterior orifices, connections and interface screens. As an historical engineered evolution, the exposed interior has matured to an exposed exterior, still governed by hidden workings and traditional 

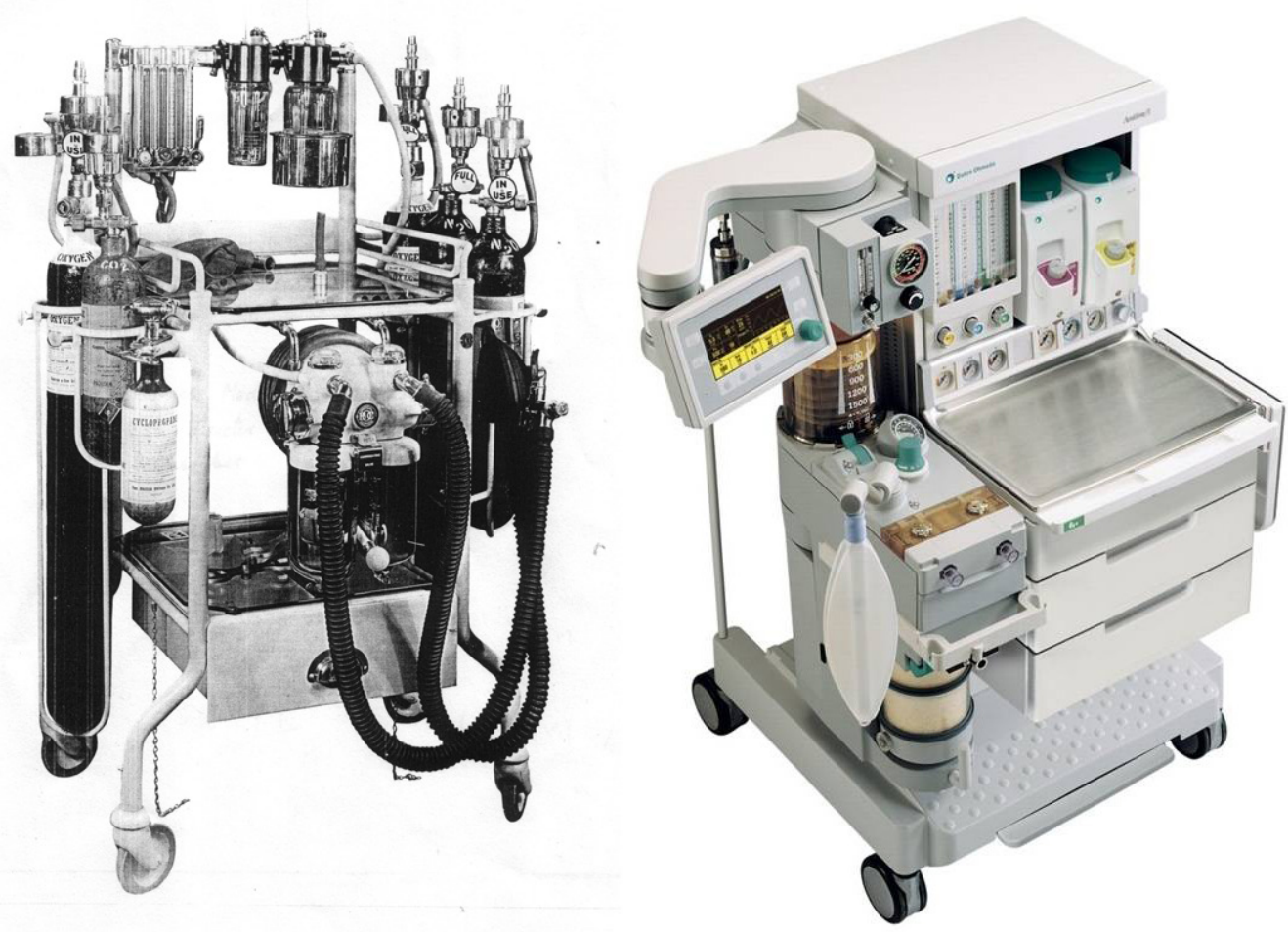

Fig 4.12 Interiors exposed and hidden.

Source: Boyles Geoffrey Kaye Museum; Datex Ohmeda Aestvia GE Healthcare.

component placement (Figure 4.12).

\subsection{The left handed origin, normal use or one mans legacy}

The left hand configuration purported to be from Boyles natural orientation is questioned, does it stem from the origins of the portable inhaler?

No research exists pertaining to the ergonomically derived evolution of the anaesthesia machine other than Rendell-Baker's statement. ${ }^{146}$ The argument prompted here is that the origins of present day machine composition can be traced back to the mask and bottle through the evolving ergonomics and asymmetry of use. Clover is illustrated administering chloroform utilising the right hand on the mask, and the left on the patient's pulse, ${ }^{147}$ (Figure 4.15) as does the image from the Geoffrey Kaye Museum (Figure 4.0). Was Roth, in his developments with Dräger in 1910, and respectively Gwathmey in 1914 with his own apparatus, ${ }^{148}$ also left handed (Figure $4.13 \& 4.6$ ).

146. Thomas, The development of anaesthetic apparatus, viii.

147. Ibid., 15.

148. Haupt, The History of Anaesthesia at Dräger, 14,18. ; Thomas, The development of anaesthetic apparatus, 141. 

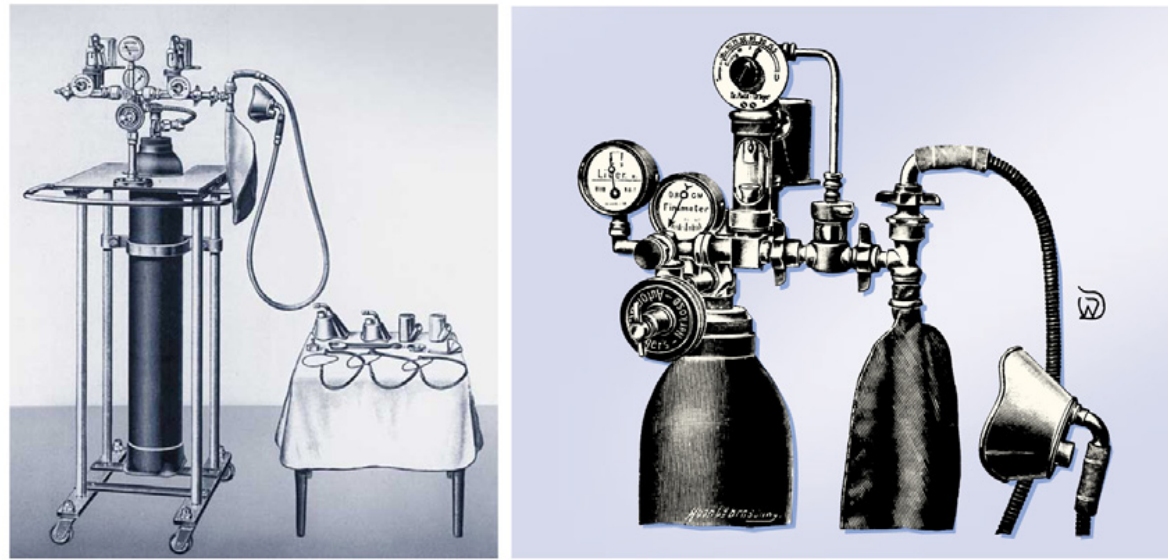

Fig 4.13 Dräger apparatus, the 1910 Roth-Dräger and 1902 drip feed. Source: DrägerMedical The History of Anaesthesia at Dräger, 1996.

If, as demonstrated by Clover and the accompanying images, the right hand on the inhaler positioning was the status quo, the natural translation for Gwathmey, Marshall and Roth in developing new apparatus, was to utilise the hand of lesser dexterity in equipment adjustment. In the application of chloroform or ether drop, resides the need to continuously and carefully locate the mask for precise administration and avoidance of suffocation. The dominant right hand controls the mask whilst tilting the drip bottle, and setting it down to take pulse measurements occupies the left hand.

The limited resources available demonstrate the subtle unrecognised translations that users' adopted through technical innovation. In the development of his

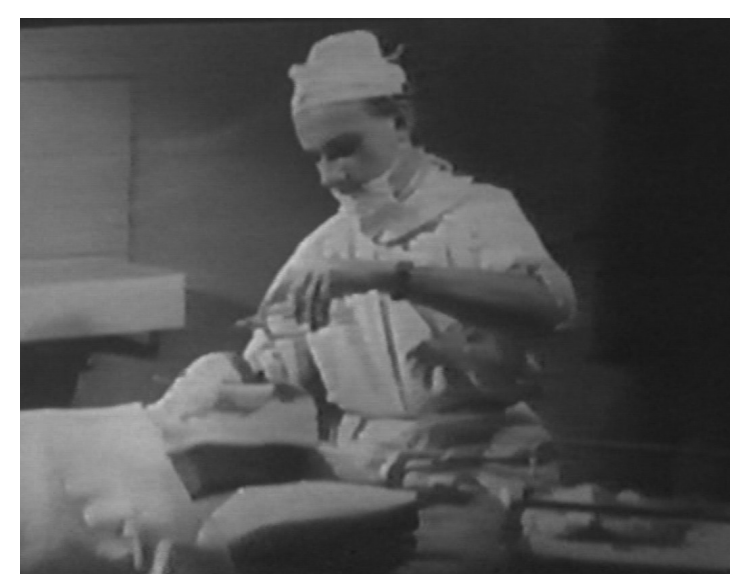

Fig 4.14 Open drop ether. Source: ICl productions 1944. apparatus, Boyle followed the example set by Gwathmey, Roth and normal use, being the more reasonable argument of reading inputs and outputs from left to right standing at the head of the patient.

Boyle either failed to comprehend the consequence of being left handed when working as a consultant to industry, devising for himself in an era before ergonomics and usability 
studies. ${ }^{149}$ Or alternatively he was following the established practice in apparatus positioning, having borrowed innovations that were already designed based on a natural progression of familiar cues, the 'normal use' of mask and bottle.

Unconsciously applying normal use may have proved helpful in the transition period between hand held and the apparatus, but this ergonomic relationship was made difficult when the apparatus was evolved by industry into a machine and moved from the left (or in some cases an unrestricted left or right position) to the right of the patient. Two reasons may account for this; first, the obvious use of the table as a repository for tools and materials that could be selected and applied with the dominate right hand. Second, the more ambiguous and speculative, that the right handed machine position provided a better field of view (work triangle) towards the patient and the surgeon in their typical right side position.

While the Boyle machine was initially user 'devised' and later industry developed, BOC was also manufacturing the design of John Gillies, a closed circuit machine that remained faithful to the design capability and innovation of a practicing anaesthetist. ${ }^{150}$ The component layout differs remarkably from the Boyle machine in providing controls at the front rather than the rear of the table (Figure 4.15). This signals that the ergonomic requirements by Gillies are practice based rather than a design reflection or devisal on the evolution of best practice.

Through this research little evidence supports Boyles acknowledgment or reason for stipulating left handed operation in the iterative development of the Gwathmey Source: McKenzie 2008

149. Boyle uses this term in the publication of his work, not design or invention. Devise; to work out, contrive, or plan in ones mind. Collins Dictionary

150. A G. McKenzie, "The Gillies anaesthetic machine," Anaesthesia 63 (2008): 771-777. 
machine. Investigation that includes an ICI teaching film (Figure 4.14) and experts, reveal predominantly, but not always, that the right hand dominated the mask and the left the bottle. ${ }^{151}$ It is inconclusive as to whether Boyles left handed disposition created the left to right asymmetry but there are too many arguments against than for. What can be concluded is that industry manoeuvred this placement (initially an anaesthetist desired use method) to the right and forced anaesthetists to adopt a new habit.

While the reasoning here behind the evolution is speculative, the methods are quantified, a direct result of design not from anaesthetists but from industry. Relevant to todays designers is that anaesthetists took so long to rid themselves of the residue of this change, in moving the outlet closer to the patient in 1960. A sign that the age of anaesthetist as innovator and maker had passed and a brand had now become an aesthetic and ergonomic standard. Anaesthetists must now endeavour to cover a 270 degree workspace as an outcome of collaboration, industry based design bias and layered technology. ${ }^{152}$ An iterative design has manipulated their habits and cannot be resolved in its entirety by installing or applying electronic device interfaces.

With the addition of ventilation came neuromuscular blockade allowing more complex surgery. The implication for the anaesthetist is an extension in operation duration, increased monitoring and unpredictable workloads during the maintenance phase of anaesthesia. ${ }^{153}$ The anaesthetists activities between task, patient, and environment require both cognitive and physical interactions, attempting to automate decision making may confront users with not only having to understand the clinical situation but also the machine's viewpoint and proposed response. ${ }^{154}$

The asymmetry generated in a product that requires side on positioning is

151. Margaret Thomson, director, "the technique of Anaesthesia Series No 2. Open drop ether," ICI productions, Produced by Realist Film Unit, 1944. ; Note; comments from the History of anaesthesia society Summer meeting, York. June (2008).

152. J Held. E Stahl. U Guggenbühl. H Krueger. "Ergonomics in Anaesthesia" Proceedings of the XIth International Ergonomics and Safety Conference (1996).

153. R Helmreich. Hans-Gerhard Schaefer, "Team performance in the operating room," in Human Error in Medicine, edited M S. Bogner (Hove UK: Lawrence Erlbaum Associates, 1994) 230. 154. E M. Roth. K B. Bennett. D D. Woods, "Human interaction with an "intelligent" machine," International Journal of Man-Machine Studies 27 (1987): 479-525. 

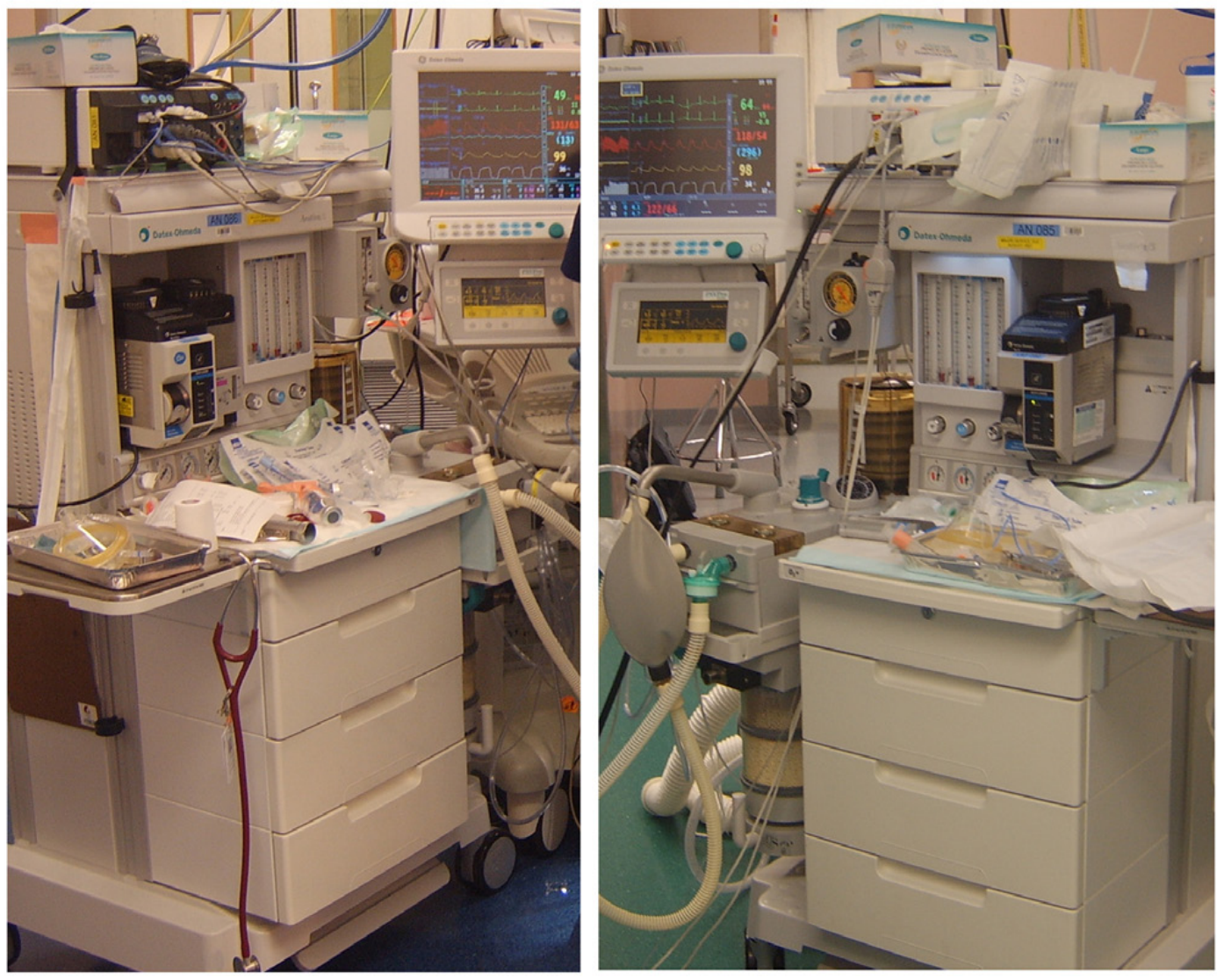

Fig 4.16 Left and right versions of the Aestiva

Source: Author

problematic in having a favoured side, and is difficult to resolve. In comparing the right and left handed versions of the Aestiva a flipped interface is revealed ${ }^{155}$ (Figure 4.16). This suggests that design sees component positioning as either unquestionable, or tethered to an underlying engineering determinate rather than human physiology. ${ }^{156}$ Research by anaesthetists between 1973 and 2004 has consistently questioned the established component layout. ${ }^{157}$ Relating this to the early anaesthetist initiated design of the apparatus in directing and reading flow towards the outlet and thus the patient, current design continues to tread a similar path. Looking back, design demonstrated a lack of empathy and understanding between 1931 and the 1950s, in retaining the outlet on the right while continuing left to right flow. Preferring, like the present, to stick with an unquestionable layout from an established yet evolving tradition.

155. http://www.gehealthcare.com/euen/anesthesia/products/aestiva-5-family/index.html

156. Dalley, "The use of high fidelity human patient simulation and the introduction of new anaesthesia delivery systems," 1737-1741.

157. Albert B. Drui. Robert J. Behm. Wayne E. Martin, "Predesign investigation of the anesthesia operational environment," Anesthesia and Analgesia Vol. 52 No. 4 (1973): 584-591. ; Seagull. "Measuring awkwardness of workplace layout: Dispersion of attentional and psychomotor resources within the anesthesia workspace," 1755-1758. 
Why was the interface laid out in this fashion? As an unconscious residue of habits, changes and manufacture. These contradictions in visual and agent flows still exist, overcome by anaesthetists in an unconscious workaround, and by design through emphasis on screen based activities and the homogenisation of form through new manufacturing techniques. It suggests that there are expectations on designers to successfully compile components, smoothing the qualities between, with methods derived from manufacturing techniques, cost, and the fashion of the day, not by the integration of functions relevant to purpose and use.

\subsection{Implications for acceptance}

Experimentation between the 1850s and 1940s reflected numerous patents, papers and documentation of incidents, followed in the 1950s by patient safety awareness. ${ }^{158}$ This accumulated knowledge has provided a pathway for technology innovation while intensifying constraints in design criteria, evaluation methodologies, error management and recently usability. ${ }^{159}$ The increasing complexity of regulations paired with new technology has played some part in the reduction of anaesthetic machine manufactures from 70 in the 1980s to currently 3 to 4 dominant companies and a handful of smaller manufactures.

Soaring costs of compliance, cost containment, production pressure ${ }^{160}$ and fear of litigation have influenced human factors innovation and redefined the rules of development. All too often, the evaluation of new machines remains focused on scientific analysis and measurement, while the ecological aspect of use and interactions are ignored. ${ }^{161}$ Although anaesthetists may evaluate new designs from a reduced manufacturing population, few avenues are available to allow practitioners to see or comment on tomorrow's world before it reaches them.

\section{Independent prototypes}

Tradition has been challenged through independent and published design research on two fronts previously mentioned in Chapter Two. First, was the

158. Pierce, "40 Years behind the Mask: Safety Revisited," 965-975.

159. IEC 62366, Medical devices, 3.17*usability

160. Pierce, "40 Years behind the Mask: Safety Revisited," 965-975.

161. A Suzuki. H Bito. T Sanjo. T Katoh. S Sato, "Evaluation of the PhysioFlex closed circuit anaesthesia machine," European journal of anaesthesiology 17 (2000): 359-363. 
control of systems electronically. The Anesthesia Bioengineering Unit (ABU) at Massachusetts General Hospital led by Jeffery Cooper (a biomedical engineer), developed a microprocessor-controlled workstation in $1976^{162}$ (Figure 2.2 \& 4.17).

Second, the design explorations by Boquet et al in 1980 explored the capability for task analysis to inform design and usability, producing a prototype based

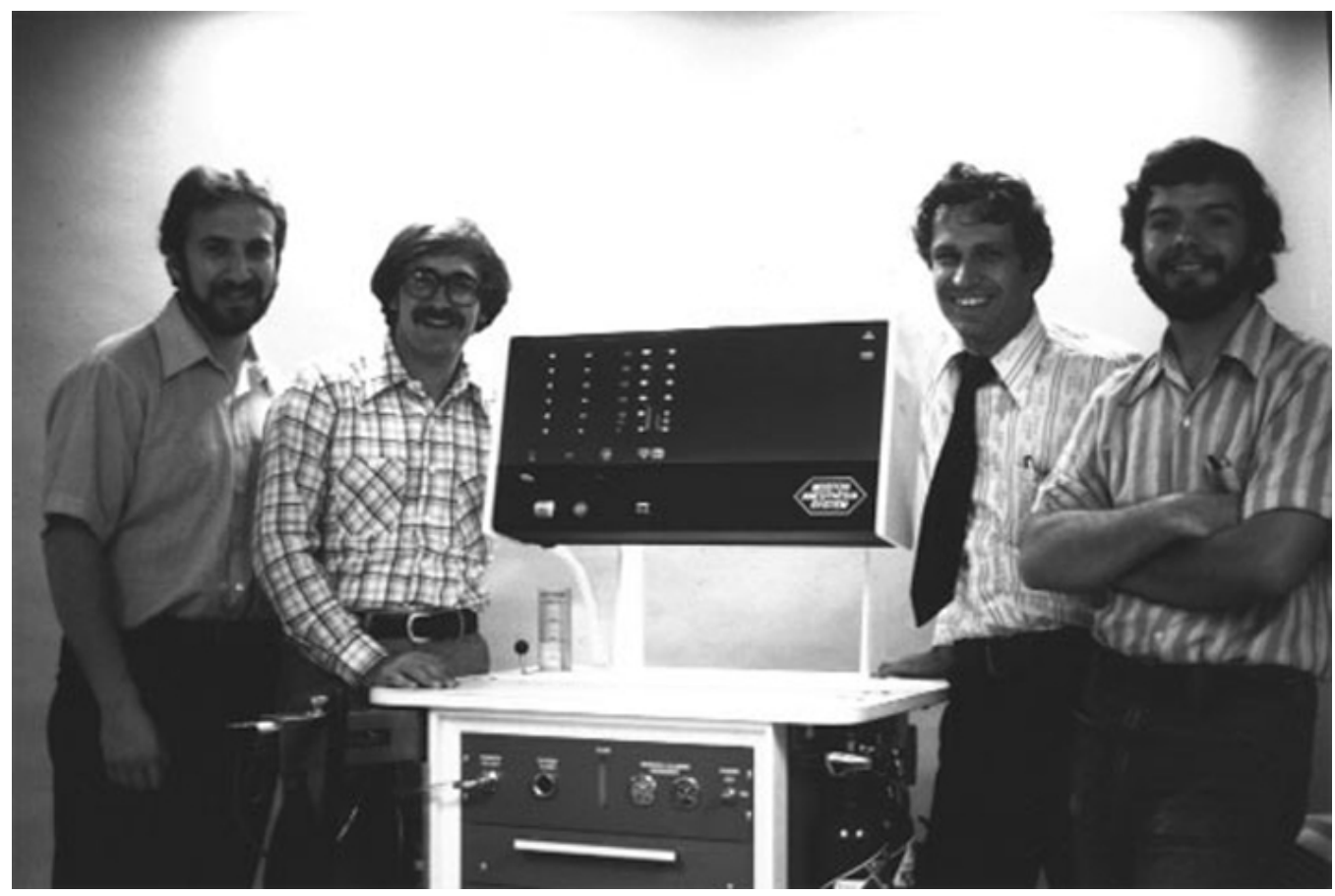

Fig 4.17 The Boston Anesthesia System, a collaboration between engineers and clinicians, 1976

Source: ASA Newsletter 2006

on a task based hierarchy (Figure 2.3). The outcome of this experiment was a prototype that moved away from the established table composition to a column structure. ${ }^{163}$ It should be noted that Gambro Engström's 2000 model was an attempt to apply the concept developed by Boquet. ${ }^{164}$

These were published reactions to an established design precedent, voicing a

162. Cooper, "A New Anesthesia Delivery System, 310-318.

163. Boquet, "The anesthesia machine: A study of function and design," 61-7.

164. Rodney N Westhorpe, communication to author, March 29, 2010. 

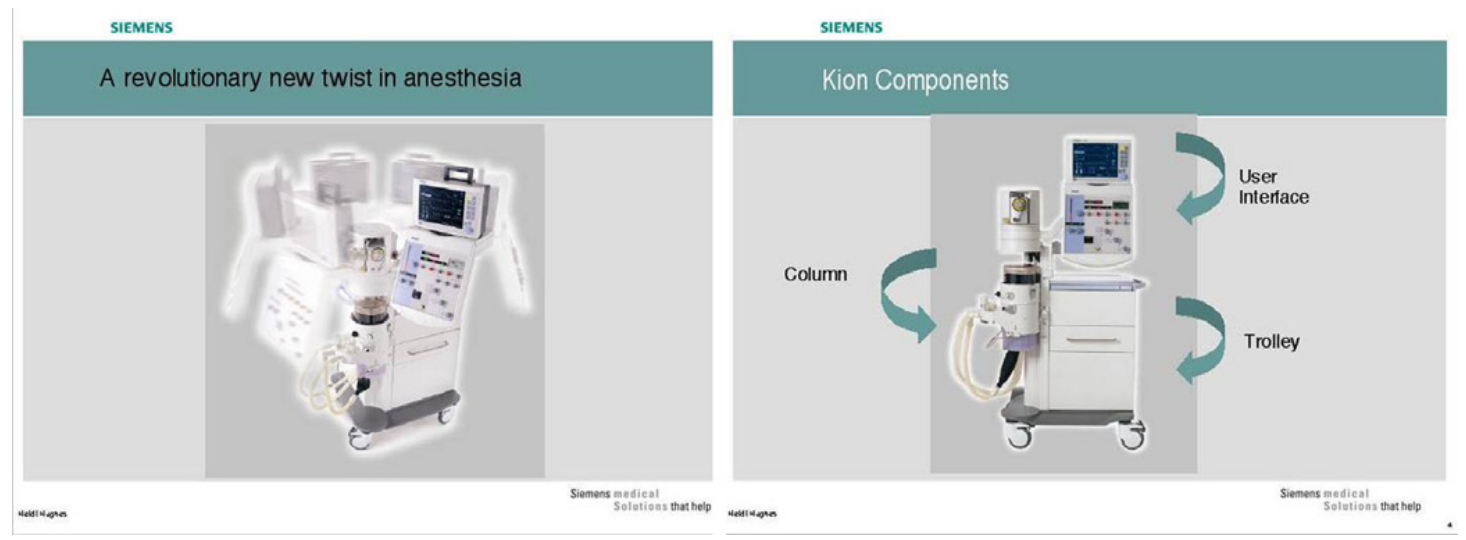

Fig 4.18 Siemens Kion 2001

Source: Hughes 2001

desire to continue the transaction of conceptual ideas from a profession to an industry. While both studies consulted the anaesthesia industry during their design process neither received support, yet ideas from these outcomes are now evident in new equipment. Institutionalism and the difficulty in scientifically evaluating conceptual ideas may be the cause of many experimental machines remaining unpublished, providing little additional input to design, or the greater anaesthesia community.

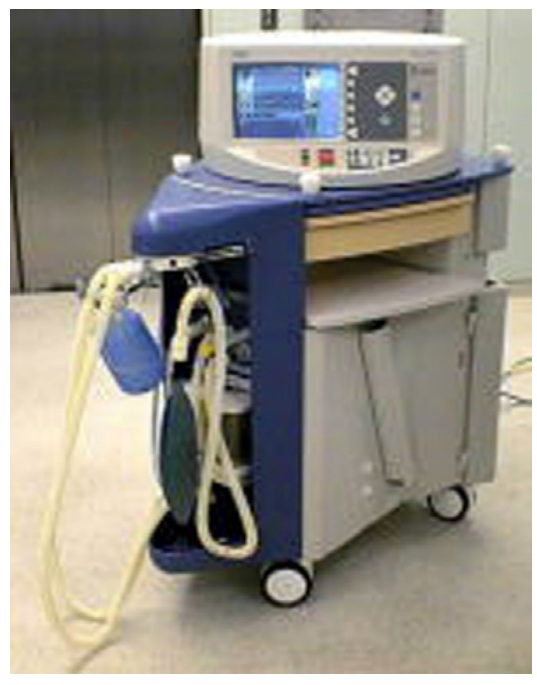

Fig 4.19 Dräger Physioflex

Source: http://www.anesth.hama-med. ac.jp

\subsection{Digital and physical, a new}

\section{composition}

From some quarters of industry, the established format has recently been questioned, not as concepts or prototypes but contemporary products that embrace technology and dispel historical layouts. These include the Engstrom 2000 and Elsa/EAS, the Dräger Cicero, and the Physioflex workstations. ${ }^{165}$

Now removed from production, the Siemens Kion demonstrated an innovative approach that draws similarities to the Engstrom 2000, Engstrom Elsa/EAS, and the research of Boquet in its vertically orientated composition of 


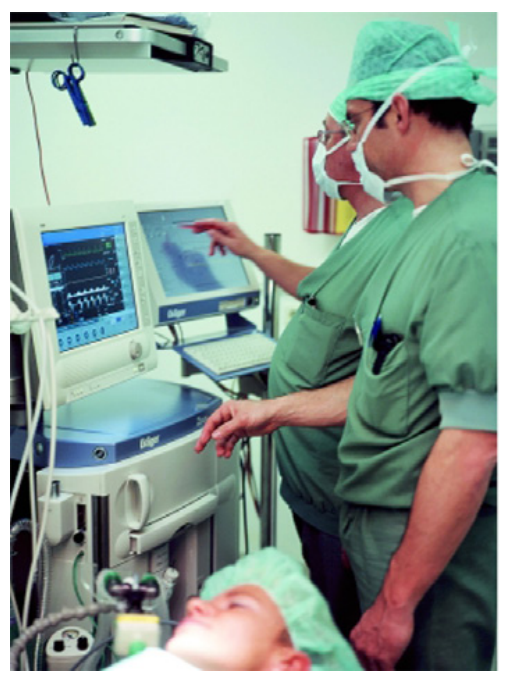

\section{Drägermedical}

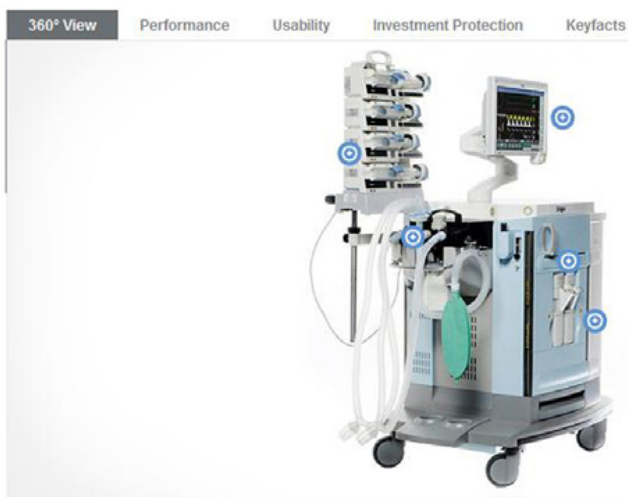

Fig 4.20 Dräger Zeus

Source: Left magazine CARE Dräger article in UK (22-2-2007). Right Dräger Medical site

(1-7-2009)

components. ${ }^{166}$ Siemens endeavoured to explore the user's physical interaction through a context of interaction flexibility and systems hierarchy (Figure 4.18). Had some of the problems with this machine been resolved prior to market immersion, outcomes may have been different. Suffering from criticism in the hands of anaesthetists due to design deficiencies e.g. not understanding where the machine front was, and out of context knob positioning. ${ }^{167}$ The Kion was a brave design proposal presenting ideas of the future, brought to market too fast and too unrefined, with what may have been limited proposed market input.

The Dräger Zeus, (Figure 4.20) a refinement of the Physioflex that was developed by a Dutch company Physio BV and purchased by Dräger, ${ }^{168}$ (Figure 4.19) seeks to solve many of the asymmetrical problems encountered in Boyle style machines. ${ }^{169}$ A clear separation between digital interaction and physical controls is presented in a structure that may be positioned on either side of the patient relevant to the task requirements. Dräger has shown a consistent designled independence, only once utilising the design layout of Boyle in the 1961 Tiberius, a response to pressure from its overseas agents for a British format. ${ }^{170}$

166. Hughes, "Siemens Kion Anesthesia Workstation," ; Engstrom 2000 catalogue, Engstrom Medical AB Bromma Sweden, 1980. Geoffrey Kaye Museum of Anaesthetic history, Melbourne, Australia.

167. http://www.oyston.com/kion/index.htm (accessed 1/5/2008)

168. Vallikari, The jolly dolphin in the school of sharks, 94

169. http://www.drager.com/local/products/zeus-ie/en/intro/index.html (accessed 1/5/2009) ; http://www.drager.es/MT/internet/pdf/CareAreas/ORAnesthesia/or_physioflex_data_es.pdf (accessed 1/5/2009)

170. Haupt, The history of anaesthesia at Dräger (Dräger AG): 67. 


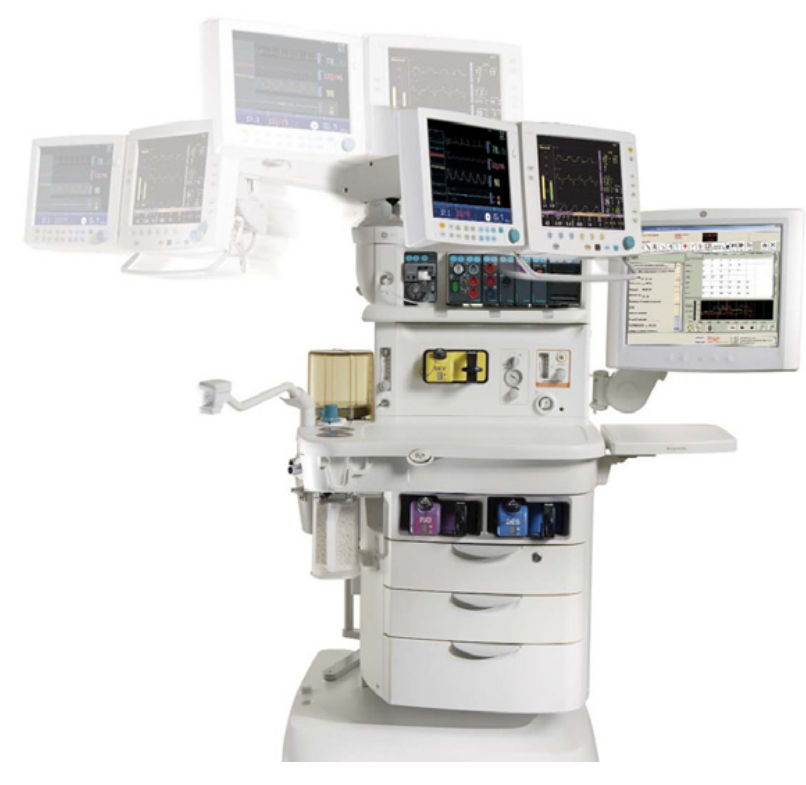

Fig 4.21 GE Aysis

Source: GE PDF 2007
The Kion is no longer produced, its short life suggests that it was a victim of institutional criticism, low sales and a visual change that was neither new and novel nor traditional (i.e. it was a mix of table and column). While simple control placement errors may have led to criticism. ${ }^{171}$ A greater factor or source of blame may be the combination of novelty in form and Siemens new entry to anaesthesia machine manufacture. Both the Zeus and the departed Kion are yet to impact on the anaesthesia market, suggesting that new designs, while distinguished in attempting to resolve problems, do not carry the traditions recognised as safe and normal, and are therefore viewed as a risk.

Finally we consider the GE Aisys, ${ }^{172}$ offering a wealth of technology, dealing with ergonomics through interface screens that can be moved to the users preferred position (Figure 4.21). The Aisys, like the Zeus is a new generation of anaesthesia machine, departing from typical practice in its determination to become digital. Patient monitoring, electronic control, and the metering and analysis of gas flows are presented via two moveable monitors. ${ }^{173}$ Many of the design iterations of later Boyle machines remain. Predominantly these are the structure relating to overall form and thus the position within the operating theatre and the anaesthetist's interaction. Subtle differences in ergonomics are apparent in comparison to its forbear, the Aestiva, a machine in widespread use that retains analogue instrumentation. Information sight lines are now

171. http://www.oyston.com/kion/index.htm

172. http://www.gehealthcare.com/usen/anesthesia/products/anesth_aisyscarestation.html (accessed 1/5/2009)

173. This may be an outcome of; Jacob F. Seagull. "Measuring awkwardness of workplace layout: Dispersion of attentional and psychomotor resources within the anesthesia workspace," 
spread between the monitors and fixed controls. This design provides for a variety of situational configurations with the intention of better ergonomics, but dependant on monitor arrangement, the visual field could expand to hide much of the physical interface. Significant changes

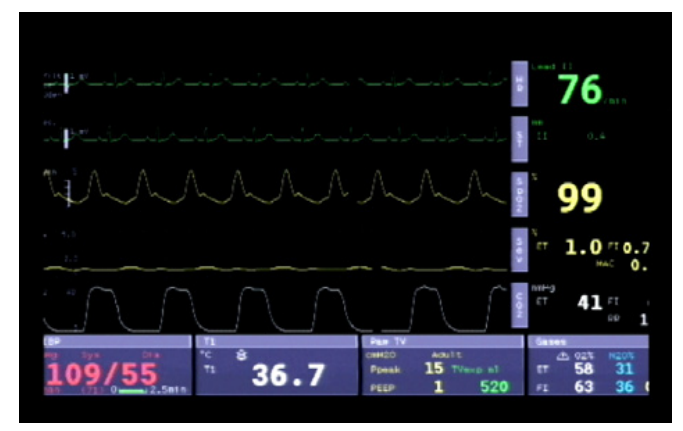

Fig 4.22 Patient status data Source: Author 2009 in the interface and how we interact with technology has not been reflected or integrated into the physical structure. Consistent with this design method is the argument that if new technology is to be accepted it must be placed on an understood form, therefore becoming usable. This demonstrates that Boyle continues to play a part in $21^{\text {st }}$ century design.

The directives seen in recent machine design are predisposed to electronic control and either analogue or digital input interfaces. This is due first to costs, as electronics are far easier to calibrate and manufacture than analogue instrumentation. Second, more capability resides in software, with more features and more systems checks, and finally more data can be presented, becoming subjectively safer. However, it carries the burden of convincing users of its benefits and safe use under crisis management.

Procedural management and patient monitoring has transferred through time from patient physiology, to analogue instrumentation, and now to new digital interfaces. The patient status output, presented via digital technologies still looks like the strip chart electrocardiograph that Sir Thomas Lewis developed in 1912. ${ }^{174}$ A representation independent of the technology that delivers it; yet symbolic of absolute and truth, two critical allies in providing a safe, simple, and highly transparent system (Figure 4.22), this interface has been conceptually challenged by Jungk et al in $2000 .{ }^{175}$ The nature of the digital environment means many functions and actions are hidden and not viewed on the operational landscape even if in a distant background. Trust in technology and truth in information, are

174. Drews "The right picture is worth a thousand numbers: data displays in anesthesia," 59-71. 175. A Jungk. B Thull. A Hoeft. G Rau, "Evaluation of two new ecological interface approaches for the anesthesia workplace," Journal of Clinical Monitoring and Computing 16 (2000): 234-258. 
the ultimate requirements in equipment during crisis management. How will we learn new digital representations given the rapid implementation of technology against a broad user age range and expertise. Will these prove worthy and errortolerant, and reversible at critical moments? ${ }^{3176}$

It has taken 40 years to move the outlet to the left (as a hangover from the mask and bottle and the need to operate at the head of the patient) and another 40 years to reach a point where we must trust electronic control over mechanical control. Whether these new machines can establish a trustworthy relationship with anaesthetists is yet to be known. The challenge for companies is in the justification and presentation of new features, and the acceptance of these by anaesthetists. Altogether change may be difficult to accept due to Boyle's legacy.

\subsection{Chapter conclusions}

Design for safe use should acknowledge how practitioners interact with equipment. Armed with reputable knowledge they intuitively explore and find the right function at the right time, producing the intended action, correspondingly being aware of threats upon these actions. Digital interfaces could have the future capability to allow a holistic operational view, meshing the functions in both interface and form. ${ }^{177}$ Similar to that provided for anaesthetists nearly 100 years ago, true functionality may provide a human-scale interaction in the presentation and activation of anaesthetic activities. The current era in product ideation and innovation is technology rich and relationship poor; humans are equipped with a sensitive touch and an instinctual tolerance between the feel of an object or material and its activity. Witness the anaesthetist holding onto the bag, truth in a reliance on ancient behaviours and a requirement to trust only themselves, as ultimately the anaesthetist is responsible for patient safety. This does not justify anaesthetists' habits or qualified actions, but stipulates that these should be addressed.

The recent work of GE and Dräger sits beside the early innovations of Boyle and his compatriots, requiring continued study to realise true capability, to

176. Jens Rasmussen, "Afterword," in Human Error in Medicine, edited M S. Bogner (Hove UK: Lawrence Erlbaum Associates, 1994). 390-391.

177. Jungk, "Evaluation of two new ecological interface approaches for the anesthesia workplace," 234-258. 
not lose the anaesthetist in machine operation, but facilitate safe and efficient anaesthesia. The substantial error management now available to the anaesthetist in these machines may allow an increasing participation in operating theatre activities, but could also lead to long periods of idle time and reduced incentive. Becoming a task dominated by technology that is overseen by people as the ultimate problem solver, carrying responsibility and liability, all at the last critical moment.

The identifiable features of the Boyle machine continue to impose a latent legacy affecting contemporary anaesthesia machine design. This legend of origin and a convention of machine use stem from the use of rag and bottle, portable inhaler, and the asymmetric layout of anaesthetic apparatus. Industry has either failed to understand the consequences of asymmetry and equipment positioning in mass production, or mitigated the changes to a design form and location as being adaptable to by anaesthetists. Designing in an era before ergonomics and usability studies, industry iterations have seeded a bias in the understanding of anaesthetists' needs that is now proving difficult to change. This illustrates in more detail another argument for Boquet's statement "what we have now is what we are used to rather than the ideal" ${ }^{178}$ and compromises both users and industry in the successful acceptance of new designs.

While human factors have led to changes, the physical layout is still reflective of iterations on Boyle's designs (1917-1950) based on gas flow, historical technology (component position) and our willingness to adopt, and then to become unadaptable to technology (as we now have a new habit and memory). The precedent set by Boyle, Gwathmey, and other early innovators has remained. Adapt to a safe and reliable, design mandate that is free of litigation as on moving forward, new risks are exposed not only for the patient but also the clinician.

Iterative design falls in line with physician conservatism, the responsibilities and consequences of which strengthen a resistance to change, resulting in a residual loss of innovation consultation between disciplines. The objective nature of technology with its quantified interface, contradicts a patient's true physiological

178. Boquet, "The anaesthesia machine - a study of function and design," 61-67. 
activity, but through this, its translation becomes simple and complete, ${ }^{179}$ and is therefore seen as safe.

179. Cassell, The nature of suffering and the goals of medicine, 22. 
PART TWO - PROSPECTIVE INITIATIVE 


\section{DEVELOPING THE METHODOLOGY}

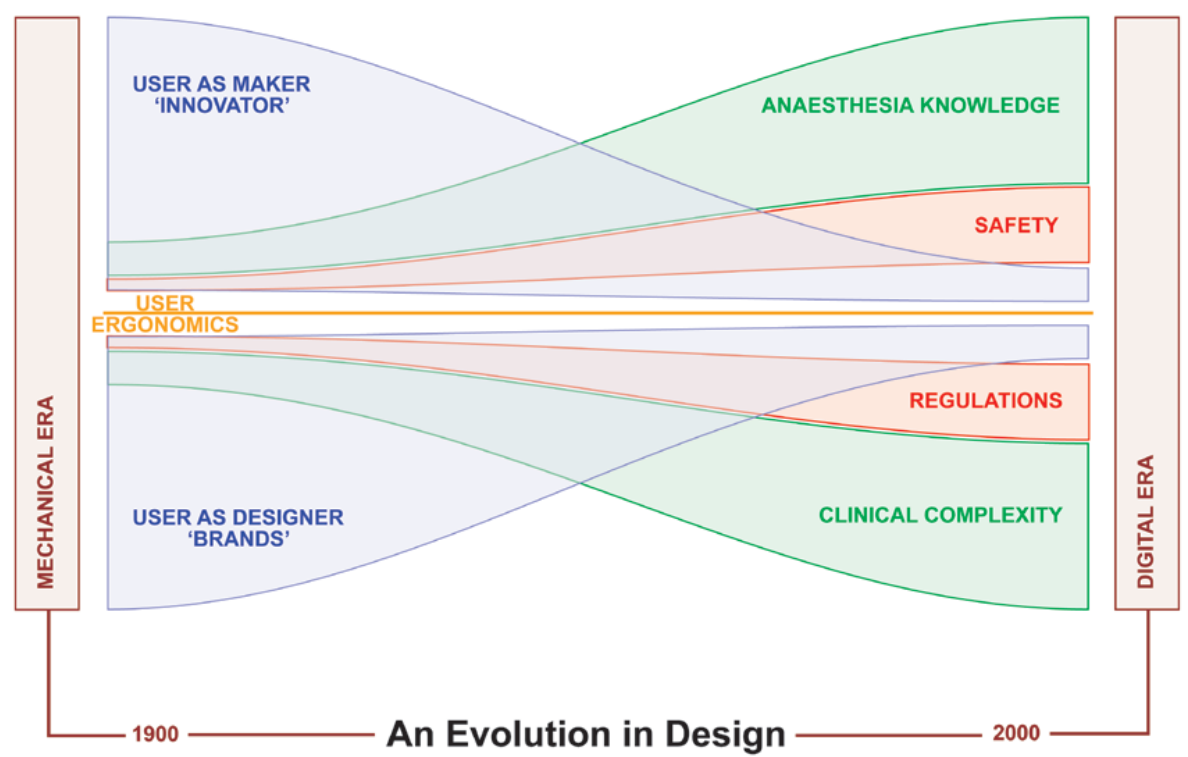

Fig 5.0 An evolution in design reflects the diminishing level of innovation in anaesthetist derived or collaborative development. As a result of anaesthesias attention to patient safety, innovation has been caught in a vortex of knowledge derived regulatory constraints

Source: Author 2008 



$$
\text { Chapter } 5
$$

\section{DEVELOPING THE METHODOLOGY}

Data is not information, information is not knowledge, and knowledge is not wisdom ${ }^{180}$

\section{Introduction to Part Two}

Rag and bottle anaesthesia survived into the 1950s, long after safer innovations had appeared. Accordingly, in the 1970s, many older anaesthetists dismissed new patient monitoring systems. ${ }^{181}$ This signified an indictment of new ideas, new technologies or new products over habit and tradition - cumulatively, the phenology of technology clashing with an elite profession's perception of a core task. ${ }^{182}$ It has taken epidemiology, regulation and peer review to overcome luddite professionalism, and force attitudinal change. These achievements in patient safety are now challenged once again by technology. Designers need to communicate with greater intimacy in opposing the precedent that design value and knowledge within the profession is still predominantly 'peer to peer', qualitative and outside today's evidence based paradigm.

Contact with anaesthetists presented a dichotomy of those feeling despondent between the raft of their own consumer technology and that of the workplace; and those happy in the cosy, intimately known relationship with tradition and traditional equipment. The lack of record keeping afforded in traditional equipment may infer a fear of blunt end professional measurement and mistrust of new equipment. ${ }^{183}$

At a time of society's rapid adoption of technology, and clear future signals in the

180. Henry Nix, "Environmental data," in address to seminar, in David Evans, How to write a better thesis or report (Melbourne: Melbourne University press, 1995): 89.

181. Cooper, "An accidental life: patient safety and biomedical engineering," 377-419.

182. B Moggridge, Designing interactions, 579.

183. Note: many anaesthetists showed little acknowledgment of new design directions until confronted with a trial of the GE Aysis. (In conversation with anaesthetists, 2007): see General Electric Aysis anaesthesia workstation. http://www.gehealthcare.com/usen/anesthesia/products/anesth_ aisyscarestation.html 
marketplace from consumer products, such as the Apple I-Pad, little exists for anaesthetists. Products that embody the rapid rise of miniaturisation, wireless, haptics, open source networks, and personal customisation, are freely available. Anaesthetists cannot be early adopters, nor can they speculate or debate future concepts as few exist (their hands are also tied as they are not responsible for purchasing.) Therefore they are left alone to ponder the future themselves.

Part One has suggested that the primary goal of a continuance in form in the anaesthesia machine is stability in acceptance, and a compromise of memories. An evolving interface of the clinician to the patient and their procedure with technology. If tradition is seen to provide confidence, and new innovation a threat, using new technology as a laminate methodology presents an imminent crisis point for design. Endeavouring to overcome inherent problems through aesthetic iterations appeals more to the design community and hospital aesthetic than a user's needs, providing little towards industrial design methods or design directions. What of anaesthesia? Does safety justify minimal form based exploration or does it only support technological wizardry tethered to a tried and tested, yet ergonomically stressed, physical arrangement?

Part Two builds upon the findings of social, technical and latent ergonomic acceptance to a design challenge - the active involvement of anaesthetists. This part of the thesis sets out to first look at established constraints for design, the current context, and how these influence what we now have. Second, the thesis sets out to test the hypothesis in exploring the second part of the aim 'what could we have'; whether the current design is what anaesthetists want, need or desire and is significant to 'questioning an evolution'. This will apply the prospective methodology to establish the capability of anaesthetists to influence future directions. Plausible benefits exist in a prospective method first in measurement of the established, and second in providing inspiration to place anaesthetists in a position of dialogue and destiny - and design in a place of learning. Addressing the possibility to search and understand the paradox of socio-technical knowledge from within. Rather than day to day cognisance, this is the assembly of knowledge - the guide-wire for design. 


\section{INVESTIGATIVE AND CONTEXTUAL CONSTRAINTS}

\section{Current context and the assembly of knowledge}

Whilst Part One tethered the response of society to science and mortality to the elite, it also identified how a new profession's normal behaviour was subverted by scientific advancement - in an evolutionary design reaction to task and form. A paradox is revealed, in the increasingly complex array of systems and information generated by the engineering profession to meet the needs of a safe activity. ${ }^{184}$ Although the heterogeneity of equipment has reduced since the mid 1980s through standardisation and new advances i.e. pulse oximetery, ${ }^{185}$ a contemporary definition has migrated to new digital interfaces, promoting an incongruous competition with tradition.

This chapter investigates the constraints on design from society's evolving desires; and the need for knowledge, safety, and innovation. The intention is to provide a contextual grounding for a methodology that has capability to influence rather than speculate.

To achieve a prospective initiative aimed at reversing or mirroring the design vortex, (Figure 5.0) the merits of simulation and user participation will be examined prior to the experiment. Allied to these methods are the constraints of ethics and clinical access necessary to create relationships and develop a methodology. Additionally, usability guidelines require inspection due to their overarching influence on established design process and the task-artefact cycle. The investigative and contextual constraints examined in this chapter call for both acknowledgement and negotiation to ascertain and refine an achievable and appropriate methodology:

- Physiology and pharmacology = Cognitive decision making based on knowledge and skills.

- Ethics $=$ A negotiable constraint for informed knowledge gathering by designers.

184. Vicente, The human factor: revolutionizing the way people live with technology, 43.

185. Kohn, To err is human: building a safer health system, 142. 
- Simulation $=$ Pedagogical, with an unrealised capability for design to safely explore.

- $\quad$ Usability $=$ Design guidelines limited by hindsight, but open to new methods (interpretation).

\section{PHYSIOLOGY AND PHARMACOLOGY}

\subsection{Physiology and pharmacology in anaesthesia}

The term Physiology connects two cultures; an anaesthetist is highly skilled in human physiology and the design engineer in technical physiology. The anaesthetic engineer should know how the machine physiology interacts and mimics patient physiology but may have little if any clinician empathy or comprehension of the clinicians socio-technical or environmental behaviour.

\section{Thinking physiologically}

The anaesthetic machine has become the command centre, a model of patient physiology; presented physically as an 'at hand' storage system for implements and consumables. Within, it is tasked with delivering measured gas mixtures and externally it is the receiver and displayer of patient physiological data. Anaesthetists do not view the anaesthetic machine as a lathe or piece of equipment with a product output made to a tolerance by the operator (it could be taken that they are designed like this with defined tasks/protocols written by engineers that need to be followed) rather as an instrument that allows human induced variability within a fundamental task. When interacted with, it provides an output in knowledge; presenting information that quantifies human qualities but allows for variation in physiological dynamics. How this information is presented, interpreted, and, at critical moments interacted with, within the framework of heavy cognitive workload, defines its capability. What equipment cannot do is balance judgement and take responsibility. Don Norman speaks of musical instruments and issues of usability, instruments are difficult to learn and take time to master often only completely by those with a natural 'bent'. ${ }^{186}$

186. Norman, "Human centered design considered harmful," 14-19. 
In 1945 Noel Gillespie, in describing the future of anaesthesia reiterated the saying "that no anaesthetic agent is safer than its worst administrator". ${ }^{187}$ An underlying echo of this statement lives on in Matt Weinger's future forecast for anaesthesiology. As a practicing anaesthetist Weinger concentrates on drug levels and states of physiology, proposing interaction through head up displays and auditory commands. ${ }^{188}$ This is what anaesthetists are interested in!

The machine is just one part in the overall goal of servicing the patient for surgical or pain related intervention. Is it seen as a part that manages physiology or is managed by our physiology? It may be seen as the parity between objects and objectives; affordance and cognition; and physiology and technology. The anaesthetist does not see the machine as sole provider, this is their knowledge of pharmacology and physiological effect, therefore the machine is an extension of their craft. Acting as the direct patient interface, a sole provider during the maintenance period of anaesthesia, managing respiration and anaesthetic delivery. If the physiology of the machine replicates the physiology of the patient, shouldn't the design of equipment allow the anaesthetist's full pharmocodynamic knowledge to be applied towards attaining and perfecting the goal, rather than in task interpretation?

\section{Bottom of the ladder anthropometrics}

Since the 1950s anthropometric information has addressed physical ergonomic interactions and specifications as data. The idea that the human-task relationship can be solved with a rotating dial catalogue of stature, gender, ethnicity and age is an oversimplification of dynamic interactions (Figure 5.1). The human factors hierarchy ranging from 'anthropometrics to sustainability' is portrayed by Bill Moggridge as an increasingly complex interaction with technology, requiring new methods to integrate scientific understanding with industrial design. ${ }^{189} \mathrm{Kim}$ Vicente approaches this categorisation with a 'physical to political' hierarchy, ${ }^{190}$ but does not dismiss that the lower levels of physicality are solved, but just simpler to understand.

187. Noel A. Gillespie, "The future of anaesthesia" in The bistory of surgical anesthesia, by Thomas E. Keys (New York: Schuman’s, 1945): 173.

188. Weinger, "A Vision of the future of perioperative information management,"

189. Bill Moggridge, A conversation about interaction design. Sebastiano Bagnara (1-27) 17.

190. Vicente, The buman factor: revolutionizing the way people live with technology, 61. 


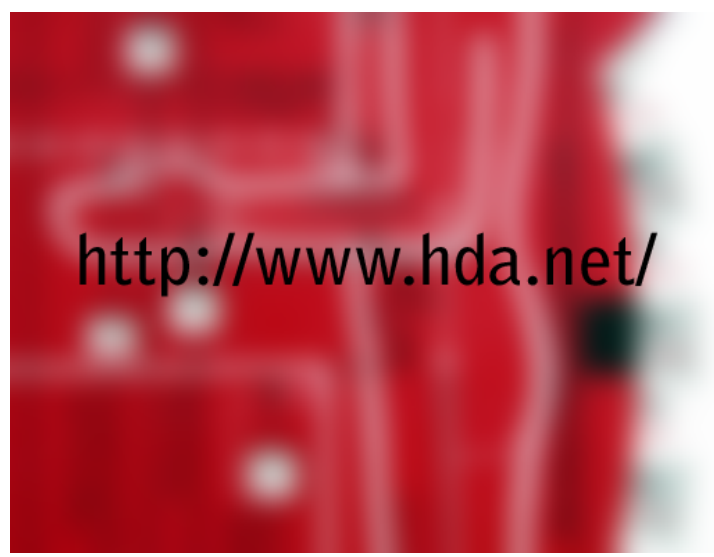

Fig 5.1 Rotating dial from Dreyfuss

Source: Dreyfuss

Technologies, in continuing to become more intelligent and applied with increasing regularity to almost every object affects and transforms physiological interactions, promoting cognitive induced behavioural adaptation. ${ }^{191}$ For every change in technology the simplest physical factors should be revisited, not relied on as 'once ok always ok'. For anaesthetists, the lowest tier of these hierarchies, (however they are termed) is distinguished by its avoidance, yet repeatedly voiced in anaesthesia and human factors publications, ${ }^{192}$ seemingly stepped over in the race towards graphic interfaces and cognition studies. In the observational studies and conversations within the operating theatre, these so called solved physicalities were the most widely critiqued. Design is directly criticised by users as responsible for the physical attributes, interface and control deemed as engineering by industry.

The response to physical anthropometric differences draws a parallel with workplace habitation, fitting a human to an object for long periods of time. The chairs and workstations developed in response to occupational overuse syndrome during the 1980-90s have focused on human factors, engineering and design. Multiple controls for adjustment have now led to materials capable of dynamic memory, affording a more human like product physiology. ${ }^{193}$ The complexities of these may only be understood if the occupier falls in love with the design to such a point as to discover and control the many knobs and levers or physically explore the dynamics of new materials. The difference, in comparison to an anaesthesia machine, is that office chairs typically belong to the same user day after day and are adjusted only once.

191. Woods, "Anticipating the effects of technological change: a new era of dynamics for human factors," 272-282.

192. Duri, Boquet, Cooper, McIntyre, Seagull.

193. Knoll Generation and the Formway Life chair, http://knoll.com and http://formway.com 


\section{SIMULATION: THE VENUE OF VISION}

In 1960, the Norwegian doll maker Asmund S. Laerdal introduced Resuci-Anne, the legend of CPR training. Wearing the death mask of an unnamed drowning victim "the girl from the River Seine" represents the first commercial medical simulator. ${ }^{194}$ Today many of the simulators are termed hi-fidelity. ${ }^{195}$ Human physiology is modelled and replicated in complex calculations to reproduce reverse engineered responses to both pharmacological and physiological interactions.

What is simulation? Is it a reproduction of events measured not as equal or a perfect replication, but equivalent to the real activity? ${ }^{196}$ The extreme capability of simulation is demonstrated in the $\mathrm{BBC}$ documentary 'The Truth About Killing' where Grub Smith experiences the intensity of contemporary simulation, developed to produce a highly tuned instinct to kill that is based upon conditioned reflexes and detached emotions. ${ }^{197}$ Effective simulation is derived not through elaborate tools but in acting out a methodological scenario. ${ }^{198}$

An environment on its own cannot provide new knowledge. Scenarios, participants, environmental props, and expertise in simulation are required to design with simulation. Adopting this method may challenge our conventional beliefs by putting our designer assumptions into jeopardy. Thereby, simulation may play both the role of democracy and contextual assurance, not at the end of the design process, but during it. Simulation also allows for video documentation, a method that is difficult to implement and gain authorisation for in the operating theatre.

Returning to the precedent studies, what if Boquet had evaluated Cooper's concept machine with simulation, would he have then acted on this 'concept' in

194. http://www.amsa.org/tnp/articles/article.cfx?id=356

195. J B. Cooper. V R. Taqueti, "A brief history of the development of mannequin simulators for clinical education and training," Qual Saf Health Care 13 (suppl 1) (2004):

196. Description provided by Dr Brian Robinson, Director C \& CDHB National Patient Simulation Center.

197. Grub Smith, "The Truth about killing," BBC

198. D M. Gaba, "The future vision of simulation in healthcare," Qual Saf Health Care 13 (Suppl 1) (2004): 
his design approach? Using simulation for either evaluation or design are very separate entities. Simulation may have potential as a design method, but this should not be confused with its established capability to evaluate.

\subsection{Simulation: the venue of vision}

Anaesthesia applies simulation technologies and techniques mainly for clinical teaching and crisis management. ${ }^{199}$ Alongside training, simulation has also been applied to the evaluation of procedures and equipment, being hailed as the future (virtual) laboratories if the response to both environments is similar. ${ }^{200}$ Yet simulation is still in its infancy and being used in less than half of US hospitals due to the cost and expertise required. An implication of this is the avoidance of simulation based accreditation. ${ }^{201}$ This example points to the very different culture and social response of healthcare to learning leadership, a direct reflection of aviation's belief, acceptance and application of simulation in the mandatory training and accreditation of pilots.

Simulation has grown out of aviation and military objectives as a means of preparation. One of the first aviation simulators, the Link trainer was patented in 1930 by its inventor as both "an efficient aeronautical training aid and a novel, profitable amusement device". ${ }^{202}$ This relationship between education and entertainment is longstanding. The acting out of adulthood as a child, - all the learning but none of the risks - would be seen as essential in simulation features. Simulation needs to train appropriately for the task, otherwise the participant may become very good at the simulation activity and disastrous in real life situations. This situation was seen in the Tenerife air disaster where simulated training and stress led the pilot to regress to the role of training controller, reverting to over-learned responses and issuing his own take off clearance that resulted in collision with a Pan Am 747.203

199. Ibid.,

200. Dalley, "The use of high fidelity human patient simulation and the introduction of new anaesthesia delivery systems,” 1737-1741. ; Y A W. De Kort. WA. Ijsselsteijn. J Kooijman. Y Schuurmans, "Virtual laboratories: Comparability of real and virtual environments for environmental psychology," Presence: Teleoperators and Virtual Environments, 12, (2003): 360-373.

201. http://www.newyorker.com/archive/2005/05/02/050502fa_fact ; Gaba. "Simulationbased training in anesthesia crisis resource management (ACRM): A decade of experience," Simulation and gaming , 175-193.

202. R L. Page, "Brief history of flight simulation,” In proceedings Sim tecT (2000).

203. Karl E. Weick, "The vulnerable system: an analysis of the Tenerife air disaster," Journal of Management Vol 16, No 3. (1990): 571-593. 


\section{Credibility and contextual assurance}

Whilst early innovators used themselves as test subjects, with success or failure seen in one's own physiology, (Figure 5.2) simulation technologies now provide a safe context for acting out real life scenarios. Accessibility to simulation environments is a critical resource for problem solving, much of the progress in aviation safety has depended on researchers having access to high fidelity training simulators and this access can be a catalyst to learning about human performance. ${ }^{204}$ To apply this method with any credibility, experience from real life situations needs to be known. These can be observed via experienced personnel, or a re-enactment from documentation of a disaster or critical situation (reverse engineering). For design, simulation offers an inherent value, the ability to record activities with methods that may not normally be allowed in the operating theatre due to ethics, management or consent. The juxtaposition of qualitative observations and quantified experiment could promote a powerful insightful contrast. ${ }^{205}$

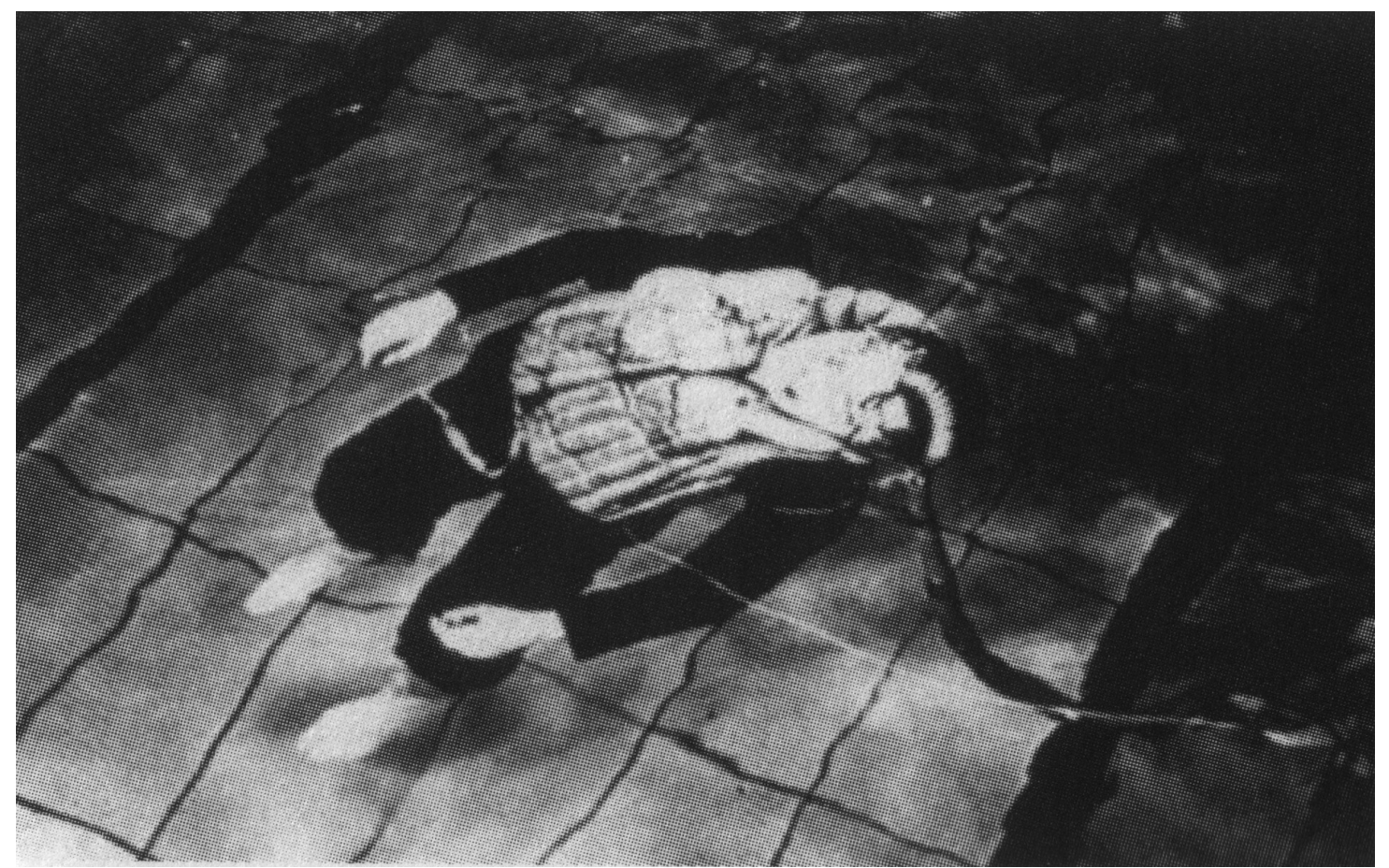

Fig 5.2 Edgar Pask,volunteering to be fully anaesthetised for research into life jackets 1943 Source: Maltby 2002. Nuffield Department of Anaesthetics.

204. David D. Woods. Emily S. Patterson. Richard I. Cook, "Behind human error. Taming complexity to improve patient safety," in Handbook of Human Factors and Ergonomics in Health Care and Patient Safety, edited Pascale Carayon (Mahwah, New Jersey: Lawrence Erlbaum associates, 2007) 459-476.

205. Cook, "A Tale of Two Stories," 
The credibility or validity of simulation as a reproduction of operational conditions is not yet fully established, ${ }^{206}$ the issues of validity focus on simulation fidelity. Of primary concern is the ecological validity, defined as 'the extent to which the environment experienced by the subjects in a scientific investigation has the properties it is supposed or assumed to have by the experimenter'. ${ }^{207}$ Ecological validity exists as an assessment measure, a guide in constructing, conducting and interpreting research in comparison to operational settings. ${ }^{208}$ The objective realism in physiological or behavioural responses seen in task performance versus the subjective experiences of the research setting, the simulated environment. To be effective does not mean that it needs be identical; qualitative deficiencies arise in the description of how the salient characteristics of the operating theatre are presented and for what purpose.

\section{Simulation and design}

To achieve the effective goals of an experiment in high risk environments would compromise safety in its investigation method. Design speculation such as prototyping requires the translation of context to a safe environment that retains environmental and behavioural credibility. This reinforces the need for design collaboration with established simulation facilities and expertise. The application of scenarios demands real world or real occasion focus rather than an experiment of imagination in how a design may be materialised. ${ }^{209}$ This is a limitation of participation design when undertaken outside of context and situation, a blindness where experiences are assumed. For simulation to demonstrate capability as a design or usability partner, the translation from reality is of paramount importance, and for anaesthesia should be based not on safe procedures but on a cross section of real events. ${ }^{210}$

Designers endeavour to embrace cultures in developing concepts or product

206. T Manser. P Dieckmann. T Wehner. M Rall, “Comparison of anaesthetists' activity patterns in the operating room and during simulation," Ergonomics 50:2, (Date): 246 - 260 URL: http:// dx.doi.org/10.1080/00140130601032655

207. U Bronfenbrenner, "Toward an experimental ecological of human development," American Psychologist 32 (1977): 513-531. ; Vicente, The buman factor: revolutionizing the way people live with technology, 178. 419-436.

208. M A. Schmuckler, "What is ecological validity? A dimensional analysis," Infancy 2, (2001):

209. David Gilmore, Interactions/business may+june (2002):

210. Drui, "Predesign investigation of the anesthesia operational environment," 586. Note: Duri references the benefits of recording open heart procedures that required close patient monitoring, duration (10 hours) and gravity. 
visions. The task of simulation experts is similar, to embrace all those qualities that add up to real life situations. These experts of simulation may be well matched as design collaborators, capable of clinically narrating a scenario that deals with quantified data and qualified experiences. In simulation, science may meet humanity in practice for delivery of healthcare, dealing with complex equipment, teamwork, and in some scenarios the patients' upset or grieving relatives. $^{211}$

Simulation inputs and outputs may be quantified but the healthcare simulation methodology is qualified, relying on interpretation. This is due to the everpresent unplanned procedural events and the dynamics of operating theatre culture. These activities are very different from 'fly by wire' aviation, thus a methodology may be borrowed, but to achieve success requires its own methods and measure of credibility. This is a better indication than interview or questionnaire assessment. This is akin to using the insight of early innovators, activity -centric anaesthetists to determine credibility.

\section{ETHICS AND ACCESSIBILITY}

David Woods in 'Behind Human Error' contrasts two disasters against the backdrop of learning from experience. He criticises healthcare in that direct learning and improvement from experience with accidents and incidents is narrow and very limited, partly due to fear of blame and litigation. ${ }^{212}$ The two disasters mentioned are the Columbia space shuttle and the death of a transplant patient. NASA openly examined and set out to improve its organisation, disseminating its deficiencies, whereas healthcare buried the legal, professional and institutional responses behind closed doors allowing only sanitised press releases.

This example demonstrates the implications and tenor of an institutional culture in the difficult partnership of creative foresight, new technologies and

211. http://www.amsa.org/tnp/articles/article.cfx?id $=356$

212. Kerm Henriksen, "Human factors and patient safety: continuing challenges," in Handbook of Human Factors and Ergonomics in Health Care and Patient Safety, edited Pascale Carayon (Mahwah, New Jersey: Lawrence Erlbaum associates, 2007) 21-37. 
patient safety. Ethics and accessibility look at access with respect to establishing relationships and recording procedures.

\subsection{Ethics and the gatekeepers}

Observation of the interactions between people, technology and environment provide for a rich contextual immersion. The origins of user observations in engineering, (ergonomics) and humanities, (anthropology) respectively lie in task analysis and human understanding. These professions work closely with ethical bodies for consent and have gone on to establish complex methodologies to extrapolate both the cognitive and tacit physical actions into error avoidance and design taxonomies.

Video recording in the operating theatre is a considerable and increasing challenge due to ethics, consent and safety. These considerations are prevalent due to patient confidentiality, occupational risk, litigation, and society's expected privacy. The operating theatre carries the irony of being more difficult to access but of greater importance. Whilst experts in this environment can pass on much valuable knowledge, this knowledge may also be tainted by their exceptional skills condemning the novice or the general populist to following this complexity. ${ }^{213}$

To establish observations in the operating theatre a new set of relationships with management, clinical supervisors and hospital staff outside of theatre was required. To access, observe and develop an empathy with the sharp end a rite of passage came from the blunt end. I did not interview these people, they interviewed me; justification, liability and a consciousness of patient and clinical privacy were the themes to negotiate. Verdicts were openly made on the nature of the study. This may have seemed negative at the time but significant resources were invested in a reciprocal relationship to understand, critique, and comment on the nature of the study. As a non formal induction, this was most beneficial in relating science to design and the understanding of 'rite of passage.' Dissection of the methodology became a test of both the study's objectives, and the reasoning behind data collection.

The blunt end required a clear indication of the outcome or likely outcome, 213. Wilcox, "Eight ways to kill innovation," in Designing usability into medical products, 99. 
something that is overlooked in design as we often browse to understand, wish to ask questions and be shown. An emerging trend is apparent, that preconceived ideas of repeating Boquet's study would not pass today's gatekeepers. The wish to use video documentation was not supported. Thus, the resolution and complexity of the contextual investigation was directly reduced.

It is of interest to note the ethical requirements of entertainment vs research, television reality documentaries deemed entertainment require only consent not formal ethics application. ${ }^{214}$

\section{A recording devolution}

During the 1970s and 80s, research into anaesthesia equipment use was conducted through the filming of operations. ${ }^{215}$ Although published and beneficial, the data's credibility may (would in many industries) now be irrelevant as clinical conditions have changed. Contradicting this, the anaesthesia machine has changed somewhat between Drui's 1973 study and Seagull's in 2004. Both arrive at the same conclusion, albeit through different technological methods. Each provides a similar concluding statement of advice to designers - to resolve the relationships of components and position of equipment.

How advances in equipment are developed and tested relies on known reputable knowledge. To explore and test the unknown in a critical environment carries risk of morbidity, mortality, litigation and professional discipline. The difficulties and concerns associated with recording mentioned by Manser et al (in a comparison of the operating room and simulation) and Roth et al, are overcome by several researchers. ${ }^{216}$ Each of these demonstrates the high level of professional collaboration required to overcome fears of evidence based repercussion. This hard fought level of trust can be easily eroded in releasing tapes beyond the

214. TVNZ programme Emergency http://tvnz.co.nz/view/page/411749/813145. (accessed $1 / 6 / 2008)$

215. Drui, "Predesign investigation of the anesthesia operational environment," 584-591. ; Boquet, "The anaesthesia machine - a study of function and design," 61-67.

216. Manser, "Comparison of anaesthetists' activity patterns in the operating room and during simulation," 246-260. ; Roth, "Using field observations as a tool for discovery: analyzing and collaborative demands in the operating room," 148-157.; Seagull, "Measuring awkwardness of workplace layout," 1755-1758. ; M B. Weinger, D C. Gonzales. J Slagle. M Syeed, "Video capture of clinical care to enhance patient safety," Qual Saf Health Care 13 (2004): 136-144. 
research team. ${ }^{217}$

To act on the repeatedly identified 31 year old ergonomic problem, designers should not be restricted to yesterday's habits, but able to observe todays activities. This act of 'seeing' needs to come in partnership rather than a text based distillation purporting to be useful to designers'. The latent denial of problems may be in effect an outcome of the growing restrictions of institutionalism, accessibility, and documentation. Pertaining as much to the blunt end as to the culture of the medical club. ${ }^{218}$ This results in the agents capable of resolving these issues, designers - no longer being anaesthetists, being spoken to, but not shown.

\section{Contextual Observations}

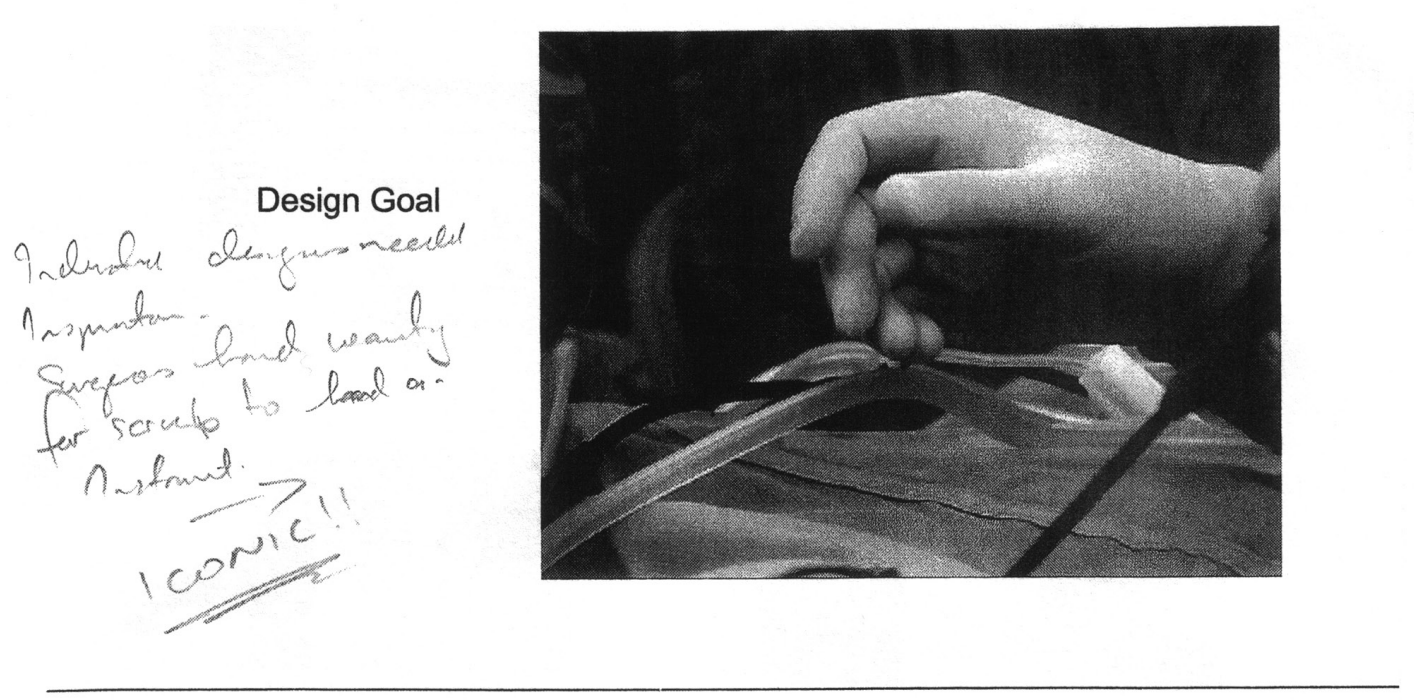

\section{I미이}

Fig 5.3 The waiting hand, a symbol of design inspiration

Source: Schwartz, IDEO. 2005.

217. J. Mallett, "Studying man-machine interfaces in the operating room," Minimally Invasive Therapy \& Allied Technologies Vol. 10 No. 3 (2001): 133-137. "Administrators welcome anything to improve performance but, in some cases, requested access to tapes for non-research purposes (those requests were not granted)"

218. Cooper, "An accidental life: patient safety and biomedical engineering," 417. 


\section{Constraints of recording methods}

Constrained from using video, still photography was allowed under the premise that this would provide sufficient contextual documentation, and avoid any recording of adverse or interruptive events. Still images are a snapshot in time, and provide excellent contextual inquiry, where information and context needs to be disseminated within a multidisciplinary design team (Figure 5.3). A danger exists in using stills as second or third hand design criteria or stimulus. Just as in reading a book; creativity may overtake reality, context imagined, or a problem misinterpreted. Correspondingly video may provide a richer context, with the capability to relive an event. However, analysis is complex and time consuming, unwittingly overtaking the research aim. This study is not seeking quantified reliability in observation. Rather exploratory observation is sought for generative knowledge and insight, territory where designers can formulate or identify avenues to explore in the design process.

How can we access an interaction, task and environment in the future? Simulation may play a part as it has in aviation, but differences between the primary objectives i.e. control of an object (aircraft) and control of a person (patient) is very different. The rapid development and implementation of technology in medical equipment means usability testing must continuously hunt out and identify the unknown unknowns. The reason for and possible effect of adding a new technology requires both an ecological understanding of real life situations and partnership in applying human factors methods, many of which require the recording of data.

The precedent studies and those mentioned here have all used some form of human factors experts or methods to analyse cognitive, task, and teamwork demands in the operating theatre. Returning to the design investigation, we are without these specialised interpretations, yet within this environment designers can apply their own unique set of skills. We will leave touched with a very different understanding from the published and pictured attributes communicated outside of the operating theatre. 


\section{USABILITY ISSUES}

Any customer can have a car painted any color that he wants so long as it is black. ${ }^{219}$

Henry Ford's comment reflects on choice and democracy as an imposed standard. Things may have been simple in Henry's day, but colour has come to represent the myriad of digital opportunities ringed by conformity and interpretation.

As usability prompts itself as a design methodology tasked with resolving the human-tech relationship, ${ }^{220}$ should it be ignored in prospective research? Can it help to answer the research questions or add to the methodology? In the defence of concomitant research, relevance exists to both discuss and critique usability. First it may be limiting forward thinking concepts. Second, it could assist in more collaborative investigation. Third, it would seem the perfect partner for simulation and fourth, can it cope with the unknown unknowns?

Is usability a design leader at the outset of the problem or a design follower and form giver?221 Industry is presently guided by the US Food and Drug Administration (FDA) mandate to use human factors engineering (HFE) and additionally the new International Electrotechnical Commission (IEC) usability standard. This is the closest thing to design guidelines for equipment interaction termed by the IEC as user interface.

These standards are essential to the safe design and use of medical equipment and great advantages derive from them. Predominantly based on events and experiences viewed in hindsight, and a mild engineering-centric approach, this is a technology systems approach to human centred design, passed off as user centred. This places innovation and design leadership in a "Catch 22" position.

The application of usability is very different between critical products and the consumer world. The consumer focus allows for intuitive experimentation to resolve functional use, a case in point may be television hard disc recorders that

219. Henry Ford, My life and work (Sydney: Angus and Robertson, 1923):

220. P Castensen comments on IEC 62366 providing a comprehensive explanation of human

factors. http://www.medicaldevicestoday.com/2007/04/new_usability_s.html

221. Friedman. "New Design Research: Leading or Following?," 8. 
provide an on screen graphical taxonomy showing where you have come from and how to get back or exit. Correlation between physical and screen interface is more difficult to map. An example is the disconnection of the circuit where an alarm signals no ventilation or $\mathrm{CO}_{2}$, and the anaesthetist searches under drapes, only to be told by passing staff it's on the floor. ${ }^{222}$

Emotions can be played to through interactions that are not only visual. The apple I-Pod reveals its actions or work flow as a tactile/sound experience - a learnt experience. There is no allowance in healthcare for user experimentation, or getting lost in the menus. Here usability is applied at a functional level with emphasis on learnability and memorizability. ${ }^{223}$

\subsection{Defining usability}

Usability is a recent term applied to a product's optimum match and capability to do the task it is intended for, in healthcare specifically addressing its primary intention. To not do a secondary task that the user desires of it as a work around or shortcut, is termed abnormal or intentional misuse. ${ }^{224}$

In healthcare, the origin of usability is embodied in error free or error aware use of equipment. Error awareness allows operators to recognise error and respond, mitigating adverse consequences. Hidden errors or cumulative unaware errors lead to unknown consequences. When these errors are unveiled little or no time exists to extrapolate an action plan as the information provided has not been encountered before. The operating theatre and the operative procedure are immersed in errors, many so insignificant that they become rectifications or adjustments. Error is not new and is part of the cognitive profile of complexity and dynamism residing in activities and environment. ${ }^{225}$

Eluding the ramifications of error is paramount in medical equipment design, and is a hallmark of successful design. Difficulty in establishing a hallmark for error or safe equipment is a constant debate, embroiled in legislation, standards,

222. An anesthesia machine Ooooops, http://nurseanesthetist.org/an-anesthesia-machineooooops/ (accessed 10/11/2008).

223. IEC 62366, Medical devices,

224. IEC 62366, Medical devices, -Annex D, 36.

225. Gaba, Simulation-based training in anesthesia crisis resource management (ACRM): A decade of experience, 175-193. 
technology and design. Usability is not common sense and cannot be empathically understood in its entirety by the multiplicity of professions involved in design. Usability aims to achieve assurance of capability in equipment, allowing clinicians to focus on patient care through safe use and interaction of equipment. ${ }^{226}$ In reality, to achieve this, design must focus on the lowest common denominator, the luddite, the tired, and the high workplace pressures, to tame complexity. ${ }^{227}$

\section{The iterative and well meaning criteria of usability}

The IEC and FDA provide literature to increase awareness of responsibility and lift the game of industry. The interpretation of this literature may be seen in two ways; first as a check box that requires creative paperwork, or second as a qualitative roadmap. ${ }^{228}$ The IEC is a carefully drafted document that requires sophisticated interpretation, although its titling seems to be directed at engineering. It may only function at the expected design level if all parties, including any users providing input, subscribe to it. Its primary function is to provide verification and validation of safe and intended use, prescribing the implementation and application of frequent use and worst case scenarios during the design process.

IEC 62366 is a design guide not an enforceable standard. This can be ignored by industry at their peril as standards accreditation would be sought by many institutions in purchasing.

How does this apply to prospective design and the observations? The IEC lists methods and techniques used in the usability engineering process as far sighted as participatory design. In their example they refer to 3D models and preferred configuration. Simulation is also mentioned, but these methods are redundant and may even be detrimental unless implemented by experts in these fields. No mention is made of user group selection or innovation.

The IEC document is for today and may increase the lamination of technology in its engineering application of iterative problem solving. ${ }^{229}$ This is not criticising

226. Mathew B. Weinger, Foreword to Designing usability into medical products, xxiii.

227. Woods, "Behind human error: taming complexity to improve patient safety," 462.

228. IEC 62366, Medical devices, 21. A usability engineering file/risk management file

229. D. Schuler and A. Namioka, Participatory Design: Principles and Practices (Hillsdale, N J: Lawrence Erlbaum Associates, 1993), 
the document as a method of validation, but it usefulness as a prospective design tool. Although the AAMI have reached out to industrial design, the FDA and IEC have retracted into compliance, complimenting the methods of industrial design (ethnography etc) but retarding the communication possibilities of prospective ideas and design as debate. Usability as a design strategy cannot cope with the unknown unknowns, and may in fact hinder farsighted investigation its strength resides as a powerful evaluative tool.

\section{Usability; research method or design process}

The issues under investigation allow three design ideologies to be prescribed as determinates in the application of usability.

- The ideology of engineering: competency and reliability. The empirical nature of the physical removed from people. Embracing technology, physiology, pharmacology, and epidemiology.

- The ideology of interactions: training and procedure. Information presentation, cognition, actions and response, from people to engineering. Embracing human factors, cognition, psychology and behaviour.

- The ideology of aesthetics:. The physical form and thus the subjective emotive response between people and equipment. Embracing path dependence, past aesthetics, habitual dependence and acceptance.

The three ideologies are bound as one in the use, application, and integration of equipment. Serving as design criteria, each carries a different weighting dependant on a quantitative or qualitative inspection. This analysis of design determinates needs to be read as a simplified explanation or postulation of design, reflecting the power of empirical knowledge and needs in a critical environment, and the reciprocal diminishing value of aesthetic 'qualities' in physical considerations. The ladder of needs (medical procedure) verses the ladder of actualisation (the equipment) leans heavily on past user familiarity to apply technology. When technology and the application of engineering accelerates, this need reaches a tipping point. Either the technology is applied to the detriment (loss of tacit knowledge and cognitive steps) of the interactions via traditional aesthetics, or a new form is designed that embraces the tasks and activity with new technology. 
In developing a new form, the issues of usability measurement may become more complex, criticised and costly. The Kion's demise may be a reflection of usability's inability to contextualise the ecological interpretations of practitioners.

A wide range of methods exist to gather design data, many of these are specialisations to their respective fields. Industrial design must not only gather information but implement it throughout the design process to achieve a capable artefact. Human factors analysis of a workspace may point to a problem, usability identifying a deficiency, together becoming knowledge through first hand information via ethics. While each of these exists in the design guide wire, simulation may be the powerful ally in the assembly of knowledge, a tool closely related to the design process and making. Simulation may allow us to safely speculate - as both a measurement tool and a design method. Avoiding designercentric prototyping and the residual devolution of the concept ideals as testing and evaluation, alter or eradicate the very factors identified as important.

Usability at its highest and lowest level may struggle to deal with issues of environment and range of anthropometrics in anaesthesia. A danger of usability may be the very confirmation bias "a human tendency to seek out (and thus find) information that is consistent with our views and to ignore (and thus fail to find) information that could falsify our views "230 A designer's blinkered intention to alleviate may be inherent in the very design process. Dependant on profession and application usability becomes contradictory, posing as both a tool of discovery and a tool of measurement, a research method and a design process.

Research and new knowledge is arriving from physiology, pharmacology, technology and simulation. Ethics, although a substantial constraint, can be overcome to retain safety and societal consent. A variant of usability could act as a validating research method if applied as a simulation search, with the results disseminated to industry and users, rather than as an internal accreditation process. This may enlighten decisions from the blunt end in medical equipment purchase, decisions that may ignore human factor considerations, environmental conditions, and clinical procedures. Additionally a complex subjective issue 
uncovered in this research; fear or untrained experimental learning in the acceptance and first use of new technology.

\subsection{Discussing knowledge assimilation}

Several design constraints particular to anaesthesia and medical equipment have been discussed and identified as implicit in the design process. Other methods of gaining insight on which to act and evaluate i.e. user centred design, provide a background for relationship centred design and the study's aim.

User centred design strives to take on an empathetic perspective in understanding the wants and needs of product users. ${ }^{231}$ This endeavours to counter designers designing for themselves, aiding in revealing new markets previously unknown or deemed the same. As a methodology it is only as good as the investigator, and requires skilled application. ${ }^{232}$ User centred design does not work directly to build a relationship with the user; Norman criticises its focus on data collection to understanding personal, cultural, and societal interactions with products, environments, behaviour, and technology. ${ }^{233}$

Exponents of participation design describe it as a key element in democracy, ${ }^{234}$ essential to social interaction and good design; this is simply respect for humanity. Democracy provides everyone with a voice should they choose to use it, and provides a slow well-ground path of consensus towards egalitarianism. The differentiation between participation design and traditional design leadership is contrasted in the introduction to the 1990 Conference on Participation Design, 'viewing the user as the experts - the ones with the most knowledge' and 'designers as technical consultants'. ${ }^{235}$ This view mirrors the early methodology aspirations in Chapter Two and is strengthened by the investigation so far, into the impact of anaesthesia in society, and the technical complexities of its safe facilitation. Anaesthetists are highly skilled experts.

231. John W. Gosbee, "Using buman factors engineering to improve patient safety," (USA: Joint commission Resources, 2005), 38.

232. Wilcox, "User-centered medical product development and the problem of egocentrism," 57.

233. Norman, "Human centered design considered harmful," 14-19.

234. Schuler, Participatory Design: Principles and Practices,

235. Schuler. Participatory Design: Principles and Practices, in Preface. 
Is democracy the design weapon of choice or practical in this complex and unforgiving environment? "We must view the user as expert", ${ }^{236}$ yes, but we need to develop the relationship to allow these 'visionary democrats' to surface and pass on design knowledge if we are to look further than iterations - or conversely, fly on the wall speculation.

Don Norman would argue that his theory of activity-centered design places designers as the visionary democrats, dismissing much of human centered research as irrelevant, in addressing only task, and not activity. ${ }^{237}$ Norman's theory may be sound for non critical design (he notes the complex system issues in critical design) but there may be few designers working in anaesthesia who have all of the attributes to accomplish his designer-centric and vision-directed design philosophy. Simulation can and should play a key role in facilitation and evaluation, a role normally taken by established process, past evidence, design precedents and design knowledge.

\section{Chapter conclusions}

The investigation has exposed historical design attributes in anaesthetists. Are anaesthetists a blend of cultures? Like designers - spread between art and science, humanity and technology. Can they do more than hand over information as answers to a question? It is suggested that they are measured by methods that find fault but do not lead to a human centred or profession centred resolution. One strategy could be to allow the designer to take over at the point where traditional data and interviews have been collected, to conceive new ideas. These concepts would be prospective and novel, and most likely designer-centric in lacking significant knowledge connections to the activity of anaesthesia.

The three studies; Cooper, Boquet and Schwartz, applied users to the problem. Through professional association, each of these researchers inherently valued the intimate knowledge of the user. This study wishes to focus on information and ideals from the user and correspondingly limit the preconceived ideals or assumptions that an external designer may have.

236. Ibid.,

237. Norman, "Human centered design considered harmful," 14-19. 

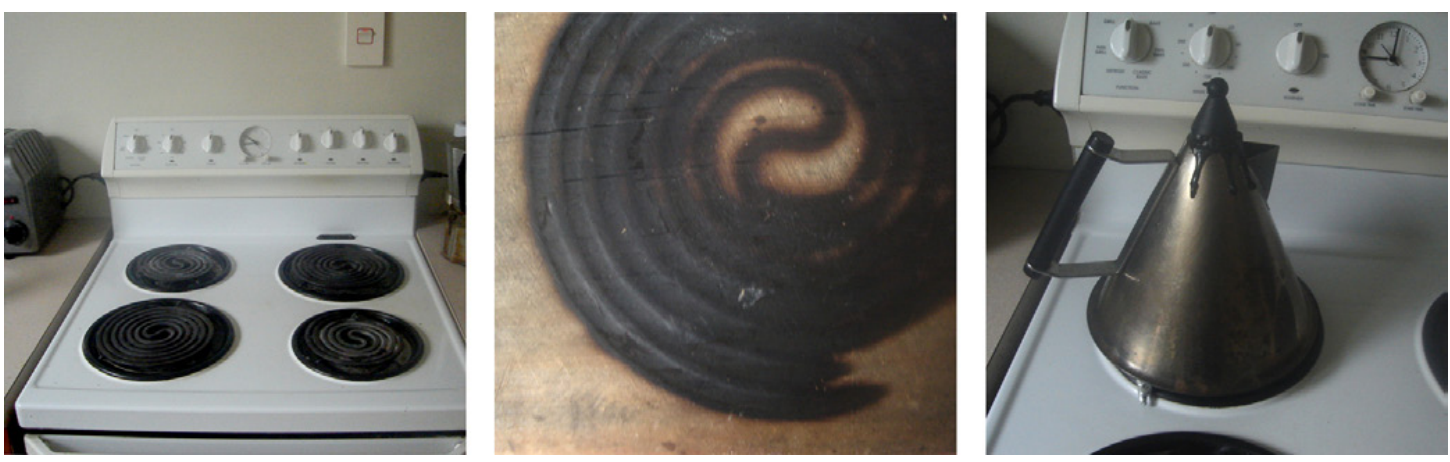

Fig 5.4 Example of a misinterpreting oven element controls, and the results of turning the wrong dial in relationship to the element

Source: Author 2009

Before this study was begun a presentation was made to practicing anaesthetists that outlined the proposed work, and introduced industrial design. Although it lacked any defined objectives or methods of collaboration, a key issue addressed was that users can fail in the use of the simplest technology due to poor design and human qualities ${ }^{238}$ (Figure 5.4). My own simple domestic example illustrates a lapse in decision making in the face of technology and a common task. Primarily that responsibility for how a product is used is not only the domain of the user, but design leadership must also play a responsive part. This example opened up the question of how the equipment anaesthetists worked with is designed, and what this ‘design leadership' could be.

Not only did anaesthetists have little knowledge of the historical development, they also seemed to have subconsciously encumbered themselves with overcoming the inadequacies of design. Somehow they felt all responsibilities belonged to them. Accordingly the idea of them being consulted or courted by design was unique. Unique was the idea that change is possible and someone is willing to listen - more unique was the relationship of bringing non clinical people into the operating theatre as questioning observers.

In early communications, anaesthetists stated that a focus group or questionnaire would provide little new information as no participant would commit themselves openly in front of their peers or an unknown independent researcher. With the idea of developing a trustworthy relationship, an underlying intention was to develop an open narrative with several anaesthetists to challenge a discipline to think deeply about their tasks. The methodology to gain trust and interest rests in the relationship between the designer and the participant. This may not be so 
in many consumer industries, but in the closed doors of healthcare, critical care and the operating theatre, it would seem paramount.

Within a complex and potentially error ridden activity, steeped in tradition and trust, the quantified gathering of information comes with a threat of evaluation, and appropriate to this study, its true usefulness. On this basis, another avenue is to utilise anaesthetists as designers. Although this carries a danger of user centric or habit based concepts; the evidence gained may first test the established, second inform us of how anaesthetists envisage their equipment, and third, how simulation could provide an alternative, unlocking the transfer of creative knowledge.

In searching for the voice of the user, I return to the relationship. To avoid constraining the future experiment by my actions I do not want to be seen as measuring participants or directing the outcome. Instead as a designer, I wish to acknowledge their hypothetical capability to contribute and communicate knowledge to tailor their providence. This requires a method suitable for designers when we don't know or are unsure of the questions, and how the method of asking them will colour the answers. Traditional methods may limit the quality of the response in view of the aim, when looking for suggestions to perceived problems and opportunities. 


\section{FIELDWORK: OBSERVATION AND EXPERIMENT}

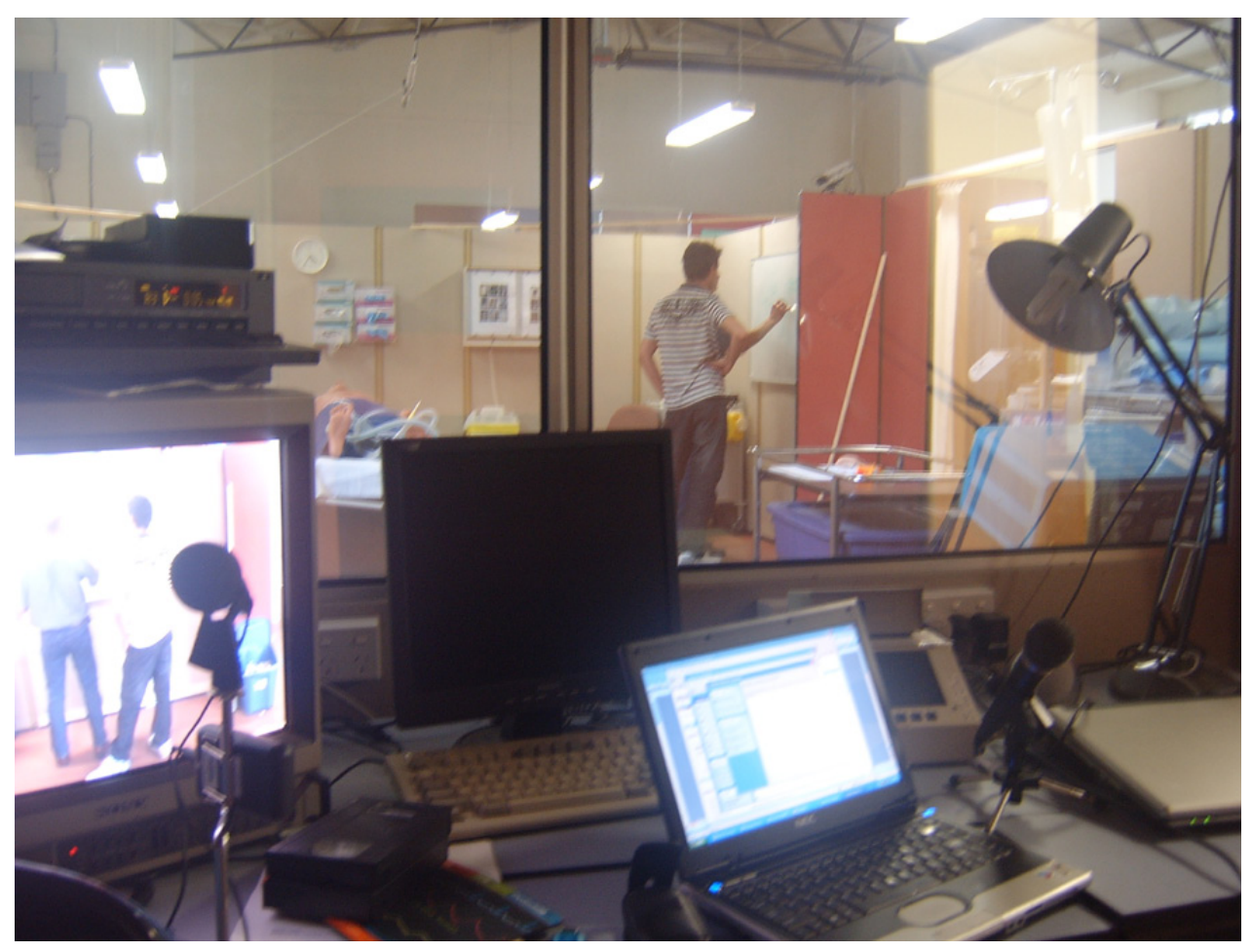

Fig 6.0 Anaesthetists passing on knowledge through design experiments 

Chapter 6

\section{FIELDWORK: OBSERVATION AND EXPERIMENT}

(E)very tool has two ends, one working on the material, the other on the man. (Halsham

$$
\text { 1907) } 239
$$

This chapter focuses on interaction with anaesthetists. Evidence from researching the past and the present prompts this relationship as an imperative concluding step to achieve:

- A contextual understanding to physically see, converse and immerse myself, not in the past, but in reality.

Adding simulation and design activity to this relationship will allow:

- An experiment applying a null hypothesis to test the established machine format.

- The opportunity for anaesthetists to reinterpret the physical manifestation of technology as components, composition and activity.

Outcomes from the experiment and the study in general will:

- Reveal ways that industrial design may partner in contributing to the body of knowledge.

Perception through observation and conversation within the operating theatre will be discussed first; this will lead into the experiment method, implementation, outcomes and analysis.

Observation can help to understand a context, thereby leading to a consolidation of the hypothesis and a refinement in experiment methods. ${ }^{240}$ The function of this chapter within the study pertains not only to the above as an experiment,

239. Kikup, The evolution of surgical instruments, 143.

240. Roth, "Using field observations as a tool for discovery: analyzing cognitive and collaborative demands in the operating room," 148-157. 
but how two disciplines (design and anaesthesia) can work and inspire each other. In Boquet's study, the methods of observation were quantitative, whilst explanation of the design process was minimal and thus not repeatable. Cooper's intuition, along with his professional and subject wisdom avoided context, while Schwartz's contextual study was empathetic. None of the studies dwell on their immersive response or the clinicians' reciprocal response to contextual observation and experiment participation. This may be due to the place or method of publication, where these subjective qualities are of little importance to their assumed audience.

Paramount to a prospective search was to get on the inside. The key was not to relent to gatekeeper suggestions or capitulate to others' observations and directives towards traditional scientific research methods. The nature and interest shown from a rapidly developing network within the hospital was pivotal in supporting this goal. In debating objectives with managerial gatekeepers, it was difficult to present the study's conceptual aims as an argument for observation. The study had become loaded with a searching criteria that held none of the apparent traditional outputs of teaching, clinical research, or the demonstrating of new equipment.

\section{Fieldwork, observation and experiment \\ 6.1 Clinical observation}

These observations aim to supplement the theory of evolutionary design, establish relationships, and strengthen the communal acknowledgement of the study as a primer to the experiment. A period of 5 months was allotted to parttime fieldwork within the hospital and operating theatre.

\section{Introduction to theatre}

After a managerial review of the proposed study, I was assigned to a specialist anaesthetist under the title 'departmental visitor'. This came with the proviso to observe and document activities (using still images only) with the consent of all those present, including the patient. With this relationship established, observation was to become more than standing back and looking. I met staff from all theatre disciplines, asked questions, and observed a broad range of 
procedures. This included first contact with patients, induction, surgery, awakening and transfer to the ICU or to the Post Operative room, as well as breaks with the staff.

Rules of the operating theatre were relayed by those who thought it necessary, and an 'ask first' approach was applied. Introduced as a designer, interest was shown by many parties; orderlies, technicians and nurses interested in theatre ergonomics. Surgeons were also keen to explain procedures. Each had relevant comments and criticisms of both the environment and equipment. This early immersion relayed surgeons as innovators, researching through the use of tools to constantly improve procedural task and outcome. Nurses were stuck with tradition, incapable of noticeable innovation due to their station and history, yet their task required knowledge, foresight and empathy.

Notes were taken including photographs and after leaving the theatre each day, these notes and images were reviewed. Often photos were reviewed with the specialist anaesthetist who showed interest in debriefing the activities I had captured. The time spent in this environment by a designer is invaluable, and cannot be attained in any other way. Thus, the effort required to gain access is in some way a method to measure your research commitment or professional status.

\section{On Observation}

The day to day observation of anaesthesia is more than watching an operation. The term observation applied in this case as investigative colleague, a voyeur of tasks, sequence, quality, conversation, communication and time. This would make many people feel as if they are somehow being measured no matter how reassured. Occasionally, staff reluctance was found in acknowledgement of the right to observe or partake in this environment; as a designer you are a foreign body. This necessitated explanation, thus connecting management to clinical investigator and the study, relaying responsibility and underlying consent.

Having some knowledge of equipment working and basic clinical tasks means the observations were not entirely naïve. Yet, with no investment in the clinical procedure, the concerns of the observed theatre staff should be significantly 
reduced. Thus observation is based on a political system of ethics, research rigour, consent and managerial/clinician trust.

\section{Describing observation}

The operating theatre has little personal comforts, to watch a surgeon for 6 hours who has no significant body movement and applies a focused intensity to the task is foreign to most of the population.

\section{- Housekeeping}

In the first observation I was enlightened to the way equipment was set up and used. Cables everywhere, narrow corridors and passages were created as equipment encroached on space and walls, whilst open luxurious spaces existed elsewhere (Figure 6.1).

These immediate conclusions were directly drawn from my past experience in the oil, gas and mining industries. High mortality accidents still plague these

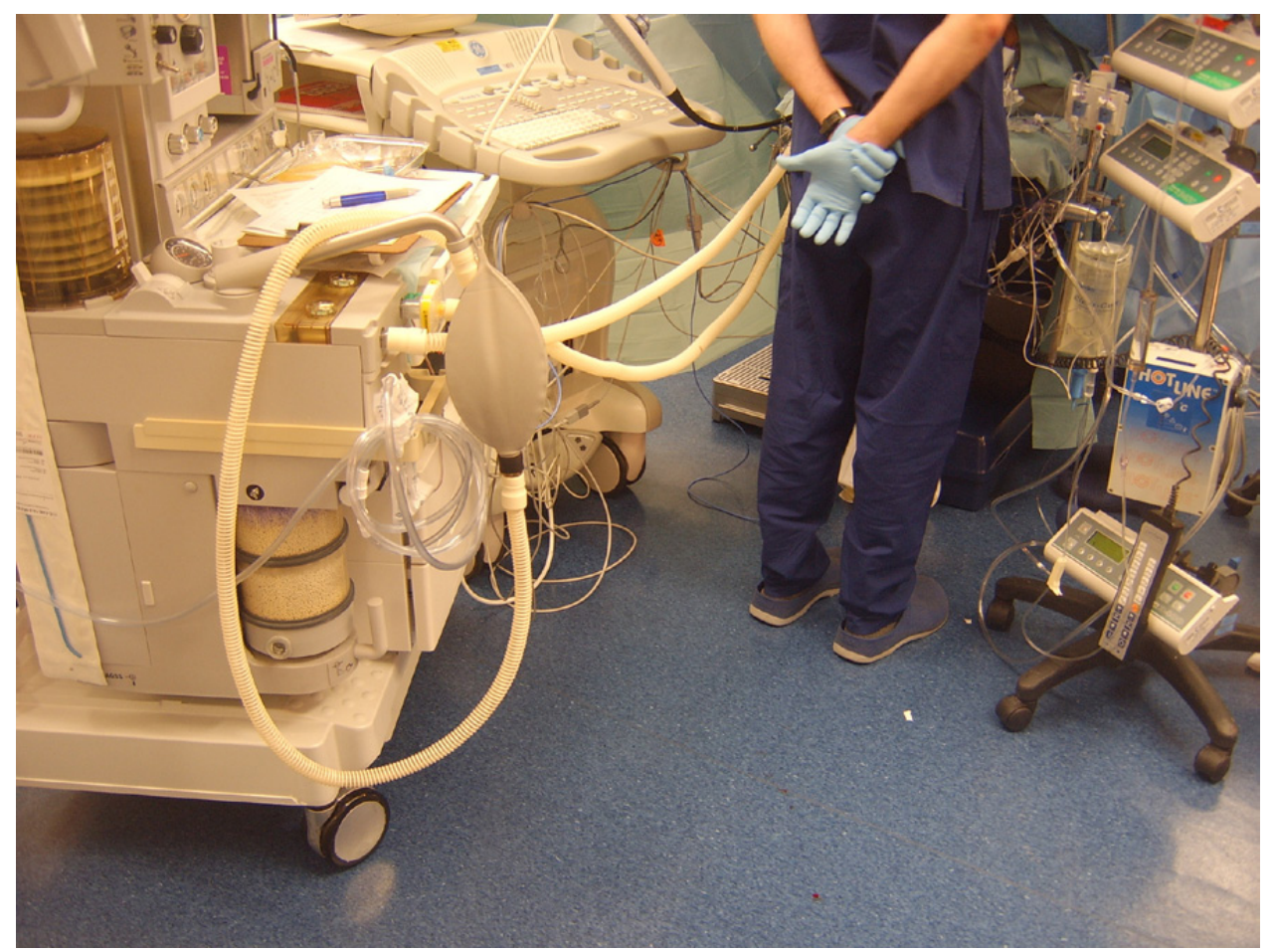

Fig 6.1 Housekeeping photo from observation 
kinds of industries. Endeavours to reduce accidents have focused on safety systems and prevention (inductions, work and personnel tagging systems) with attention to basic housekeeping and safety.

Anaesthesia housekeeping seems to consist of attention to the 'plugs and sockets' and not the spanning of tube and cable, whereas industrial practice places paramount concern on the 'span'. This reveals patient, environment and time as a driving operating theatre constraint. Visible connections from equipment converge through a closed landscape of drapes, cables and tubes to the patient, and the general area of procedural activity. I later understood that there is method in this madness, although of concern - every anaesthetist had a different method or madness. On the opposite side, housekeeping for nurses has been an historical analogue of ritual based safety. One profession was dealing with technology and the result of external design and engineering. The other with history; practice based design established on an epidemiological foundation of hierarchy, system and function.

- Moving the anaesthesia machine

Machine position in relation to patient and anaesthetist is dependant on the procedure, meaning every procedure requires the equipment to be positioned appropriately; anaesthesia assistants do much in this role. Movement of the machine often continues throughout a procedure, surgeons change location, new equipment is brought into theatre and others removed. The patient is the stationary nucleus and belongs to everyone. Whereas the anaesthesia machine belongs to one profession and its form clearly infers movement; 'I have wheels, I can be manipulated easily'. To observe a person of small statue manipulating an anaesthesia machine into a position suitable for the procedure, then in them giving up the task as 'close enough', was a reality check. Is this call for assistance really necessary? The action of castors, significant weight, independent brakes and token hand holds become a poor design excuse at a 'nuts and bolts' level.

A senior consultant commented on the many close calls or incidents attended in the operating theatre, stating that in many cases the hallmark of the problem was in basic housekeeping, procedural planning, and equipment positioning. 

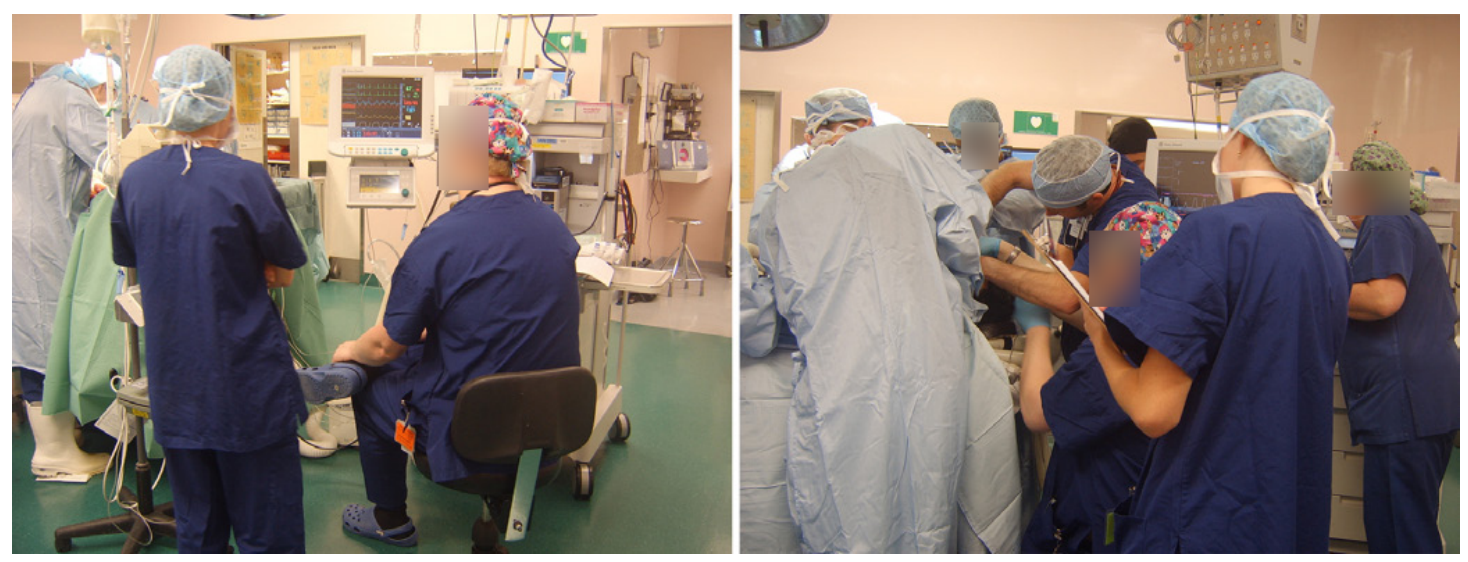

Fig 6.2 The rapid change in environment

- Anaesthesia machine position

The anaesthesia machine is a substantial object in weight and size, and may be mounted on wheels or supported on a pendant. This means it can reside anywhere there is floor space. In reality, its best ergonomic habitat is as close as possible to the patient, while allowing space for the anaesthetist. Physically this means that the machine is often adjacent to or behind the user. This is a direct result of its habit based pedigree, increasing size and common asymmetrical format. The awkward position is quite obvious, yet has received little study. ${ }^{241}$ If applying usability evaluation out of context, these problems may draw little notice, as interprocedural movements and process require careful study in a range of procedural contexts and events (Figure 6.2). This is a case for informed observation and effective translation methods to designers.

- Anaesthesia machine setup

Anaesthesia assistants test and ready the machine for every procedure, although it is still the responsibility of the anaesthetists to ascertain a safe system. Once the safety check is complete, the machine is 'dressed' as if it was still the dressing table of the past. Every flat surface is covered in extras, every vertical protrusion is utilised as a clothes hook. A machine ready for use is very different from its designed, evaluated in testing, or advertised form.

- Anaesthesia machine customisation

The machine may have been designed to provide anaesthesia, and its historical characteristics provide a table and draws for auxiliary equipment and consumables. 
In truth, the real design team is active within the operating theatre, customising this 'object' to perform (Figure 6.3). The taping $\left(\right.$ Sleek $^{\mathrm{TM}}$ ) of objects to machines is a strong message of deficiency in design and a profession's tailoring of technology, to make devices work as an activity centre and system. Is design doing its job? Engineering may not be interested and it is not their domain, while human factors may be concentrating on high soy

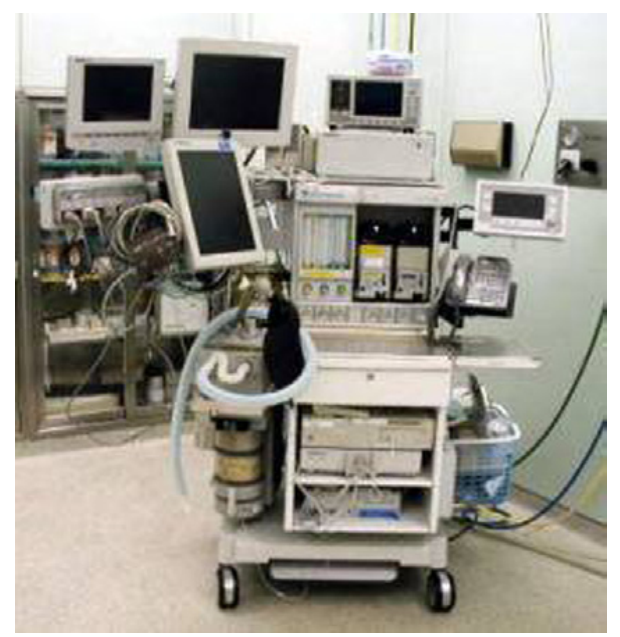

Fig 6.3 Machine customisation. level cognition heuristics and workarounds. Anedepartment/museum-masuiki.asp

- Anaesthesia machine connections

Numerous connections are made between the machine, other equipment and the patient. These may be tubing or cables, which are prone to disconnection, wrong connection, damage, disability, entanglement and failure to be of the appropriate dimension or length for the task. Those that are connected directly to the patient are often covered from view in readiness for surgery. Evidence from past errors has led to a multitude of connection designs to prevent cross connections. Yet cases exist of both intentional and unintentional creative cross connections. ${ }^{242}$

- Body posture and fatigue

Issues of operating theatre staff fatigue and leaning were isolated when viewing the days notes and images. In the next session I documented cases where posture was communicating how the anaesthetists and staff were dealing with ergonomics and body support. These images send a clear message to designers of the ramifications of technology (Figure 6.4).

\section{- Communication}

Communication is paramount in the operating theatre, which is often a domain of intense noise, with a persistent drum of air directed downwards around the surgical field, and a variety of alarms from monitoring equipment (Figure 6.5). 
Information, be it peer to peer or equipment based, needs to reach the intended personnel clearly with a corresponding reply or result.
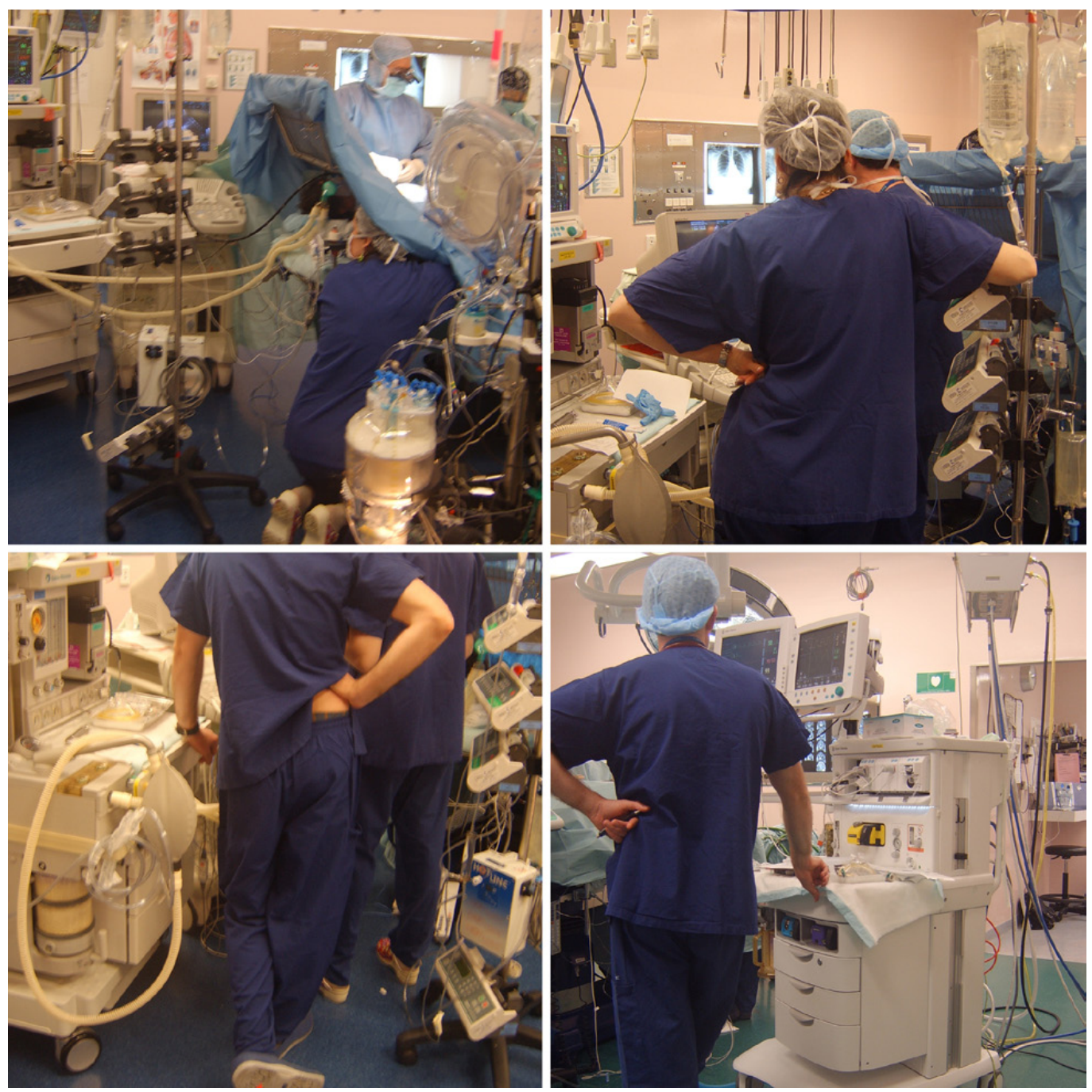

Fig 6.4 Body posture and fatigue

Communication is not only verbal or audible, visual cues are seen in body language, physical signals in posture, and head movements as an indication of cognitive attention, i.e. looking directly at someone when an item is required. There is an underlying awareness that everyone should know what is happening. While many verbal requests are made with 'eyes on the job at hand', when additional 


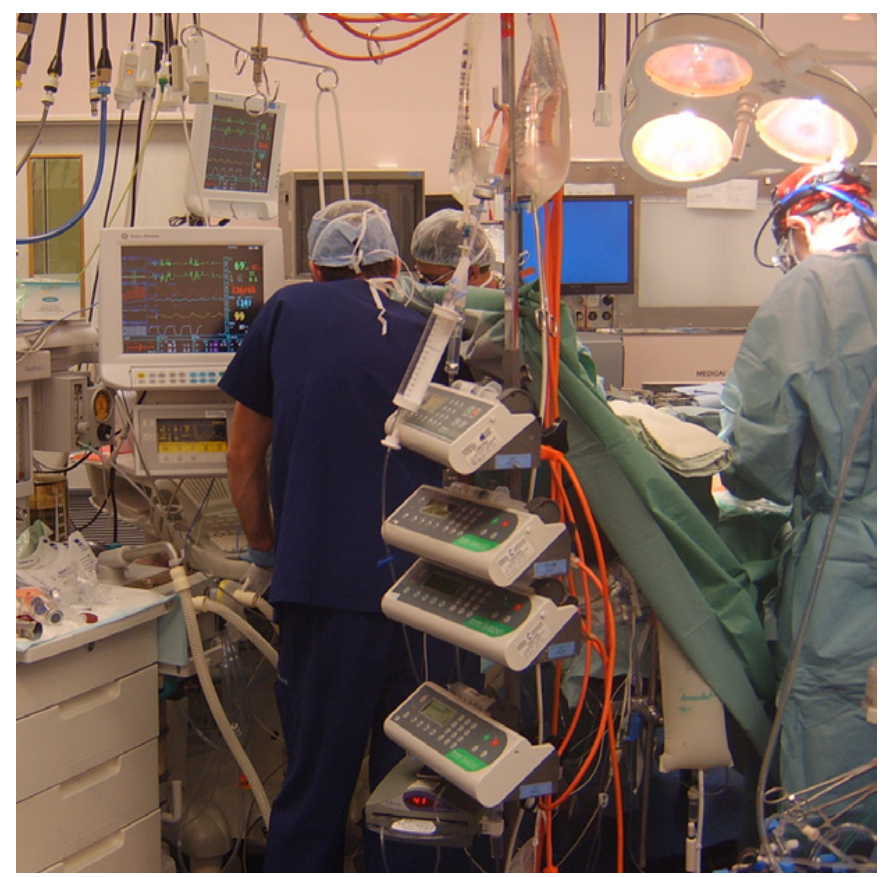

Fig 6.5 Communication

impetus is required or the required objective is not reached, body actions take over to reinforce the demand. Observation revealed missed communications as the cognitive workload increased.

The balance of information, knowledge and communication, both during normal activity and crisis management, demonstrated why the anaesthesia machine was customised to overcome its deficiencies. Predominantly this is an adaptation to an evolving procedural criteria warranting logistical dynamics between user, machine and the operating teams task.

\section{Conclusions on observation}

Observation revealed the operating theatre as a hostile environment. A residue of developing professions, patient variables and technology's increasing role; all ringed by safety and concerns for both patient and throughput.

To accommodate the vast complexities and range of procedures, many customisations can be seen. These cannot be understood completely until observed when procedures do not go to plan. A great deal can be observed and understood in the operating theatre, but time and procedural variety is required to see both the day to day, and an unfolding event. Only then can designers understand the gravity of their task and the importance of their relationship with clinicians, engineers and human factors. 
Real concern to industrial design exists in the lack of design resolution, in the pragmatic relationship between anaesthetists and equipment. These are not operational interface variables, but the obvious inadequacies of a design evolution faced with a constant logistical challenge of manoeuvring, setup and adjustment. There is a lack of hand holds and safe touch zones coexisting with excessive weight and instability. This is low level design that plagues use and sits outside of standards and usability evaluation, impacting directly on user satisfaction and the ecological relationship of use.

Observation revealed a considerable disparity between published studies and the anaesthetist's activity in the operating theatre. Of primary concern, is a machine tasked with adapting to a multitude of positions and procedures. Directly related, are the interactions by anaesthetists in a complex variety of methods to afford the best procedural process (intubation, monitoring and awakening), while endeavouring to cover every possible outcome in their own personal way.

Once developed, collegial relationships divulged many other concerns and the well reasoned argument, that you will never satisfy everyone, is well understood. Design proved to be a non-threatening topic, and the whole operating theatre was interested, bringing many problems to the fore. All staff thought that operating theatre ergonomics were paramount (some practised these more than others). This speculates that the lay person relationship with the operating team offers considerable merit when this role is taken by the designer.

\section{THE PROTOTYPING WORKSHOP}

\subsection{Experiment}

Reiterating a phrase from Chapter Two, the discovery phase of hypothesis generation is integral to any design investigation. A point now exists where substantial understanding can lead to implementing a controlled experiment to test the established evolutionary outcome, and address the ergonomic capability 
of the anaesthesia machine. ${ }^{243}$ The term ergonomic is applied here to encompass both human physiology and the physiology of equipment.

The study's early aim of validating simulation (Figure 2.1) required the use of video recording within the operating theatre and intended to mirror Boquet's study. Ethical and consent issues denied this approach. A result was to carry forward the experiment.

\section{Aims, outcomes, and goals}

The experiment hypothesis is treated as a primary aim. Would anaesthetists, given the opportunity to design the composition of an anaesthetic machine, create machines different in comparison to the anaesthetic machines they currently use? This questions the evolutionary consensus that what we have is best. Secondary to this, the experiment would indicate the capability of both the method and anaesthetists to communicate knowledge, facilitate making and evaluate outcomes. This results in a collaborative process aimed at questioning and influencing 'what we have' to gauge whether or not "what we have now is what we are used to rather than the ideal." The aim will be explored in two parts, in order to evaluate whether or not the method can provide a valid user derived critique of established equipment. These two parts are:

- The static arrangement of components as a design composition, to deduce similarities in component hierarchy and environmental impact.

- The dynamic interaction between participants and components as a commentary on actions and reasons; allowing the experiment to interpret the user's physiological relationship to the environment, equipment, and personnel.

Goals of the experiment relate to the capability of anaesthetists to provide design insight through a methodology of making, evaluation and simulation. This requires methods to explain the design outcome, thereby extracting latent knowledge; the reasons for doing, or perception of need, for a requirement. Utilising three dimensional prototypes and simulation will help to understand how anaesthetists communicate information about their interaction with the

243. Roth, "Using field observations as a tool for discovery: analysing cognitive and collaborative demands in the operating room," 148-157 
anaesthetic machine.

\section{Procedure}

Nine specialist anaesthetists were recruited as volunteer participants. Each participant individually attended a three hour prototyping workshop to construct and test their ideal machine concept. The National Patient Simulation Centre was enlisted to carry out the simulations and to provide documentation (video recording) and a clinical setting. The room where the subjects constructed and tested their prototype is similar to an operating theatre, and includes trolleys and other theatre equipment. A simulation mannequin takes the place of a patient (Appendix 1).

One week prior to the workshop, participants attended a 15 minute discussion outlining the study objectives and methods. This gave participants time to prepare, make notes and think critically about which ideas they wished to pursue during the workshop.

Observations of the experiments were made from the control room. A 'one way' view of the proceedings and equipment for sound and video recording was provided (Figure 6.0). Notes were taken as the experiment progressed, at points of interest rather than set duration timings. Points of interest were interpreted as a key design activity or communication process, for example sketching, making, acting out, and in dialogue. These notes, or design script provided timings for occurrences of interest to be reviewed later.

At the beginning of the workshop the researcher introduced each participant to the design assistant and their own set of prototype components (See Appendix 2). Participants began by communicating their prepared ideas to the design assistant by sketching out the concept. (The design assistant is a third party and not a member of the research team so as to avoid any bias). As the sketch concept was developed, the components were placed and supported at the requested height and position. The participants were required to refine their arrangement, simulating reach distances, eye-lines, visibility, and task relationship between patient, machine and other personnel. 
On completion of each concept the prototype machine dimensions were recorded for static analysis. The participant and their prototype then took part in a 15 minute simple simulation to ensure feasibility of the concept. This consisted of an anaesthetic induction, maintenance, and reversal for a noncomplicated surgical procedure (e.g. appendix removal). Each experiment was video recorded from start to finish.

\section{Analysis}

Static: Each prototype, when translated into a 3 dimensional computer drawing, allows for comparison and isolates correlations of clusters, patterns, and themes. These are made through looking at a lamination of the prototypes from a variety of views i.e. elevation and plan.

Dynamic: the video recording will be reviewed to provide a build narrative, contextual assurance, and preferential hierarchy of components in relationship to simulated task and environment.

\section{EVALUATION AND MEASUREMENT}

The prototyping experiments yielded 9 physical concepts, 20 hours of video recording and 60 hours of computer documentation. All participants produced dissimilar concepts. The diversity in concepts and the gradual intensity in the physical design process during the prototyping sessions was unexpected. Developing and testing ideas through non critical making was met by some participants with initial scepticism. This attitude was later reversed in the prototype simulation procedure. The motivation of the participants to the study and the use of simulation played an important role in measurement, context, and convincement of value.

\subsection{Results and analysis}

Trends, associations and correlations were sought for in both the visual measuring and mapping of the results, and the data gathered from the process of making. Low resolution measuring and mapping in line with the prototyping 
method provided comparative evidence of the actual outcomes. A commentary on the process provided a qualitative layer relating to educating designers and discovering issues that surface through designing. The analysis focuses on understanding the success, limitations and deficiencies of the research process not the capability of these concepts to take the place of current day equipment or somehow be combined as one.

The design process will be reviewed first, then the prototypes, and finally the method as design insight versus design information.

\section{Design process}

Drawing, talking, making, playing out, simulating and revising: all constitute communication. The experiment relied on the participant relaying their desires through materials, to the activity and to the design assistant.

\section{Drawing}

Although I had asked participants to note down ideas and make sketches at the introductory talk, only five out of nine brought physical notes. All seemed private about their sketches, providing comments like "oh I can't draw" and "they're just scribbles," and "I have a few notes". It was when participants drew on the white board that it was apparent all had spent some time planning (Figure 6.6). For some, these plans were matured over an entire career, others had put some time aside prior to the experiment. All were drawing from their own experience. The act of drawing was not problem solving as designers, but as a form of communication. In any future experiments this should be clarified in the introductory talk and

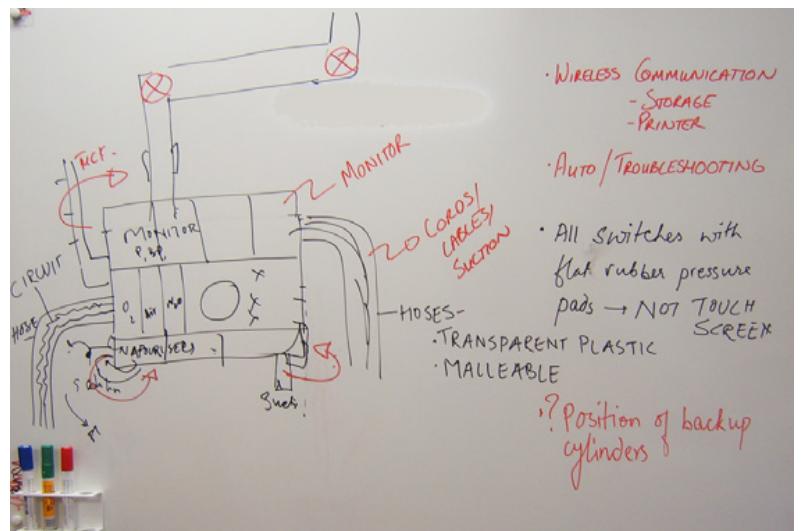

Fig 6.6 Participant drawing some example sketches shown (not subject related). Seemingly naïve, these sketches contain important information - the quality of drawing is unimportant in comparison to its capability to communicate in tandem with making.

I had hoped that participants 
would use the sketching process to explore ideas, but it was not apparent this had happened; instead, participants had applied the sketch to illustrating a solution to their own problem. The sketching out of ideas between the introductory talk and the experiment was conceived as a 'communication' take off point for each session. Initially I had considered that without these 'plans' the participants may try and reverse the experiment process; trying to answer a question of novelty rather than solve or project problems as they see. This concern was unnecessary, as each participant arrived with the capability to communicate and build their ideas.

Drawing was not a mandatory process but all participants used the white board as a discussion point to sketch up their idea. As a focus tool it was invaluable, as both participant and design assistant moved backward and forward, clarifying the idea. Some used the drawing as a plan and returned to it for directions; others used the drawing as an inter-process communicator to describe to the assistant an attribute or idea. A limitation of two dimensional illustrations is that many problems are not apparent, nor are the intricacies of the author's intentions fully understood. Limited use could be made of the sketches by external designers outside of the experiment.

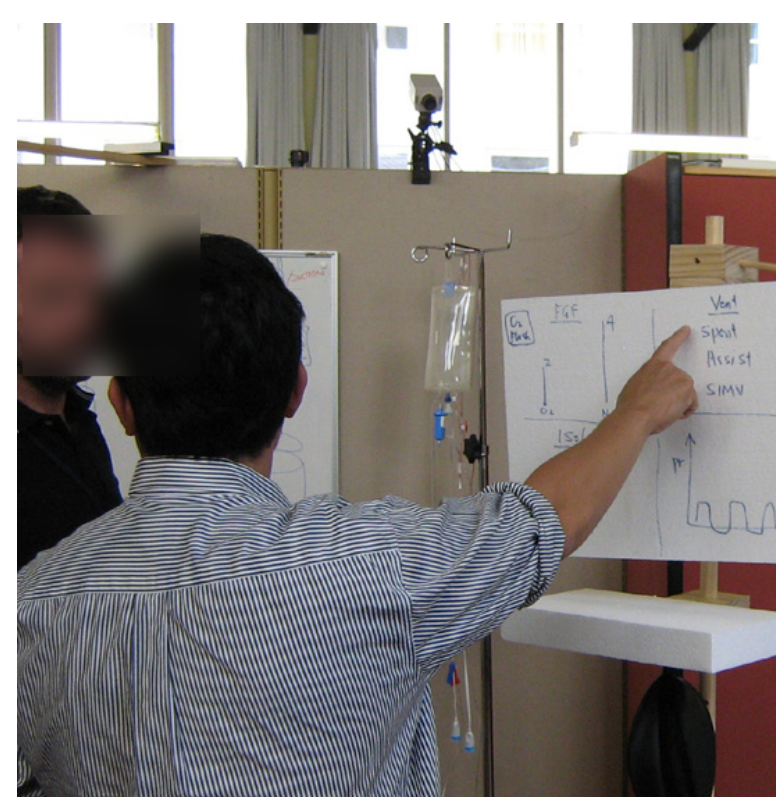

Fig 6.7 Participant communicating 


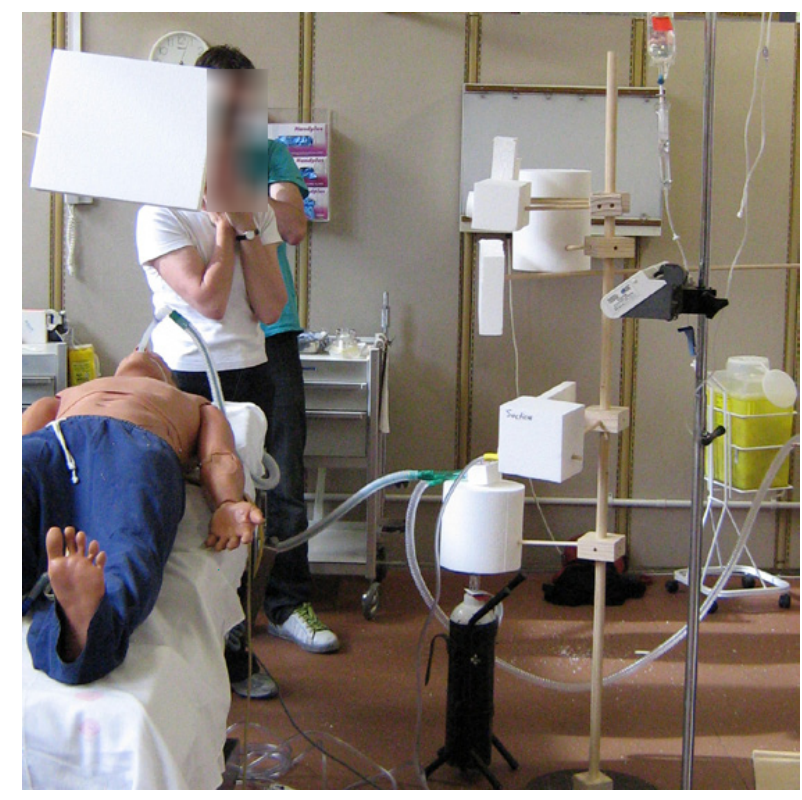

Fig 6.9 Participants making

Talking

'Thinking aloud' describes the build narrative. The need to communicate verbally to a naive assistant revealed participants were not just explaining, but problem solving (Figure 6.7). Analogies were common in conversation between the participant and assistant designer as a build direction tool. This was most effective in the simulation debriefs, where concept ideas of technology were related via known products i.e. the tactile physical feedback of I-Pods. Conversations

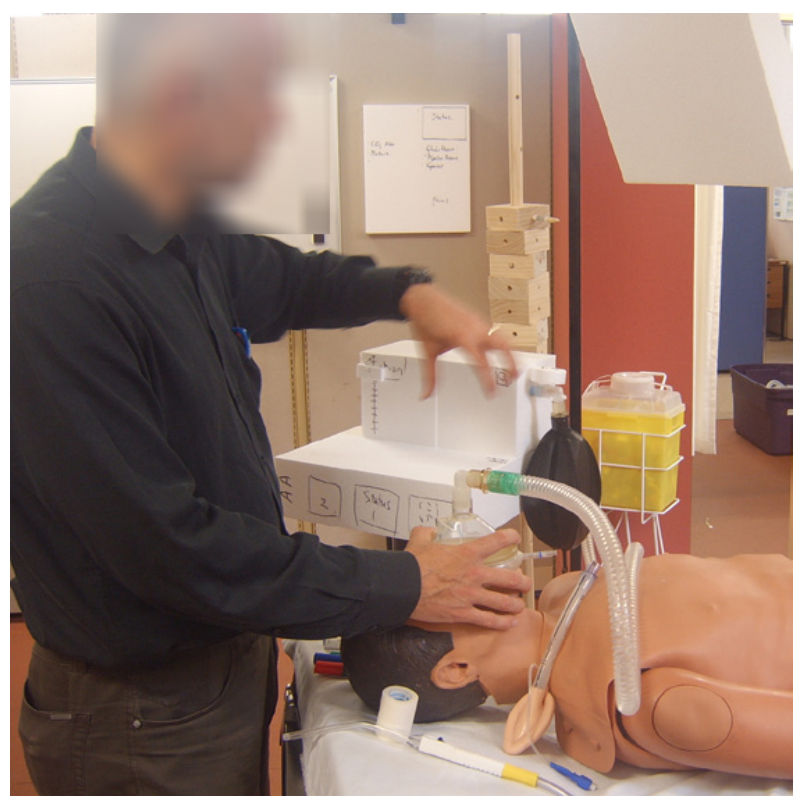

Fig 6.8 Participants playing out between the participant and the design assistant often diverged into the personal reasons behind decisions. For example, a mistrust of digital technologies, the impact of various procedures on the environment, and the need to accommodate and interact with staff as a team.

\section{Making}

The method of making did not influence the desired outcomes and so proved suitable. All participated in the building, some 
with more enthusiasm than others. The low resolution method of construction allowed for a variety of skill levels, which very quickly brought enjoyment to the process. The choice of materials proved suitable and adaptable, as they were light, fast to cut, capable of being drawn on and not prescriptive of current anaesthesia components. Reducing the resolution to this level freed up thinking and reinforced the methodology of prospecting (Figure 6.8).

\section{Playing out}

Through acting out the use of the concept, participants iterated ideas; moving, raising, lowering, and adding or removing components. This physical acting allowed their physiology to respond to the design physiology. Some talked through this process and issued instructions to the assistant whilst others took more direct actions, with their reasons uncommunicated (Figure 6.9).

\section{Simulation}

Simulation was a key method to step beyond the preferential test, to a test of function as an equivalence of context and activity. Underlying this was a prescription that by utilising a simulation facility, equipment and expertise, an emphasis was placed on participants that the workshop was about endeavouring to physically facilitate ideas. This method controlled the experiment fidelity, limiting assumptions from both the researcher and the participant. It provided a continual opportunity to act out the idea and iron out any difficulties. On completion of the prototype and the participants' own reflective test, a scenario was acted out (Figure 6.10). This confirmation walk-through directed by the simulation expert required participants to reproduce a set procedure and interact with the prototype. Being physical, contact could be made as gesture, i.e. a 'block' screen could be touched on the 'drawn in' controls. Again, more things came up in the simulation debrief, for example:

Simulation director - "would that component show the information in analogue or digital representation?"

Simulation director - "Do you have any ideas on how that interface may look or feel?” 


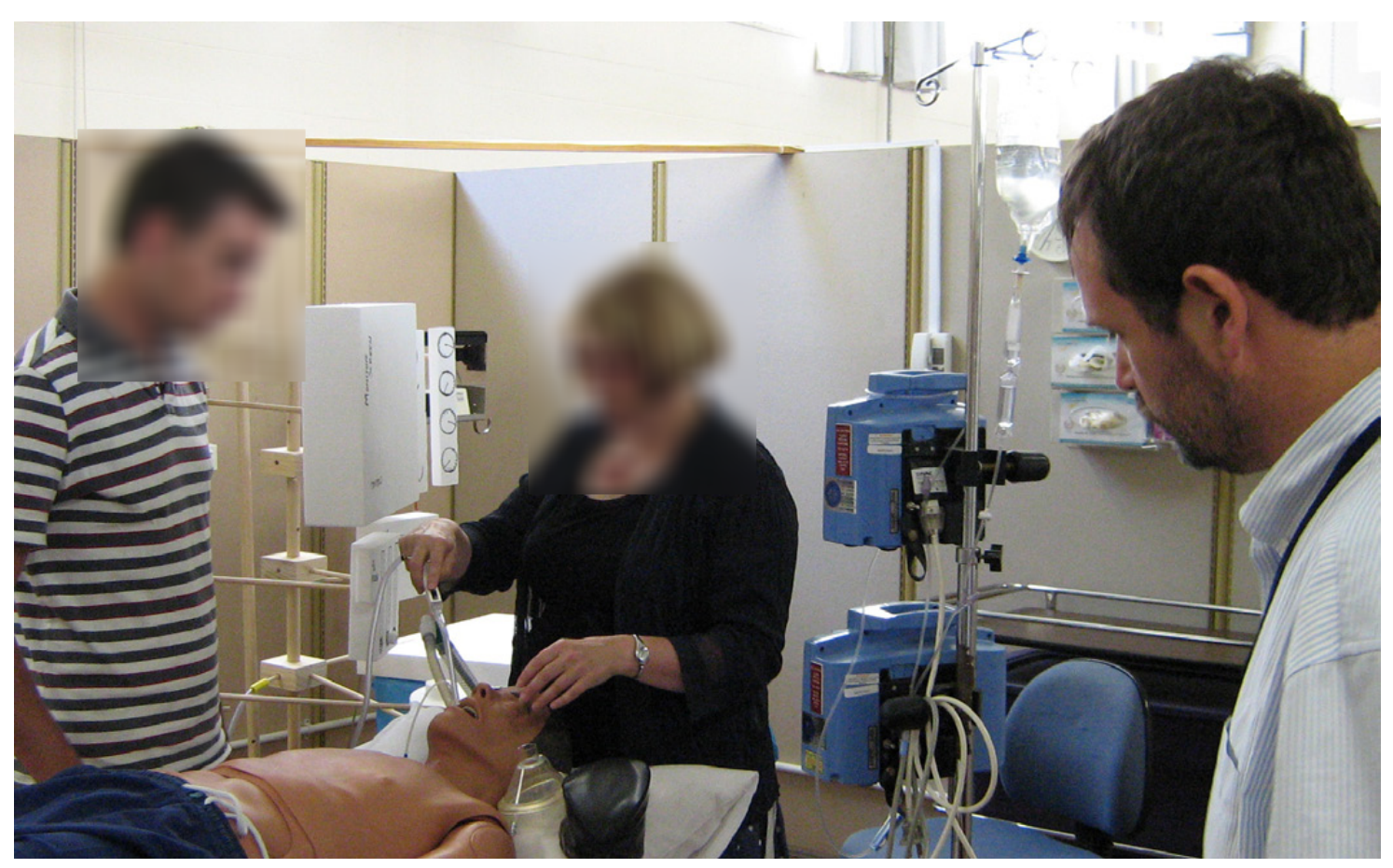

Fig 6.10 Simulation validation of concept

Participant - "I would like this part to rotate and fit to the side"

Simulation director -"Where would you now put the suction down as an intermediate?"

Participant - "Where can I hang the bag?"

Finally, a walk through with all those involved occurred. This allowed further questions to arise, from both the participant and the experiment team. This stage gave participants the opportunity to move from the ideas they represented through modelling, to communicating their conceptual views of the future.

Simulation revealed how substantial the prototypes and method was, in particular:

- How each participant articulated their ideas

- Whether their ideas were capable of being articulated with the methods

- Whether the participant had a need or enthusiasm to buy into articulating ideas

- Whether the participant had any ideas

- Whether they had problems that they wished to overcome 


\section{Prototype revision and completion}

All participants initially failed to build a prototype that would work, as they consistently forgot a control or attribute that would allow a successful simulation. The oxygen flush was the most common component left out, but omissions were eventually resolved and the scenario was repeated. Several participants whose specialties required mid-procedure repositioning of the anaesthesia machine evaluated their prototypes in more than one position as a contextual check. This brought out subtle changes and reconfigurations.

Visual aesthetics were brought up as a topic. The question received little interest other than keeping up with consumer technology i.e. Bluetooth wireless communication. Most felt that they could differentiate between styled surface aesthetics and form based active aesthetics of component composition and use. Criticism was made of the functional implications of superficial skin deep styling and how many of the recent aesthetic changes had an impact on usability. Gauges had reduced in size and often resided in places capable of being hidden by clutter. Components were rearranged to fit the chassis, rather than a hierarchical (visual and tactile) interaction suitable for crisis management. Other comments were directed to easy-clean surfaces, an overuse or simplistic use of fashionable colours, and the excessive reduction of physical affordances in order to move screens components etc. This validated the observation and historical discoveries of a need for greater consideration given to physical connections including hand holds, rest points, touch zones, and counter-balanced or weighted movement in dynamic components.

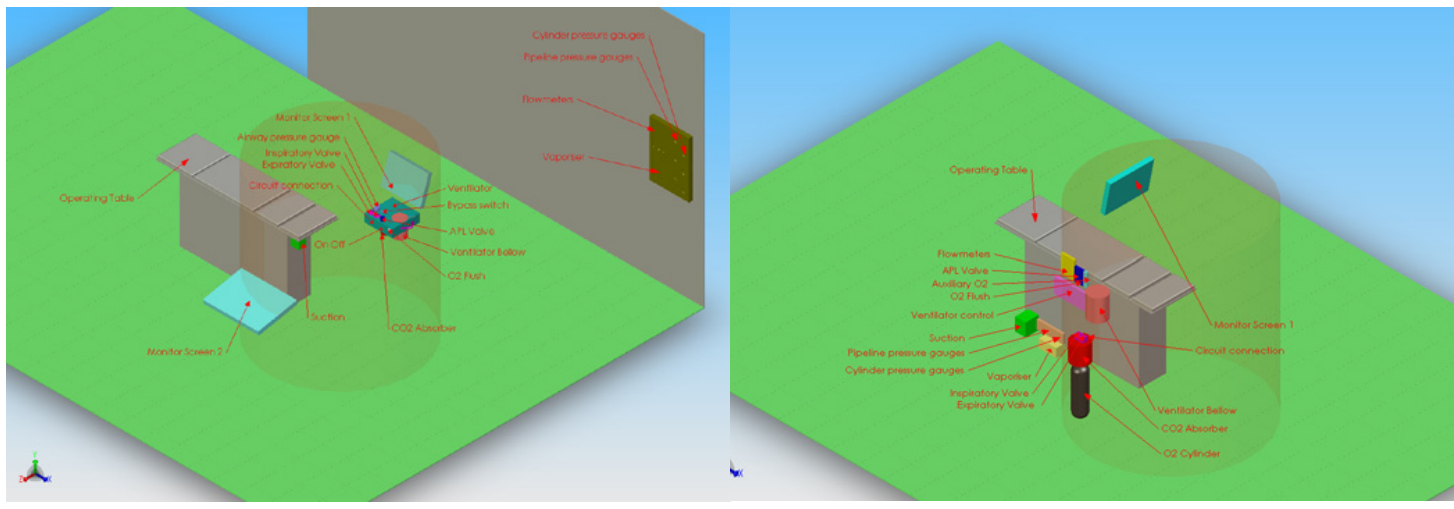

Fig 6.11 Component positions mapped into computer 

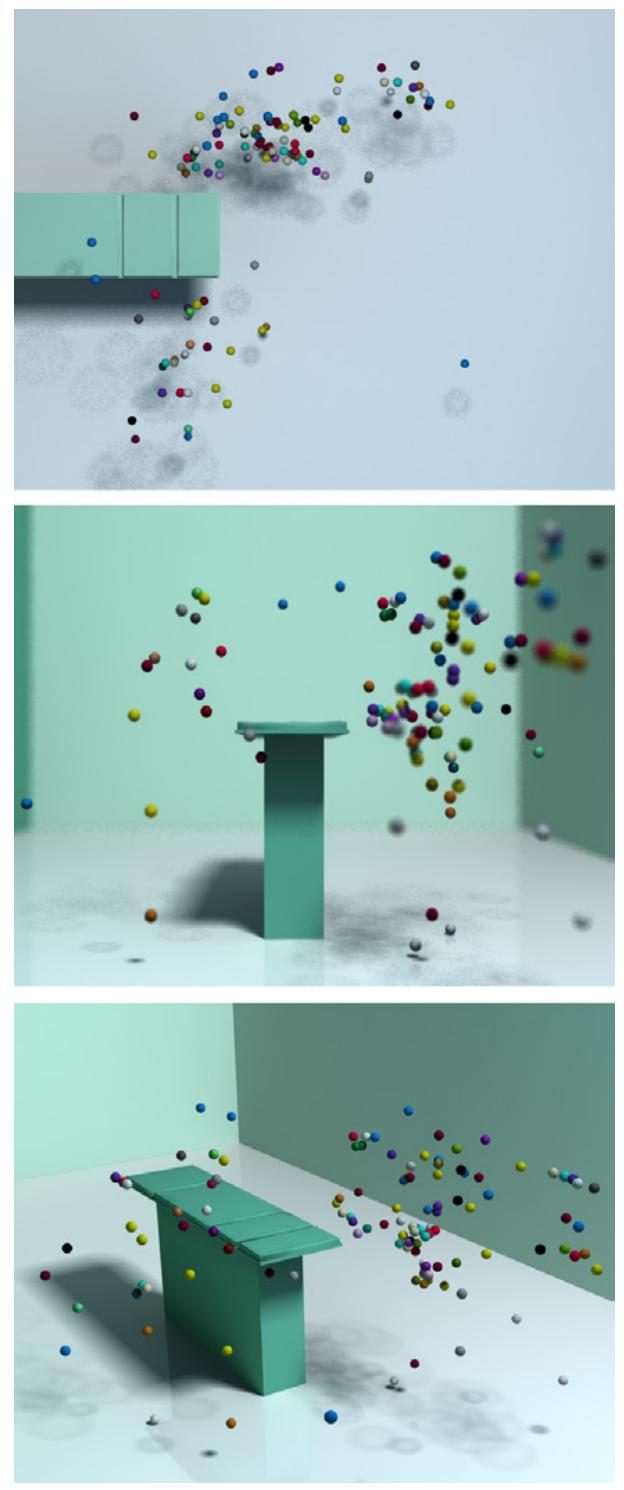

Fig 6.12 The prototype compositions are combined and represented here as spheres to show how participants envisage both the working space, and the equipment space, in relation to the operating table

its positioning (Figure 6.12).

- Component hierarchies

\section{Measuring and mapping the prototypes}

\author{
Static Analysis
}

As each prototype was transcribed onto the computer, components were given an associated name and mapped in a Cartesian coordinate system of $x-y-z$. The reference point was the operating table. This provided a schematic that could be animated and viewed from any position. Correlations (clusters, patterns and themes) between preferred positions of components could be ascertained in two ways; first as separate entities in relationship to the patient and the environment; and second, in comparison with other participant's prototypes (Figure 6.11).

- Component clusters and patterns

The $x-y-z$ maps provided evidence of patterns. The most obvious was the tactile and visual arc from the participant position during induction formed by components. Second to this, was the negative space of occupation. The components were initially replaced with simple elements of the same form i.e. spheres and colour coded. This provided a composition that clearly demonstrated the need for equipment that is dynamic in both its machine physiology and

Deducing a hierarchy of components is difficult, as the obvious are the close proximity of tactical controls and activities to the participant (in relationship to 


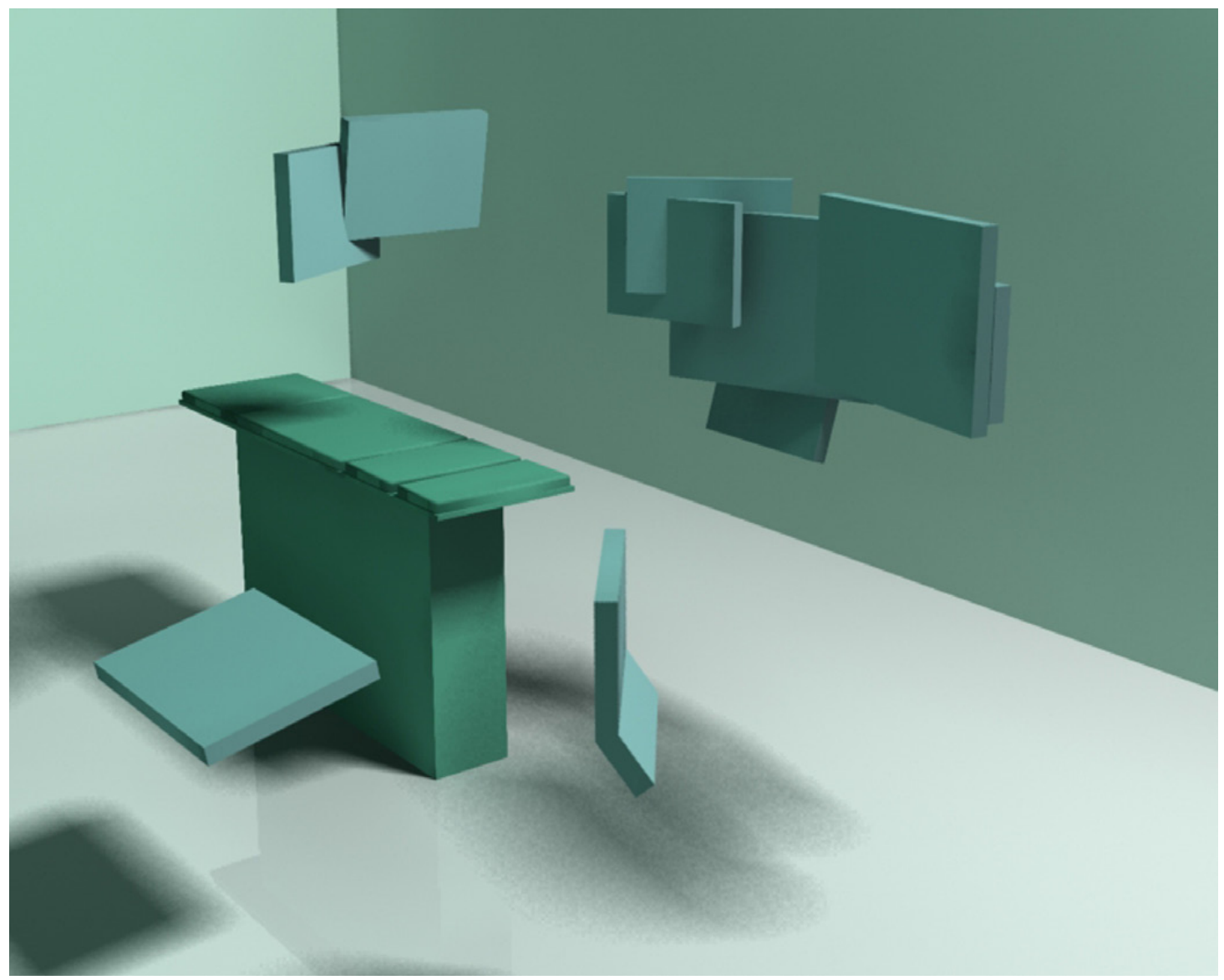

Fig 6.13 The screen positions by all participants are shown here combined, this demonstrates both a desire for traditional right hand viewing, and more novel approaches in above patient screens, and monitoring stations

the patient). Components were nested very carefully by many reflecting the form based considerations of early apparatus. $80 \%$ of the concepts were without table or storage, and capable of easy manipulation into a narrow range of use and view in comparison with established machines. Other similarities in concepts (20\%) existed in location of a secondary 'monitoring' position that included screens and controls (Figure 6.13). These were designed as withdrawal stations by participants who specialised in cardiology and longer cases. Wall screens were also designed that relayed information to the theatre team to share information (Appendix 3).

Graphical representations of component clusters were used rather than statistical evidence. Benefits of statistics would be in providing guidance as to the number of participants required to attain a sufficient range. While the method allows for statistical measurements and absolute placement of components, this is not part 


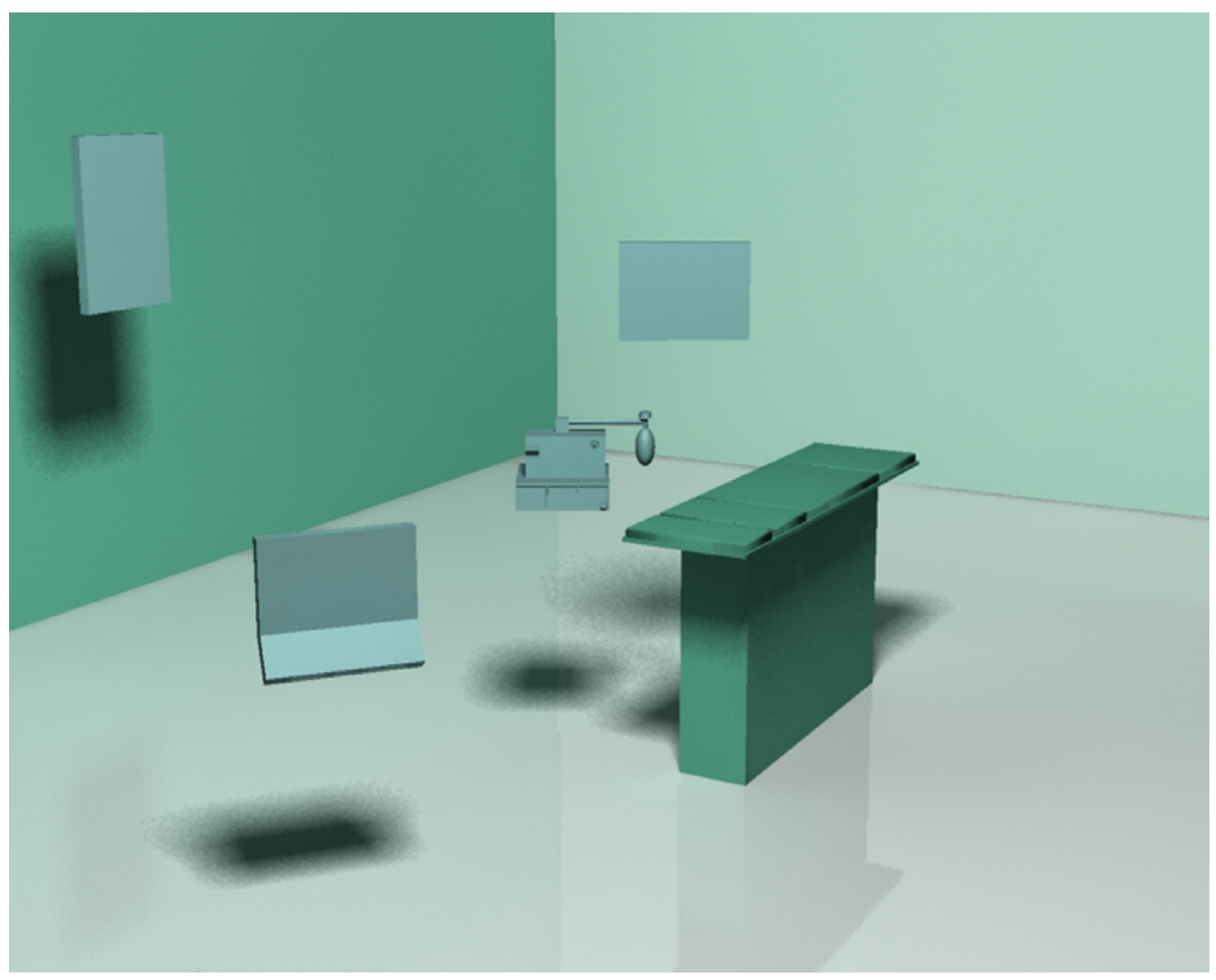

Fig 6.14 One participants general layout where three screens are utilised. An above patient movable screen for close proximity, an 'on wall' screen to share basic information, and a withdrawal work station screen where progress can be monitored during the operation.

of the experiment's criteria. If applied it would contradict the essence of the study and the hypothesis of looking for indications similar or contradictory to the established (Figure 6.14).

\section{Dynamic analysis}

The video recording was extremely useful as a commentary, and allowed a more precise understanding of the participants' design ideas and rational. The experiment recordings revealed the participants' desire to control their workspace environment according to their speciality. This happened in three ways. First of all, to push or encroach into the surgical territory gaining a superior tactile relationship, direct eye-lines, and screen viewing/interaction proximity. This was achieved by either articulating screens over, or adjacent to, the patient and making the machine smaller so as to 'nest' closer to the patient (akin to the apparatus of the past) therefore reducing body rotation and the loss of visual 
contact with patient, surgeon and machine. Second, pushing back was done to provide a better visual perspective of the operative team. This occurred by designing a seated tablet based work station to withdraw to. This was a slave system to the master machine where patient management could occur during longer cases. This reflects the desired need to free up the operating environment close to the patient, yet enable control of the area. It suggests that the issue of sedentary fatigue, procedural awareness and visual contact could be overcome without relegation. Third, the mirroring of monitor information and pipeline data onto the wall as shared information, mitigating against an overseen error or equipment failure.

Acreage was a term used by some anaesthetists to describe how important and difficult it was to control the use of territory or space, to keep an area clear to move within and make allowances that this space is for more than one person. In the operating theatre, this zone becomes quickly infiltrated with equipment and is
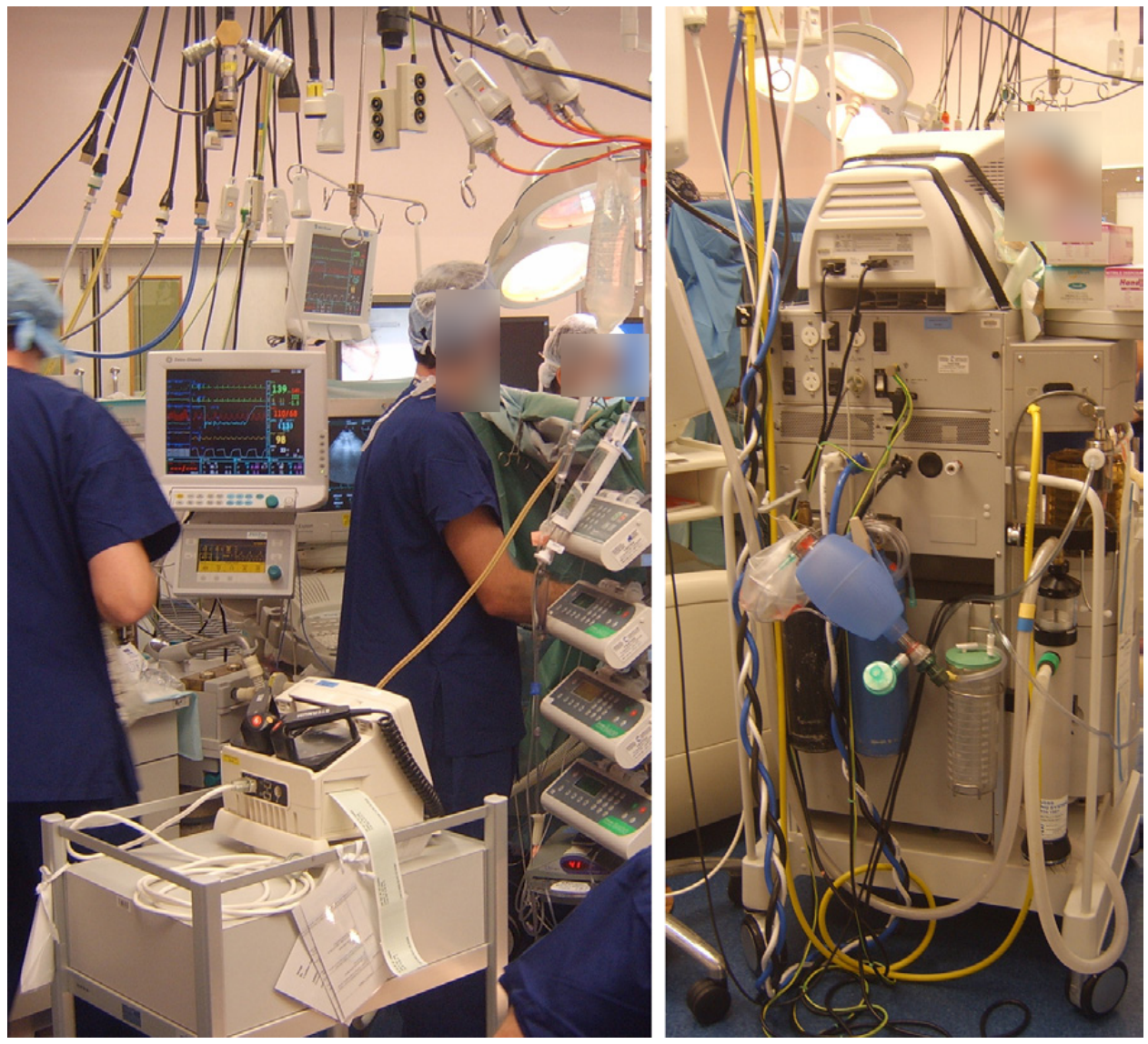

Fig 6.15 'Covered wagon' situation and the rear of a machine. Left, the anaesthetists are surrounded (clockwise) by the anaesthetic machine, trans oesophageal echo machine, operating table, syringe pumps and defibrillator. 
difficult to move within. Other industries are aware of this need for demarcation of space using floor colour or outlines; the operating theatre is too dynamic for this. As standard operating procedure and clinical approach determines layout, the anaesthesia machine, drug trolley and other equipment is used to stamp or control the turf, often in foresight of the perceived need or risk of unplanned intervention.

The machine is therefore used not only for anaesthesia but also as a boundary; this can prevent a 'walk through invasion'. Using the machine as a boundary exposes the rear and sides to contact. There are four sides to a machine and all are important, carrying equipment and visual status information, (i.e. do I have reserve oxygen, yes I can see the bottle and read the gauge). When other equipment of similar size is required, a covered wagon approach is inevitable with machines encircling the anaesthetists. Standing stationary, one or at the most, two sides can be viewed directly. Memory is used to 'see through' equipment, but this memory can only happen or develop through interaction. The front of the machine becomes a visual landscape, the sides and within, the memorable landscape (Figure 6.15).

\section{Participant feedback}

On the completion of all experiments, the participants were invited to provide feedback on the process and their prototypes. This provided clarification of the design models, and an opportunity to further elaborate on the ideas and how successful they were in realising them. A further point was the reinforcement of the relationship and value in their work. Rather than being used to demonstrate or test, this was about long term goals and a real interest in more than a research project. The interviews were greeted with more variation than the experiment. Some wanted to elaborate a lot more on their concept and talk about the possible technologies and what was going to happen next, a significant research buy in. Others showed little interest in follow-up communication. A point must be made that the profession under study is time deficient and gaining appointment periods can be difficult. The time between experiment and follow up showed no loss of knowledge in ideas. On the contrary, ideas of innovation seemed clearer than ever. These were seen as important by the participants, and rated on their own scale as innovations that seek to solve problems, problems that had been 
observed but not yet fully understood or recognised by the designer. These are powerful findings, as small innovations reveal the context of the problems and demonstrate the idea that prospective research has the capability to inform.

Was the experiment process useful for the participants? Many later commented on a refreshed view of their work environment, the situational ergonomics, and future technologies. Participants also commented on the limited training in ergonomic setup and adjustment, concluding that the 'see one do one' method meant bad setup habits could be passed onto new staff.

\section{Innovations in the experiments}

Each participant demonstrated a capability to innovate. We cannot measure the exact value of these innovations within this work but participants projected a personally identified problem with a design response. Each of the suggestions below can be seen as communication of real or perceived problems.

- Screens positioned to share both monitoring information and machine status i.e. pipeline pressure within the theatre

- Simple handles and methods of moving equipment

- Rests for components i.e. suction and the circuit

- Places to put auxiliary equipment including disposables in a system of 'clean' and 'dirty'

- Symmetry in machine design for left and right hand usage

- Respiration bag and circuit storage, a recoil storage system

- Touch screens with tactile feedback

- Easy transition of machine from place of induction to monitoring

- Screen based tablets

- Computer access to outside data e.g. patient records etc

- Listening and verbal devices including head up displays and data glove

- Blue tooth and wireless

- New types of conduit the has memory to enable more efficient cable 
management and setup

- Transformer like machines that expand and contract in size

- Anaesthesia and patient management should denote the architecture of the operating theatre

\section{DESIGN INSIGHT VS DESIGN INFORMATION}

\subsection{Key findings}

Time spent in the operating theatre allowed more than a 'supervised look' at activities. Seen as the anaesthetist's office, the operating theatre is both hostile to technological change and human capability. However a strengthened relationship and shared interest between designers and anaesthetists that was atypical of the clinical setting developed. Evidence from observations justified previous published studies critical of theatre ergonomics and equipment composition, although the 'activity complexity' and 'art' of anaesthesia differs between procedures and anaesthetists.

From observation to experiment, the simulation facility provided a neutral and well known ground in which to explore; while the method of making was simple, it was also achievable and recordable. Allowing participants to prospect with their knowledge revealed a range of desires, from traditional analogue to high tech tactile interfaces, from small 'transformer' like machines to more complex systems that were ambidextrous, from unique innovations for dealing with cabling to withdrawal stations with seating-based control panels and worktablets.

Participants arrived with concepts and ideas that were well established over time. While simulation scenarios showed up missing components, all were resolved. The established form of the anaesthesia machine dating from its change from apparatus to table was contradicted by the experiment outcomes. This is an indictment of the established and a three-dimensional criticism of environment use and component arrangement. Each prototype distinguished the problematic attributes of current equipment, the compromised hierarchy of ergonomic 
use and component heuristics. In all, it revealed a wish for a more ecological approach to design.

The diversity of prototype designs would not be capable of designers working via second or third hand information such as photos, focus groups or conversations. This suggests that participants had brought new knowledge through a prospective method unattainable by traditional methods of translation. Each participant showed a capability to communicate and manage ideas in producing a complete three dimensional prototype. Dialogue from the video recordings was initially seen as communication on how something should be or where in the prototyping process it should go, becoming an ergonomic description. These descriptions are much more telling than first thought. First, they demonstrate the capability of experienced anaesthetists to communicate with naive designers; second, they show a cognisant awareness in verbalising intentions; and third, an insight into how a profession's knowledge is applied in visualisation.

Information gained from the experiment provided preference positions (component hierarchy) and a preference range (component technology). Removed from its quantified measurement these are graded as: mistrust (true analogue only), acceptance (digital) and tactile hybrids (electronic analogies). Similarly, some of the subtle reasons why and where components were placed revealed much about operating theatre culture and behaviour: fear, trust, hiding and sharing.

While anaesthetists were interested, willing and keen to participate, a later proposed initiative of a participant group 'build' was unsupported. This maintains the earlier comments by anaesthetists on the limitation of focus groups. This supports the traditional evolutionary and democratic design approach by industry and the external vision that anaesthetists are individualists wishing to tailor actions rather than follow rule based systems that are typical of digital technology.

Outcomes from this work must be viewed with caution in applying design changes, as while it seeks to answer the question, it is not a design mandate or plan for new equipment. It is rather a concept methodology that draws 
from many other methods as a partnership to inform design directions. This is supported by the design assistant's comment "while some solved problems others rearranged". Limitations in range and the number of participants to gain a statistically correct study would require a statistical model.

Future steps after this work would be to develop more effective test models/ prototypes, and gauge how much detail would be required to test the ideas promoted e.g. very small tactile membranes. Some solutions came from the participants on how to collectively share design ideas using a Web based portal to peer review each others' concepts. 


\section{DISCUSSION AND CONCLUSIONS}





\section{DISCUSSION AND CONCLUSIONS}

In an ideal world an evolutionary approach that incorporates the old and the new would be appealing. Economics speak against it. What excites an engineer is not always what excites

$$
\text { a user }{ }^{244}
$$

In the eyes of some engineers the evolution is over. Patient safety has acted for over 30 years to rectify the deficiencies of mechanical and electronic devices. Now that digital systems have arrived, this signals the end of the analogue evolution of artefact and art in anaesthesia machine operation. However, the evolution continues for ergonomics, anaesthetists, and machine form.

\section{Discussion}

Fieldwork, observation and experiment were applied as actions to test the established composition and form of the anaesthesia machine. The method was penned in Chapter Two as a prospective search through which an understanding of design through time and reasoning for alternatives could be established. Cultured by relationships with anaesthetists and simulation, the method was refined consolidated and applied in a test. The discussion will take this one step further, in integrating artefact, method and methodology with the hypothesis of an industry derived evolution.

This chapter discusses the outcome of these contemporary actions upon a null hypothesis. The results of these are interpreted with literature findings to account for the incongruities in the outcome. Exhibiting these connections accounts for why we have what we have, while what we could have is expressed by looking at the design relationship in a new way.

244. Jeffrey M. Feldman, comment on STAMEMBERS@LISTSERV.ARIZONA.EDU(Society for technology in anesthesia, December 9, 2006): (accessed 12/2/2007). 
To achieve this, requires the identification of four affecting actions that have impacted on the designed outcome (the anaesthesia machine) and the design process:

- First, this requires setting out to disprove the established design doctrine.

- Second, revealing where changes have been made that have impacted on machine form (form follows habit - becoming habit following form).

- Third, how have these actions (changes) become comfortable to industry and acceptable to users, and therefore seen as safe.

- Fourth, what actions can be taken to address the problem and the significance of this, can we push the evolution (inside out) through concepts?

\subsection{Disproving the hypothesis}

Setting out to disprove the established.

From early apparatus equipment to today's workstation, the form and composition initiated by Nissen Deacon has become transformed by manufacturing methods and technologies. Yet through this seventy year span it still resides in the same dressing table guise. This form is now a given for many manufactures as a proven method of providing technology and control in the administration of a task. While 34 years of ergonomic studies have contradicted this, little action has been taken; meanwhile engineering has developed its own habit based habitat within the anaesthesia machine - in their own interpretation of needs.

In testing a design evolution, the methodology of safe iteration as a hypothesis is evaluated by applying user knowledge and experience. When 9 anaesthetists were challenged with prototyping their ideals, the results showed little correlation or affiliation to the conventional design. The established design evolution may masquerade as a democratic solution but not one of the anaesthetists desired it.

Why were the results so different from the established, and also different from each other? Distinct attributable themes can be drawn from the prototypes in 
the wish for better placement of screens (patient monitoring), the integration of wireless technology, smaller/lighter/mobile equipment, and a closer proximity to the patient. The participants were all specialists with many years of experience, and each has areas of procedural sub-speciality (e.g cardiac surgery, vascular surgery and plastic surgery). Thus concerns, or problems addressed in the experiment are singular and seek to solve individual and independent issues; this is not the consensus that a designer would be tasked with. Exploring the commonalities in the light of activity, each participant endeavoured to account for the procedural goal, environment and operating team. Therefore, the physical may not be transformable, but the consensus of requirements may be. These requirements are echoed in observation, and freedom to move, see, and communicate. Speculating that the prototypes could be cobbled instantly together as a new product is a dangerous assumption. The results reflect common threads in a new design criteria, rather than attributes to be manifested in a new design.

The commonalities between the prototypes far outweigh any suggestion of similarities to tradition. Boquet's study used tradition as a starting point, analysing the interactions from captured data and the then current equipment, whereas the data in this experiment came from the participant's captured knowledge. It should also be recognised that a potential margin for variation exists in this study in the form of user habit, personal taste or user-centric nuances. In Boquet's case, established use patterns from equipment were already speculated as ergonomically deficient by Drui. In focusing on physical form, the themes between experiment prototypes, Boquet's concept and Cooper's machine reveal more similarities to Boquet's conclusion. This is due primarily to the prototyping method and the experiment's aim to concentrate on component composition. The simulation debrief revealed and discussed additional information that could be applied to move the prototypes towards Cooper's work as interface and interactions between anaesthetists and machine control, unable to be prototyped within the method. Having few case studies to make comparisons with, and little change in seventy years, limits any outright winners in projecting what we could have.

Although there is a common method of machine use, anaesthetists may still 
work like the early administrators applying 'mask and bottle till it feels right'. This suggestion is strengthened by observation; anaesthetists demonstrating commitment to the procedure, safety, and patient physiology - not to equipment and technology, questioning or ignoring quantified data and technology with qualified judgement.

Returning to the hypothesis, an evolutionary design approach from industry does not meet the wants of users, but can be seen as sufficient to meet well trained needs. This suggests that anaesthetists can adapt their use of machines safely. How much adaptation can users accommodate before a danger exists in the very adapting of equipment? The activity of operating theatre customisation was observed as a design deficiency or design signal in equipment use; dispersing into the complex multidisciplinary team working in a constrained environment as a turf war. Schwartz captured these workarounds, calling them jury rigged solutions or design problems. To the designer, these are opportunities that can be used to suggest design solutions. The experiment captured them as design concepts. The prototypes strove to solve the logistical problems in either separation of an anaesthetist's position during the procedure between intubation and monitoring (longer cases), or reduction in size and increase in capability to 'close in' on the patient to open up the environment.

\section{The method}

Prototyping can help to iteratively define and validate an innovation or change, to test a hypothesis that is formed through observation. It is also a method of researching, creating different sets of conditions to learn more about a system. A further closely related option applied to the study, is to use prototyping to gain answers when the questions may be difficult to articulate or are still in the discovery phase. This option states that either the investigator is not an expert in the field, or is searching to overcome an assumption in seeking further evidence through new methods.

As a design method, prototyping provided a measurable result in physical terms and a qualitative outcome through the designer/participant and participant/ method relationship. It also evaluated simulation as a rudimentary design tool, together resulting in a searching test of the hypothesis and evidence for the 
continuance of research into this problem. Rather than identifying the problem repetitively with ever more complex tools, the method findings suggest directions - a need for a deeper conceptual investigation, not based on criticism of the established machine, but on the user's ability to keep up with Moore's law.

If the designer is an engineer, focus will be on the result of testing engineering concerns, rather than the relationships in testing. Engineers' solutions focus on the current and not on the future, and suggest that an innovative evolution of machine technologies will bring development to anaesthesia delivery, not the user. Therefore, in returning to the early suggestions of prospective and prospecting, engineering is seeking to solve society's physiological problems with technology governed by constraints, while ignoring the professional, institutional and ecological activity. A solution for today but not tomorrow, suggesting assumptions will continue in parallel with an evolutionary approach.

\section{Concomitant research}

The early proposition of evaluating simulation equivalence and Boquet's method through video recording were denied by issues of consent. Beneath this decision lies a greater concern. Reluctance is due in part to the record keeping of events, a 'black box' capable of unleashing not only research data but possible repercussions for those recorded if procedures do not go to plan. Design was an unknown entity to healthcare gatekeepers who had traditional models of scientific research as precedent. Difficulties arising from accessibility and methods of observational recording have been discussed in Chapter Five. In retrospect these should not be seen as insurmountable difficulties. But a valuable relationship to understand, clarify and acknowledge the clinical, social and ergonomic conventions governed by our time. In establishing relationships, the hypothesis has been guided through negotiation, providing 'sharp end' commentary and participation. Negotiation can prepare a healthcare institution as a design partner, but too close a relationship may also impact adversely on the aims and outcomes of the research.

The constraint of denying real time recording, may be cautiously overcome in future by simulation and scenario modelling. This measurement of equivalence requires a context comparison not a scenario recording - a task that I now 
recognise as suitable for the simulation expert. Tampering with the preconceived study ideals by the healthcare relationship, unconsciously negotiated out the testing of Boquet's reactive (i.e. reaction to the established) design approach. This has helped to manage the study, in avoiding collecting data that would have led to a conflicting juxtaposition of analytical bias and prospective aim. Instead, this has directed the search to design, simulation, and the wisdom of users.

Researching history impacted not so much on the aim, hypothesis or need for the experiment, but the unrecognised capability of clinicians in this paradigm shift to new technologies. Additionally, this has afforded a better understanding of elite professions and institutionalism, and how this has grown through clinical research to reveal error and its moral partner blame. These findings have installed a significant empathy and understanding in issues of consent to observe and ask.

While the relationships with the blunt end impacted on the study objectives, the sharp end and simulation impacted on methods. Cementing a relationship with a profession was acted on after the discovery of ergonomic origins. A similar knowledge deficiency was unearthed within the profession alongside a simmering disenchantment with industry design goals. Operating theatre conversations revealed satisfaction and admiration of design, but it was always about a particular component or technology as singular entities, whereas other components were viewed with distrust and frustration. The magnitude of ergonomic traits discovered through background research, became usable knowledge in observation, often revealing ritual. This adoption of technology and manufacture could easily be misunderstood and naively acted upon by designers.

The experiment demonstrated the capability of anaesthetists to transfer knowledge through verbal and physical description, as cognitive communication between expert and clinically naive designer. With low resolution prototyping, these descriptions are capable of being iteratively stepped up to working prototypes using the prospector/designer/simulation relationship.

Designing with simulation is a strategy that allows elite professions to facilitate and guide design. The result for designers may be a more empathetic and 
comprehensive understanding, assisting in calibrating design assumption to context and use. This is a qualitative approach. But so are the many actions and habits of anaesthetists within the operating theatre, due in part, to the evolutionary composition of the anaesthesia machine. Alone, simulation is capable of delivering innovative results. Enlarging the design team with human factor specialists could add more rigour. The concern here is: what is to be scientifically measured and why. As a prospective search, these results, as data, may provide little in the creation of new ideas.

\subsection{Form follows habit and habit follows form}

- Revealing where changes have been made that have impacted on machine form.

The notion put forward here suggests that form followed normal use in the design of early hand held equipment. The folding of a handkerchief followed by the complex user inspired design of the folds in a cloth. The design of a mask that happens to fit a top hat, and the close fitting Junkers inhaler, all had their faults but were conceived to fit between patient, user, and the technology of the time. These artefacts are not based on form following a function, but form following new technologies and the need to physically and cognitively apply them.

Normal use patterns established with the mask and bottle were translated to the apparatus as form, following established habits. Design ergonomics prescribed to the need to see patients physiological affect as part of the task, in effect the need for physiological data. The close proximity of the apparatus was then literally transcribed to a larger and deeper table format, retaining the left handed normal use configuration. By installing this new layout in a right handed location, anaesthetists were forced by industry to adapt. Observation and literature identify that anaesthetists have failed to adapt, but have instead adopted, taking ownership of this evolutionary design shift and the problems that it has brought.

While much could be condemned of early apparatus if we applied today's human factors tools, design with all its methodologies and analysis has not significantly moved on - still denying adoption over adaptation. While new technologies could solve many of these problems, they may also exacerbate them, caught in an 
evolution of adopted habits, manifested in a form future proofed in the 1930s.

Form has been guided by technology. Components have been assimilated and partnered in a plastic landscape, burying inter-component connections whilst revealing data and controls. This is the surface of industrial design, a surface following society and the healthcare doctrine of sterility and purity, the clinical aesthetic. While this may appeal to a hospital's aesthetic and the conveyance of safety through style, the homogenised (democratic) apolitical aesthetic says - I can do no harm. This contradicts an industrial designer's moral intention and we may ask why in this instance that industrial design, although alinged as a capable partner with much to offer, is equally trapped in its own qualitative evolution between users, society, regulations and the purchaser.

Designed plastic structures are capable of communicating intended use and therefore a physiology that can be read, yet current design dogmas are endeavouring to replicate the interface of 100 years ago as a dressing table. Design must challenge this evolution with new ideas that may be passed onto those who can make it debatable if not achievable.

\subsection{The safe precedent, or form as a safe precedent}

- How these actions (changes) have become comfortable.

In continuing to produce machines based on an accepted but now redundant format, industry is subscribing to a set of design rules implemented by the constraints of society and regulatory bodies. Recognised as tried and true, safe in being a known entity, this form has been adopted but not requested by anaesthetists. Giving fairness to this design methodology in the light of 'if it works don't mess with it', design is now forced to chase its tail in the implementation of new technologies.

Designers, in recognising problems, may find that the solution is to iteratively refine the form, not jeopardising the usable while working to slowly change enforced habits. Instead, the form has remained as a safe precedent and refinement is seen in providing intermediary surfaces that fold away and screens that can swivel. This is comfortable design, yet even these small changes are risky in an industry under surveillance, as they are often teamed with significant 
digital interface changes. These are the changes that really have an effect at the sharp end, not in procedural variation or new knowledge but information that is presented and interacted with in new ways. These changes cannot be carried on the back of a safe and traditional form, having drawers and a table does not provide any more confidence and if this is intended, may be dangerous.

The Kion demonstrates an in-between approach; some new, some old, tradition embellished with an clinical design aesthetic including an innovative ventilation column based on well intentioned 'design intuition' to a recognised problem. It proved an inaccurate perception of needs. While it may have looked $21^{\text {st }}$ century, in use it carried many flaws of a concept product and a disregard of the 'craft' of anaesthesia; capable in the consumer world but dangerous in the operating theatre.

Dräger is one company to have acted on inherent ergonomic problems and set out, initially in the purchase of the Physioflex and later the design of the Zeus to confront these issues. Dräger machines are unique from model to model especially when compared to GE. The limited success of these machines outside of their manufactured country possibly reflects on the users' part in accepting an iterative global design.

The experiment demonstrated a request for change yet the greater anaesthesia community have stuck with tradition. Reasons may be held in the relationship with a known form, a cultural bias, purchasing directive or cost. These may be dismissed in returning to thinking physiologically and the users' relationship with knowledge provided by a known interface rather than an understood form. The experiment showed that the participants rearranged components and dismissed the established form, rather than redesigning technology. This in effect, demands a prototype that retains known knowledge, and also seeks to overcome the very problems that are at issue for anaesthetists.

Participants identified that they have what they need, but not where they need it. This suggests that engineers are implementing new technology concepts while industrial design is tasked with following, in packaging a predetermined, 'seen to be safe' outcome. In following, the industrial design profession's growing 
capability to empathetically innovate is restricted to its historical status of commercial advantage through styled form.

The danger of assumed design advancement by placing a radical design into the marketplace, was a direct cause in the demise of the Kion. Design form being the greatest product identifier is implicated as an excuse for any lack of success in a new product. In reality, it may be the technology interface that threatens the company and the brand. Thus form is a safe precedent, safe in form, unknown in use.

\subsection{Pushing the evolution}

- What actions can be taken to address the problem, can we push the evolution (inside out) through concepts?

Throughout the study clinicians seemed blind to the future, new equipment was greeted by agitated surprise not relish. Opposed to this, in the experiments, many revealed an appreciation of consumer technology products. It could be deduced that the anaesthesia machine industry was not communicating through the overall design. Instead, by translating through a tweaked traditional form, possible evolutionary learning connections (in the technological communication of patient physiology) are lost.

This relationship with technology is a based on retaining a comfortable and known artefact, which is therefore usable. Doing so contradicts the recognised ergonomic deficiencies of reach, interaction, congestion and fatigue, validated in observation. In continuing along this path, industry is promoting the notion that problems can be lived with; co-existing with elite status, being ignored or seen as acceptable and impossible to design out, or finally forgotten.

Changes to this form are risky. The Kion presented a hybrid of table and column and succeeded as a design concept, but failed in the hands of the users who adopted habits from an institutional environment. The precedent studies have sought to question and instigate a significant evolutionary shift to address Boyle's residue, and the methodologies and processes of the design engineering connection. Hidden under the skin of new machines, but apparent in use, engineering is pursuing its own path and pushing a new evolution. By 
implementing many of the technological attributes of Cooper's 1978 concept, as task based information with little concern for the activity, responsibility is passed to and shouldered by the user.

Studies of criticism are not completely ineffectual; industry has recognised and reacted at a range of levels from denial to a complete metamorphosis, yet there is no communication passage to anaesthetists of what they may be using in ten years. Producing concepts may help to ease this dysfunctional design crossroad and presenting them outside of the closed doors of industry may allow for discussion and validation. Just as Boquet wished to apply his methods to Cooper's study, medical simulation at an advanced level can go several steps further and act on anaesthetists' knowledge. This will not instantly produce the best product but will raise the bar, connect professions, develop truly contextual or tailor-made methodologies, and lead to a safer activity for both the patient and the anaesthetist.

Essential to any future design concepts are methods to recognise, understand and attain a technological and physiological transparency. Relative to but independent of the prospective methodology, the outcomes here provide clues for conceptual case studies where the experiments could become working examples - an arrestment of complacency. Anaesthetists have demonstrated a capability to communicate both ideas for today and far-sighted blue sky thoughts - these should not be lost but acted upon.

Cooper tailored the critical incident technique to establish causes of mortality and morbidity, and then acted on the findings as a communication of future possibilities. Similarly, designers need to develop tools to move forward beyond superficial assumption and problem identification, to active communication, collaboration, evaluation and change.

\section{CONCLUSIONS}

Stunning success and appalling failure are arrayed in contrast to each other. It is in this 
setting that discussions about patient safety are now taking place ${ }^{245}$

\subsection{Conclusions}

In the prelude to the 1998 National Patient Safety Foundation Workshop, the National Health Care Safety Council applied a quote from Dickens to the paradoxes and contrasts in healthcare. ${ }^{246}$ Jeff Cooper in 'This is No Humbug' relays a similar theme that he has learnt to acknowledge 'that you do not see a problem but a solution'. ${ }^{247}$ In this study the contrast is projected on the intimate role of concomitant design; while there resides a need for today, designers need to see beyond the practitioner's interpretations to question the established and provide insight.

Humanity continues to demonstrate resilience to technological change, yet it struggles to relinquish complete control of decisions. Even when prompted with conceptual ideas, prototypes, and test models, boundaries will continue to be discovered in error, and reacted against if professions continue to work around each other. The study advocates that risk goes hand in hand with industry calibrating their assumptions, - assumptions based on their interpretation of hindsight and a calibration measured by technological information (data). Anaesthesia has had far fewer pharmacological developments in the past decade than in the previous three or four. New drugs or methods of administration for anaesthesia are now relatively rare. Any future advances in anaesthesia may now be dependant on the applied use of technology, be it existing or future based.

More 'assumptions' are required, founded and tested on the objectives of anaesthesia and its administration, built on a calibration of the technological transfer of knowledge. A system is required that includes established and postulated knowledge in anaesthesia, tools of simulation, and industry willingness to invest, share, explore and educate.

245. Cook, "A Tale of Two Stories,"

246. Ibid,. ; Note: It was the best of times, it was the worst of times, it was the age of wisdom, it was the age of foolishness, it was the epoch of belief, it was the epoch of disbelief, it was the epoch of incredulity, it was the season of Light, it was the season of Darkness, it was the spring of hope, it was the winter of despair, we had everything before us, we had nothing before us, we were all going to Heaven, we were all going direct the other way - in short, the period was so far like the present period, that some of its noisiest authorities insisted on its being received, for good or evil, in the superlative degree of comparison only. Charles Dickens, A tale of two cities, 1859.

247. Cooper, "An accidental life: patient safety and biomedical engineering," 377-419. 
Early anaesthetists were steeped in innovation and error; yet arising from this was a design mandate present in a physiological relationship. This has been eroded by an industry bias implementing their ideals on a profession. In not addressing environmental ergonomics and Sleek $^{\mathrm{TM}}$ amended deficiencies in this hostile environment, an elite profession is pushed into new habits. Designers and engineers have failed to recognise the needs of the activity; laying anaesthesia at the door of society awaiting judgement, with anaesthetists bearing the responsibility as a form of technological inadequacy. This also implicates the culture of the medical profession and its elite obsession that thrives on institutionalism and barriers. Design has chosen to act in denial and collaborate with dogma, avoiding many issues. By hiding behind regulatory (engineering) constraints and not recognising user error (as slips and lapses), ${ }^{248}$ design methods fail to proactively generate, debate, evaluate, and communicate concepts. Industrial design should actively engage in idea facilitation with anaesthetists, rather than its current engagement with aesthetic style and function. This is not a negative criticism, all too easy to make in hindsight, but a reflective critique established within the focus of this study.

Within the scope of the study, industrial design is seen to lack evidence and thus power, due in part to its own institutionalism, contributory nature and lack of clarity in publication. To realise its role, industrial design requires partnership, design leadership and its own set of methodologies and interpretations to complement those of other specialties.

Significant in this work is investigating and recognising how anaesthetists perceive and are perceived. Joseph Clover demonstrated his capability for clinician empathy in his innovations, not as personal products but as a design perception. Whereas Edmund Boyle's design was limited to his peers' schema, with industry taking on the role of clinician empathy to create a design precedent (mass production specification) and a design standard represented through brand. This in turn has accelerated within an engineering-centric philosophy, to give us what we have.

A further outcome from this work is the reflective finding of participant selection, a precipitative method to recognise those with characteristics of 248. Weinger, "Anesthesia equipment and human error," 322. 
innovation or perception. These are not lead users or renowned anaesthetists but the workaround adapters, clinical thought leaders, simulation experts, and designers acting to harmonise the irregular forays into new concepts. This design collective may be a somewhat idealised view but this ideological belief reaches over 'democracy' to understand and to be prospective in innovation. Applied to healthcare, this goes far beyond usability to produce a dignity for society that encompasses both patient and practitioner; returning to our earliest quest of applying the sensitivity of humanity to technology.

The definition of an elite profession may be in doubt, if and as the tools of work come closer to the actual task, in the way they think, communicate and deliver. It is the notion of procedural craft and art giving way to empowered physiological tools. Attaining this transition requires a relationship based on observation and reciprocal interest, not knee-jerk measurement, in projecting how we might develop and apply technology in envisioning for others.

The experiments have shown capability to progress towards a methodology that may communicate a range of design possibilities, including the hope of producing conceptual equipment to enlighten the anaesthesia profession to forthcoming technologies. In the evidence of capability and diversity from a small sample group, there are some similarities and some disparities. There is no contemporary tradition, no replicas or unfeasible concepts, however strong criticisms of the established were voiced. I did not ask participants for evidence of their errors, mishaps, or failure. Rather I have taken the approach that these events belong and remain the anaesthetists', and that these memories may be revealed in their concepts. A surprising outcome was that anaesthetists responded with a greater level of criticism of the environment and equipment they worked with. The experiment had helped both researcher and participants to understand their habits and isolate design issues with new clarity.

Through building and articulating information, each prototype becomes unusable for anyone other than the maker. Each concept had emotional attachment, meaning and maker knowledge that only the participant could translate. This is due in part to the low resolution prototyping method. This is how the ideas from the engineering discipline are required to be translated by design through 
machine structure, component form and graphics - to become usable in human interaction. It reveals the importance of historical habit and the task of design. Is the concluding directive a new question, in determining what level of resolution is required where we can test concepts with other users? Does user knowledge thereby become transparent in the design and to others?

In starting this study I asked the question 'why do we have what we have and what could we have'? I could now refine the later part of this, in having achieved several steps towards a new approach, to ask 'how could we have'? It may be it is not a solution we are looking for but the right way (or process) to ask the question', to manifest a new answer in a format that is useful to designers and therefore society.

In noting this, the study should now lead onto realising the postulated ideals of 'what could we have'? This part now resides with industry for a future collaborative initiative. This is a reluctant criticism in the capability of the study. First in its academic level, second in the need for experts in digital and interaction technologies, third the need for industry collaboration, and finally the prospect of a financial commitment well beyond this work. 


\section{APPENDICES}

\subsection{Appendix 1}

\section{Experiment brief PROTOTYPING WORKSHOP: THE ANAESTHESIA MACHINE}

\section{Principle Investigators}

Bernard Guy, BDes, Lecturer, Victoria University. School of Design.

Dr Brian Robinson, PhD, Director, National Patient Simulation Training Centre

Dr Paul Dally, FANZCA, Specialist Anaesthetist, Wellington Hospital

8

Address for Correspondence

National Patient Simulation Centre

Wellington Hospital

Private Bag 7902

Wellington South

Phone: 3855999

Fax: $\quad 3855879$

\section{Research Title}

Anaesthetists informing design: improved ergonomics and usability through component composition.

\section{The Project}

\section{Aim}

This project aims to employ user participation and simulated anaesthesia machine components to address the question: can anaesthetists provide information into the composition and arrangement of components to explore usability and increased ergonomic capability?

The project hypothesis is to test whether anaesthetists, given the components of the anaesthetic machine, would create anaesthetic machines different in comparison to the anaesthetic machines they currently use.

\section{Background}

New technology is expected to improve healthcare quality and outcomes. However the interaction between health professionals and emerging 
technologies negatively affects healthcare safety through inadequate design. ${ }^{1}{ }^{2}$ New opportunities utilising user participation and simulation, have been identified to develop collaborative design methodologies that investigate the human-machine relationship in critical equipment ${ }^{3}-{ }^{4}$.

This project will research the ergonomics of the anaesthetist-anaesthetic machine relationship as, from observational and historical research, ${ }^{5}$ this is an area with recognised needs. Manufactures have shown little evidential recognition in the design of equipment to accommodate the physical requirements of the operation theatre environment; procedure duration, anthropometric differences and user fatigue. Increasingly emphasis has been placed on engineering and screen based digital interaction. This brings about a condition where the anaesthetists must both physically and cognitively adapt to the equipment as the equipment is adapted to a variety of clinical situations.

The anaesthetic machine is a physical composition of components that present both operational controls and sensory feedback to the user. Little has changed in this structural form over the last 80 years as a result of iterative design. Limited future concepts in anaesthesia machine design exist. Only one research paper has been published in the past 25 years relating to the ergonomics of the anaesthetic machine. ${ }^{6}$

Manufactures are now creating anaesthetic machines that reduce the physical interactions, hide the machinery, and replicate these with computer generated screen based activities. This exposes an increasingly complex educational (training) and operational requirement on the users, as many new features are layered upon earlier advances. Consequently this masks the anaesthetists understanding of the machine safely required to operate in both normal and critical situations.

The questions to be asked, include why does this still look like a traditional machine when these functions are rapidly disappearing and what advantages can we bring to the user through investigation of the ergonomic or physical structure of the anaesthetic machine?

1 Kohn LT, Corrigan JM, Donaldson MS eds. To err is human: building a safer health system. National Academy Press Washington, USA. 2000.

2 Vicente K. The human factor: revolutionizing the way people live with technology. Alfred A. Knopf, Toronto, Canada, 2003.

3 Wiklund ME, Wilcox SB. Designing usability into medical products. Taylor \& Francis, London, 2004

4 Guy, B. Technology for Industry Fellowship CCHX0501. Probe affect simulation for critical equipment evaluation and design.

5 Guy B. As part of a postgraduate study the author is researching anaesthesia machine design. Operating theatre observations have shown a deficiency in design for the user, leading to awkward postures indicating fatigue and incompatibility of equipment to user anthropometrics, environment, task, and operation duration.

6 Boquet G, Bushman J, Davenport $\mathrm{H}$ : The anaesthesia machine: A study of function and design. Br J Anaesth 1980; 52: 61-7 
The methodology of participation design is not new and has been utilised by companies to gain first hand knowledge from medical practitioners ${ }^{7}$, it has not been applied to the critical nature of anaesthesiology.

\section{Research Design.}

\section{Ethical Approval}

Ethical approval has been discussed with the local Ethics Committee and is not required for this study.

\section{Method}

Nine anaesthetist specialists will be recruited as volunteer subjects. The subjects will be drawn from Wellington Hospital and Hutt Hospital. All subjects will individually attend a workshop.

Prior to attendance each subject will receive a booklet that outlines the study objectives, and methods. This will give them time to prepare, make notes, and think critically about what ideas they wish to pursue.

The prototyping materials and simulated components for the investigation will be constructed and tested by the research team in the proposed environment (National Patient Simulation Training Centre, Wellington Hospital) prior to the commencement of the workshop.

A one hour background session will introduce the subject to the facilitating designer and technician, the study objectives and methodology. Each anaesthetist will receive a set of polystyrene blocks representing components; this will comprise sizes relevant to, but not limited to; ventilator, $\mathrm{CO}_{2}$ absorber, $\mathrm{O}_{2}$ flush, anaesthetic agent canisters, rotameters, auxiliary $\mathrm{O}_{2}$, patient monitoring, etc.

The components will be pre-prepared in polystyrene, these can be adapted, cut and drawn upon.

The room where the subjects construct and test their prototype will be similar in space to an operating theatre, and this will include drapes, trolleys, and other theatre equipment. A manikin will take the place of a patient.

Each subject will commence by communicating their idea for arrangement to the facilitating designer who will then sketch out the concept (the facilitating designer is a third party, and not a member of the research team so as to avoid any bias). As the sketch concept is developed the components will be placed on stands or supported from an overhead structure at the requested height and position for the subject. The subject will be required to adapt their arrangement as they simulate reach distances, eye-lines, visibility and task 
relationships between patient, machine, and other personnel.

On completion of each concept the prototype machine and volunteer anaesthetist will undergo a 15 minute simple simulation. This will be recorded in both elevation and plan view on videotape.

When the subjects complete their concepts these will be stored and remain unseen till the workshop conclusion.

\section{Analysis}

The prototype will be measured and mapped dimensionally using a computer design programme to provide a preferential hierarchy of each component.

At the conclusion of the workshop all participants will present their concept and provide a design defence.

\section{Relevance}

The anaesthesia machine is a complex machine that interfaces both physically and digitally with the user. This study may indicate that users have the capability to demonstrate change, influence design, and improve the usability and ergonomics of equipment.

Outcomes

1. Can anaesthetists provide information about their interaction and the usability with the anaesthetic machine through 3 dimensional prototypes?

2. Is this information usable in either;

a) Radically new prospective designs

b) Small iterative design changes to the current arrangement

Conclusions may lead to a new design process leading to safer and usable biomedical equipment and development of a participation methodology for the gathering of user lead information. 


\title{
Participant Brief \\ PROTOTYPING WORKSHOP: THE ANAESTHESIA MACHINE
}

\author{
Informing Design through the Composition of Components \\ (Composition $=$ The act of putting together or making up by combining parts) \\ Wellington Hospital Simulation Centre \\ Victoria University \& Wellington Hospital Anaesthesia Department
}

\section{Design your anaesthetic machine?}

As part of an industrial design research project we would like you to become a designer. This only seems natural as you are the users.

The early history of Anaesthesiology is fertile in its user innovation, adaptation, and lateral thinking. Has the age of Anaesthetists designing for Anaesthetists disappeared completely? Can the user apply design to balance, and interpret, the rapid application of new technology.

Participation of end users in initial conceptual design may challenge current trends in anaesthesia machine design. The project aims to explore the development of design concepts; investigating future directions, and present new ideas for debate.

It is now time to consider your experience, challenge the established options, and present your ideas, opportunities and benefits in three dimensions.

\section{Workshop Focus}

The anaesthesia machine consists of a system of components that work together in operation to facilitate and manage anaesthesia. Many of these components have tangible interfaces (switches, knobs etc) that you interact with physically and 
visually at different times and frequency. Some items are interacted differently dependant on the user and procedure. How do you see this system working the best for you?

\section{What is expected?}

You will be required to build a prototype machine with the given components, these may be adapted. Think latterly, and explore alternatives. Reflect on your working environment.

\section{You are designing for yourself}

Explore how the components are assembled/arranged/manipulated to provide a personal composition. Realise there may be two anaesthetists at your machine, but, design for yourself. Be aware of your own physical attributes, reach, accessibility, visual sightlines, operation duration, and fatigue/posture.

\section{What will you start with?}

All the components will be provided as white models (cardboard or similar) the digital interface screens will be modelled and printed (these can be adjusted to provide additional requirements).

Capability will be provided for ideas that may not sit on the floor (pendant arrangements etc).

Compose with the assistance of the designers and technicians, a prototype that utilises the components provided. If you wish to substitute certain components in another ways stipulate as required e.g. digital etc.

A simulated operating theatre will be provided that will include many of the environmental fixtures denoting other personnel and equipment.

Time; you will have up to $1 / 2$ a day to complete your concept.

Your design concept must feasibly work and be tested (have all the requirements).

Do not digress into technical and engineering based issues. 


\title{
What tools will I have?
}

The designer and technician are at your disposal to realise your concepts.

They will:

\author{
Assemble components to your directions \\ Produce parts to support components \\ Adapt components
}

They will require details when adapting or making parts. The construction and assembly methods of components will allow for changes.

They will not design for you.

They will require direction.

\section{Will I have a scenario or procedure?}

Your anaesthetic machine must provide capability for all procedures. You may additionally develop a particular attribute or design for a certain procedure/ environment.

\section{The Workshop}

The construction of prototypes will be undertaken with the assistance of a model-maker technician. All equipment will be provided.

\section{What will I need to bring?}

Your ideas, either as notes, sketches, or images 


\subsection{Appendix 2}

Experiment materials

Component list per participant

Polystyrene Medium density

All dimensions mm

SHAPES and SIZE

Cylinders

200dia x 250

200dia x 200

60 dia $\times 200$

23 dia $\mathrm{x} 200$ or 100

Cubes

$75 \times 75 \times 75$

$100 \times 100 \times 100$

$150 \times 150 \times 150$

Rectangles

$100 \times 100 \times 25$

$200 \times 150 \times 50$

$120 \times 150 \times 150$

$300 \times 23 \times 50$

$420 \times 350 \times 50$

$700 \times 500 \times 50$

$350 \times 350 \times 100$ 


\subsection{Appendix 3}

\section{Experiment compositions}

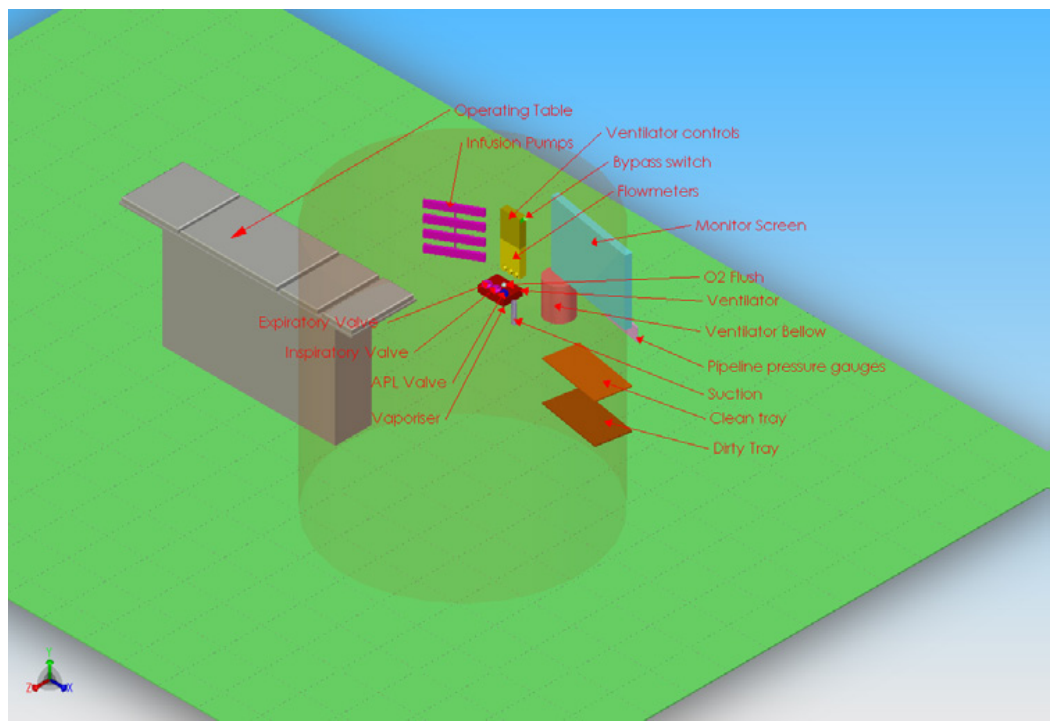

Fig 8.0 Planar composition, dedicated clean and dirty trays, rotates as two parts to facilitate left and right use

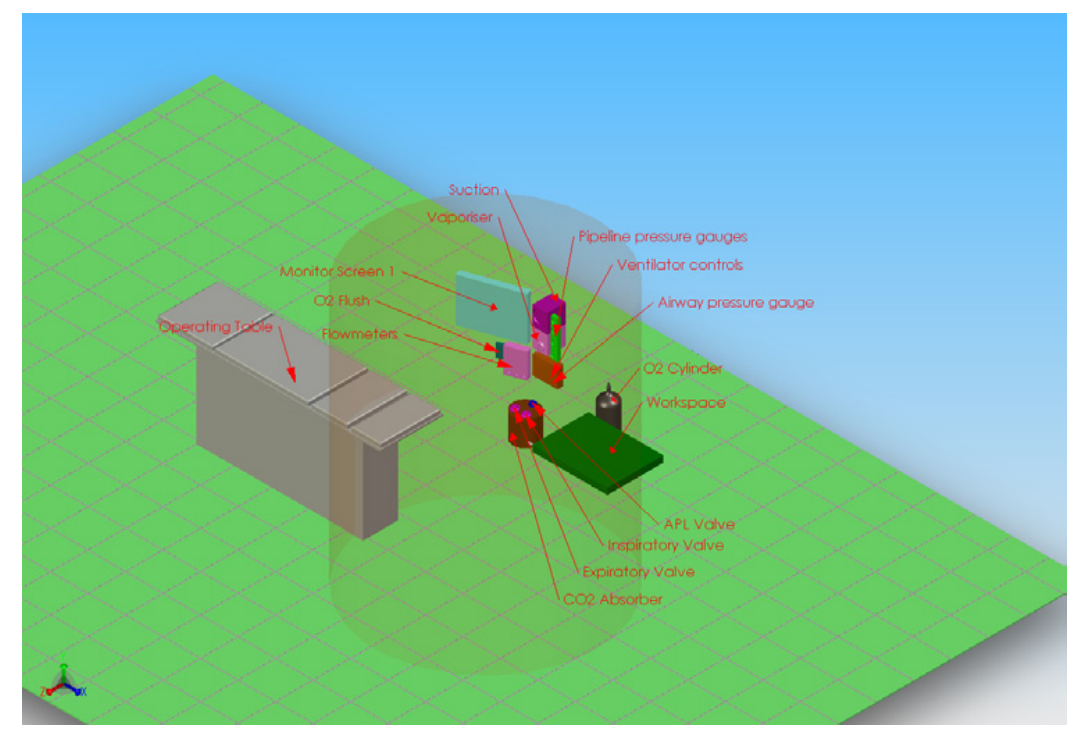

Fig 8.1 Interface controls brought forward by placing work-space table to the side, controls rotate around table for left and right use. 


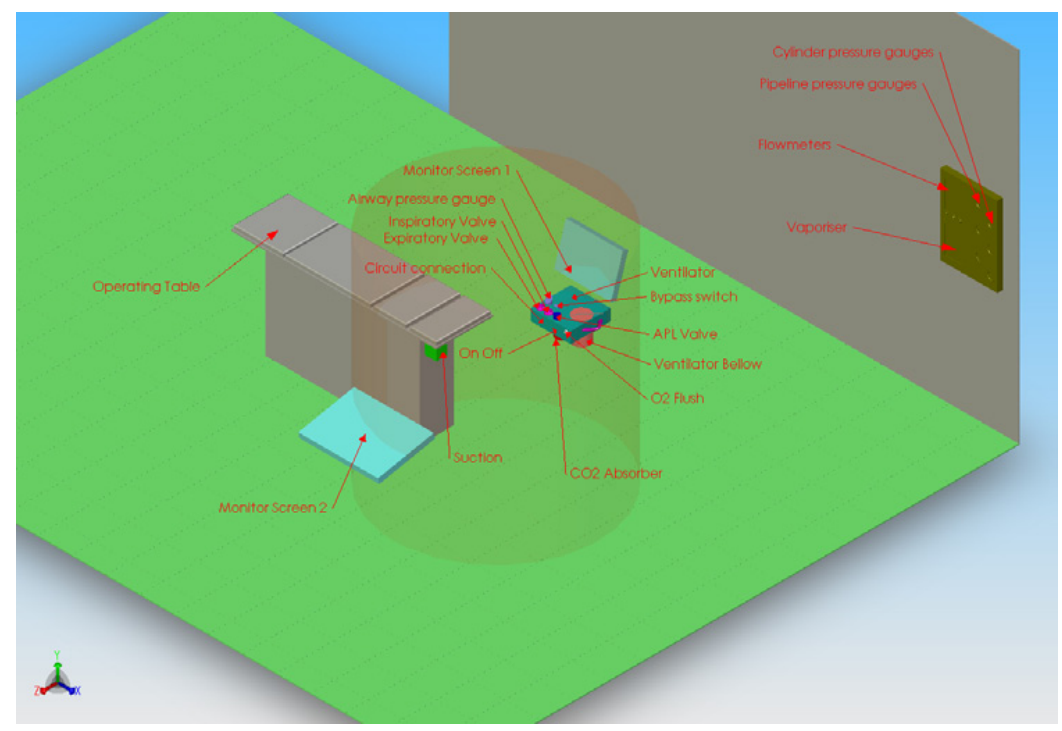

Fig 8.2 Small nested components with on wall interface (analogue) to share basic information, screen 2 is a monitoring 'tablet based' workspace with control of machine.

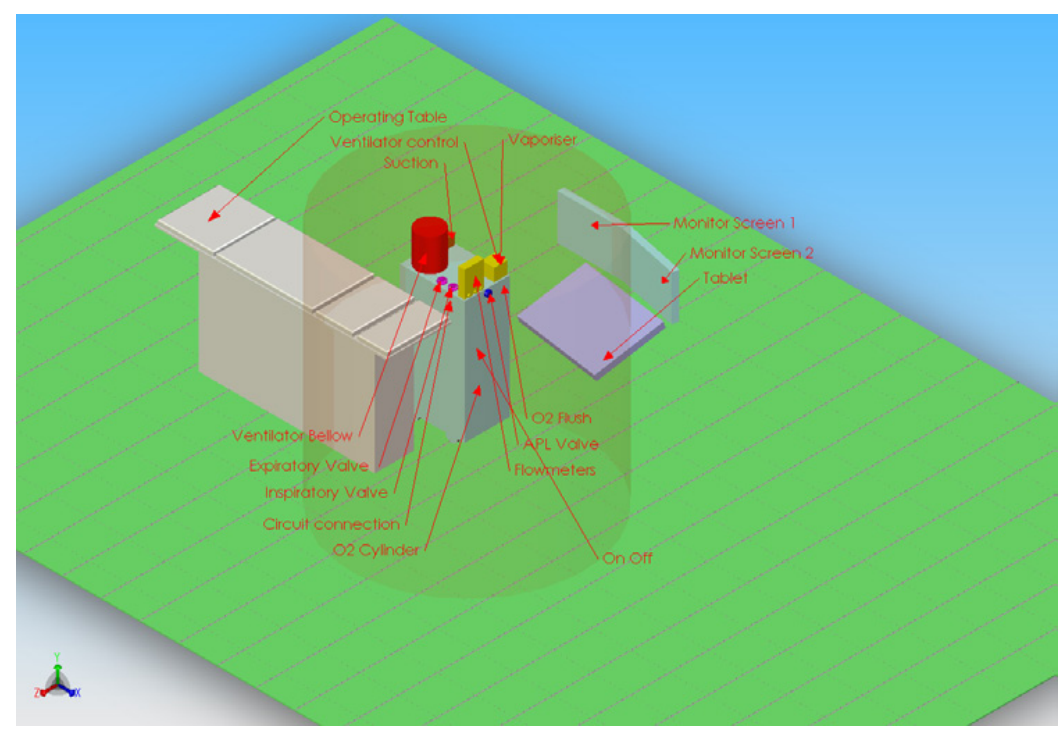

Fig 8.3 Column structure, separated from monitor screens and work tablet. 


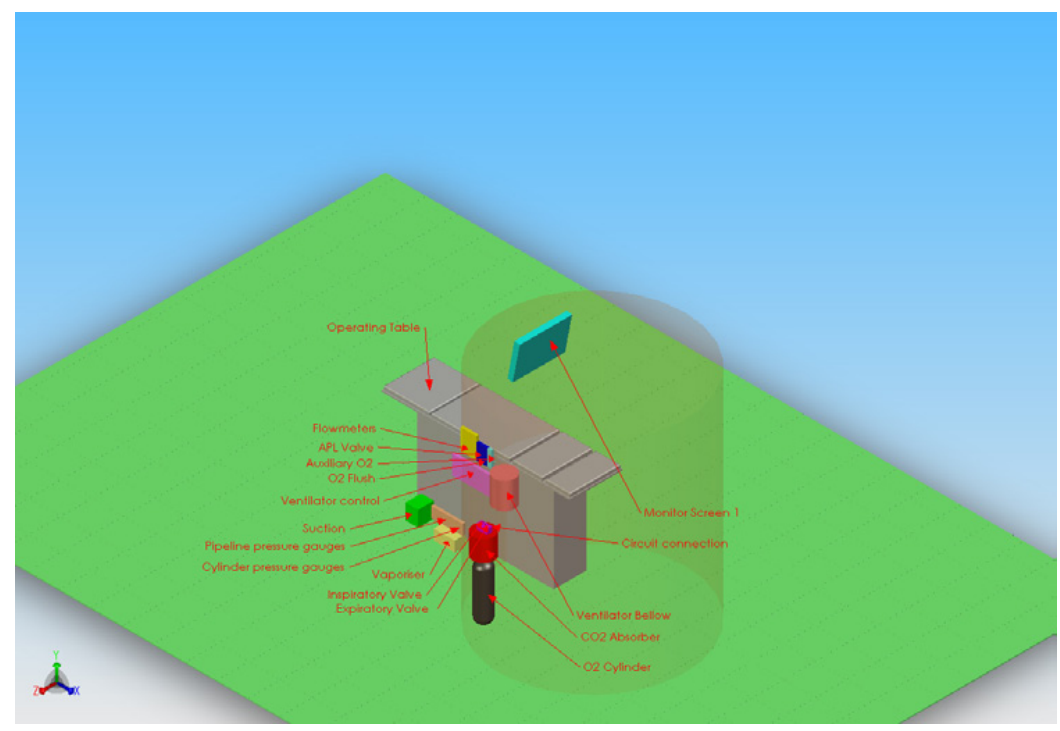

Fig 8.4 Left handed composition with extended monitor reach and dynamics, planar layout of components.

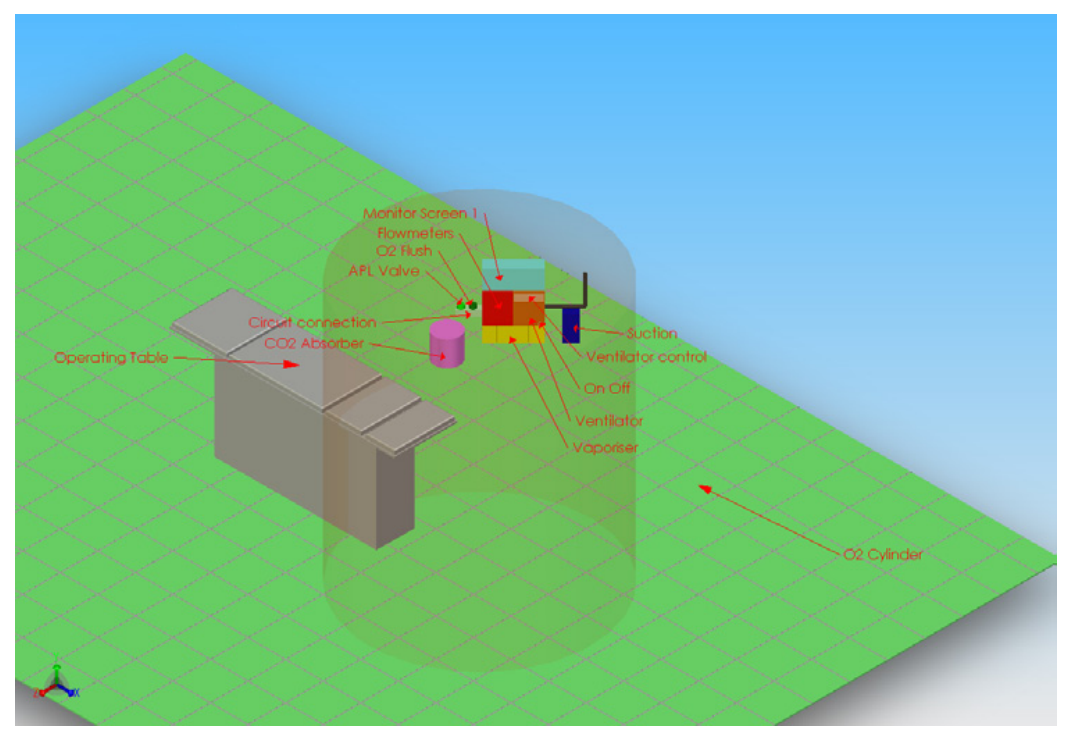

Fig 8.5 Small nested composition, infusion pumps and suction rotate to transform machine to requirements. 


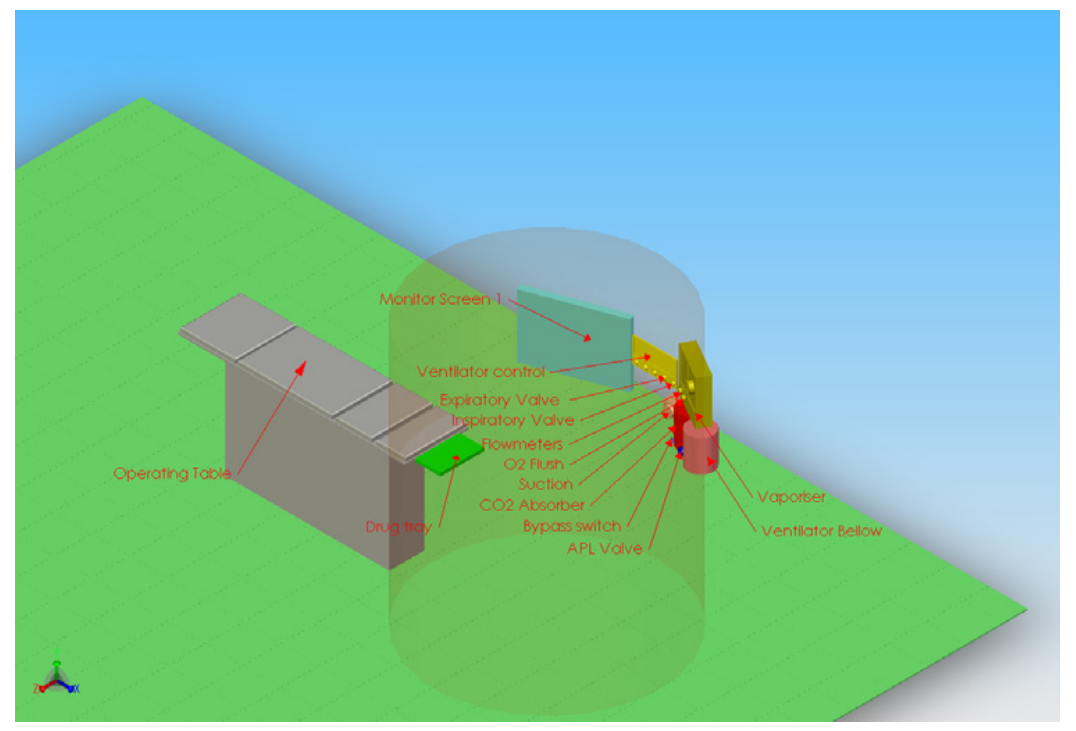

Fig 8.6 Planar composition in a 'reach arc' drug tray close to patient.

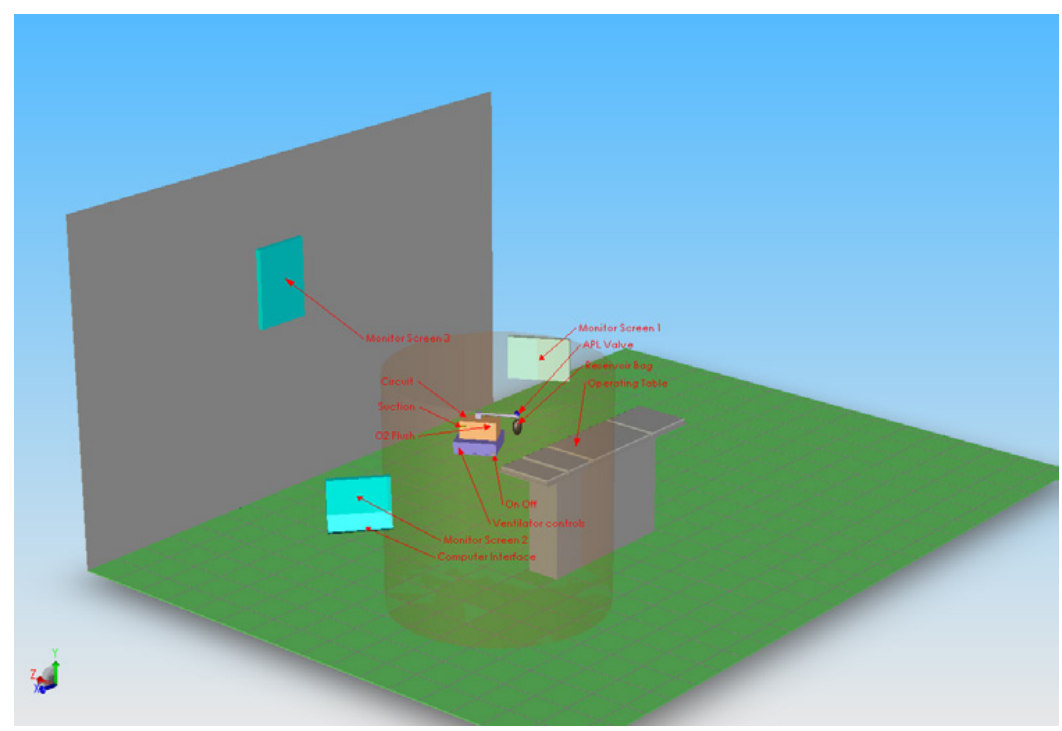

Fig 8.7 Small nested machine, monitor screen 1 for induction, screen 2 for sharing information, screen 3 a monitoring chair based work-space with tablet, and machine controls. 


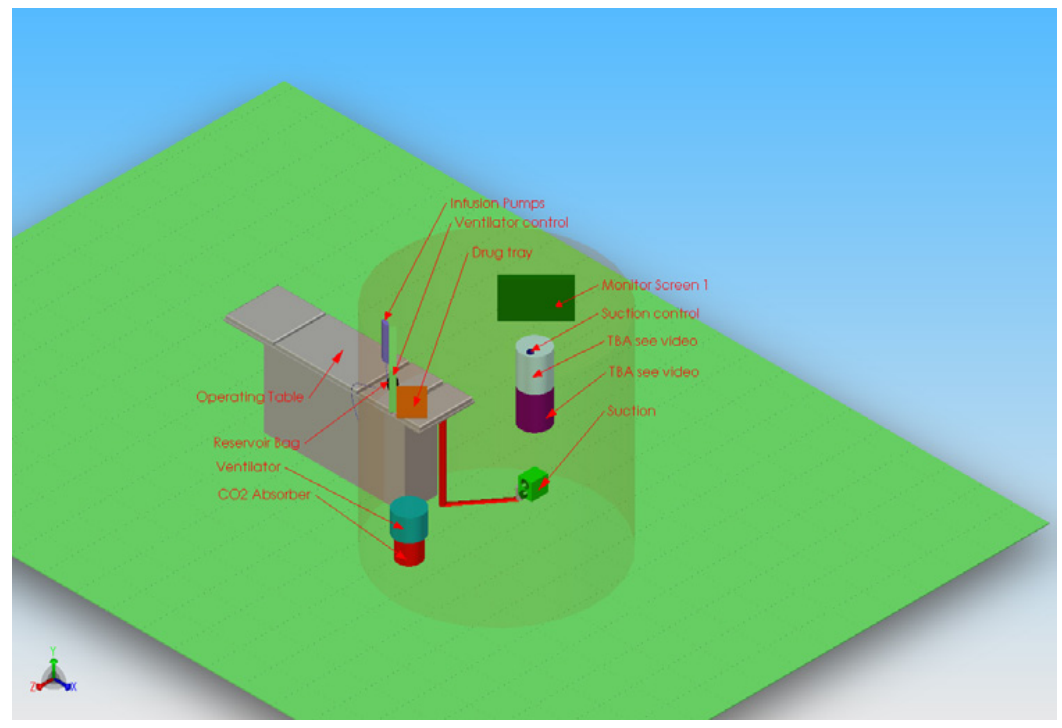

Fig 8.8 Small nested machine in two parts, interface is digital and includes a tactile touch response. 


\section{BIBLIOGRAPHY}

AAMI Human factors, ergonomics, and patient safety for medical devices meeting, Washington, DC. June 28-30, 2005.

Abajian, Jr. Arrowood, J G. Barrett, R H. Dwyer, C S. Eversole, U H. Fine, J H. Hand, L V. Howrie, W C Jr. Marcus, P S. Martin, S J. Nicholson, M J. Saklad, E. Saklad, M. Sellman, P. Smith, M. Woodbridge, P D. "Critique of - A study of deaths associated with anesthesia and surgery," Annals of Surgery 142 (1955): 138-141.

Aitkenhead, A R. "Injuries associated with anaesthesia. A global perspective," British Journal of Anaesthesia May 20, (2005): 6.

Archer, B. "The nature of research," Co-Design Journal 2 (1995): 6-13. 26

Ball, C. Westhorpe, R. "The Coxeter Bolye gas anaesthesia apparatus," Anaesthesia and intensive care, 27,2. (1999): 2.

Beecher, H K. Todd, D P. "A study of deaths associated with anesthesia and surgery," Annals of Surgery 140 (1954): 2-24.

Boquet, G. Bushman, J A. Davenport, H T. "The anaesthesia machine: a study of function and design," British Journal of Anaesthesia 52 (1980): 61-67.

Boyle, H E G. "The use of nitrous oxide and oxygen with rebreathing in military surgery," Lancet 2 (1917): 667-669.

Bronfenbrenner, U. "Toward an experimental ecological of human development," American Psychologist 32 (1977): 513-531.

Bulmer, Michael. Francis Galton: Pioneer of Heredity and Biometry, Johns Hopkins University Press. 2003.

Cassell, Eric J. The nature of suffering and the goals of medicine, Oxford: Oxford University Press, 1991.

C Perrow, Normal accidents: Living with high risk technologies, NJ: Princeton University Press, 1999.

Cook, Richard I. Woods, David D. Miller, Charlotte. "A Tale of Two Stories: Contrasting Views of Patient Safety," (Report from a workshop on assembling the scientific basis for progress on patient safety, National Health Care Safety Council of the National Patient Safety Foundation at the AMA, 1998):

Cook, R I. Woods, David. "Operating at the Sharp end: the complexity of human error," in Human Error in Medicine, edited M S. Bogner, 302. Hove UK: Lawrence Erlbaum Associates, 1994. 
Cooper, J B. Newbower, R S. Long, C. D. McPeek, B. "Preventable anesthesia mishaps: a study of human factors," Anesthesiology Vol 9. No 6. (1978): 399-406.

Cooper, J B. "Toward prevention of anesthetic mishaps" in Analysis of Anesthetic Mishaps, edited by E C Pierce Jr. J B. Cooper, 167-183. Boston: Little Brown, 1984.

Cooper, J B. Taqueti, V R. "A brief history of the development of mannequin simulators for clinical education and training," Qual Saf Health Care 13 (suppl 1) (2004):

Cooper, Jeffrey B. "An accidental life: patient safety and biomedical engineering," in This is no bumbug!, Reminisences of the department of anesthesia at the Massachusetts general hospital, ed. Richard J. Kitz (Ohio: Atlas books, 2003), 377-419.

Cooper, Jeffrey B. Newbower, Ronald S. Moore, Jeffrey W. Trautman, Edwin D. "A new anesthesia delivery system," Anesthesiology Vol 49 No 5 (1978): 310-318.

Dalley, P. Robinson, B. Weller, J. Caldwell, C. "The use of high fidelity human patient simulation and the introduction of new anaesthesia delivery systems," Anesthesia and Analgesia 58 (2004): 1737-1741.

Decker, K. Bauer, M. "Ergonomics in the operating room-from the anesthesiologist's point of view," Minimally Invasive Therapy \& Allied Technolologies Vol.12, No. 6 (2003): 268-277.

Dekker, Sidney W A. "Doctors are more dangerous than gun owners," Human factors Vol49. No 2. (2007): 177-184.

Dekker, Sidney W. “The re-invention of human error," (Technical report, Lund school of aviation, Ljungbyhed Sweden, 2002-01), 1-15.

De Kort, Y A W. Ijsselsteijn, WA. Kooijman, J. Schuurmans, Y. "Virtual laboratories: Comparability of real and virtual environments for environmental psychology," Presence: Teleoperators and Virtual Environments, 12, (2003): 360-373.

Drews Frank A. Westenskow, Dwayne R. "The right picture is worth a thousand numbers: data displays in anesthesia," Human Factors Vol 48 No 1 (2006): 59-71

Drui, Albert B. Behm, Robert J. Martin, Wayne E. "Predesign investigation of the anesthesia operational environment," Anesthesia and Analgesia Vol. 52 No. 4 (1973): 584-591.

Evans, Barbara. "A doctor in the great war-an interview with sir Geoffrey Marshall," British medical journal Vol 285 18-25 (1982): 1780-1783 
Fitts, P M. Jones, R E. "Analysis of factors contributing to 460 'pilot error' experiences in operating aircraft controls," in Memorandum Report TSEAA-694-12, Aero Medical Laboratory, Air Material Command, Wright-Patterson Air Force Base, (Dayton, Ohio, July 1, 1947).

Flanagan, John C. "The critical incident technique," Psychological Bulletin Vol 51, No 4. (1954): 327-358.

Ford, Henry. My life and work, Sydney: Angus and Robertson, 1923.

Foregger, Richard. "Richard von Foregger, PhD 1872-1960: Manufacturer of Anesthesia Equipment," Anesthesiology Vol 84 No 1. (1996): 190-200.

Frens, Joep. Designing for rich interaction: Integrating form, interaction, and function, Eindhoven: J.F. Schouten School for User-system Interaction Research, 2006.

Friedman, Meyer. Friedman, Gerald W. Medicine's 10 greatest discoveries, New Haven: Yale university press,1998.

Friedman, Ken. VanPatter, G K. "New Design Research: Leading or Following?,” NextD Journal ReReThinking Design. Issue 1 Conversation 1.2 (2003), http://www.nextd.org/pdf_download/NextD_1_2.pdf

Gaba, David M. "Anaesthesiology as a model for patient safety in health care," British Medical Journal 320 (2000): 785-788.

Gaba, David M. Howard, Steven K. Fish, Kevin J. Smith, Brian E. Sowb, Yasser A. "Simulation-based training in anesthesia crisis resource management (ACRM): A decade of experience," Simulation and gaming Vol 32, No 2, (2001): 175-193.

Gaba, D M. "The future vision of simulation in healthcare," Qual Saf Health Care 13 (Suppl 1) (2004):

Gillespie, Noel A. "The future of anaesthesia" in The history of surgical anesthesia, by Thomas E. Keys, New York: Schuman's, 1945.Gilmore, David. Interactions/business may+june (2002):

Goerig, M. Nemes, C. Peterman, H. "Paul Zweifel-his importance in German obstetric anaesthesia," in The History of Anesthesia: Fifth International Congress edited Jose C. Diz. Avelino Franco. Douglas R. Bacon. (Amsterdam: Elsevier Science, 2002).

Goldstein, A.Jr. Keats, AS. "The risk of anesthesia: wherein lies the cause?, Anesthesiology 50: (1979): 387-392.

Gosbee, John W. Using human factors engineering to improve patient safety, USA: Joint commission Resources, 2005.

Guy, B. "The anaesthesia machine: questioning a design evolution," Thesis., Victoria University of Wellington, 2009. 
Hadfield, Charles F. "Eminent Anaesthetists H. Edmund G. Boyle," British Journal of Anaesthesia 22 (1950): 107-117.

Haupt, Josef. The History of Anaesthesia at Dräger, Drägerwerk AG. Vol 1. 1996.

Held, J. Stahl, E. Guggenbühl, U. Krueger, H. "Ergonomics in Anaesthesia" Proceedings of the XIth International Ergonomics and Safety Conference (1996).

Helmreich, R. Schaefer, Hans-Gerhard. "Team performance in the operating room," in Human Error in Medicine, edited M S. Bogner, 230. Hove UK: Lawrence Erlbaum Associates, 1994.

Henriksen, Kerm. "Human factors and patient safety: continuing challenges," in Handbook of Human Factors and Ergonomics in Health Care and Patient Safety, edited Pascale Carayon, 21-37. Mahwah, New Jersey: Lawrence Erlbaum associates, 2007.

Henry Dreyfuss Associates, The measure of man, New York: Whitney library of design, 1959.

Herr, K. Anderson, G L. The action research dissertation: a guide for students and faculty, California USA: Sage publications, 2005.

Hollingham, R. Blood and guts: a history of surgery, UK: BBC books, 2008.

Hughes, Heidi. "Siemens Kion Anesthesia Workstation," The Society for Technology in Anesthesia Vol 12, No 1. (2001)

Hussey, W D. British history 1815-1939, Cambridge: Cambridge university press, 1971.

IEC 62366, Ed.1: Medical devices - Application of usability engineering to medical Devices (IEC, 2007).

Ibrahim, Joseph. Majoor, Jenny. Loff, Bebe. "Combating medical errors," Correspondence The Lancet 356 (2000): 166.

Jackson, D E. "Anesthesia equipment from 1914 to 1954 and experiments leading to its development," Anesthesiology Vol 16 (1955): 953-969.

Jungk, A. Thull, B. Hoeft, A. Rau, G. "Evaluation of two new ecological interface approaches for the anesthesia workplace," Journal of Clinical Monitoring and Computing 16 (2000): 234-258.

Keys, T E. The history of surgical anesthesia, New York: Schumans, 1945.

Kirkup, John. The evolution of surgical instruments, Novato, California: Historyofscience, 2006.

Kohn, Linda T. Corrigan, Janet M. and Donaldson, Molla S. To err is buman, Washington, D.C.: Institute of Medicine, 2000.

Le Fanu, James. The rise and fall of modern medicine, London: Little, Brown and 
Company, 1999.

Liddle, David. in "Designing interactions," by Bill Moggridge, xii and 239. Cambridge, Massachusetts: MIT press, 2007.

Loeb, R. Weinger, M B. Englund, C E. "Ergonomics of the anesthesia workspace," in Anesthesia equipment: principles and applications, edited by J Ehrenwerth. J B. Eisenkraft, P A. Malvern, 385-404. Mosby Year Book, 1993.

Lohr, Steve. "Doctors journal says computing is no panacea," New York Times, March 3, 2005, http//www.nytimes.com/2005/03/09/ technology/09compute.html (accessed January 18, 2008).

Low, C H. "The Challenges in Surgery-Past, Present and Future, and in Search of the 4Cs," 10th Chapter of Surgeons' Lecture: Ann Acad Med Singapore Vol. 29 No. 1 (January 2000), 140-145.

Mallett, J. "Studying man-machine interfaces in the operating room," Minimally Invasive Therapy \& Allied Technologies Vol. 10 No. 3 (2001): 133-137.

Maltby, J Rodger. Notable names in anaesthesia, London: Royal Society of Medicine press, 2002.

McIntyre, J.W.R. "Man-machine interface: The position of the anaesthetic machine in the operating room," Can. Anaesth. Soc. J Vol. 29, No. 1 (1982): 74-78.

McKenzie, A G. “The Gillies anaesthetic machine," Anaesthesia 63 (2008): 771 777.

Manser, T. Dieckmann, P. Wehner, T. Rall, M. "Comparison of anaesthetists' activity patterns in the operating room and during simulation," Ergonomics 50:2, (Date): 246 - 260 URL: http://dx.doi. org $/ 10.1080 / 00140130601032655$

Moggridge, B. Designing interactions, Cambridge, Mass: MIT Press, 2007.

Moggridge, Bill. A conversation about interaction design. Sebastiano Bagnara (1-27) 17.

Morrison-Low, A D. Making scientific instruments in the industrial revolution, England: Ashgate publishing, 2007.

Mushin, W W. Ezard, D. “The reservoir bag in a different position," British Journal Anaesthesia Vol 22. No 3. (1950): 183-186.

National Patient Safety Foundation at the AMA. "Public opinion of patient safety issues research findings," (Louis Harris \& Associates. September 1997): http://www.npsf.org/pdf/r/1997survey.pdf (accessed 1/8/2008).

Nix, Henry. "Environmental data," in address to seminar, in David Evans, How to write a better thesis or report, Melbourne: Melbourne University press, 1995. 
Norman, D. "Human centered design considered harmful," Interactions 12;4 July August (2005): 14-19.

Norman, Donald. The design of everyday things, New York: Doubleday, 1990.

Norman, Donald. The design of future things, New York: Basic books, 2007.Page, R L. "Brief history of flight simulation," In proceedings Sim tecT (2000).

Papper, E M. Romance, poetry, and surgical sleep, London: Greenwood Press, 1995.

Perper, Joshua A. "Life-threatening and fatal therapeutic misadventures," in Human Error in Medicine, edited M S. Bogner (Hove UK: Lawrence Erlbaum Associates, 1994), 28.

Pierce, Ellison C. "40 years behind the mask: Safety revisited," Anesthesiology, Vol. 84 No. 4 Special article: The 34th Rovenstine Lecture, (1996): 965975 .

Pope, Alexander. An Essay on Criticism, 1711.

Porter, Roy. Blood and guts, a short bistory of medicine, London: Penguin Books, 2002.Rasmussen, Jens. "Afterword," in Human Error in Medicine, edited M S. Bogner, 390-391. Hove UK: Lawrence Erlbaum Associates, 1994.

Ream, Allen K. "New directions: The anesthesia machine and the practice of anesthesia," Anesthesiology Vol 49, No 5. (1978): 307-308.

Reason, J. Human Error, England: Cambridge University Press 1990.

Roth, E M. Christian, Gustafson, M. Seridan, T B. Dwyer, K. Gandhi, T K. Zinner, Dierks, "Using field observations as a tool for discovery: analyzing cognitive and collaborative demands in the operating room," Cogn Tech Work 6 (2004): 148-157.

Roth, E M. Bennett, Woods, "Human interaction with an "intelligent" machine," International Journal of Man-Machine Studies 27 (1987): 479-525. Royston,

Pike E. Human documents of the industrial revolution in Britain, UK: Routledge 2006.

Salas, Eduardo. Baker, David. King, Heidi. Battles, James. "Opportunities and challenges for human factors and ergonomics in enhancing patient safety" Human Factors Vol 48 No 1 (2006): 1-4.

Schmuckler, "What is ecological validity? A dimensional analysis," Infancy 2, (2001): 419-436.

Schuler, D. and Namioka, A. Participatory Design: Principles and Practices, Hillsdale, N J: Lawrence Erlbaum Associates, 1993.

Schwartz, Amy. "Collaborative design: turning surgeons into design partners" (Paper presented at the AAMI Human factors, ergonomics, and patient safety for medical devices meeting, Washington, DC. June 28-30, 2005). 
Seagull, Jacob F. Ward, Russ. Mills, Julie. Goodrich, Christopher. Xiao, Yan. "Measuring awkwardness of workplace layout: dispersion of attentional and psychomotor resources within the anesthesia workspace," Proceedings of the human factors and ergonomics society 48th annual meeting (2004): 17551758.

Shuman, Joel James. The Body of Compassion: Ethics, Medicine, and the Church, Westview Press Inc1999.

Smith, Grub. "The Truth about killing," BBC

Snow, C P. The two cultures and the scientific revolution, Cambridge, England: Cambridge University Press,1959.

Suzuki, A. Bito, H. Sanjo, T. Katoh, T. Sato, S. "Evaluation of the PhysioFlex closed circuit anaesthesia machine," European journal of anaesthesiology 17 (2000): 359-363.

Sykes, Stanley W. Essays on the first hundred years of anaesthesia, Edinburgh: E\&S Livingstone Ltd, 1961. Vol II, Essay II.

Sutton, Thomas. "Innovation and control," (2008): http:/ /www.frogdesign. com/design-mind/articles/febuary-2008/innovation-and-control.html

Taylor, Frederick Winslow. The principles of scientific management, Harper \& Bros. New York. 1911.

Thomas, K Bryn. The development of anaesthetic apparatus, London UK: Blackwell Scientific Publications, 1975.

Thomson, Margaret."The technique of Anaesthesia Series No 2. Open drop ether," ICI productions, Produced by Realist Film Unit, 1944.

Tomlin, Janice. (producer), “The Deep Sleep: 6,000 will die or suffer brain damage,"WLS-TV Chicago, 20/20, April 22, 1982.

Vallikari, Jouko. The jolly dolphin in the school of sharks, Hämeenlina, Finland: Finnish Healthcare Technology Association, FiHTA, 2009.

Verbeek, Peter Paul. What things do, Pennsylvania: University park, Pennsylvania state university press, 2005.

Vicente, Kim. The human factor: revolutionizing the way people live with technology, Toronto, Canada: Alfred A. Knopf, 2003.

Wallroth, Carl. Carstensen, Peter. Osborn, Dave. Panitz, Gerald. Sidebottom, Charles. Weinger, Matthew B. Wiklund, Michael. Westenskow, Dwayne. "Development of a Standard for Reducing Use Errors with Medical Devices," Society for Technology in Anesthesia January 16-19 (2008) S-24.

Watt, O M. "The evolution of the Boyle apparatus, 1917-67," Anaesthesia 23 (1968): 103-118. 
Webb, R K. Russell, W J. Klepper, I. Runciman, W B. "Equipment failure: an analysis of 2000 incident reports," Anaesthesia and Intensive Care 21 (1993): 673-677.

Webel, N. Harrison, B. Southorn, P. "Anaesthesia origins of the intensive care physician," in The History of Anesthesia: Fifth International Congress edited. Jose C. Diz. Avelino Franco. Douglas R. Bacon. 613-617. Amsterdam: Elsevier Science, 2002.

Weick, Karl E. "The vulnerable system: an analysis of the Tenerife air disaster," Journal of Management Vol 16, No 3. (1990): 571-593.

Weinger, M B. "Anesthesia equipment and human error," Journal Clinical Monitoring and Computing 15 (Jul 1999): 319-323.

Weinger, M B. Foreword A Clinician's perspective on designing better medical devices; in Designing usability into medical products, by Michael E. Wiklund and Stephen B. Wilcox, ix. Boca Raton : CRC Press 2005.

Weinger, M B. Gonzales, D C. Slagle, J. Syeed, M. "Video capture of clinical care to enhance patient safety," Qual Saf Health Care 13 (2004): 136-144.

Weinger, M B. "A Vision of the future of perioperative information management," Anesthesia Patient safety Foundation newsletter 15, 4. (2000):

Whitehead, J. McNiff, J. Action research living theory, London: Sage Publications, 2006.

Wickham, J E A. "Future developments," British Medical Journal Vol 308. No 6922 (1994): 193-196.

Wilcox, Stephen B. "User-centered medical product development and the problem of egocentrism," in Designing usability into medical products by Michael E. Wiklund. Stephen B. Wilcox, 55. Boca Raton: CRC Press, 2005.

Wilkinson, D J. "Henry Edmund Gaskin Boyle 1875-1941," in The History of Anesthesia: Fifth International Congress ed. Jose C. Diz. Avelino Franco. Douglas R. Bacon. (Amsterdam: Elsevier Science, 2002).

Woods, David. Dekker, Sidney. "Anticipating the effects of technological change: a new era of dynamics for human factors," Theoretical issues in ergonomics science $\mathrm{Vol}$ 1, No 3, (2000): 272-282

Woods, David D. Patterson, Emily S. Cook, Richard I. "Behind human error. Taming complexity to improve patient safety," in Handbook of Human Factors and Ergonomics in Health Care and Patient Safety, edited Pascale Carayon, 459-476. Mahwah, New Jersey: Lawrence Erlbaum associates, 2007.

Wright, Ronald. A short history of progress, Toronto: Anasi press, 2004. 


\section{GLOSSARY}

AAMI -Association for the Advancement of Medical Instrumentation

ABU -Anesthesia Bioengineering Unit (Massachusetts general hospital)

ASA -Anesthesia Society of America

APSF -Australian Patient Safety Foundation

BAS -Boston Anesthesia System

BOC -British Oxygen Company

BIS -Bispectral Index (monitoring)

ENT -Ear Nose and Throat

FDA -U.S. Food and Drug Administration

GE -General Electric

HFE -Human Factors Engineering

ICI -Imperial Chemical Industries

ICU -Intensive Care Unit

IEC -International Electrotechnical Commission

NASA -National Aeronautics and Space Administration

NPSA -National Patient Safety Agency

NPSF -National Patient Safety Foundation

Standards -Standard specifications and codes provide the basis for uniformity in design, safety, performance, purchase and application of equipment

TGA -Therapeutic Goods Administration

WHO -World Health Organisation 
